\title{
Technetium Inventory, Distribution, and Speciation in Hanford Tanks
}

\author{
RJ Serne \\ BM Rapko
}

May 2014

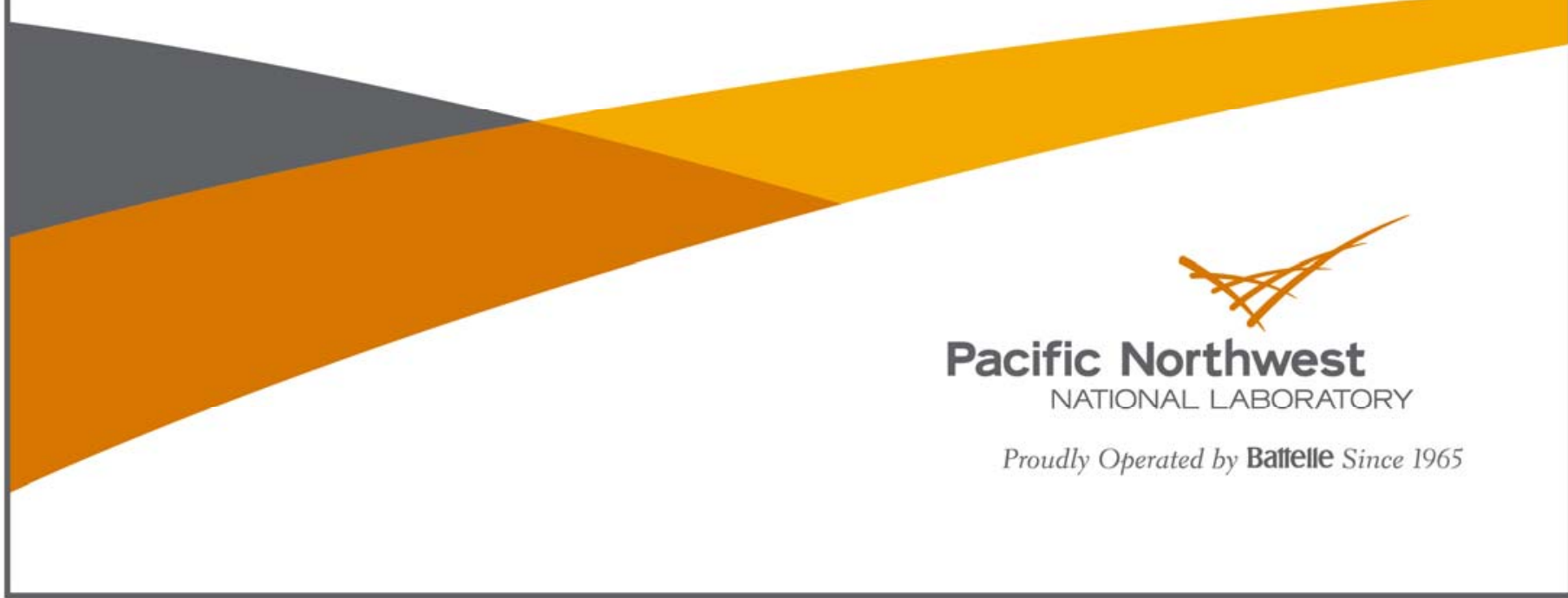




\title{
DISCLAIMER
}

This report was prepared as an account of work sponsored by an agency of the United States Government. Neither the United States Government nor any agency thereof, nor Battelle Memorial Institute, nor any of their employees, makes any warranty, express or implied, or assumes any legal liability or responsibility for the accuracy, completeness, or usefulness of any information, apparatus, product, or process disclosed, or represents that its use would not infringe privately owned rights. Reference herein to any specific commercial product, process, or service by trade name, trademark, manufacturer, or otherwise does not necessarily constitute or imply its endorsement, recommendation, or favoring by the United States Government or any agency thereof, or Battelle Memorial Institute. The views and opinions of authors expressed herein do not necessarily state or reflect those of the United States Government or any agency thereof.

\author{
PACIFIC NORTHWEST NATIONAL LABORATORY \\ operated by \\ BATTELLE \\ for the \\ UNITED STATES DEPARTMENT OF ENERGY \\ under Contract DE-AC05-76RL01830 \\ Printed in the United States of America \\ Available to DOE and DOE contractors from the \\ Office of Scientific and Technical Information, \\ P.O. Box 62, Oak Ridge, TN 37831-0062; \\ ph: (865) 576-8401 \\ fax: (865) 576-5728 \\ email: reports@adonis.osti.gov \\ Available to the public from the National Technical Information Service \\ 5301 Shawnee Rd., Alexandria, VA 22312 \\ ph: (800) 553-NTIS (6847) \\ email: orders antis.gov <http://www.ntis.gov/about/form.aspx> \\ Online ordering: http://www.ntis.gov
}

This document was printed on recycled paper.

(8/2010) 


\section{Technetium Inventory, Distribution, and Speciation in Hanford Tanks}

RJ Serne

BM Rapko

May 2014

Prepared for

the U.S. Department of Energy

under Contract DE-AC05-76RL01830

Pacific Northwest National Laboratory

Richland, Washington 99352 



\section{Acknowledgements}

The authors would like to thank Dan McCabe, Savannah River National Laboratory, for providing a list and several new reports pertinent to the topics reviewed in this report, John Swanson (retired) and Gregg Lumetta, Pacific Northwest National Laboratory, for historical Hanford reports and useful discussion on topics reviewed in this report. We thank Kristen Schwab (Washington State Department of Health, Waste Management Group, Olympia, WA) for supplying reports and web links to information on the US Ecology commercial low-level burial ground located on the Hanford Site.

Finally, we thank David Lanigan for graphics support, Sam Bryan, Reid Peterson, and Jim Poppiti (DOE-EM) for technical comments on the draft report and Matt Wilburn and Mona Champion for editing and formatting the report for final publication. 



\section{Executive Summary}

The purpose of this report is three fold: 1) assemble the available information regarding technetium (Tc) inventory, distribution between phases, and speciation in Hanford's 177 storage tanks into a single, detailed, comprehensive assessment; 2) discuss the fate (distribution/speciation) of Tc once retrieved from the storage tanks and processed into a final waste form; and 3) discuss/document in less detail the available data on the inventory of Tc in other "pools" such as the vadose zone below inactive cribs and trenches, below single-shell tanks (SSTs) that have leaked, and in the groundwater below the Hanford Site.

A thorough understanding of the inventory for mobile contaminants is key to any performance or risk assessment for Hanford Site facilities because potential groundwater and river contamination levels are proportional to the amount of contaminants disposed at the Hanford Site. Because the majority of the total ${ }^{99} \mathrm{Tc}$ produced at Hanford $(\sim 32,600 \mathrm{Ci})$ is currently stored in Hanford's 177 tanks $(\sim 26,500 \mathrm{Ci})$, there is a critical need for knowledge of the fate of this ${ }^{99} \mathrm{Tc}$ as it is removed from the tanks and processed into a final solid waste form. Current flow sheets for the Hanford Waste Treatment and Immobilization Plant (WTP) process show most of the ${ }^{99} \mathrm{Tc}$ will be immobilized as low-activity waste (LAW) glass that will remain on the Hanford Site and disposed at the Integrated Disposal Facility (IDF); only a small fraction will be shipped to a geologic repository with the immobilized high-level waste. Past performance assessment studies, which focused on groundwater protection, have shown that ${ }^{99} \mathrm{Tc}$ within various waste forms disposed in the IDF would be the primary dose contributor to the IDF performance.

The best basis inventory (BBI) is the current official estimate of the current contents in SSTs and double-shell tanks (DSTs). The BBI data are stored in an electronic database called the Tank Waste Information Network System (TWINS). A query of the TWINS database in late January 2014 and subsequent analysis of the data led to the following observations:

- The 28 DSTs contain more total ${ }^{99} \mathrm{Tc}\left(1.51 \times 10^{4} \mathrm{Ci}\right)$ than the 149 SSTs $\left(1.14 \times 10^{4} \mathrm{Ci}\right)$.

- The DSTs contain $57 \%\left(1.51 \times 10^{4} \mathrm{Ci}\right)$ of the total ${ }^{99} \mathrm{Tc}$ inventory $\left(2.65 \times 10^{4} \mathrm{Ci}\right)$ in Hanford tanks, with the bulk $\left(1.33 \times 10^{4} \mathrm{Ci}\right)$ being in four DST farms (AP, AN, AW, and AZ) in the 200-E Area.

A key issue addressed in this literature review was to estimate the amount of ${ }^{99} \mathrm{Tc}$ present as non-pertechnetate (n-Tc) species. This is important because this species has been shown to be difficult to separate from treated liquid tank wastes, should ${ }^{99} \mathrm{Tc}$ removal prior to vitrification become the preferred path forward. Further, there are no data on how n-Tc species will interact in the melters or whether they will partition into the glass similar to the pertechnetate form, which has been studied.

The review of all available studies found that the non-pertechnetate species has not been definitively identified. However, based on all investigations and detailed measurements, $n$-Tc species in the Hanford DST supernates are tentatively identified as Tc(I) carbonyl complexes derived from either $\mathrm{Tc}(\mathrm{CO})_{3}{ }^{+}$or $\mathrm{Tc}(\mathrm{CO})_{2}(\mathrm{NO})^{2+}$ precursor molecules that may lead to final species such as $\mathrm{Tc}(\mathrm{CO})_{3}(\text { gluconate })^{2-}$ as a result of the radiolytic decomposition of organics and nitrite in the DSTs.

A summary of the n-Tc percentages in the supernates from DSTs that have had samples analyzed (10 DSTs) or that can be estimated from similarity of supernates (5 DSTs) shows between 963 and $1160 \mathrm{Ci}$ of $\mathrm{n}$-Tc species may be present in these DSTs. These 15 DSTs for which we can estimate the 
mass of $\mathrm{n}$ - Tc species contain 5,530 Ci of ${ }^{99} \mathrm{Tc}$. There is a total ${ }^{99} \mathrm{Tc}$ content of $10,900 \mathrm{Ci}$ in all $28 \mathrm{DST}$ supernates. The 13 DST tank supernates for which there is no information as to what the n-Tc species content might be contain $5370 \mathrm{Ci}$ of ${ }^{99} \mathrm{Tc}$. Therefore our estimate that there are between 963 to $1160 \mathrm{Ci}$ of $n$-Tc species does not include the possibility that there is more $n-T c$ species in the supernates in the 13 DSTs for which no information is available. Because the BBI does not give any information on what source or type of waste is in the 13 DSTs supernates, we cannot speculate on what percentages of n-Tc species might be present. Details on these estimates are found in Section 7.0.

Based on the current WTP process flow sheets, almost all of the ${ }^{99} \mathrm{Tc}$ in retrieved tank wastes after processing in the Pretreatment Facility will be found in the low-level portion of the liquid waste sent to the LAW melter. In the LAW melter, Tc is volatile (estimates are from $<10 \%$ to $80 \%$ volatile), causing most of it to partition to the off-gas systems. Off-gas units (submerged bed scrubber [SBS], wet electrostatic precipitator [WESP], and caustic scrubber) downstream of the LAW melter are used to condense the hot gases back to a liquid waste stream. The current WTP flow sheets plan on continually recycling these condensates by mixing them with fresh LAW feed. Abramowitz et al. (2012) ${ }^{1}$ performed the first LAW off-gas condensate recycle testing of this concept using the DM10 melter at the Catholic University of America Vitreous State Laboratory. They used seven different LAW simulants, each spiked with known amounts of ${ }^{99 \mathrm{~m}} \mathrm{Tc}$, a short-lived, gamma-emitting isotope of Tc. They performed a mass balance for the ${ }^{99 \mathrm{~m}} \mathrm{Tc}$ throughout the DM-10 melter and off-gas condensate systems configured in the LAW continuous recycle loop. Key findings from this work include the following:

- With recycle, retention of Tc in the glass product is increased by factors of at least 2 to 3 over the corresponding single-pass values for almost all glasses made. For all but two LAW compositions, Tc retention in glass ranged from $68 \%$ to $84 \%$ of the total. In comparison, in 72 previously conducted single-pass DM10 tests (without recycle), the average of $35.2 \%$ of Tc was incorporated into LAW glass.

- The increase in Tc retention in LAW glass was limited by holdup of material, including Tc in the system, particularly in the WESP internals, the film cooler, and transition lines between the off-gas sequential trains. Mobilizing the "held up" material to make it available for recycle back to the melter along with fresh LAW feed would likely further increase Tc retention in glass.

- While the measured Tc retention values for the LAW glass with recycle are much increased over the single-pass values, they are significantly lower than previous assumptions and estimates used in WTP planning calculations.

Regarding the speciation of ${ }^{99} \mathrm{Tc}$ in the off-gas and their condensates, several reports suggest that when the hot gases contact the water in the SBS and WESP condensers, ${ }^{99} \mathrm{Tc}$ should become pertechnetate. This assumption seems reasonable given the likely oxidizing environment in the SBS and WESP condensers. The Abramowitz et al. (2012) study did not address any ${ }^{99} \mathrm{Tc}$ speciation issues because only the total ${ }^{99 \mathrm{~m}}$ Tc activity could be measured.

The main focus of the Tc Management Program is to improve the understanding of the fate of the ${ }^{99} \mathrm{Tc}$ currently stored in the 177 storage tanks at Hanford. Based on the analysis in this review, 26,500 Ci currently reside in the tanks. At a high level there is a good mass balance for how the ${ }^{99} \mathrm{Tc}$ produced at

\footnotetext{
${ }^{1}$ Abramowitz, H, M Brandys, R Cecil, N D’Angelo, KS Matlack, IS Muller, IL Pegg, and RA Callow. 2012. Technetium Retention in WTP LAW Glass with Recycle Flow-Sheet: DM10 Melter Testing. RPP-54130, Rev. 0, Washington River Protection Solutions LLC, Richland, WA.
} 
the Hanford Site is currently distributed. About $80 \%$ of the ${ }^{99}$ Tc produced at Hanford currently resides in the 177 storage tanks, $\sim 20 \%$ was shipped off-site with reprocessed uranium that was recycled/purified for other uses and $\sim 2 \%$ was released to the Hanford sediments. The partitioning of the "pool" of ${ }^{99} \mathrm{Tc}$ released to Hanford sediments in the past and in the future after the ${ }^{99} \mathrm{Tc}$ currently in the storage tanks has been dispositioned are and will remain important in the future for making site remediation decisions and site risk assessments, but are not the main scope of the Tc Management Program that is funding this report.

Final observations and recommendations for determining the amount and identity of $\mathrm{n}$-Tc in Hanford tank wastes from this report and the companion document ${ }^{1}$ are provided. Unfortunately, there is no clear method for identifying n-Tc species in Hanford tank supernate or the resultant liquids from dissolving tank saltcake and sludges. It is possible to use the pertechnetate specific "exchange" resins to evaluate the amount of $\mathrm{n}$-Tc species in a sample, but this does not identify what the $\mathrm{n}$-Tc species is/are. Identification of the n-Tc species would be useful to understand how it may be formed in the tanks and how best to convert it to a form that is amenable to separation from liquid wastes or to convert it to pertechnetate, for which removal/separation processes are available. Of the commonly used methods for inorganic compound identification, UV-vis and vibrational spectroscopy are perhaps the most routine, but to date these methods have not provided any useful information or any characteristic signal that can be associated with the presence of $\mathrm{n}-\mathrm{Tc}$. To date, only two methods have given information as to the oxidation state and structural features of n-Tc: 1) X-ray absorption spectroscopy (XAS) of one form or another and 2) nuclear magnetic resonance (NMR). Unfortunately, XAS analysis is both time- and labor-intensive and ${ }^{99}$ Tc NMR cannot observe Tc compounds when in several of the the available oxidation states. Still, to the extent possible, continued analysis of new DST supernates for $\mathrm{n}$-Tc once its presence has been indicated by other methods by X-ray adsorption near edge structure and/or extended X-ray absorption fine structure is recommended. Size exclusion chromatography may also have some merit on separating ${ }^{99} \mathrm{Tc}$ species from each other prior to analysis (in hopes of simplifying the sample matrix) by the recommended NMR and XAS methods.

\footnotetext{
${ }^{1}$ Rapko BM. 2014. Protocol for Identifying the Presence of and Understanding the Nature of Soluble, Nonpertechnetate Technetium in Hanford Tank Supernatants. PNNL-23180, EMSP-RPT-020, Pacific Northwest National Laboratory, Richland, WA.
} 



\section{Acronyms and Abbreviations}

BBI

CSM

detn

DOE

DST

DTPA

EDDA

EDTA

en

EPR

ETF

EXAFS

HDW

HEDTA

HLW

HTWOS

ICP-MS

IDA

IDF

IHLW

ILAW

LANL

LAW

LSC

MRT

MWd/MTU

$\mathrm{n}-\mathrm{Tc}$

NMR

NTA

ORP

PA

PNNL

PT

RA best basis inventory

conceptual site model

diethylenetriamine; tri-dentate organic ligand

U.S. Department of Energy

double-shell tank

diethylene triamine pentaacetic acid; formula $\mathrm{C}_{14} \mathrm{H}_{23} \mathrm{~N}_{3} \mathrm{O}_{10}$; chelating agent

ethylenediiminodiacetic acid; formula $\mathrm{C}_{6} \mathrm{H}_{12} \mathrm{~N}_{2} \mathrm{O}_{4}$ degradation product of EDTA

ethylenediaminetetraacetic acid; formula $\mathrm{C}_{10} \mathrm{H}_{16} \mathrm{~N}_{2} \mathrm{O}_{8}$; chelating agent

ethhylenediamine; chelator and precursor ligand to make EDTA

electron paramagnetic resonance

Effluent Treatment Facility

extended X-ray absorption fine structure; XAS technique

Hanford Defined Waste; categorization of Hanford reprocessing waste streams

$\mathrm{N}$-(2-hydroxyethyl) ethylenediamine-N,N',N'-triacetic acid; $\mathrm{C}_{10} \mathrm{H}_{18} \mathrm{~N}_{2} \mathrm{O}_{7}$;

chelating agent

high-level waste

Hanford Tank Waste Operations Simulator; computer code

inductively coupled plasma mass spectrometry

iminodiacetic acid; formula $\mathrm{C}_{4} \mathrm{H}_{7} \mathrm{NO}_{4}$; chelating agent

Integrated Disposal Facility

immobilized high-level waste

immobilized low-activity waste

Los Alamos National Laboratory

low-activity waste

liquid scintillation counting

Molecular Recognition Technology

megawatt-days per metric ton of uranium; measure of how much energy is extracted from a primary nuclear fuel source

non-pertechnetate species found in Hanford DST supernates

nuclear magnetic resonance

nitrilotritacetic acid; formula $\mathrm{N}\left(\mathrm{CH}_{2} \mathrm{CO}_{2} \mathrm{H}\right)_{3}$; chelating agent

Office of River Protection

performance assessment

Pacific Northwest National Laboratory

Pretreatment (Facility)

risk assessment 
SBS

SIM

SRNL

SST

TC\&WM EIS

tetn

TWINS

WESP

WTP

XANES

XAS submerged bed scrubber; off-gas collector/condenser

Soil Inventory Model

Savannah River National Laboratory

single-shell tank

Tank Closure and Waste Management Environmental Impact Statement

triethylenetetraamine; chelating agent

Tank Waste Information Network System; electronic database

wet electrostatic precipitator; off-gas collector/condenser

Hanford Tank Waste Treatment and Immobilization Plant

X-ray absorption near edge structure; XAS technique

X-ray absorption spectroscopy 


\section{Contents}

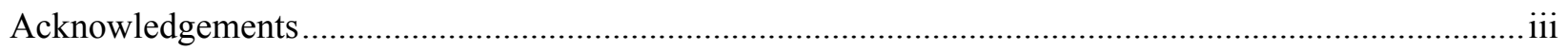

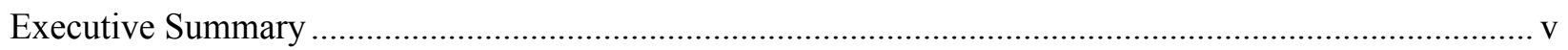

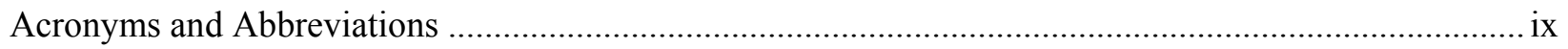

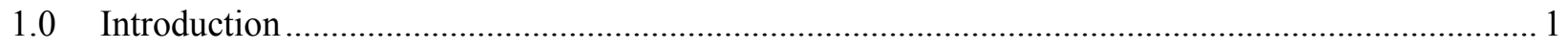

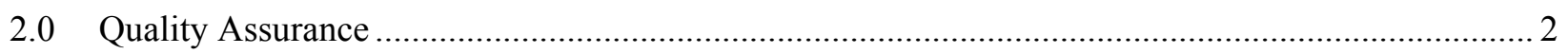

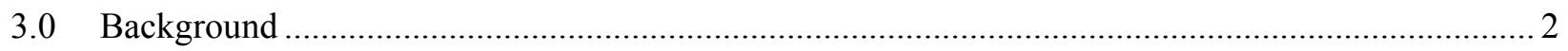

4.0 Te Inventory, Distribution, and Speciation in Hanford Tanks .................................................. 4

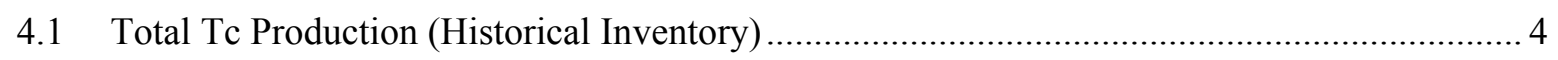

$4.2{ }^{99} \mathrm{Tc}$ Inventory Currently Stored in Hanford Tanks........................................................... 7

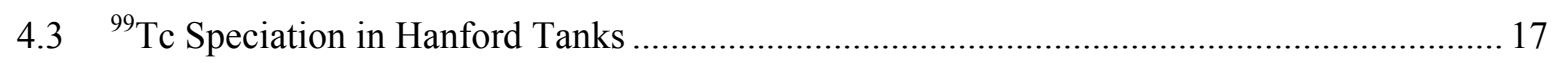

4.3.1 Precis on Discovery and Confirmation of Existence of $n$-Tc species in DST

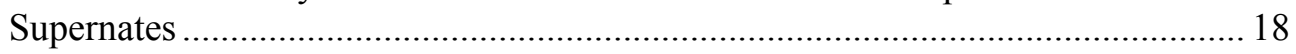

4.3.2 Speciation Inferred from Ion Selective Resin Tests .............................................. 24

4.3.3 Additional Studies that Probe Tc Speciation ....................................................... 26

4.3.4 Spectroscopic Studies used to Determine Tc Speciation ........................................ 29

4.3.5 Correlation of Non-pertechnetate Percentages with Other DST Supernate

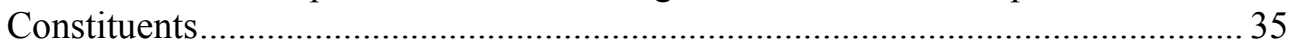

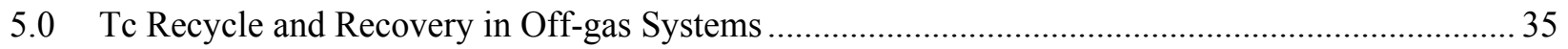

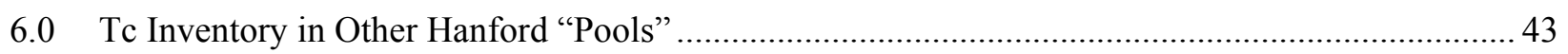

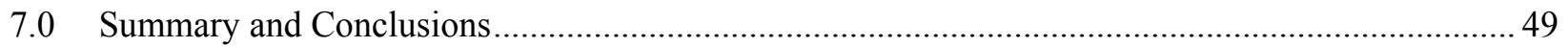

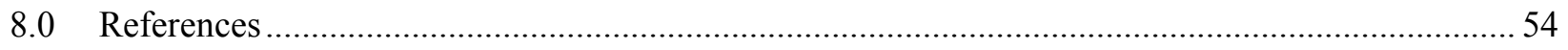

Appendix A Additional Outputs from TWINS 1-27-2014 …........................................................... A.1

Appendix B Listing of Reports on Characterization of Residual Sludge in SSTs That Have Been

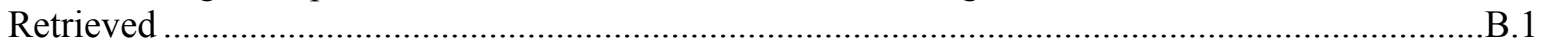

Appendix C Description of the HTWOS Computer Code..................................................................

Appendix D Discussion and List of Resources for ${ }^{99} \mathrm{Tc}$ in Hanford Mass Balance "Pools" ................... D.1

\section{Figures}

3.1. Structure of the Pertechnetate Anion and Selected Thermodynamic Properties.............................. 3

4.1. Timeline of the Hanford Site Uranium Fuel Reprocessing ........................................................... 7

4.2. Trend in ${ }^{99} \mathrm{Tc}$ Inventory Estimates in Hanford Storage Tanks as Function of Time........................ 11

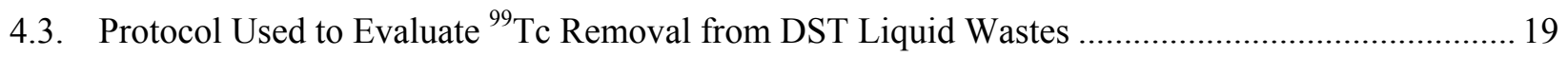

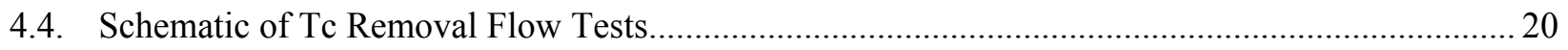

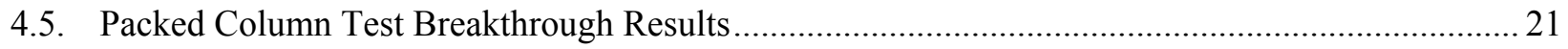

4.6. Breakthrough Curves for SuperLig 639 Columns Contacted with AN-102 Supernate .................. 22

4.7. Structure of Reillex HPQ Anion Exchange Resin................................................................... 25 
4.8. Comparison of XANES Spectra for AN-107 and SY-103 Supernates with Two Tc Standards

4.9. Comparison of XANES Spectra for SY-103 Supernates ............................................................. 31

4.10. Comparison of XANES Spectra for AW-101 and SY-103 Supernates with the Pertechnetate Standard ......

4.11. Structure for the Tc(I) Tri-Carbonyl Fully Hydrated Cation

4.12. Tc K-edge XANES spectra of a) non-pertechnetate species in tank SY-103 and $\mathrm{Tc}(\mathrm{CO})_{3}$ (gluconate) $)^{2-}, \mathrm{b}$ ) non-pertechnetate species in tank $\mathrm{SY}-101$ and $93 \%$ $\mathrm{Tc}(\mathrm{CO})_{3}(\text { gluconate })^{2-}$ with $\left.7 \% \mathrm{TcO}_{4}^{-}, \mathrm{c}\right) \mathrm{Tc}(\mathrm{CO})_{3}(\text { gluconate })^{2-}$, d) $\mathrm{Tc}(\mathrm{CO})_{3}(\mathrm{OH})\left(\mathrm{H}_{2} \mathrm{O}\right)_{2}$, e) $\mathrm{Tc}(\mathrm{CO})_{3}\left(\mathrm{H}_{2} \mathrm{O}\right)_{3}{ }^{+}$

5.1. Simplified Off-gas System in Baseline WTP Unit Operations

5.2. Schematic of the DM10 Melter and Continuous Recycle Testing Platform.................................. 39

5.3. Photograph of the DM10 Melter and Continuous Off-gas Recycle Test Facility.....

5.4. Comparison of Tc Retention in LAW Glass Between Single and Continuous Recycle of Off-gas Condensate

6.1. Schematic of the Distribution and Fate of ${ }^{99} \mathrm{Tc}$ Between the Various "Pools" .............................. 45

6.2. DOE/ORP 2010 Estimate of the Distribution of ${ }^{99}$ Tc Between the Various "Pools" ...................... 46

\section{Tables}

4.1. Hanford Site Fuel Reprocessing Plant Summary ..................................................................... 5

4.2. Range in Total Tc Inventory Produced at the Hanford Site ....................................................... 6

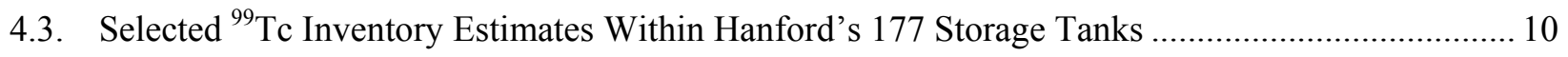

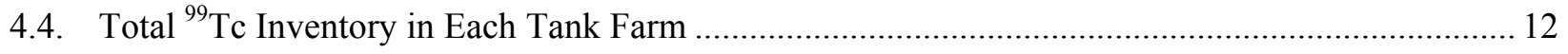



4.6. BBI Categories Used to Described How Inventory Values Were Derived.................................... 14

4.7. Tanks and ${ }^{99} \mathrm{Tc}$ Inventory that Have Better Certainty ............................................................... 15

4.8. Potential Split of Soluble versus Non-soluble ${ }^{99} \mathrm{Tc}$ in Hanford Storage Tanks Before Pretreatment

4.9. Reported Distribution of Non-pertechnetate Technetium Present in Various Hanford Tank Supernatants

5.1. Estimated Distribution of All ${ }^{99} \mathrm{Tc}$ Currently in Hanford Tanks After Vitrification......

6.1. ${ }^{99}$ Tc Distribution in Various "Pools" used to Calculate Mass Balance or Hanford Site ${ }^{99} \mathrm{Tc}$ Conceptual Model. ... 46

7.1. Estimates of Non-pertechnetate ${ }^{99} \mathrm{Tc}$ Inventory in DST Supernates 


\subsection{Introduction}

This report was funded by the Technetium Management Program. The Technetium Management Program represents an integrated effort that includes work funded directly by the Office of River Protection (ORP), U.S. Department of Energy (DOE) subcontractors, and the DOE Office of Environmental Management. Scientists from Pacific Northwest National Laboratory (PNNL), Savannah River National Laboratory (SRNL), Hanford Site operations contractor Washington River Protection Solutions, and several subcontractors (synchrotron support-Stanford Radiation Laboratory, used by collaborators at Lawrence Berkeley National Laboratory), along with experts in Tc sensor development from the University of Cincinnati, are all engaged in performing the work. This report is part of this integrated effort.

The objectives of this report are as follows:

1. Assemble the available information regarding technetium (Tc) inventory, distribution of soluble and insoluble Tc between the three phases in the tanks (supernate, saltcake, and sludge), and Tc speciation in each phase into a single, comprehensive assessment.

2. Discuss anticipated amounts and fate of Tc during melter operations, and recovery and recycle of the condensates from various off-gas units.

3. Document and discuss available information on Tc inventory and distribution in other "pools" on the Hanford Site such as releases to inactive cribs, trenches, and ponds, and releases from single-shell tanks (SSTs) and their infrastructure and in the aquifer.

There remain several significant uncertainties in the understanding and modeling of the fate and speciation of ${ }^{99} \mathrm{Tc}$ currently in the Hanford tanks, and in the glass and low-temperature waste forms that are contemplated as final waste forms destined for permanent disposal in the subsurface. A particularly vexing issue arises should significant Tc removal be required from the waste after it is sluiced from the tanks and sent to "pretreatment" facilities. A significant (2\% to 25\%) fraction of the ${ }^{99} \mathrm{Tc}$ currently stored in many of the 177 tanks appears to be present as a supernatant-soluble, non-pertechnetate species that has only been partially identified and, based on experimentation to date, cannot be effectively separated from the tank waste or easily converted to the pertechnetate species that is readily removable from the various liquid wastes.

In Section 4.3 the available information on the non-pertechnetate species is discussed. To summarize, taken in total, the available evidence for existence of soluble non-pertechnetate species in several of the double-shell tank supernates is strong. The evidence includes direct spectroscopic evidence using XANES and ${ }^{99} \mathrm{Tc}$ NMR. Multiple instances and types of indirect evidence also exist involving differing behaviors in the amount of ${ }^{99} \mathrm{Tc}$ in DST supernates sorbed onto pertechnetate-specific resins when compared to the amount of pertechnetate radiotracers spiked into the supernate. Finally, and as the weakest indirect evidence, batch contacts for ${ }^{99} \mathrm{Tc}$ added as pertechnetate in simulants and ${ }^{99} \mathrm{Tc}$ in actual tank waste differ.

In total, approximately 30 studies have been published by researchers from four DOE national laboratories on these findings. Interestingly, good agreement between laboratories as to the amount of soluble non-pertechnetate species deduced by these methods is generally observed. However, the number and identities of the non-pertechnetate species have not been conclusively determined. 
Available data suggest that the soluble non-pertechnetate species have a Tc valence of $+1[\mathrm{Tc}(\mathrm{I})]$ and may be complexed with carbon monoxide or nitrous oxide generated in the high radiation fields within the Hanford tanks.

While there has been significant work on the removal of the pertechnetate anion from tank liquid wastes, there has been limited work in areas such as whether the non-pertechnetate species incorporates into glass similar to pertechnetate, and whether the non-pertechnetate species is captured and similarly condensed in off-gas systems downstream from the melters like pertechnetate. One preliminary test has been performed to explore condensing pertechnetate from off-gas streams, which capture volatiles and entrained solids from the glass melters, and to quantify the recycle of the pertechnetate in the condensates back to the LAW melter. This test is summarized in Section 5.0.

\subsection{Quality Assurance}

This work was performed in accordance with PNNL's Quality Management System Description and associated Quality Assurance Program Description (QAPD), which are maintained electronically as part of the HDI system. Details of this project's approach to assuring quality are contained in the Environmental Management Support Program Quality Assurance Plan (QA-EMSP-001). Preparation of this report was conducted in accordance with QA-EMSP-1102, Scientific Investigation for Applied Research. All staff members contributing to the work received proper technical and quality assurance training prior to commencing quality-affecting work.

\subsection{Background}

Technetium is one of the most difficult contaminants to address at the DOE Hanford Site because of its complex chemical behavior in tank waste, limited incorporation in mid- to high-temperature immobilization processes (vitrification, steam reformation, etc.), and high mobility in subsurface environments. Approximately 32,600 to $34,000 \mathrm{Ci}$ of ${ }^{99} \mathrm{Tc}$ were produced at the Hanford Site (see Section 4.1). Of this, a small amount either has been released purposefully to cribs/trenches or has leaked from the SSTs, and an even smaller amount is found in the unconfined aquifer below the Hanford Site. Thus, most ( 26,500 Ci; see Section 4.2) of the ${ }^{99} \mathrm{Tc}$ inventory remains in the Hanford storage tanks (149 SSTs and 28 double-shell tanks [DSTs]) and must be dispositioned into approved waste forms.

Because the majority of the ${ }^{99} \mathrm{Tc}$ will be immobilized as LAW, with a smaller fraction immobilized as a secondary waste, it will remain on the Hanford Site and be disposed at the Integrated Disposal Facility (IDF); only a small fraction will be shipped to a geologic repository with the immobilized high-level waste (IHLW). Past performance assessment studies, which focused on groundwater protection, have shown that ${ }^{99} \mathrm{Tc}$ would be the primary dose contributor to the IDF performance. Due to its solubility and potential volatility during high-temperature vitrification processes, effective Tc management is important to the success of the overall ORP mission. Removal of Tc from LAW and/or off-gas secondary wastes would eliminate a key risk driver for the IDF performance assessment (as long as the separated Tc was shipped off-site or immobilized in a robust waste from with performance equivalent to glass).

Technetium in its typical Tc(VII) [pertechnetate; $\mathrm{TcO}_{4}{ }^{-}$] form (see Figure 3.1) is problematic in LAW due to its long half-life (213,000 years), complex redox chemistry, high solubility, and volatility at high 
temperatures. While most of the long-lived radionuclides in tank waste (e.g., plutonium and uranium) are largely insoluble under storage conditions, such as high $\mathrm{pH}$ and low temperature, Tc is predominantly in the aqueous phase and is highly mobile in Hanford's subsurface environments - vadose zone and aquifer sediment pore-water/groundwater. In addition, Tc volatility at LAW vitrification melter temperatures creates the potential for high Tc concentrations in the secondary waste streams formed when condensing the melter off-gas. To reduce the technical uncertainty associated with the long-term environmental impact of Tc, the Tc Management Program is addressing these ${ }^{99} \mathrm{Tc}$ management issues by evaluating and developing science and engineering options to treat, immobilize, and dispose of the ${ }^{99} \mathrm{Tc}$ contained in tank wastes.
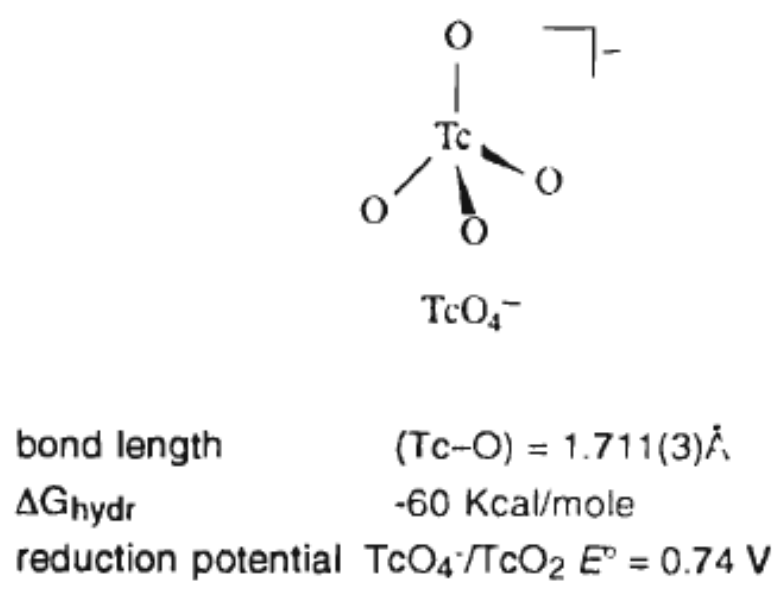

Figure 3.1. Structure of the Pertechnetate Anion and Selected Thermodynamic Properties

Over the past two decades, considerable work has been done examining the effectiveness of anion exchange-like resins for their ability to remove soluble Tc from Hanford tank supernatants. As discussed in Rapko et al. (2013a,b) and elsewhere, in most cases, excellent removal of pertechnetate Tc has been observed. However, in several instances, there appeared to be a source of Tc that behaves differently than pertechnetate, $\left[\mathrm{TcO}_{4}{ }^{-}\right]$. The fraction of soluble $\mathrm{Tc}$ that is not pertechnetate appears to vary significantly between tanks as well, ranging from effectively none to being the majority of the soluble Tc present in select tank supernates (see Tc Management Program Task 1 companion report, Rapko 2014 and references within).

This report is organized into eight sections and four appendices that document available information of the three objectives described in the introduction.

- Section 1.0 is the introduction and Section 3.0 includes background.

- Section 4.0 covers objective 1 , which summarizes information on Tc inventory, distribution of soluble and insoluble Tc between the three phases in the tanks (supernate, saltcake, and sludge), and Tc speciation in each phase into a single, comprehensive assessment.

- Section 5.0 covers available information on objective 2, anticipated Tc recycle and recovery during melter operations, and off-gas recycle testing data.

- Section 6.0 covers objective 3, which briefly reviews available information on Tc inventory and distribution in other "pools" on the Hanford Site such as releases to inactive cribs, trenches, and ponds and releases from SSTs and their infrastructure. 
- Section 7.0 summarizes the information presented in the report and Section 8.0 lists references cited in the main report.

The appendices provide additional details on several of the objectives:

- Appendix A presents additional data on estimated inventory of ${ }^{99} \mathrm{Tc}$ currently stored in the 177 Hanford tanks.

- Appendix B lists available reports and a short summary of findings on ${ }^{99} \mathrm{Tc}$ leachability from residual sludges left in SSTs after retrieval.

- Appendix C describes the Hanford Tank Waste Operations Simulator (HTWOS) computer code, which is used to estimate the partitioning of radionuclides and chemicals retrieved from the Hanford tanks as they are processed through the WTP.

- Appendix D briefly discusses and lists many available documents with information on the distribution and fate of ${ }^{99} \mathrm{Tc}$ not currently stored in the 177 Hanford tanks.

\subsection{Tc Inventory, Distribution, and Speciation in Hanford Tanks}

An understanding of the total Tc inventory currently stored in Hanford SSTs and DSTs is useful for several reasons. Human health and environmental impacts are proportional to the amount (or inventory) of the key contaminants present at a given disposal/storage site. Thus, knowing the inventory for key contaminants is crucial to risk assessments. At the Hanford Site, the final disposition of LAW will be on site in the IDF, a shallow land burial facility. Groundwater is the most probable pathway to the biosphere for contaminants presently 1) stored in SSTs and DSTs, 2) currently in the vadose zone sediments from past disposal to trenches, cribs, and ponds, and 3) released inadvertently from SSTs. Given that Tc is quite mobile when present in its pertechnetate form and that the majority of Tc currently on site is stored in the 177 Hanford tanks, a thorough understanding of the current inventory in the Hanford tanks is key to any risk assessment of the impacts of Tc present at the Hanford Site. Past long-term groundwater impact predictions (Mann et al. 2001 [2001 IDF PA]; Mann et al. 2003 [Supplemental ILAW risk assessment]; DOE 2012 [TC\&WM EIS]) show that ${ }^{99} \mathrm{Tc}$ reigns as the radioactive waste constituent contributing the highest impacts.

\subsection{Total Tc Production (Historical Inventory)}

A key to performing a mass balance on the ${ }^{99} \mathrm{Tc}$ at the Hanford Site is an estimate of the total mass (kilograms) or activity (curies) that was produced during the irradiation of fuel used to produce plutonium. A single source of inventory data does not exist for the 60-plus years of Hanford operations. However, records on the amounts and types of fuel (percentage of ${ }^{235} \mathrm{U}$ enrichment, Th-based fuel) and reactor burn-up were fairly well documented in comparison to records of liquid and solid waste discharges and disposals.

Detailed records show that $\sim 99,000$ metric tons of uranium were processed in separations facilities at the Hanford Site (Kupfer et al. 1997, Appendix B). Table 4.1 (from Kupfer et al. 1997) provides details on the dates and facilities used for reprocessing the irradiated fuels, including two campaigns where 
thorium oxide was irradiated. Figure 4.1 (from DOE/ORP 2010) shows the reprocessing timeline and states $\sim 100,000$ metric tons of irradiated fuel were processed. These two sources generally agree on the mass of fuel that was irradiated and processed to extract plutonium. Detailed records of the dates, fuel types, and fuel cladding loaded into each Hanford reactor and the fuel exposure (megawatt days per metric ton of fuel [MWd/MTU] for monthly and for some shorter periods were documented. In all, $\sim 1300$ distinct fuel batch records are available that document the dates, fuel and cladding types, fuel tonnage placed in reactor, burn-up (exposure), date irradiated fuel was removed from reactor, cooling time before separation, and dates of reprocessing to remove the plutonium (and later also uranium in the REDOX and PUREX processes). The type of cladding, especially impurities within, has an important impact on the amounts and types of activation products that are formed during the irradiation of the fuel elements. Because ${ }^{99} \mathrm{Tc}$ is a fission product, its production is not sensitive to the cladding type. The fuel reprocessing began in 1944 and ended in 1989.

Most recently, the ORIGEN2 code (Croff 1980) has been used to calculate the curie amounts of fission and activation products created during the fuel irradiations using the detailed historical records (just mentioned) available at the Hanford Site. To limit the number of ORIGEN2 runs needed to calculate the production of fission and activation products, the $\sim 1300$ fuel batch records were categorized into 15 bins of similar conditions and only 15 distinct ORIGEN2 runs were performed to estimate the masses and activities of fission and activation products. Note that some fission products are stable nuclides. A second computer code, DKPRO, was created at Hanford to generate output files that conveniently list the curie values for 46 key radionuclides associated with each of the $\sim 1300$ batches of irradiated fuel that was processed through the various reprocessing plants. DKPRO splits the calculated activities of the 46 radionuclides into two categories: 1) curies in the cladding and 2) curies in the fuel "cores."

Table 4.1. Hanford Site Fuel Reprocessing Plant Summary (from Kupfer et al. 1997)

\begin{tabular}{lccc}
\hline \multirow{2}{*}{$\begin{array}{c}\text { Separations Plant } \\
\text { (operating periods) }\end{array}$} & \multicolumn{2}{c}{ Aluminum Cladding } & Zirconium Cladding \\
\cline { 2 - 4 } & $\begin{array}{c}\text { Natural Uranium } \\
\text { (MT) }\end{array}$ & $\begin{array}{c}\text { Enriched Uranium } \\
\text { (MT) }\end{array}$ & $\begin{array}{c}\text { Natural Uranium } \\
\text { (MT) }\end{array}$ \\
\hline $\begin{array}{l}\text { T Plant } \\
\text { (1944 to 1956) }\end{array}$ & 5,034 & 0 & 0 \\
$\begin{array}{l}\text { B Plant } \\
(1945 \text { to 1952) }\end{array}$ & 2,766 & 0 & 0 \\
$\begin{array}{l}\text { REDOX } \\
(1952 \text { to 1966) }\end{array}$ & 11,609 & 7,852 & 245 \\
$\begin{array}{l}\text { PUREX } \\
(1956 \text { to 1972) }\end{array}$ & 58,748 & 7,176 & 1572.3 \\
$\begin{array}{l}\text { PUREX } \\
(1983 \text { to 1989) }\end{array}$ & 0 & 0 & $3,890.4$ \\
$\begin{array}{l}\text { Thorium Oxide } \\
\text { Purex (1966, 1970) }\end{array}$ & $629\left(\mathrm{ThO}_{2}\right)$ & -- & -- \\
\hline
\end{tabular}

Table 4.2 shows the range in total curie inventory of ${ }^{99} \mathrm{Tc}$ produced at the Hanford Site - as found in various technical reports and environmental impacts statements and decay corrected to January 1, 2000 created from irradiating fuel to produce plutonium. The slight difference in total curies appears to be caused by the earlier estimates using a different code (RIBD-II; Gumprecht 1968) than ORIGEN2 to calculate fission product production rates per fuel burn-up (MWd/MTU). Because of the long half-life of 
${ }^{99} \mathrm{Tc}$, making decay corrections to the present (January 1, 2014) does not change the inventory estimates. The $\sim 32,600 \mathrm{Ci}$ of ${ }^{99} \mathrm{Tc}$ produced at Hanford equates to $1922 \mathrm{~kg}$ of ${ }^{99} \mathrm{Tc}$.

Table 4.2. Range in Total Tc Inventory (curies) Produced at the Hanford Site

\begin{tabular}{cl}
\hline $\begin{array}{c}{ }^{99} \text { Tc Inventory (curies) } \\
\text { Decay corrected to } 01 / 01 / 2000\end{array}$ & \multicolumn{1}{c}{ Source } \\
\hline $3.43 \times 10^{4}$ & Puigh and Wood 2005; Table 2-1 based on Watrous 2002 \\
$3.26 \times 10^{4}$ & Kupfer et al. (1999) (Table ES-2); Kupfer et al. (1997) (Table ES-2) \\
$3.21 \times 10^{4}$ & DOE 1996 (Appendix A), DOE 1997 (Table 2.11) \\
$3.13 \times 10^{4}$ & Kincaid et al. (2006) \\
\hline${ }^{99}$ Tc Inventory (curies) & \\
Decay corrected to 01/01/2014 & \\
\hline $3.2598 \times 10^{4}$ & Kupfer et al. (1999) (Table ES-2); Kupfer et al. (1997) (Table ES-2) \\
$3.2098 \times 10^{4}$ & DOE 1996 (Appendix A), DOE 1997 (Table 2.11) \\
\hline $3.13 \times 10^{4}$ & Kincaid et al. (2006) \\
\hline
\end{tabular}

The only other sources of ${ }^{99} \mathrm{Tc}$ present on the Hanford Site would be imported from other sites. The commercial low-level waste burial ground located south of the 200-E Area, currently operated by US Ecology, Inc., has ${ }^{99} \mathrm{Tc}$ inventory not related to Hanford fuel reprocessing. Kincaid et al. (2006) estimated that the US Ecology commercial burial ground contained $\sim 50.3 \mathrm{Ci}$ of ${ }^{99} \mathrm{Tc}$. The Final Environmental Impact Statement for the US Ecology site in Table 2.D states that between the start of operations through 2002, an estimated $50.1 \mathrm{Ci}$ of ${ }^{99} \mathrm{Tc}$ have been disposed at the site, and it is projected that the average ${ }^{99} \mathrm{Tc}$ curies expected each ensuing year is $0.093 \mathrm{Ci} / \mathrm{yr}$. The Final Environmental Impact Statement for the US Ecology site can be accessed at http://www.doh.wa.gov/Portals/1/Documents/Pubs/320-031_vol1_w.pdf. Records of waste inventories and volumes disposed at the US Ecology burial grounds are kept at the Washington State Department of Health. Through calendar year 2012, the Washington State Department of Health Waste Management Division documents a total ${ }^{99} \mathrm{Tc}$ inventory at the US Ecology site at $50.2 \mathrm{Ci}^{1}$

The current Radioactive Materials License (WN-I019-2 Amendment 40) issued by the Washington State Department of Health states that the maximum amount of ${ }^{99} \mathrm{Tc}$ that can be disposed at the US Ecology site is $55.10 \mathrm{Ci}$, so this would appear to set an upper bound on the ${ }^{99} \mathrm{Tc}$ that could be in the commercial burial ground and this quantity is insignificant compared to the ${ }^{99} \mathrm{Tc}$ produced during the fuel irradiation to generate plutonium. The Radioactive Materials License (WN-I019-2 Amendment 40) is available at http://www.usecology.com/richland_docs_forms.htm.

\footnotetext{
${ }^{1}$ Phone conversation with Kristen Schwab (Washington Department of Health, Waste Management Division on March 5, 2014. Also can be found in Table 1 of Facility Utilization Report -2012 prepared by US Ecology but not available on the internet and provided by Kristen Schwab.
} 


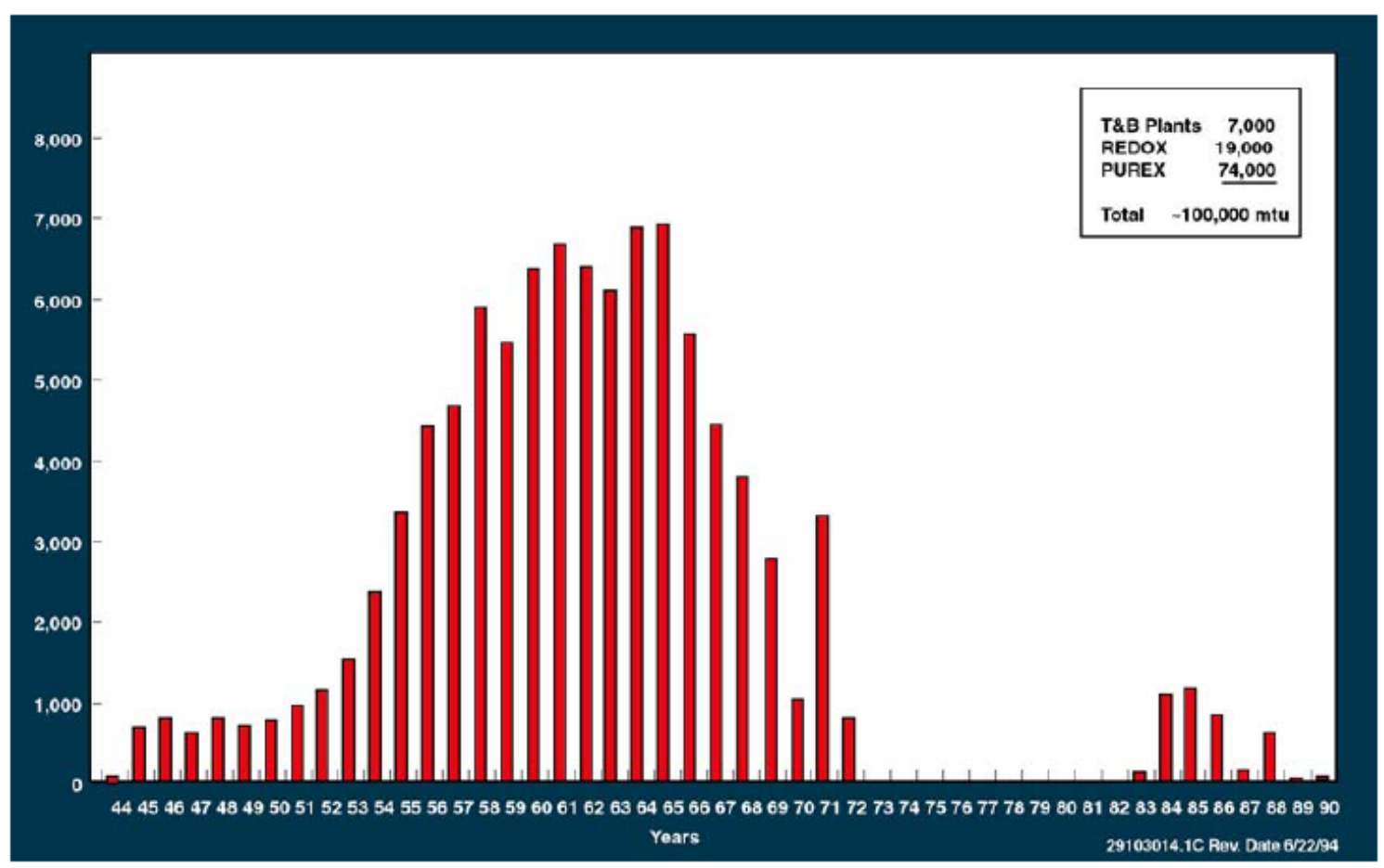

Figure 4.1. Timeline of the Hanford Site Uranium Fuel Reprocessing (Metric Tons of Uranium)

A second off-site source of ${ }^{99} \mathrm{Tc}$ that may in the future be shipped to the Hanford Site is discussed in the Final Tank Closure and Waste Management Environmental Impact Statement for the Hanford Site, Richland, Washington (TC\&WM EIS; DOE 2012). Appendix D of the TC\&WM EIS discusses the potential shipment of nuclear waste from other DOE sites for final disposal at Hanford. Whether or not such off-sites wastes will be allowed to be shipped to Hanford is an ongoing legal debate. Appendix D, Table D-87 of DOE 2012 estimates that the maximum off-site ${ }^{99} \mathrm{Tc}$ inventory that might be shipped to Hanford for final disposal is $1460 \mathrm{Ci}(86 \mathrm{~kg})$ [see http://www.hanford.gov/page.cfm/FinalTCWMEIS ]. The total ${ }^{99} \mathrm{Tc}$ produced or shipped onto the Hanford Site can be used as the starting inventory for comparing with ${ }^{99} \mathrm{Tc}$ inventories in other "pools" such as in SSTs and DSTs, present in the vadose zone from purposeful disposals to cribs, trenches, and ponds, and inadvertently released/leaked from SSTs, etc. A brief discussion of ${ }^{99} \mathrm{Tc}$ mass balance and the inventories in these other "pools" is presented in Section 6.0. Finding a good mass balance on ${ }^{99} \mathrm{Tc}$ at the Hanford Site would be of great value to future decision makers responsible for selecting remediation alternatives and to convince stakeholders that we understand what quantities and where this problematic contaminant resides at the Hanford Site.

\section{2 ${ }^{99} \mathrm{Tc}$ Inventory Currently Stored in Hanford Tanks}

For several decades there has been a concerted effort to estimate the inventory of key radionuclides and chemicals within the 177 storage tanks (149 SSTs and 28 DSTs) at the Hanford Site. The key reason estimates of the inventories of radionuclides and chemicals and the volumes of waste in the tanks are needed is to provide basic information to the complicated task of removing the wastes from the tanks and determining the size and logistics of the processing facilities needed (e.g., WTP) to convert the wastes into acceptable final solid waste forms and to project the volumes of final solid wastes and types (IHLW, 
immobilized low-activity waste [ILAW], and transuranic waste). Each of these three waste types likely will need to be disposed at different facilities and locations.

Over the years there have been several attempts to estimate how much of the total ${ }^{99} \mathrm{Tc}$ produced at Hanford remains in the storage tanks and to determine the inventory in each tank. Estimating the individual tank ${ }^{99} \mathrm{Tc}$ inventories relies on actual sample analyses when available and waste processing knowledge and waste transfer (both into and out of each tank) records. The waste processing knowledge relies on the same $\sim 1300$ distinct fuel batch records mentioned in Section 4.1, but relies on different computer codes and methodologies to calculate how much of the produced fission and activation products that formed in the irradiated fuel ended up in the waste streams created during fuel dissolution and reprocessing.

Because some of the reprocessing wastes were sent directly to cribs and trenches, not all reprocessing wastes ended up in the Hanford storage tanks. Several different conceptual models and computer algorithms were created over the years to estimate the split in the mass/activity of chemicals and radionuclides that ultimately went to the storage tanks. One of the earlier tank inventory protocols was named TRAC (see for example Jungfliesh and Simpson 1993).

As time progressed, efforts to refine the methodology and computer codes for predicting inventories in the storage tanks continued such that by about 1999 (see Kupfer et al. 1999) a suite of computer codes that collectively produced a best basis inventory (BBI) of the waste volumes, separated into three phases (supernate, salt cake, and sludge) and inventories (curies for radionuclide and kilograms for chemicals) was adopted. Historical tank inventories thus varied with time both because of transfers in and out of the tanks and because different "split" factors were used to estimate the amount of each constituent in each of the many waste streams generated by the fuel reprocessing steps. In addition, wastes from the bismuth phosphate fuel reprocessing were later removed from SSTs and reprocessed to recover uranium. Other isotope recovery campaigns using yet additional processes removed ${ }^{90} \mathrm{Sr},{ }^{137} \mathrm{Cs}$, and for a small volume of tank waste other nuclides/chemicals deemed of economic or scientific importance. A good summary of the three main fuel reprocessing operations and the later $\mathrm{U},{ }^{90} \mathrm{Sr},{ }^{137} \mathrm{Cs}$, and other element separation/recovery processes is found in Appendix B of DOE/ORP 2010.

In summary, the history of various fuel reprocessing and isotope recoveries, utilization of and transfers between the 177 storage tanks, and difficulties obtaining and analyzing samples from the tanks presents a complicated chemical, logistical, and bookkeeping challenge to estimating the inventories in each tank. This challenge has received much attention and for decades efforts have been made to improve and refine both conceptual and mathematical models to establish defensible estimates of the inventory of chemicals and radionuclides within the storage tanks. The reconciliation process used to produce the global (all tanks) and individual tank inventories has been described in detail by Kupfer et al. (1997, 1999). One key component of the inventory process is determining the fate of each component (element, nuclide, etc.) during the dissolution and reprocessing of the fuel to extract plutonium and later both plutonium and uranium. One model used early in the inventory estimation exercises in conjunction with DKPRO (the bookkeeping algorithm) was called SPLIT. Later, scientists at Los Alamos National Laboratory (LANL) created a different and independent conceptual and computer algorithm, called the Hanford Defined Waste (HDW) model, to follow the fate of key constituents. The HDW model simulates the paths of the irradiated fuel and cladding into the process plants, where the chemical operations took place. Chemicals added to process the irradiated fuel and treat the resultant liquid streams are also tracked. Improvements to HDW over time included treating fuel and cladding separately as discrete 
entities, incorporation of process losses, improved chemical process models, redefining selected physical and chemical assumptions, and an improved solubility model. HDW has undergone five revisions over the years in attempts to accurately determine the chemical fate (solubility-precipitation reactions) and waste stream association (how much ends up in which waste stream) for each key chemical and radionuclide for each fuel reprocessing or isotope recovery operation. The current version, HDW version 5, is discussed in detail in Higley and Place 2005. Estimating the solubility of key constituents in each process is a key to determining how much of the starting inventory goes to each waste stream, and is an important consideration because cascading of wastes was a common practice in the $1950 \mathrm{~s} .{ }^{1}$ The SPLIT code did not account for inventory losses from the cascading activities.

SPLIT assumed that $24 \%$ of the ${ }^{99}$ Tc present in reprocessed fuels using the PUREX process and $37 \%$ in the REDOX process remained with the uranium product and thus was not sent to storage tanks. SPLIT assumed that only $<1 \%$ of the ${ }^{99} \mathrm{Tc}$ in the bismuth phosphate fuel reprocessing campaign remained with the plutonium product after the first two precipitation/purifications steps and did not get sent to storage tanks. Serne et al. (2007) corroborate the fact that $\approx<1 \%$ of the ${ }^{99} \mathrm{Tc}$ in the bismuth phosphate fuel reprocessing campaign was not sent to the SSTs. After accounting for the larger quantity of fuel reprocessed using the REDOX and PUREX processes, the HDW version 5 model estimates that approximately $20 \%$ to $23 \%$ of the ${ }^{99} \mathrm{Tc}$ produced in the reactors was shipped offsite with recovered uranium, not sent to the Hanford storage tanks. In contrast, the early versions of the HDW model did not consider ${ }^{99} \mathrm{Tc}$ remaining with the uranium product in the REDOX and PUREX reprocessing campaigns but did consider ${ }^{99} \mathrm{Tc}$ "losses" from tank inventories via the cascading activities. HDW version 5 (see Higley and Place 2005) does account for ${ }^{99} \mathrm{Tc}$ sent off-site with uranium product.

Table 4.3 lists some early-to-present total ${ }^{99}$ Tc inventory estimates in the Hanford storage tanks. A more complete listing of ${ }^{99} \mathrm{Tc}$ total inventories in the storage tanks and a description of how they were derived is found in Puigh and Wood 2005. Figure 4.2 taken from Puigh and Wood 2005 shows a slow reduction in the ${ }^{99} \mathrm{Tc}$ total inventory in the storage tanks with time, likely because of a combination of more sampling and chemical analyses availability and refinements in the HDW model that estimates the fate of ${ }^{99} \mathrm{Tc}$ in the overall reprocessing chemistry. The only high ${ }^{99} \mathrm{Tc}$ inventory value $\left(4.7 \times 10^{4} \mathrm{Ci}\right)$ is based on limited DST sampling data and HDW version 1, which did not allow any loss of ${ }^{99} \mathrm{Tc}$ to waste streams not sent to tanks.

The BBI is the current official estimate of the current contents (46 radionuclides and 25 chemicals) in SSTs and DSTs and is based on Kupfer et al. (1999). Separate inventories are provided for supernate, saltcake, and sludge waste. Supernate, especially in the DSTs, is an aqueous solution of sodium nitrate, nitrite, and hydroxide, and various organic compounds including citrate, gluconate, formate, oxalate, ethylenediaminetetraacetate (EDTA), and NTA. Most of the supernate in the SSTs has been removed over the past several decades to promote SST stabilization. Saltcake consists of water-soluble salts that have precipitated during reduction of supernate volume by evaporation and consists mainly of sodium nitrate and nitrite. Sludge consists of the waste components that are insoluble under strongly alkaline conditions and includes most of the fission products and actinides plus large quantities of aluminum and

\footnotetext{
${ }^{1}$ Waste cascading was a process where fuel reprocessing liquid wastes containing suspended solids was piped into a chain (usually three) of connected SSTs. As the waste filled the first tank, suspended solids settled and the relatively clarified liquid would then flow into the second tank (buried at a slightly lower elevation), with the prospect that any residual suspended solids would settle out before the supernate flowed into the third tank (again buried lower than the second tank). Ultimately, very-clarified supernate from the third tank would flow directly to cribs, where the clarified liquid seeped into the ground.
} 
iron oxides and aluminosilicates. Whenever possible, measured analytical values for each particular phase are used to develop the BBI. If such actual measurements for any of the three phases are not available, then measured values in a similar phase in another tank with similar waste history are used. Finally, if no analogous measurements are available, then values from the HDW model are used. In most cases, inventory estimates for radionuclides, including ${ }^{99} \mathrm{Tc}$, are based on estimated values from the HDW model.

Table 4.3. Selected ${ }^{99} \mathrm{Tc}$ Inventory Estimates Within Hanford's 177 Storage Tanks

\begin{tabular}{|c|c|c|}
\hline $\begin{array}{l}{ }^{99} \mathrm{Tc} \text { Inventory (curies) } \\
\text { and Approximate Date } \\
\text { for Estimate }\end{array}$ & Split Between SSTs and DSTs & Source \\
\hline $2.99 \times 10^{4}(1980)$ & & Jungfliesh and Simpson 1993 \\
\hline $3.00 \times 10^{4}(1990)$ & $\begin{array}{l}2.00 \times 10^{4} \text { in SSTs } \\
1.00 \times 10^{4} \text { in DSTs }\end{array}$ & Morgan et al. (1988) \\
\hline $2.83 \times 10^{4}(1997-99)$ & Total ${ }^{99} \mathrm{Tc}$ reprocessed & $\begin{array}{l}\text { Kupfer et al. (1999) (Table ES-2; Table } \\
6.1-3 \text { ) }\end{array}$ \\
\hline $2.47 \times 10^{4}(1997)$ & $\begin{array}{l}\text { Used SPLIT model to estimate }{ }^{99} \mathrm{Tc} \text { that } \\
\text { stayed with U product }\end{array}$ & Kupfer et al. (1999) (Table 6.1-3) \\
\hline $2.97 \times 10^{4}(2002)$ & $\begin{array}{l}1.55 \times 10^{4} \text { in SSTs } \\
1.42 \times 10^{4} \text { in DSTs }\end{array}$ & DOE TC\&WM EIS; DOE 2012 \\
\hline $2.64 \times 10^{4}(2010)$ & $\begin{array}{l}\text { Used HDW version } 5 \text {, removes }{ }^{99} \mathrm{Tc} \\
\text { that went offsite with } \mathrm{U} \text { product }\end{array}$ & DOE TC\&WM EIS; DOE 2012 \\
\hline $2.68 \times 10^{4}(2004)$ & $\begin{array}{l}\text { Includes future Hanford tank receipts } \\
\text { (see Kirkbride et al. 2005) }\end{array}$ & Puigh and Wood 2005 (Table ES-1) \\
\hline $2.64 \times 10^{4}$ & BBI in TWINS database July 2012 & Robbins and May 2013 \\
\hline $2.65 \times 10^{4}(2014)$ & $\begin{array}{l}\text { Current BBI in TWINS database 01-24- } \\
2014\end{array}$ & This report \\
\hline
\end{tabular}

The requirements for the BBI process are given in Place 2006. A very detailed protocol (see Nguyen 2010) for evaluating analytical data from cores, grab samples, and archived samples is followed. This protocol accounts for potential sample evaporation during storage, potential matrix interferences, and how to average data from multiple samplings of a particular phase. If more than one analytical method can be used for measurement, the one that has shown more accurate results is chosen, and other considerations are reviewed by a team of experienced tank experts. Today the BBI is updated quarterly for each of the 177 storage tanks for which changes in volume and inventories (caused by retrieval activities or tank-to-tank transfers) have occurred or new data becomes available such as new sampling and analyses activities. The BBI data are stored in an electronic database called the Tank Waste Information Network System (TWINS), which can be found at the following URL ${ }^{1}$ for those with access to the Hanford intranet https://twins.labworks.org/twinsdata/Forms/About.aspx.

\footnotetext{
${ }^{1}$ TWINS is operated and maintained by the Pacific Northwest National Laboratory for Washington River Protection Solutions. Anyone who has a PNNL or HLAN account has access to this site. Others who require access to TWINS data may do so by requesting authorization to TWINS via an external website. Requests may be made to matthew_rodgers@rl.gov or by calling (509) 376-2993.
} 


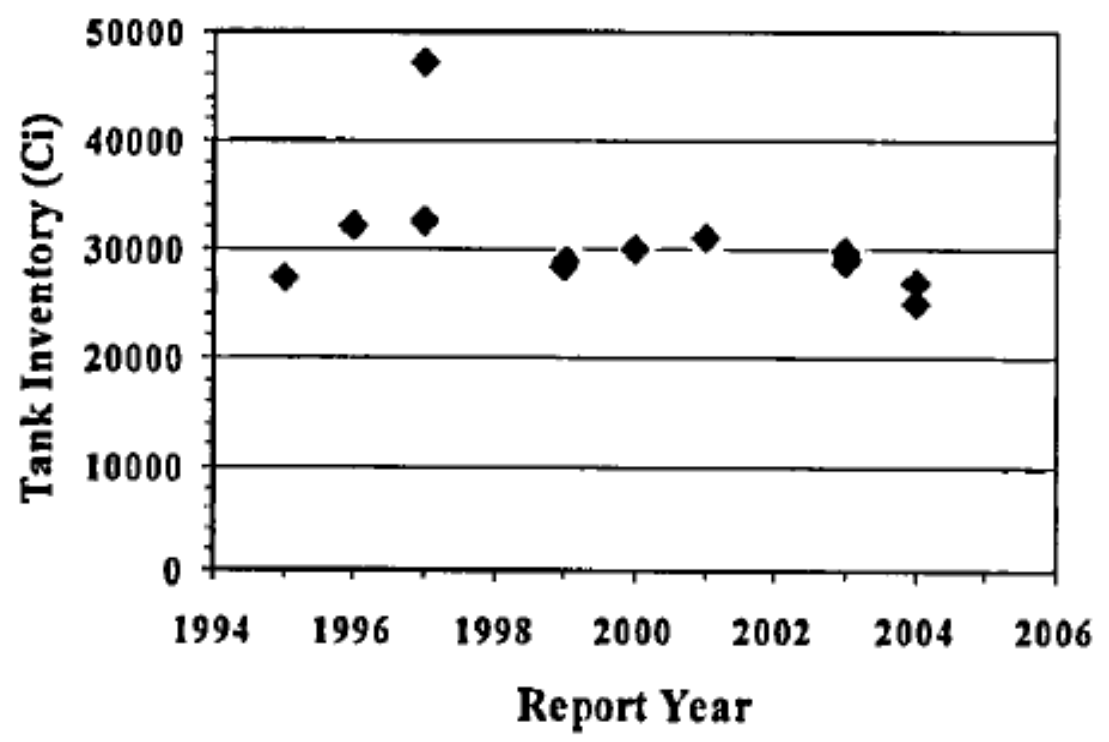

Figure 4.2. Trend in ${ }^{99} \mathrm{Tc}$ Inventory Estimates in Hanford Storage Tanks as Function of Time (from Puigh and Wood 2005)

The following two tables were constructed using data for the 177 Hanford storage tanks downloaded from TWINS on January 27, 2014, and are the current BBI for the 177 Hanford storage tanks. More details from TWINS are presented in Appendix A. Assuming that the BBI is an accurate tabulation of the current inventory in the Hanford storage tanks, Table 4.4 shows the total ${ }^{99} \mathrm{Tc}$ inventory in each tank farm ranked from highest to lowest total ${ }^{99} \mathrm{Tc}$ and differentiated between SST and DST farms. Appendix A shows the ranking of highest to lowest ${ }^{99} \mathrm{Tc}$ inventories for all 177 tanks. Observations from the data in Table 4.4 show that there is more total ${ }^{99} \mathrm{Tc}\left(1.51 \times 10^{4} \mathrm{Ci}\right)$ in the $28 \mathrm{DST}$ s than in the $149 \mathrm{SSTs}$ $\left(1.14 \times 10^{4} \mathrm{Ci}\right)$. The ${ }^{99} \mathrm{Tc}$ present in three of the $200-\mathrm{W}$ farms (TX, S, and SX) accounts for $54 \%$ of the ${ }^{99} \mathrm{Tc}$ in all SSTs (and $23.4 \%$ of the total ${ }^{99} \mathrm{Tc}$ inventory) and in 200 -E the BY SST farm contains $\sim 14 \%$ of the total ${ }^{99} \mathrm{Tc}$ in all SSTs (or $6 \%$ of the total ${ }^{99} \mathrm{Tc}$ inventory). The DSTs contain $57 \%$ of the total ${ }^{99} \mathrm{Tc}$ inventory in Hanford tanks, with the bulk $\left(1.33 \times 10^{4} \mathrm{Ci}\right)$ within four DST farms (AP, AN, AW, and AZ) in the 200-E Area.

Table 4.5 shows that the supernate in the SSTs contains insignificant $(32.8 \mathrm{Ci}$ or $0.1 \%$ of the total ${ }^{99} \mathrm{Tc}$ in Hanford storage tanks) amounts of ${ }^{99} \mathrm{Tc}$. This is expected because the SSTs have been rigorously pumped to remove drainable liquids, leaving only very small volumes of supernate. On the other hand, the SST saltcake (combined solids and un-pumpable liquids) contains the bulk $\left(1.02 \times 10^{4} \mathrm{Ci}\right)$ of the ${ }^{99} \mathrm{Tc}$ in SSTs. The saltcake ${ }^{99} \mathrm{Tc}$ may be more present as liquid within the saltcake solids that could not be removed by saltwell pumping as opposed to being present as discrete ${ }^{99} \mathrm{Tc}$-bearing evaporated salts. In Appendix A, the ${ }^{99} \mathrm{Tc}$ distribution between the three major phases is split further into 5 categories: 1) supernate, 2) salt-cake liquids, 3) saltcake solids, 4) sludge liquids, and 5) sludge solids for many tanks when samples were obtained and the salt cake and sludge phases were either manipulated (e.g., centrifuged or filtered) or allowed to gravity separate into a liquid and solid phase. Within the SSTs only about $5 \%(1230 \mathrm{Ci})$ of the total ${ }^{99} \mathrm{Tc}$ inventory is associated with sludge. In contrast, within the DSTs $1.09 \times 10^{4} \mathrm{Ci}$, or $41 \%$, of the ${ }^{99} \mathrm{Tc}$ is found in the supernate and is thus considered "soluble." About $13 \%$ (3520 Ci) of the total ${ }^{99} \mathrm{Tc}$ inventory is found in DST saltcake and $652 \mathrm{Ci}$, or $2.5 \%$, in DST sludge. Again, Appendix A shows more detailed data on the ${ }^{99} \mathrm{Tc}$ distribution between liquids and solids in the DST saltcake and DST sludge. Given the current BBI values, overall, $41.2 \%$ of the total ${ }^{99} \mathrm{Tc}$ in the 
177 storage tanks is found in supernate, $51.6 \%$ is associated with saltcake, and $7.2 \%$ is associated with sludge.

Table 4.4. Total ${ }^{99} \mathrm{Tc}$ Inventory (Ci) in Each Tank Farm

\begin{tabular}{|c|c|c|c|c|c|c|c|}
\hline SST Farm & $\begin{array}{l}{ }^{99} \mathrm{Tc} \\
(\mathrm{Ci})\end{array}$ & $\begin{array}{c}\text { SST Farm } \\
\text { Ranking }\end{array}$ & $\begin{array}{c}\text { Overall } \\
\text { Ranking }\end{array}$ & DST Farm & $\begin{array}{l}{ }^{99} \mathrm{Tc} \\
(\mathrm{Ci})\end{array}$ & $\begin{array}{c}\text { DST Farm } \\
\text { Ranking }\end{array}$ & $\begin{array}{l}\text { Overall } \\
\text { Ranking }\end{array}$ \\
\hline TX & $2.52 \mathrm{E}+03$ & $\overline{1}$ & 4 & AP & $4.79 \mathrm{E}+03$ & 1 & 1 \\
\hline $\mathrm{S}$ & $2.20 \mathrm{E}+03$ & 2 & 5 & AN & $3.95 \mathrm{E}+03$ & 2 & 2 \\
\hline BY & $1.55 \mathrm{E}+03$ & 3 & 7 & AW & $2.90 \mathrm{E}+03$ & 3 & 3 \\
\hline SX & $1.48 \mathrm{E}+03$ & 4 & 9 & AZ & $1.63 \mathrm{E}+03$ & 4 & 6 \\
\hline A & $7.15 \mathrm{E}+02$ & 5 & 10 & SY & $1.55 \mathrm{E}+03$ & 5 & 8 \\
\hline $\mathrm{AX}$ & $3.87 \mathrm{E}+02$ & 6 & 11 & AY & $2.38 \mathrm{E}+02$ & 6 & 13 \\
\hline $\mathrm{BX}$ & $3.66 \mathrm{E}+02$ & 7 & 12 & & & & \\
\hline B & $2.08 \mathrm{E}+02$ & 8 & 14 & & & & \\
\hline $\mathrm{T}$ & $1.51 \mathrm{E}+02$ & 9 & 15 & & & & \\
\hline $\mathrm{C}$ & $1.02 \mathrm{E}+02$ & 10 & 16 & & & & \\
\hline TY & $9.57 \mathrm{E}+01$ & 11 & 17 & & & & \\
\hline U & $1.66 \mathrm{E}+03$ & 12 & 18 & & & & \\
\hline SST Total & $1.14 E+04$ & & & DST Total & $1.51 E+04$ & & \\
\hline & & Total ${ }^{99} \mathrm{Tc}$ & $2.65 E+04$ & curies & & & \\
\hline
\end{tabular}


Table 4.5. Total ${ }^{99} \mathrm{Tc}$ Inventory (Ci) in Each Phase by Tank Farm

\begin{tabular}{|c|c|c|c|c|}
\hline SST Tank Farm & Supernate & Saltcake & Sludge & Total \\
\hline A & $8.48 \mathrm{E}+00$ & $5.70 \mathrm{E}+02$ & $1.38 \mathrm{E}+02$ & $7.15 \mathrm{E}+02$ \\
\hline $\mathrm{AX}$ & $0.00 \mathrm{E}+00$ & $3.62 \mathrm{E}+02$ & $2.54 \mathrm{E}+01$ & $3.87 \mathrm{E}+02$ \\
\hline B & $3.38 \mathrm{E}+00$ & $1.11 \mathrm{E}+01$ & $1.95 \mathrm{E}+02$ & $2.08 \mathrm{E}+02$ \\
\hline $\mathrm{BX}$ & $4.20 \mathrm{E}+00$ & $1.65 \mathrm{E}+02$ & $1.96 \mathrm{E}+02$ & $3.66 \mathrm{E}+02$ \\
\hline BY & $0.00 \mathrm{E}+00$ & $1.55 \mathrm{E}+03$ & $1.40 \mathrm{E}+00$ & $1.55 \mathrm{E}+03$ \\
\hline $\mathrm{C}$ & $5.67 \mathrm{E}-03$ & $5.77 \mathrm{E}-02$ & $1.02 \mathrm{E}+02$ & $1.02 \mathrm{E}+02$ \\
\hline S & $1.04 \mathrm{E}+00$ & $2.11 \mathrm{E}+03$ & $9.16 \mathrm{E}+01$ & $2.20 \mathrm{E}+03$ \\
\hline SX & $0.00 \mathrm{E}+00$ & $1.34 \mathrm{E}+03$ & $1.46 \mathrm{E}+02$ & $1.48 \mathrm{E}+03$ \\
\hline $\mathrm{T}$ & $9.91 \mathrm{E}+00$ & $3.47 \mathrm{E}+01$ & $1.06 \mathrm{E}+02$ & $1.51 \mathrm{E}+02$ \\
\hline TX & $2.23 \mathrm{E}+00$ & $2.36 \mathrm{E}+03$ & $1.57 \mathrm{E}+02$ & $2.52 \mathrm{E}+03$ \\
\hline TY & $2.55 \mathrm{E}-01$ & $2.75 \mathrm{E}+01$ & $6.80 \mathrm{E}+01$ & $9.57 \mathrm{E}+01$ \\
\hline $\mathrm{U}$ & $3.33 \mathrm{E}+00$ & $1.63 \mathrm{E}+03$ & $2.65 \mathrm{E}+01$ & $1.66 \mathrm{E}+03$ \\
\hline SST (TOTAL) & $3.28 \mathrm{E}+01$ & $1.02 \mathrm{E}+04$ & $1.25 \mathrm{E}+03$ & $1.14 \mathrm{E}+04$ \\
\hline$\%$ of Total & $0.1 \%$ & $38.3 \%$ & $4.7 \%$ & $43.2 \%$ \\
\hline DST Tank Farm & Supernate & Saltcake & Sludge & Total \\
\hline AN & $2.18 \mathrm{E}+03$ & $1.55 \mathrm{E}+03$ & $2.23 \mathrm{E}+02$ & $3.95 \mathrm{E}+03$ \\
\hline AP & $4.47 \mathrm{E}+03$ & $3.13 \mathrm{E}+02$ & $1.34 \mathrm{E}+01$ & $4.79 \mathrm{E}+03$ \\
\hline AW & $1.96 \mathrm{E}+03$ & $8.72 \mathrm{E}+02$ & $6.49 \mathrm{E}+01$ & $2.90 \mathrm{E}+03$ \\
\hline AY & $1.97 \mathrm{E}+02$ & $0.00 \mathrm{E}+00$ & $4.07 \mathrm{E}+01$ & $2.37 \mathrm{E}+02$ \\
\hline $\mathrm{AZ}$ & $1.49 \mathrm{E}+03$ & $0.00 \mathrm{E}+00$ & $1.37 \mathrm{E}+02$ & $1.63 \mathrm{E}+03$ \\
\hline SY & $5.96 \mathrm{E}+02$ & $7.84 \mathrm{E}+02$ & $1.73 E+02$ & $1.55 \mathrm{E}+03$ \\
\hline DST (TOTAL) & $1.09 \mathrm{E}+04$ & $3.52 \mathrm{E}+03$ & $6.52 \mathrm{E}+02$ & $1.51 \mathrm{E}+04$ \\
\hline$\%$ of Total & $41.1 \%$ & $13.3 \%$ & $2.5 \%$ & $56.8 \%$ \\
\hline
\end{tabular}

Another important consideration is how each tank's ${ }^{99} \mathrm{Tc}$ inventory was estimated. The BBI protocol uses several "bases" or categories to represent how the inventory value was derived. The bases/categories are shown in Table 4.6, briefly explained, and ranked by technical robustness or certainty. 
Table 4.6. BBI Categories Used to Described How Inventory Values Were Derived

\begin{tabular}{|c|c|c|}
\hline Category & Category Description & $\begin{array}{l}\text { Level of } \\
\text { Certainty }\end{array}$ \\
\hline$S$ & $\begin{array}{l}\text { Sample based; values from different samplings of the same layer in a specific tank are } \\
\text { averaged; sometimes samples from two or more tanks that contain the same waste type are } \\
\text { averaged and designated "S." }\end{array}$ & Highest \\
\hline E & $\begin{array}{l}\text { Process knowledge based; generally derived from sample-based results; concentrations } \\
\text { generated from new data such as 1) weighted average values for waste transfers, } \\
\text { 2) reconstituted values for centrifuged samples or precipitated solids, 3) pre-1989 sample } \\
\text { data that is not in TWINS because QA/QC was not as good as today, and 4) sample data } \\
\text { from another similar tank is applied. }\end{array}$ & $\begin{array}{l}\text { Second } \\
\text { highest }\end{array}$ \\
\hline TS & $\begin{array}{l}\text { Template sample based; tank-specific sampling or process knowledge values not available; } \\
\text { TS values are average values for the waste type (designated for the tank in question) } \\
\text { derived from analytical results from two or more tanks that contain the designated waste } \\
\text { type. }\end{array}$ & $\begin{array}{l}\text { Third } \\
\text { highest }\end{array}$ \\
\hline $\mathrm{TE}$ & $\begin{array}{l}\text { Template engineering based; tank-specific sampling or process knowledge values not } \\
\text { available; TE values are from version } 5 \text { of the HDW model (RPP 19822). Values are } \\
\text { based on fuel activity estimates, separation plant process records, and waste transfer } \\
\text { records. }\end{array}$ & Lowest \\
\hline
\end{tabular}

Table 4.7 lists tanks and their ${ }^{99} \mathrm{Tc}$ inventories that have at least one of the phases in the tank actually sampled and then the ${ }^{99} \mathrm{Tc}$ directly measured (earning and "S" basis) or had the ${ }^{99} \mathrm{Tc}$ inventory estimated based on process knowledge (earning the "E" basis). These two basis categories are of higher quality or certainty. It can be seen in Table 4.7 that some portion of the tank contents (supernate, saltcake, or sludge) was actually sampled and the ${ }^{99} \mathrm{Tc}$ directly measured for 49 tanks, containing $1.00 \times 10^{4} \mathrm{Ci}$ of ${ }^{99} \mathrm{Tc}$. This represents $37.8 \%$ of the total ${ }^{99} \mathrm{Tc}$ estimated to reside currently within all the tanks. An additional 26 tanks have some portion of their tank content ${ }^{99} \mathrm{Tc}$ mass known from "process knowledge," the second-best quality basis. These 26 tanks contain an additional $6.51 \times 10^{3} \mathrm{Ci}$ of ${ }^{99} \mathrm{Tc}$, or an additional $24.6 \%$ of the total ${ }^{99} \mathrm{Tc}$ inventory estimated to reside currently in the Hanford tanks. Thus, about $62.4 \%$ of the total ${ }^{99} \mathrm{Tc}$ inventory estimate is based on more-certain information, leaving $37.6 \%$ of the total estimated ${ }^{99} \mathrm{Tc}$ inventory as more-uncertain. 
Table 4.7. Tanks and ${ }^{99} \mathrm{Tc}$ Inventory (Ci) that Have Better Certainty

\begin{tabular}{|c|c|c|c|c|c|}
\hline Tank & Total ${ }^{99} \mathrm{Tc}$ & Basis & Tank & Total ${ }^{99} \mathrm{Tc}$ & Basis \\
\hline AN-101 & $2.01 \mathrm{E}+02$ & $\mathrm{~S} / \mathrm{E} / \mathrm{TS} / \mathrm{TE}$ & A-102 & $3.70 \mathrm{E}+01$ & $\bar{E} / \mathrm{TE}$ \\
\hline AN-102 & $5.80 \mathrm{E}+02$ & $\mathrm{~S} / \mathrm{E}$ & A-103 & $2.59 \mathrm{E}+02$ & $\mathrm{E} / \mathrm{TE}$ \\
\hline AN-103 & $6.81 \mathrm{E}+02$ & $\mathrm{~S}$ & A-106 & $1.48 \mathrm{E}+02$ & $\mathrm{E}$ \\
\hline AN-104 & $7.94 \mathrm{E}+02$ & $\mathrm{~S}$ & AN-106 & $1.44 \mathrm{E}+02$ & $\mathrm{E} / \mathrm{TE}$ \\
\hline AN-105 & $1.12 \mathrm{E}+03$ & $\mathrm{~S}$ & AP-101 & $7.55 E+02$ & E \\
\hline AN-107 & $4.34 \mathrm{E}+02$ & $\mathrm{~S} / \mathrm{E}$ & AP-102 & $7.03 \mathrm{E}+02$ & $\mathrm{E}$ \\
\hline AP-107 & $1.77 \mathrm{E}+02$ & $\mathrm{~S}$ & AP-103 & $9.59 \mathrm{E}+02$ & $\mathrm{E} / \mathrm{TS}$ \\
\hline AW-101 & $8.18 \mathrm{E}+02$ & $\mathrm{~S}$ & AP-104 & $1.55 \mathrm{E}+02$ & E \\
\hline AW-103 & $3.97 \mathrm{E}+02$ & $\mathrm{~S} / \mathrm{E} / \mathrm{TS}$ & AP-105 & $9.51 \mathrm{E}+02$ & $\mathrm{E} / \mathrm{TS}$ \\
\hline AW-106 & $5.93 \mathrm{E}+02$ & $\mathrm{~S} / \mathrm{TS}$ & AP-106 & $3.68 \mathrm{E}+02$ & $\mathrm{E}$ \\
\hline AX-102 & $6.30 \mathrm{E}+00$ & $\mathrm{~S} / \mathrm{TE}$ & AP-108 & $7.24 \mathrm{E}+02$ & $\mathrm{E}$ \\
\hline AX-104 & $2.06 \mathrm{E}+01$ & $\mathrm{~S}$ & AW-102 & $3.21 \mathrm{E}+02$ & $\mathrm{E} / \mathrm{TE}$ \\
\hline AY-101 & $5.55 \mathrm{E}+01$ & $\mathrm{~S} / \mathrm{E}$ & AW-104 & $7.59 \mathrm{E}+02$ & $\mathrm{E} / \mathrm{TS} / \mathrm{TE}$ \\
\hline AY-102 & $1.82 \mathrm{E}+02$ & $\mathrm{~S} / \mathrm{E}$ & B-110 & $2.13 \mathrm{E}+01$ & $\mathrm{E} / \mathrm{TE}$ \\
\hline AZ-101 & $1.23 \mathrm{E}+03$ & $\mathrm{~S} / \mathrm{E}$ & BX-101 & $1.03 \mathrm{E}+01$ & $\mathrm{E}$ \\
\hline AZ-102 & $4.01 \mathrm{E}+02$ & $\mathrm{~S} / \mathrm{E}$ & BX-102 & $1.19 \mathrm{E}-01$ & $\mathrm{E} / \mathrm{TE}$ \\
\hline B-111 & $1.32 \mathrm{E}+02$ & $\mathrm{~S} / \mathrm{TE}$ & C-101 & $4.34 \mathrm{E}-02$ & $\mathrm{E} / \mathrm{TE}$ \\
\hline B-202 & $6.85 \mathrm{E}-01$ & $\mathrm{~S}$ & C-105 & $8.14 \mathrm{E}+01$ & $\mathrm{E}$ \\
\hline BX-107 & $6.98 \mathrm{E}+01$ & $\mathrm{~S}$ & C-201 & $2.63 \mathrm{E}-03$ & $\mathrm{E}$ \\
\hline BY-105 & $4.63 \mathrm{E}+01$ & $\mathrm{~S} / \mathrm{E} / \mathrm{TE}$ & S-102 & $2.00 \mathrm{E}+01$ & $\mathrm{E} / \mathrm{TE}$ \\
\hline C-103 & 4.48E-02 & $\mathrm{S}$ & T-112 & $2.12 \mathrm{E}+00$ & $\mathrm{E} / \mathrm{TE}$ \\
\hline C-104 & 1.73E-01 & $\mathrm{S} / \mathrm{E}$ & TY-101 & $5.26 \mathrm{E}+00$ & $\mathrm{E} / \mathrm{TE}$ \\
\hline C-106 & $1.64 \mathrm{E}-01$ & $\mathrm{~S}$ & TY-102 & $9.37 \mathrm{E}+00$ & $\mathrm{E} / \mathrm{TS} / \mathrm{TE}$ \\
\hline C-107 & $4.00 \mathrm{E}+00$ & $\mathrm{~S} / \mathrm{E}$ & TY-103 & $2.71 \mathrm{E}+01$ & $\mathrm{E} / \mathrm{TS}$ \\
\hline C-108 & $3.96 \mathrm{E}-02$ & $\mathrm{~S} / \mathrm{E}$ & TY-104 & $8.86 \mathrm{E}+00$ & $\mathrm{E}$ \\
\hline C-109 & $7.50 \mathrm{E}-03$ & S & TY-105 & $4.40 \mathrm{E}+01$ & E \\
\hline C-110 & $5.77 \mathrm{E}-02$ & $\mathrm{~S}$ & Total & $6.51 E+03$ & \\
\hline C-112 & $1.29 \mathrm{E}+01$ & $\mathrm{~S} / \mathrm{TS}$ & & & \\
\hline C-202 & $2.50 \mathrm{E}-03$ & $\mathrm{~S} / \mathrm{E}$ & & & \\
\hline C-203 & $2.32 \mathrm{E}-03$ & $\mathrm{~S} / \mathrm{E}$ & & & \\
\hline C-204 & $3.18 \mathrm{E}-03$ & $\mathrm{~S} / \mathrm{E}$ & & & \\
\hline S-101 & $1.06 \mathrm{E}+02$ & $\mathrm{~S} / \mathrm{E} / \mathrm{TE}$ & & & \\
\hline S-104 & $5.12 \mathrm{E}+01$ & $\mathrm{~S} / \mathrm{TE}$ & & & \\
\hline S-112 & $1.37 \mathrm{E}-01$ & $\mathrm{~S} / \mathrm{E}$ & & & \\
\hline SY-101 & $2.98 \mathrm{E}+02$ & $\mathrm{~S} / \mathrm{E}$ & & & \\
\hline SY-102 & $2.44 \mathrm{E}+02$ & $\mathrm{~S} / \mathrm{E}$ & & & \\
\hline SY-103 & $1.01 \mathrm{E}+03$ & $\mathrm{~S} / \mathrm{E}$ & & & \\
\hline T-102 & $7.13 \mathrm{E}+00$ & $\mathrm{~S} / \mathrm{TE}$ & & & \\
\hline $\mathrm{T}-104$ & $9.74 \mathrm{E}-01$ & $\mathrm{~S} / \mathrm{E}$ & & & \\
\hline $\mathrm{T}-105$ & $3.50 \mathrm{E}+01$ & $\mathrm{~S} / \mathrm{TE}$ & & & \\
\hline $\mathrm{T}-107$ & $4.83 \mathrm{E}+01$ & $\mathrm{~S}$ & & & \\
\hline $\mathrm{T}-111$ & $1.66 \mathrm{E}+01$ & $\mathrm{~S}$ & & & \\
\hline TY-106 & $1.08 \mathrm{E}+00$ & $\mathrm{~S}$ & & & \\
\hline U-107 & $2.35 \mathrm{E}+02$ & $\mathrm{~S} / \mathrm{TS} / \mathrm{TE}$ & & & \\
\hline U-110 & $1.10 \mathrm{E}+01$ & $\mathrm{~S} / \mathrm{TS}$ & & & \\
\hline U-201 & $1.22 \mathrm{E}-01$ & S & & & \\
\hline U-202 & $1.10 \mathrm{E}-01$ & S & & & \\
\hline U-203 & 9.94E-02 & $\mathrm{S}$ & & & \\
\hline U-204 & $3.56 \mathrm{E}-02$ & $\mathrm{~S}$ & & & \\
\hline Total & $1.00 \mathrm{E}+04$ & & & & \\
\hline
\end{tabular}


It is realistic to assume that ${ }^{99} \mathrm{Tc}$ in the supernate and drainable liquids within the saltcake and sludge are soluble forms/species of technetium. It is also probable that some of the ${ }^{99} \mathrm{Tc}$ in saltcake that was not differentiated between drainable liquid and saltcake solids, and even the saltcake solids for tanks where the split between drainable saltcake liquid and saltcake solids is available, would be solubilized during retrieval operations, which in general use some water. Given this assumption (that supernate, drainable liquids, and saltcake categorized Tc are soluble), the split between soluble and not soluble ${ }^{99} \mathrm{Tc}$ is shown in Table 4.8, based on data in Table 4.5 and Appendix A. Thus, the values of "soluble ${ }^{99} \mathrm{Tc}$ " shown in row 6 of Table 4.8 are simplistic estimates of the $\mathrm{Ci}$ and percentages of ${ }^{99} \mathrm{Tc}$ that would be readily water-soluble in the retrieved tank wastes sent to the WTP PT Facility, prior to being further processed for vitrification or sent to supplemental waste solidification facilities. The values in row 10 of Table 4.8 for "insoluble" assume that all the ${ }^{99} \mathrm{Tc}$ in saltcake (undifferentiated and/or solids) is soluble, but that any the ${ }^{99} \mathrm{Tc}$ in the sludge solids would not be soluble prior to any pretreatment manipulations. Thus, the estimated total ${ }^{99} \mathrm{Tc}$ that is readily water-soluble in the 177 storage tanks today ranges from greater than $47 \%$ to likely less than $93 \%$.

Table 4.8. Potential Split of Soluble versus Non-soluble ${ }^{99}$ Tc in Hanford Storage Tanks Before Pretreatment

\begin{tabular}{|c|c|c|c|c|c|c|c|}
\hline $\begin{array}{c}\text { Tank } \\
\text { "Phases" or } \\
\text { Categories }\end{array}$ & $\begin{array}{c}\mathrm{SST}^{99} \mathrm{Tc} \\
(\mathrm{Ci})\end{array}$ & $\%$ of SSTs & $\begin{array}{c}\text { \% All } 177 \\
\text { Tanks }\end{array}$ & $\begin{array}{c}\mathrm{DST}^{99} \mathrm{Tc} \\
\text { (Ci) }\end{array}$ & \% DSTs & $\begin{array}{c}\text { \% All } 177 \\
\text { Tanks }\end{array}$ & $\begin{array}{c}\% \text { of Total } \\
{ }^{99} \mathrm{Tc} \\
\text { Inventory }\end{array}$ \\
\hline Supernatant & $3.28 \mathrm{E}+01$ & $0.3 \%$ & $0.1 \%$ & $1.09 \mathrm{E}+04$ & $72.3 \%$ & $41.1 \%$ & \\
\hline $\begin{array}{l}\text { Saltcake } \\
\text { (Liquid \& } \\
\text { Solid) }\end{array}$ & $4.60 \mathrm{E}+01$ & $0.4 \%$ & $0.2 \%$ & $3.28 \mathrm{E}+03$ & $21.8 \%$ & $12.4 \%$ & \\
\hline $\begin{array}{l}\text { Saltcake } \\
\text { Interstitial } \\
\text { Liquid }\end{array}$ & $1.50 \mathrm{E}+03$ & $13.1 \%$ & $5.7 \%$ & $5.18 \mathrm{E}+01$ & $0.3 \%$ & $0.2 \%$ & \\
\hline $\begin{array}{l}\text { Saltcake } \\
\text { Solids }\end{array}$ & $8.62 \mathrm{E}+03$ & $75.3 \%$ & $32.5 \%$ & $1.57 \mathrm{E}+02$ & $1.0 \%$ & $0.6 \%$ & \\
\hline "Soluble" & $1.02 \mathrm{E}+04$ & $89.1 \%$ & $38.4 \%$ & $1.44 \mathrm{E}+04$ & $95.5 \%$ & $54.2 \%$ & $92.7 \%$ \\
\hline $\begin{array}{l}\text { Sludge } \\
\text { (Liquid \& } \\
\text { Solid) }\end{array}$ & $1.15 \mathrm{E}+03$ & $10.0 \%$ & $4.3 \%$ & $4.14 \mathrm{E}+02$ & $2.7 \%$ & $1.6 \%$ & \\
\hline $\begin{array}{l}\text { Sludge } \\
\text { Solids }\end{array}$ & $1.02 \mathrm{E}+02$ & $0.9 \%$ & $0.4 \%$ & $2.10 \mathrm{E}+02$ & $1.4 \%$ & $0.8 \%$ & \\
\hline $\begin{array}{l}\text { Sludge } \\
\text { Interstitial } \\
\text { Liquid }\end{array}$ & $0.00 \mathrm{E}+00$ & $0.0 \%$ & $0.0 \%$ & $6.16 \mathrm{E}+01$ & $0.4 \%$ & $0.2 \%$ & \\
\hline "Insoluble" & $1.25 \mathrm{E}+03$ & $10.9 \%$ & $4.7 \%$ & $6.86 \mathrm{E}+02$ & $4.5 \%$ & $2.6 \%$ & $7.3 \%$ \\
\hline $\begin{array}{l}\text { Sum of all } \\
\text { categories } \\
\text { (Ci) or \% }\end{array}$ & $1.15 E+04$ & $100.0 \%$ & $43.2 \%$ & $1.51 E+04$ & $100.0 \%$ & $56.8 \%$ & \\
\hline
\end{tabular}

There is some water solubility data available on ${ }^{99} \mathrm{Tc}$ for leach tests on two archived sludges from BX-101 SST and AY-102 DST (Krupka et al. 2004; Lindberg and Deutsch 2003). The focus of these reports was to generate data that could be used to address post-tank-farm-closure fate of contaminants left in residual sludge. These water solubility results should not be confused with sludge washing solubility 
within the PT Facility. These two reports show that $\sim 25 \%$ of the ${ }^{99} \mathrm{Tc}$ in the AY-102 sludge was leached in water over a 30 -day period and $100 \%$ of the ${ }^{99} \mathrm{Tc}$ in the BX-101 sludge was water leached in the same period. More ${ }^{99} \mathrm{Tc}$ water leach studies have been done on residual sludge left in tanks that have been retrieved. The retrieved tanks for which sludge has been studied are C-103, C-106, C-108, C-202, C-203, and S-112. A detailed listing of available reports and journal articles describing the studies on residual sludges after retrieval is found in Appendix B. Retrieving the waste from the tanks with water or an oxalic acid solution (as was done for tank C-106) removes the readily soluble solids, leaving behind relatively insoluble sludge solid phases. In general, all the studies listed in Appendix B suggest that the percentage of Tc that dissolved from residual sludge from tanks in $\mathrm{C}$ tank farm ranged from approximately $6 \%$ to $10 \%$, and for the S-112 residual sludge $17 \%$ of the ${ }^{99} \mathrm{Tc}$ was readily water leachable. Solid-phase characterization results indicate that the recalcitrant forms (non-water leachable ${ }^{99} \mathrm{Tc}$ ) are associated with iron oxides. X-ray absorption near edge structure (XANES) analysis of Tc in one C tank farm residual sludge indicates that the ${ }^{99} \mathrm{Tc}$ (and other generally mobile contaminants such as chromate) occur in Fe oxide particles as their lower, less-soluble oxidation state [Tc(IV)]. The form of these generally mobile contaminants, ${ }^{99} \mathrm{Tc}$ included, in the residual (post-retrieval) sludge is likely as lower valence oxides or hydroxides incorporated within the structure of the Fe oxide. The key useful information generated by these residual sludge studies is that ${ }^{99} \mathrm{Tc}$ in sludge appears to be found as co-precipitates with ferric oxides that can be readily dissolved by the caustic sludge washing process that will be used in the PT Facility. Recall that soluble waste will be sent to the LAW portion of WTP for vitrification as LAW glass and/or some other supplemental waste form.

Therefore, based on the water leaching tests on residual tank sludge, it appears that the ${ }^{99} \mathrm{Tc}$ in some tank sludges is readily solubilized in water and thus the estimate of $93 \%$ of the ${ }^{99} \mathrm{Tc}$ in Table 4.8 may be low. Further, it is known that within the PT Facility vigorous sludge washing with strong caustic will solubilize almost all the ${ }^{99} \mathrm{Tc}$ (see for example Geeting et al. 2003).

\section{3 ${ }^{99}$ Tc Speciation in Hanford Tanks}

The TWINS database and BBI protocol do not track ${ }^{99} \mathrm{Tc}$ speciation in the various materials (supernate, salt cake, and sludge) within the storage tanks. Further, the HDW model that estimates the fate of ${ }^{99} \mathrm{Tc}$ as it is released from the dissolved fuel elements and cladding during the reprocessing of irradiated fuel makes no attempts to speciate the ${ }^{99} \mathrm{Tc}$. The aforementioned companion document (Rapko 2014) and an earlier report (Rapko et al. 2013a) introduce the ${ }^{99} \mathrm{Tc}$ speciation issue with emphasis on the unexpected finding of soluble non-pertechnetate species(n-Tc species) in supernate within DSTs. Both Rapko reports discuss the importance of the non-pertechnetate species after waste retrieval and most of the available ${ }^{99} \mathrm{Tc}$ speciation data. In this subsection we will briefly summarize the work that discovered the non-pertechnetate species and subsequent studies that confirm n-Tc species do exist in DST supernate. By the end of this subsection 4.3 it will be concluded that the identity of the n-Tc species has not yet been established but based on detailed laboratory synthesis studies there is evidence that plausible candidates are all $\mathrm{Tc}(\mathrm{I})$ moieties likely associated with carbon monoxide or nitrous oxide that further complex with -hydroxide, inorganic anions, or dissolved organic anions such as gluconate. 


\subsubsection{Precis on Discovery and Confirmation of Existence of $n$-Tc species in DST Supernates}

When ${ }^{99} \mathrm{Tc}$ removal testing from Hanford tank waste supernates began in the mid-1990s, it soon became apparent that a fraction of the soluble Tc, variable from tank waste supernate to tank waste supernate, was not being captured by materials generally considered to be efficient at pertechnetate removal from high-sodium, high-nitrate solutions. Three pertechnetate "ion exchange" materials that received early attention were ABEC-2000 and Reillex-HPQ, anion exchange resins studied primarily at LANL and PNNL, and SuperLig-639, a material that extracts the sodium/potassium pertechnetate ion pair, studied primarily at SRNL and PNNL. Specific references with all the details are cited in Rapko et al. (2013a) and in subsection 4.3.2 through 4.3.4 below. Another comprehensive review of Tc-specific sorption media was performed by Duncan et al. (2011). Useful information on the characteristics of these three resins, including performance properties for removing Tc from various types of wastes, are tabulated in Table 3-6 within the Duncan et al. (2011) report. The Duncan et al. (2011) report summarizes Tc removal literature for these three "ion exchange" materials in Sections 3.2.1, 3.2.5, and 3.2.7, respectively. These sections within Duncan et al. (2011) cite several more references and give short abstracts on the cited reports' findings. We mention this to show that much work has been done on Tc removal from many waste streams using these three materials. Duncan et al. (2011) identifies several reports besides citations discussed in this report and Rapko et al. (2013a) that observe the n-Tc species phenomenon. Duncan et al. (2011) does not delve into the identifying what the $\mathrm{n}-\mathrm{Tc}$ species may be.

After the initial discovery of the unexpected poor Tc removal by the pertechnetate-specific "ion exchange" media, subsequent work attempted to determine the cause of the unexpected early breakthrough of a portion of the ${ }^{99}$ Tc. Several possibilities were considered: 1) that it was due to channeling or some other artifact of column testing, 2) that it was due to another soluble component in the tank supernates that was either a beta emitter (for tests that used scintillation counting as the Tc monitoring method or another mass 99 element for tests that used ICP-MS as the detection method) or 3 ) that it was due to an alkaline-waste-soluble, non-pertechnetate form of technetium. The general conclusion after numerous investigations (a few described next and others discussed below in subsections 4.3.2 through 4.3.4) has been that this phenomenon is due to the third possibility, (i.e., that non-pertechnetate form(s) of Tc that do not respond to standard pertechnetate capture technologies exist in some Hanford DST tank waste supernates).

The first relevant report, Blanchard et al. (1996), describes both batch and column testing of two

pertechnetate removal resins, ABEC-2000 and Reillex-HPQ, using AW-101 tank supernatant. The testing protocol presented in the report is shown in Figure 4.3. 


\section{Tc Removal Event Diagram}

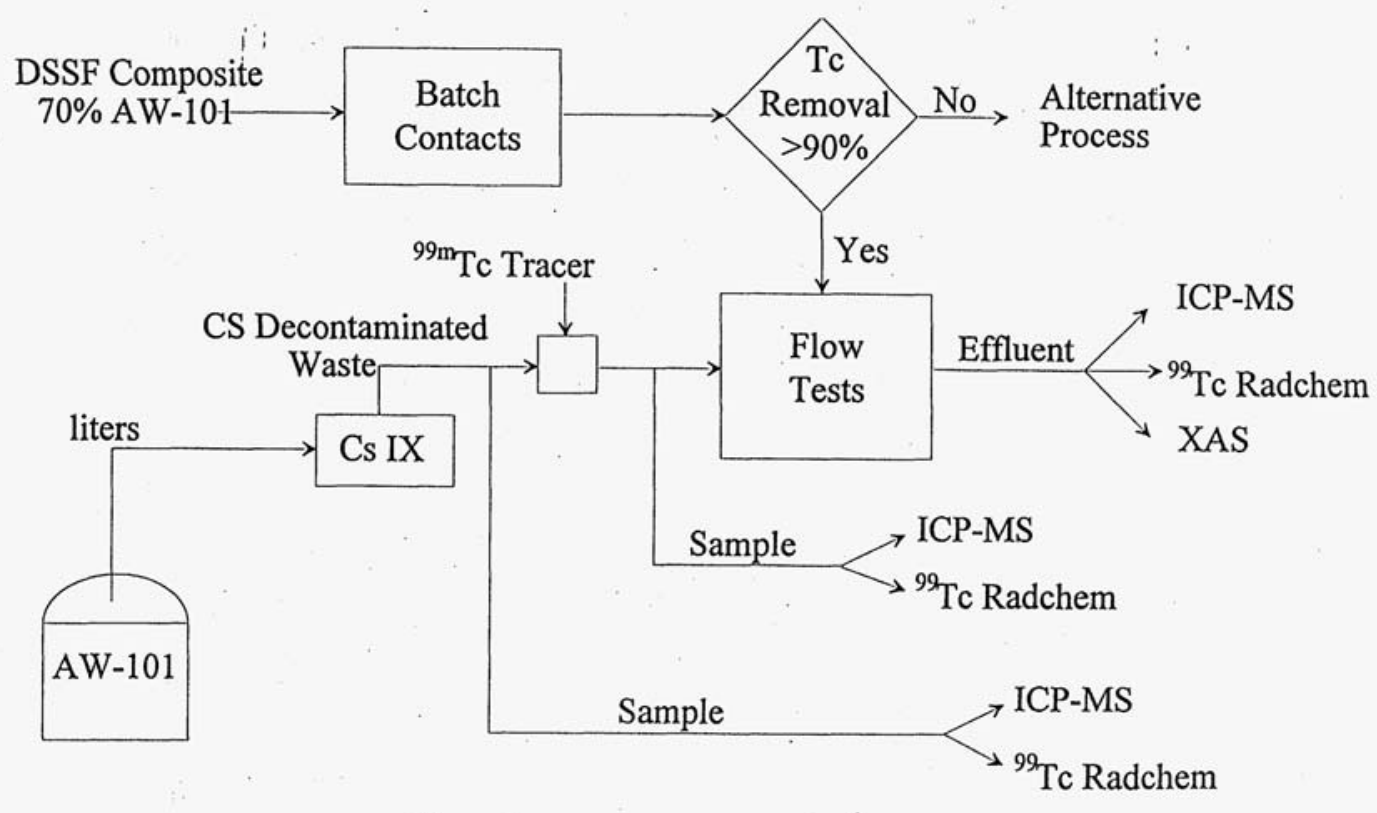

Figure 4.3. Protocol Used to Evaluate ${ }^{99}$ Tc Removal from DST Liquid Wastes

Note that the AW-101 DST waste was first processed to remove ${ }^{137} \mathrm{Cs}$ and then a pertechnetate radiotracer, ${ }^{99 \mathrm{~m}} \mathrm{Tc}$, was added solely as pertechnetate to the DST supernate. The use of ${ }^{99 \mathrm{~m}} \mathrm{Tc}$ allows for a distinction between pertechnetate behavior and that of the "bulk" Tc-99 present in the AW-101 supernate to be determined. The ${ }^{99 \mathrm{~m}} \mathrm{Tc}$ tracer is conveniently and accurately determined by high purity germanium (HPGe) gamma spectroscopy with energy resolution that precludes other gamma emitters in the DST waste from confounding the pertechnetate radiotracer analyses. The radiotraced DST liquid waste was then contacted with two pertechnetate-specific ion exchange resins (portrayed in the Figure 4.3 flow diagram by the box named Flow Tests) in separate packed column tests. Two small columns were packed with each of the resins and set up in series, the first column was the "lead" and the second was the "lag" column. The flow tests were then conducted in a fashion that simulates the full-scale process for removal of ${ }^{99} \mathrm{Tc}$ from DST supernate: 1) resin conditioning, 2) resin loading, 3) caustic wash to remove residual feed and prevent the precipitation of $\mathrm{Al}(\mathrm{OH})_{3}$, and 4) ${ }^{99} \mathrm{Tc}$ elution. Figure 4.4 shows a schematic of the flow tests. Small aliquots of the liquid effluent from the lead column and all the effluent from the lag column in each flow test were collected (which were described by the cumulative number of packed column bed volumes) from the start to the end of the Tc loading phase. Influent samples of the DST supernate before and after adding the ${ }^{99 \mathrm{~m}} \mathrm{Tc}$ tracer but before contacting the resins were also collected and Tc measured. All three liquid sample types were then analyzed for ${ }^{99 \mathrm{~m}} \mathrm{Tc}$ and ${ }^{99} \mathrm{Tc}$ content using gamma counting for the ${ }^{99 \mathrm{~m}} \mathrm{Tc}$, and for ${ }^{99} \mathrm{Tc}$ ICP-MS and beta counting after vigorous sample oxidation. The ${ }^{99 \mathrm{~m}} \mathrm{Tc}$ and ${ }^{99} \mathrm{Tc}$ concentrations in the effluent as a function of time (measured as cumulative bed volumes) were then compared with the influent concentrations to calculate the typical $\mathrm{C} / \mathrm{C}_{0}$ breakthrough curves. The Figure 4.3 flow chart also shows that some of the effluents from the ion exchange columns were analyzed by synchrotron XAS. The flow chart also shows that before flow through packed column testing was performed, simpler and less costly batch tests were performed to be certain that the two ion 
exchange resins were capable of removing ${ }^{99} \mathrm{Tc}$ from the DST supernate. The results of the batch sorption tests were positive such that the packed column tests were performed. The results of the packed column tests are shown in Figure 4.5.



Figure 4.4. Schematic of Tc Removal Flow Tests 


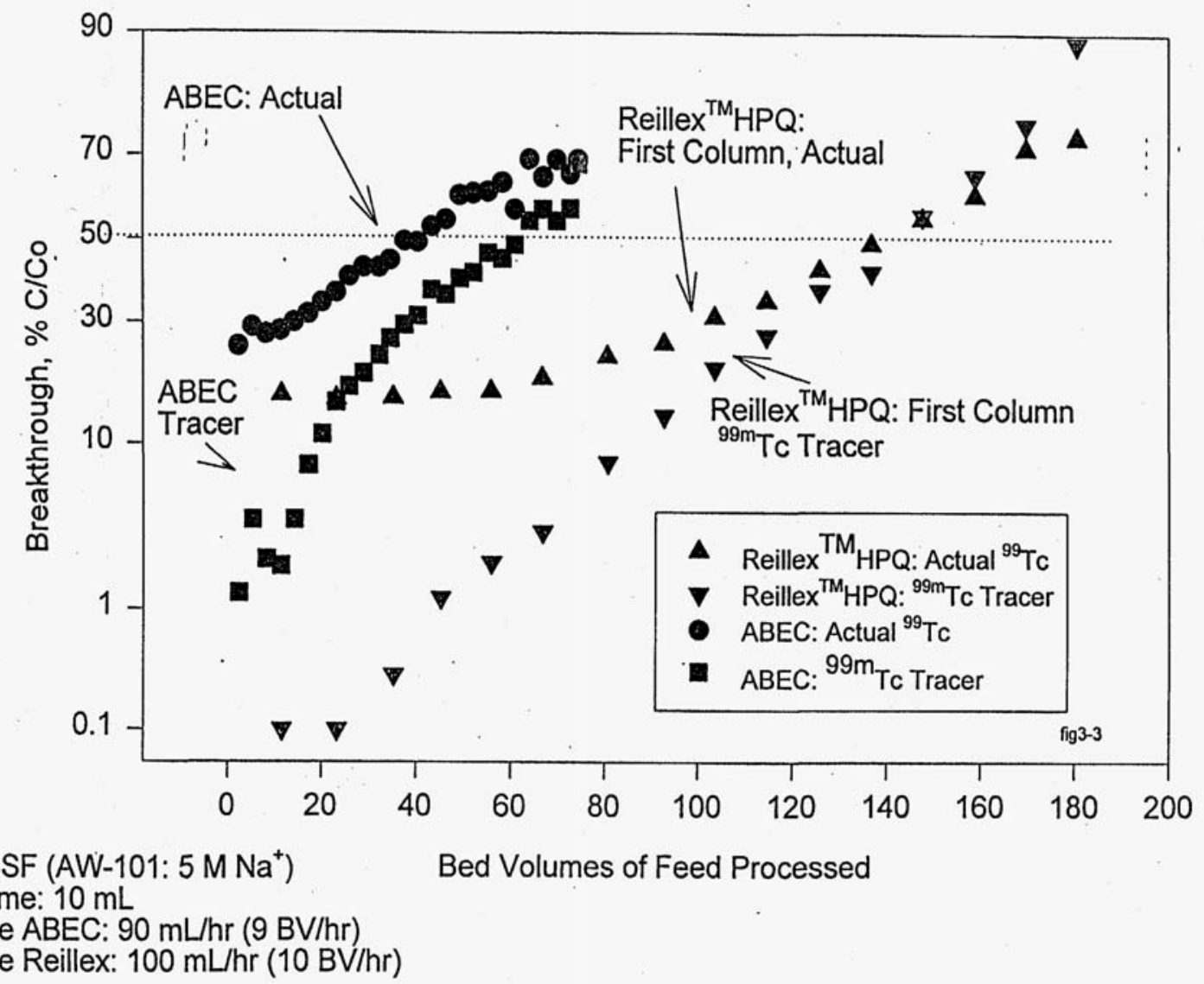

Figure 4.5. Packed Column Test Breakthrough Results

Note the dramatically different breakthrough behavior for both resins between pertechnetate, as represented by the ${ }^{99 \mathrm{~m}} \mathrm{Tc}$ and the "bulk" ${ }^{99} \mathrm{Tc}$ in the AW-101 DST effluents from the first (lead) column. The two breakthrough curves for ${ }^{99 \mathrm{~m}} \mathrm{Tc}$ show low normalized $\left(\mathrm{C} / \mathrm{C}_{0}\right)$ values for the first 60 to 80 bed volumes of cumulative effluent in comparison to the ${ }^{99} \mathrm{Tc}$ breakthrough curves. The two breakthrough curves $\left({ }^{99 \mathrm{~m}} \mathrm{Tc}\right.$ vs $\left.{ }^{99} \mathrm{Tc}\right)$ start to converge after about 80 and 140 bed volumes of effluent are collected for the ABEC and Reillex HPQ resins, respectively. These breakthrough results show that both resins remove significantly higher percentages of the pertechnetate $\left({ }^{99 \mathrm{~m}} \mathrm{Tc}\right)$ than the "bulk" ${ }^{99} \mathrm{Tc}$ from the DST supernate. Further, the Reillex resin removes more Tc before the resin starts to become loaded with Tc than the ABEC resin. The fact that all four breakthrough curves show the typical progression towards full breakthrough, eliminates the possibility of column mechanical artifacts, such as channeling, from being responsible for the early breakthrough observed for the "bulk" Tc-99. There was a good comparison of the ${ }^{99} \mathrm{Tc}$ concentrations in the effluents between ICP-MS and beta counting results. Figure 4.5 shows only the loading portion of test for the lead column. Other data for the lag column and for the wash and Tc elution phases of the resin testing are found in Blanchard et al. (1996) and further support the presence of $\mathrm{n}$-Tc species in the AW-101 supernate. The XAS results from characterizing the valence state of Tc in selected effluents from the packed columns and the original AW-101 supernate (after ${ }^{137} \mathrm{Cs}$ removal) are discussed in Section 4.3.4. 
Similar early breakthrough of "bulk" ${ }^{99} \mathrm{Tc}$ in DST supernates from several other Hanford tanks have been observed when the resin used is SuperLig-639. For example, Burgeson et al. (2004a) performed a column test using a mixture of AN-102 supernate and C-104 filtrate, wash and leach solution. In these tests no pertechnetate radio-spike was used but the same two columns in series protocol shown in Figure 4.4 was used. The breakthrough curves for effluent from both the lead and lag columns are shown in Figure 4.6.

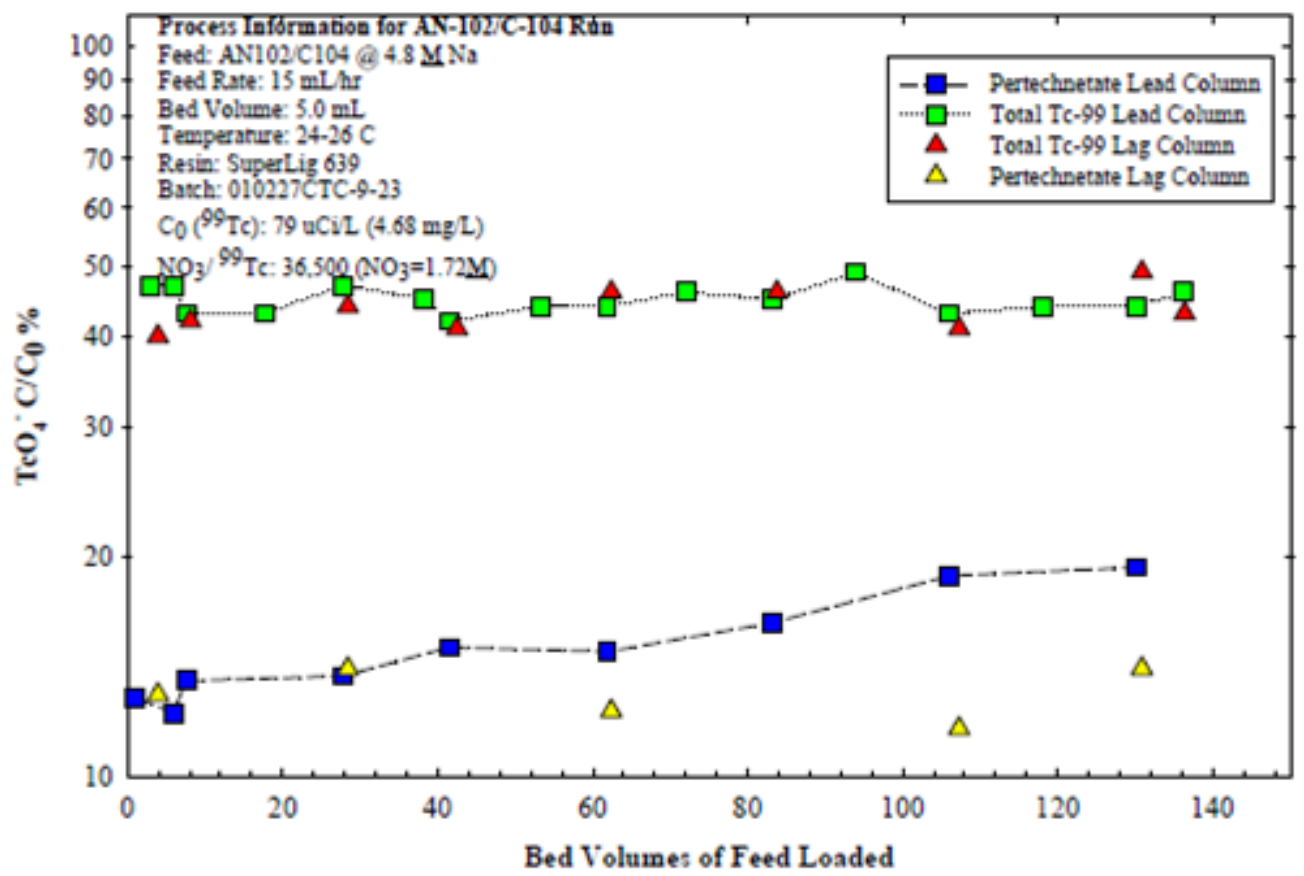

Figure 4.6. Breakthrough Curves for SuperLig 639 Columns Contacted with AN-102 Supernate

In Figure 4.6, total Tc was determined by ICP-MS at mass 99 and pertechnetate was determined by Eichrom TEVA resin (pertechnetate-specific) extraction methods for the column effluents followed by liquid scintillation counting. The influent or $\mathrm{C}_{0}$ value for ${ }^{99} \mathrm{Tc}$ was determined by both ICP-MS and after vigorous oxidation of the influent by liquid scintillation. Both methods gave similar concentrations for Tc in the influent. The large differences between total Tc-99 and pertechnetate breakthrough behavior observed in both the lead and lag column effluents are consistent with the hypothesis that this DST supernate contains a significant amount of a non-pertechnetate species. Figure 4.6 shows only the first portion of the SuperLig 639 resin loading phase. After stopping influent loading and performing resin washing and Tc elution, Burgeson et al. (2004) performed a mass balance calculation. They found excellent recovery (97 to 101\%) of the total ${ }^{99} \mathrm{Tc}$ injected into the dual column test. This suggests that their breakthrough data presented in Figure 4.6 are accurate and that the hypothesis of the presence of $\mathrm{n}$-Tc species in the AN-102 supernate is confirmed.

Additional measurements that support the assignment of an alkaline-soluble, non-pertechnetate, source of Tc in various Hanford waste tanks include: the direct measurement by Tc-99 NMR of an increased pertechnetate concentration in the supernatant following exhaustive oxidation by contact with hot concentrated nitric acid/Ce(IV) (Schroeder et al. 1995) and by capture of additional activity by a pertechnetate-selective resin following microwave/persulfate oxidation of four (4) different Hanford tank 
supernatants (Egorov et al. 2004; Egorov et al. 2012). Other supporting evidence includes very low batch $\mathrm{K}_{\mathrm{d}}$ values for the pertechnetate specific resins such as SuperLig 639 and Reillex HPQ for actual DST supernates as compared to pure pertechnetate tracers $\left({ }^{95 \mathrm{~m}} \mathrm{Tc}\right.$ or ${ }^{99 \mathrm{~m}} \mathrm{Tc}$ ) added to the DST supernates or spiked simulants of similar composition. More discussion on some of these findings follows in Sections 4.3.2 through 4.3.4.

In summary, Table 4.9 adapted from Rapko et al. (2013a) lists the percentages of non-pertechnetate that have been directly measured or inferred from studies of the ${ }^{99} \mathrm{Tc}$ contents in DST supernates. Table 4.9 also lists the methods used to support the hypothesis that $\mathrm{n}-\mathrm{Tc}$ species are present. Methods include batch and flow-through column tests using pertechnetate-specific resins, pre- and post- vigorous oxidation Tc analyses of DST supernates, and NMR and XANES direct spectroscopic analyses of DST wastes. In total, researchers at four national labs have published approximately 30 reports or journal articles supporting the presence of $\mathrm{n}$-Tc species in Hanford DST supernates. What remains to be determined is the identity or identities of the n-Tc species and how they impact the processing of retrieved tank waste and the final disposition of treated wastes within the WTP and/or supplemental waste facilities.

Table 4.9. Reported Distribution of Non-pertechnetate Technetium Present in Various Hanford Tank Supernatants (modified from Rapko et al. 2013a)

\begin{tabular}{|c|c|c|c|c|}
\hline Tank & Method & $\begin{array}{c}\% \text { Non- } \\
\text { pertechnetate } \\
\text { (Max) }\end{array}$ & $\begin{array}{c}\% \text { Non- } \\
\text { pertechnetate } \\
\text { (Min) }\end{array}$ & Reference \\
\hline AN-102 & SL-639 lag breakthrough & 70 & 60 & King et al. $(2001,2003)$ \\
\hline AN-102 & SL-639 column & 80 & 70 & Hassan et al. (2000b) \\
\hline AN-102 & SL-639 column & 70 & & King et al. (2000) \\
\hline AN-102 & Multiple SL-639 batch contacts & 63 & & Hassan et al. $(2001 b, 2002)$ \\
\hline AN-102 & $\begin{array}{l}\text { MP-1 captured } \mathrm{TcO}_{4}^{-} \\
\text {before/after oxidation }\end{array}$ & 57 & & Egorov et al. (2012) \\
\hline AN-102 & SL-639 column & 48 & & Egorov et al. (2012) \\
\hline $\begin{array}{l}\text { AN-102 } \\
/ \text { C-104 } \\
\operatorname{mix}\end{array}$ & SL-639 batch $K_{d}$ & 50 & & Burgeson et al. (2004a) \\
\hline AN-103 & SL-639 lag breakthrough & 8 & 7 & King et al. $(2001,2003)$ \\
\hline AN-103 & SL-639 column & 8 & 3 & McCabe et al. (2000) \\
\hline AN-103 & SL-639 column & 2.4 & 2.3 & Hassan et al. (2000a) \\
\hline AN-103 & Multiple SL-639 batch contacts & 1.6 & & Hassan et al. $(2001 b, 2002)$ \\
\hline AN-107 & XANES fit & 62 & & Blanchard et al. (1997) \\
\hline AN-107 & SL-639 batch $K_{d}$ & 78 & 75 & Kurath et al. (2000) \\
\hline AN-107 & SL-639 column & 80 & & Blanchard et al. (2000b) \\
\hline AN-107 & Fit to batch $K_{d}$ Reillex HPQ & 63 & 48 & Schroeder et al. (1998) \\
\hline AN-107 & Fit to batch $K_{d}$ Reillex HPQ & $66 \pm 9$ & & Schroeder and Ashley (2005) \\
\hline AN-107 & $\begin{array}{l}\text { MP-1 captured } \mathrm{TcO}_{4}^{-} \\
\text {before/after oxidation }\end{array}$ & 57 & & Egorov et al. (2004) \\
\hline AN-107 & SL-639 column & 50 & & Egorov et al. (2012) \\
\hline AP-101 & $\begin{array}{l}\% \text { Tc in feed by inductively } \\
\text { coupled plasma mass } \\
\text { spectrometry (ICP-MS) (total) } \\
\text { vs } \mathrm{TcO}_{4}^{-} \text {by rad separation }\end{array}$ & $\begin{array}{c}13 \\
\text { suspect result }\end{array}$ & & Burgeson et al. (2002) \\
\hline AP-101 & SL-639 column & $<0.5$ & & Burgeson et al. (2002) \\
\hline AP-104 & SL-639 column & 69 & & Burgeson et al. (2005) \\
\hline AP-104 & $\begin{array}{l}\text { MP-1 captured } \mathrm{TcO}_{4}^{-} \\
\text {before/after oxidation }\end{array}$ & 72 & & Egorov et al. (2004) \\
\hline AP-104 & SL-639 column & 72 & & Egorov et al. (2012) \\
\hline
\end{tabular}




\begin{tabular}{|c|c|c|c|c|}
\hline Tank & Method & $\begin{array}{l}\text { \% Non- } \\
\text { pertechnetate } \\
\text { (Max) }\end{array}$ & $\begin{array}{c}\% \text { Non- } \\
\text { pertechnetate } \\
\text { (Min) }\end{array}$ & Reference \\
\hline AW-101 & SL-639 column & 0.06 & 0 & Hassan et al. (2003) \\
\hline AW-101 & Reillex HPQ column & 15 & & Blanchard et al. (1996,2000a) \\
\hline AW-101 & SL-639 batch $\mathrm{K}_{\mathrm{d}}$ & 2.9 & & Kurath et al. (2000) \\
\hline AW-101 & $\begin{array}{c}\% \text { Tc in feed vs SL-639 column } \\
\text { effluent }\end{array}$ & 4.5 & & Hassan et al. (2003) \\
\hline AZ-101 & SL-639 column & 0 & 0 & $\begin{array}{l}\text { Burgeson et al. (2004b); } \\
\text { Egorov et al. ( } 2012)\end{array}$ \\
\hline AZ-102 & SL-639 column & 0 & 0 & Egorov et al. (2012) \\
\hline AZ-102 & $\begin{array}{c}\% \text { Tc in feed vs SL-639 column } \\
\text { effluent }\end{array}$ & 33 & & Hassan et al. (2003) \\
\hline AZ-102 & SL-639 column & 0.04 & 0 & Hassan et al. (2001a) \\
\hline AZ-102 & Multiple SL-639 batch contacts & $<0.1$ & & Hassan et al. $(2001 b, 2002)$ \\
\hline DSSF & Reillex HPQ batch $K_{d}$ & 7 & & Blanchard et al. (1997) \\
\hline SY-101 & Reillex HPQ batch $K_{d}$ & 53 & & Blanchard et al. (1997) \\
\hline SY-101 & Fit to batch Kd Reillex HPQ & 63 & & $\begin{array}{l}\text { Schroeder et al. (1998) } \\
\text { Schroeder et al. (1995) }\end{array}$ \\
\hline SY-101 & $\begin{array}{c}\text { Fit to batch Kd Reillex HPQ } \\
\& \mathrm{TcO}_{4}^{-} \text {by nuclear magnetic } \\
\text { resonance (NMR) }\end{array}$ & 70 & 63 & Schroeder et al. (2001) \\
\hline SY-103 & Reillex HPQ batch $\mathrm{K}_{\mathrm{d}}$ & 54 & & Blanchard et al. (1997) \\
\hline SY-103 & XANES fit & 78 & & Blanchard et al. (1997) \\
\hline SY-103 & Fit to $\mathrm{K}_{\mathrm{d}}$ Reillex HPQ & 70 & & $\begin{array}{l}\text { Schroeder et al. (1998) } \\
\text { Schroeder et al. (1995) }\end{array}$ \\
\hline SY-103 & $\begin{array}{c}\text { Fit to batch } \mathrm{K}_{\mathrm{d}} \text { Reillex HPQ } \\
\quad \& \mathrm{TcO}_{4}^{-} \text {by NMR }\end{array}$ & 70 & 64 & Schroeder et al. (2001) \\
\hline
\end{tabular}

\subsubsection{Speciation Inferred from Ion Selective Resin Tests}

In this subsection we provide some more details on using pertechnetate-specific materials to identify and confirm that $n-T c$ species exist in Hanford DST supernates. Numerous reports describe the use of organic-based resins that preferentially sequester pertechnetate anions out of Hanford liquid waste streams. Most of the studies used pertechnetate-specific resins called SuperLig ${ }^{\circledR} 639$ (IBC Advanced Technologies, Inc., American Fork, Utah), which is a proprietary product that uses molecular recognition theory to design a substrate highly selective to sequestering the species of interest ${ }^{1}$, or Reillex ${ }^{\circledR}$ HPQ (Vertellus Health \& Specialty Products LLC, Indianapolis, Indiana 46204). SuperLig 639 functions by extracting the sodium pertechnetate salt-pair out of liquid waste at fairly high sodium concentrations

\footnotetext{
${ }^{1}$ SuperLig proprietary products are solid phase particles $(\sim 0.5 \mathrm{~mm})$ generally based on silica gel or polymer substrates to which a selective ligand has been chemically attached. The choice of ligand uses Molecular Recognition Technology (MRT) - a highly selective, non-ion exchange process, using specially designed organic chelating agents or ligands. The MRT process utilizes supramolecular, "lock and key" or "host guest" chemistry as the basis for its high selectivity. Feed solution is passed through a column packed with the SuperLig particles and the target species is removed selectively from the solution. SuperLig products are designed to bind selectively with ions based on multiple parameters such as size, coordination chemistry, and geometry. In contrast, separation methods used in conventional ion exchange, solvent extraction, or precipitation processes generally recognize differences between ions based only on a single parameter (e.g., charge, solubility, size). SuperLig products bind ions selectively even when the ions are present in highly acidic or basic solution and/or in solutions containing high concentrations of competing ions. High species selectivity, high binding factors, and rapid reaction kinetics result in very efficient separations. The elution chemistry for SuperLig products facilitates a wide choice of eluent formulations to ensure compatibility with particular separation requirements. Since small volumes of eluate are used, highly concentrated eluent solutions are produced.
} 
(generally $\sim 4-5 \mathrm{M} \mathrm{Na}$ ). Reillex-HPQ resin is a co-polymer of divinylbenzene and 4-vinylpyridine that has been subsequently methylated at the pyridine nitrogen to give pyridinium $\left[-\mathrm{C}_{5} \mathrm{H}_{4} \mathrm{~N}\left(\mathrm{CH}_{3}\right)^{+}\right]$strong base anionic sites (Figure 4.7). The pyridinium functionality of Reillex -HPQ resin is unique compared to most other strong base anion resins. Reillex-HPQ is $-25 \%$ cross-linked and $70 \%$ methylated at the pyridine nitrogen to give pyridinium anionic sites. The total exchange capacity provided by the manufacturer for 30-60 mesh resins in the chloride form is $4.6 \mathrm{meq} \mathrm{Cl} / \mathrm{g}$ (dry) and $1.2 \mathrm{meq} \mathrm{Cl} / \mathrm{mL}$ (wet). Reillex-HPQ, compared to other resins, has superior stability to radiolysis and nitric acid.

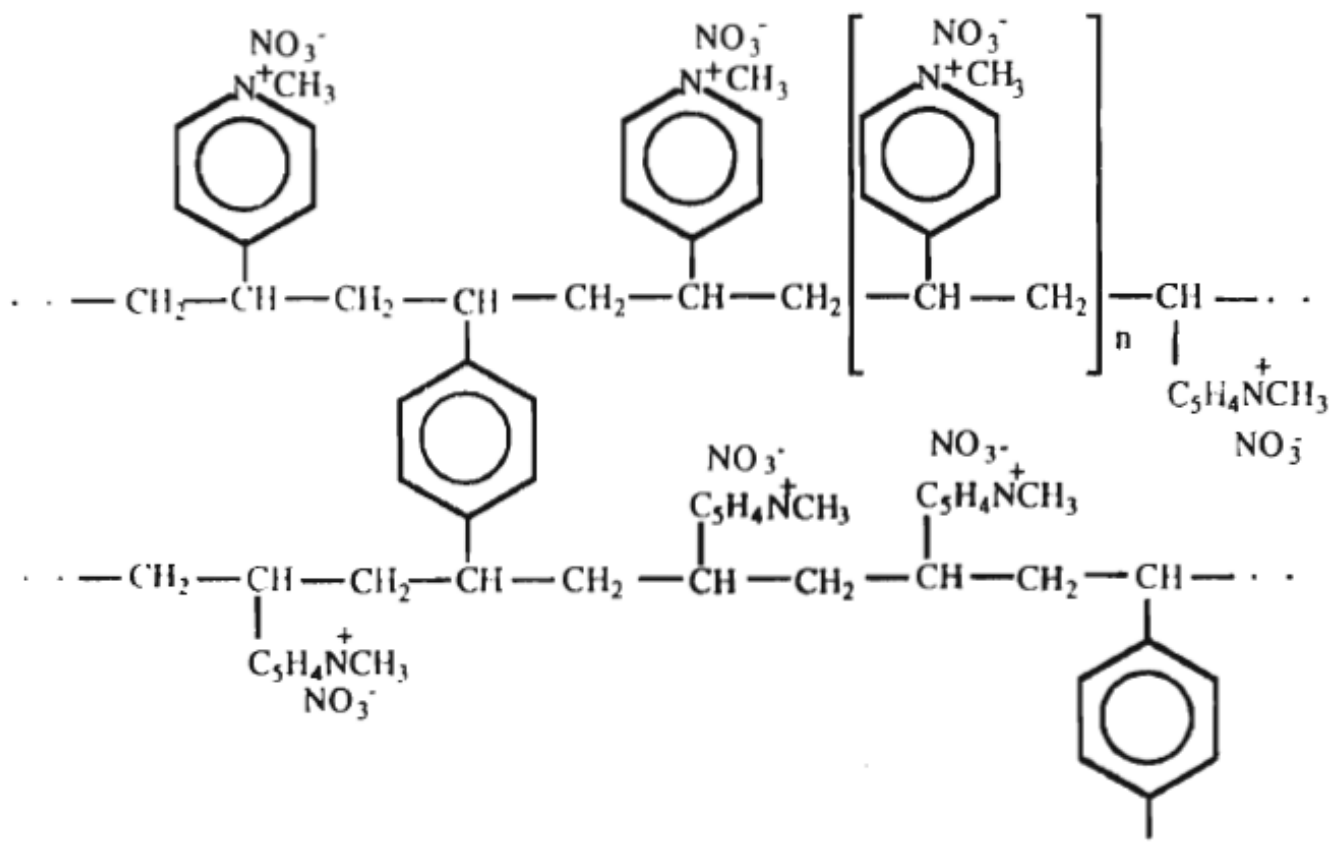

Figure 4.7. Structure of Reillex HPQ Anion Exchange Resin

As briefly described in Section 4.3.1, while processing Hanford liquid wastes (generally supernate from various DSTs) through columns packed with SuperLig 639, it was observed for some of the supernates that there was an immediate breakthrough of some of the ${ }^{99} \mathrm{Tc}$ present. For other Hanford DST supernates (e.g., AZ-101) and Hanford liquid waste simulants, which had been spiked with known amounts of ${ }^{99} \mathrm{Tc}$ and/or ${ }^{95 \mathrm{~m}} \mathrm{Tc}$ both in the pertechnetate form, the SuperLig 639 resin retained all of the Tc for tens to a few hundred pore volumes of effluent before any Tc was found to break through. A second methodology, batch sorption tests, has been used to identify the presence of non-pertechnetate. For the batch tests, known amounts of SuperLig 639 or another pertechnetate-specific resin, (e.g., Reillex HPQ) are contacted with actual Hanford DST supernatant liquids, usually at 100:1 (liquid volume to resin) for 4-day contacts. The batch slurry is then separated by centrifugation and/or filtration and the concentration of ${ }^{99} \mathrm{Tc}$ in the effluent is compared to the concentration in the influent using the traditional $\mathrm{K}_{\mathrm{d}}$ construct. The Tc $K_{d}$ values for DST supernatants that were suspected to contain non-pertechnetate species were significantly lower than the $\mathrm{K}_{\mathrm{d}}$ values for DST supernatants that contained only the pertechnetate species and for simulants that had been spiked with known amounts of pertechnetate, often using the convenient gamma-emitting ${ }^{95 \mathrm{~m}} \mathrm{Tc}$ isotope.

The best hypothesis that explains the immediate breakthrough of some Tc from the DST supernatant in the packed SuperLig 639 columns and the low $\mathrm{K}_{\mathrm{d}}$ values found in the batch sorption tests is that soluble 
species of ${ }^{99}$ Tc were present in the DST supernates that were not pertechnetate. Because all of the DST supernates that exhibited the early breakthrough of ${ }^{99} \mathrm{Tc}$ also contained significant concentrations of dissolved organic matter, ${ }^{99} \mathrm{Tc}$-organic complexes were thought to cause the unexpected Tc behavior. Table 4.9 as mentioned originates in Rapko et al. (2013a) and has been updated herein with a few more values found in additional reports. Rapko et al. (2013a) also mention a correlation between the percentage of non-pertechnetate and DST supernate calculated dose (mostly ${ }^{137} \mathrm{Cs}$ content). But the correlation is negative (high non-pertechnetate correlates with low dose or ${ }^{137} \mathrm{Cs}$ ), which is counterintuitive if radiolysis influences the formation of the dissolved non-pertechnetate content in the Hanford storage tanks.

\subsubsection{Additional Studies that Probe Tc Speciation}

The second method used to help identify the speciation of the non-pertechnetate species found in DST supernates relied on carefully planned laboratory studies that attempted to create non-pertechnetate compounds using irradiation or after creation to use size exclusion chromatography to isolate the species. Shuh et al. (2001) and Lukens et al. (2002) performed radiolysis experiments (using a $600 \mathrm{Ci}{ }^{60} \mathrm{Co}$ irradiation facility) on $0.002 \mathrm{M}^{99} \mathrm{TcO}_{4}{ }^{-}$spiked $2 \mathrm{M} \mathrm{NaOH}$ solutions that contained various dissolved organics at concentrations between 0.1 and $0.5 \mathrm{M}$. The organic molecules studied individually were formate, glycolate, glyoxylate, ethylene glycol, ethanol, EDTA, nitrilotriacetate (NTA), iminodiacetate (IDA), diphenylphosphate, dibutylphosphate, citrate, acetate, and formaldehyde. The solutions were irradiated for up to 16 hours (absorbed dose rates varied between 3.4 and 19.6 kilo-grays or $10^{5}$ rads).

The major findings of Shuh et al. (2001) and Lukens et al. (2002) follow. Reduction of $\mathrm{TcO}_{4}{ }^{-}$requires the presence of organic materials to scavenge the oxidizing $\mathrm{O}^{-}$radical produced during radiolysis. Based on Lukens et al. (2001), radiolytic reduction of $\mathrm{TcO}_{4}{ }^{-}$is also efficient in the presence of excess nitrate, which is a major soluble component in Hanford supernates. In the presence of most organic molecules, the reduced Tc species was an insoluble solid, $\mathrm{TcO}_{2} \bullet \mathrm{xH}_{2} \mathrm{O}$ (identified by extended X-ray absorption fine structure [EXAFS] and electron paramagnetic resonance [EPR]). However, when the organic molecules are diols or polyols, ${ }^{1}$ soluble Tc radiolysis products are observed. The polyols studied that formed soluble Tc radiolysis products were ethylene glycol, glyoxylate, and formaldehyde. These soluble Tc radiolysis products were found to be soluble Tc(IV) diolates (see next paragraph). In addition, none of the organic compounds that yielded the insoluble $\mathrm{TcO}_{2} \bullet \mathrm{xH}_{2} \mathrm{O}$ is a diol. The soluble $\mathrm{Tc}(\mathrm{IV})$ compounds were prone to re-oxidation to $\mathrm{TcO}_{4}{ }^{-}$over a period of days to one week in the presence of air at the caustic $\mathrm{pH}$ in the $2 \mathrm{M} \mathrm{NaOH}$ background electrolyte. The insoluble $\mathrm{TcO}_{2}{ }^{\bullet} \mathrm{xH}_{2} \mathrm{O}$ also oxidizes to $\mathrm{TcO}_{4}{ }^{-}$, but over a longer period.

\footnotetext{
${ }^{1}$ A molecule with two hydroxyl groups is a diol. A polyol is an alcohol containing multiple hydroxyl groups.
} 
Shuh et al. (2001) and Lukens et al. (2002) used UV-Visible spectra and EXAFS on the soluble Tc-organic complexes and found these radiolysis-induced Tc-diol complexes are Tc(IV) with binuclear $\mathrm{Tc}_{2}(\mu-\mathrm{O})_{2}$ core structures similar to a well-known $\left(\mathrm{H}_{2} \mathrm{EDTA}\right)_{2} \mathrm{Tc}_{2}(\mu-\mathrm{O})_{2} .{ }^{1}$ However, relatively high Tc concentrations $(1 \mathrm{mM})$ were necessary to obtain the EXAFS spectrum. At lower Tc concentrations, it is likely that monomeric alkoxide complexes would be formed rather than binuclear complexes. The authors also caveat their findings in that few of the polyol ligands used in the radiolysis tests are present in Hanford tank waste in such high concentrations as were used in the radiolysis experiments to account for the formation of the soluble non-pertechnetate species. The one potential alkoxide ligand present in large enough quantities in high organic DSTs is gluconate.

These radiolysis experiments support the finding of reduced soluble Tc species in DST supernates because the tanks contain a myriad of molecules, and thermal and radiation vectors that in combination could produce unexpected chemical changes in the Tc species present. Shuh et al. (2001) and Lukens et al. (2002) also opine that, given the air sensitivity of the reduced Tc species formed in the radiolysis tests, archived supernate samples from the Hanford tanks will not accurately reflect the proportion of reduced technetium species. Thus, experiments to measure accurately the proportion of reduced technetium species in a given tank must be carried out on freshly sampled material. Outside the tank's radiolysis environment, the reduced technetium species could be removed, albeit slowly, by aeration.

Another interesting study, Bernard et al. (2001), showed that a soluble non-pertechnetate species could be produced by heating (to $65^{\circ} \mathrm{C}$ for $24 \mathrm{hr}$ ) a DST caustic supernate simulant containing ${ }^{99} \mathrm{Tc}$ spiked as pertechnetate, $0.05 \mathrm{M}$ gluconate, and soluble noble metal ( $\mathrm{Rh}, \mathrm{Ru}$, and $\mathrm{Pd}$ ) catalysts. Other organic complexants also promote reduction of pertechnetate, but the product is insoluble black precipitate suspected to be $\mathrm{TcO}_{2} \bullet \mathrm{XH}_{2} \mathrm{O}$. When using gluconate as the organic, more than $99 \%$ of the Tc remained in solution, but only $76 \%$ of the soluble ${ }^{99} \mathrm{Tc}$ was extracted by the pertechnetate-sequestering Reillex HPQ resin. Thus, some $(\sim 23 \%)$ unidentified soluble non-pertechnetate species was apparently formed without the need for radiolysis processes. Bernard et al. (2001) also claim that the noble metal-catalysts are an essential component of the pertechnetate reduction process in the presence of organic complexants - at least for a thermally driven system. When no noble metal catalysts were present, the DST caustic simulant inoculated with various organic complexants did not show pertechnetate reduction over a 4-day period at $65^{\circ} \mathrm{C}$. Inoculating the batch reactors containing DST simulant, but with no noble metal catalysts and no organic compounds, with hydrogen gas also did not show pertechnetate reduction, but adding any or all three noble metal catalysts (again with no organic complexants) reduced $84 \%$ to $99 \%$ of the

${ }^{1}$ Compounds with $\mathrm{Tc}_{2}(\mu-\mathrm{O})_{2}$ cores are shown in the figure.
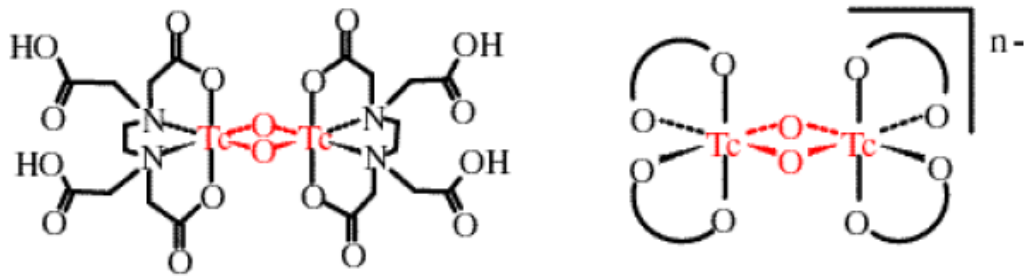

Left: $\left(\mathrm{H}_{2} \mathrm{EDTA}\right)_{2} \mathrm{Tc}_{2}(\mu-\mathrm{O})_{2}$. Right: proposed structure of the product of radiolysis of $\mathrm{TcO}_{4}{ }^{-}$in alkaline solutions containing diols. The diolate ligand is represented by the curved line.

$$
C_{0}^{\mathrm{O}}=\text { diolate ligand }
$$


pertechnetate to the insoluble black precipitate after 1 day at $65^{\circ} \mathrm{C}$. The need for noble metal catalysts to be present along with organics to effect $\mathrm{TcO}_{4}{ }^{-}$reduction was peculiar to this study. Shuh et al. (2001) and Lukens et al. (2002), as mentioned in the previous paragraphs, effected the $\mathrm{TcO}_{4}{ }^{-}$reduction via ${ }^{60} \mathrm{Co}$ radiolysis with no noble metal catalysts present.

Schroeder and Ashley (2005) suggest that some of the soluble ${ }^{99} \mathrm{Tc}$ in AN-107 supernate is cationic because it is removed during sample cleanup procedures to remove ${ }^{90} \mathrm{Sr}$ and other cations prior to attempting to separate Tc species using size exclusion chromatography through a Sephadex ${ }^{\circledR}$ G-10 column (registered trademark of GE Healthcare). G10 separates molecules with molecular weights $<700$ daltons based on the molecules size. Preliminary experiments determined that ${ }^{99} \mathrm{TcO}_{4}{ }^{-}$, whether dissolved in water or in a solution of $1.50 \mathrm{M} \mathrm{NaNO}_{3} / 1.00 \mathrm{M} \mathrm{NaOH}$, is not retained by G-10 columns. That is, pertechnetate elutes ${ }^{1}$ from the G-10 column but AN-107 supernate (after removal of ${ }^{90} \mathrm{Sr}$ and other cationic beta emitters) had $25 \%$ of its technetium retained by the G-10 column. Because size exclusion chromatography media are not supposed to interact strongly with the solutes being separated, this strong interaction (retention within the column) confounds simple interpretation. However, based on other studies that showed AN-107 supernate contains $\sim 60 \%$ non-pertechnetate and $40 \% \mathrm{TcO}_{4}^{-}$, Schroeder and Ashley assumed that the pertechnetate ( $\sim 40 \%$ of the total ${ }^{99} \mathrm{Tc}$ in AN-107 supernate) is not held up in the G-10 column, then approximately $42 \%(25 / 60)$ of the non-pertechnetate is retained in the G-10 column. Thus, G-10 beads have a strong interaction with some of the non-pertechnetate species but not pertechnetate. Although not stated in Schroeder and Ashley 2005, one might conclude their results suggest the presence of at least two n-Tc species, one $(\sim 58 \%)$ that elutes and one that is retained $(\sim 42 \%)$ within the column. Schroeder and Ashley (2005) conclude that size exclusion chromatography (using G-10) offers the possibility of separating some of the non-pertechnetate species from themselves and from pertechnetate, and that using a different eluent (water was used in this study) such as ethylene glycol that could compete with the dextran alcohol functionalities in the G-10 beads might improve the elution of all the ${ }^{99} \mathrm{Tc}$ from the G-10 column. In a second study, the fate of ${ }^{99} \mathrm{Tc}$ in the $\mathrm{AN}-107$ supernate was followed as it was pumped through two cation exchange columns (Dowex AG50WX8) and then a G-10 size exclusion column. This study determined that $10 \%$ to $20 \%$ of the total ${ }^{99} \mathrm{Tc}$ in the AN-107 supernate was retained in the cation exchange column, $53 \%$ of the ${ }^{99} \mathrm{Tc}$ eluted in two bands from the G-10 column, and $30 \%$ of the ${ }^{99} \mathrm{Tc}$ remained stuck in the G-10 column. Combining results from the various column studies, the authors hypothesized that one of the ${ }^{99} \mathrm{Tc}$ species in the AN-107 supernate might be fac- $\mathrm{Tc}(\mathrm{CO})_{3}\left(\mathrm{H}_{2} \mathrm{O}\right)_{3}{ }^{+}$, which would be retained on the cation exchange resin.

A companion document (Ashley et al. 2004) reports more details on the size exclusion chromatography studies. Ashley et al. (2004) studied the performance of two separation media, Sephadex G-10 and BioGel P-2 ${ }^{2}$ (Bio-Rad Inc., Hercules, California) and found that the ${ }^{99}$ Tc species, including pertechnetate, in AN-107 supernate do interact with both size exclusion separation media, complicating the interpretation of the various effluent curves. Further, simple water solutions spiked with either ${ }^{95} \mathrm{TcO}_{4}{ }^{-}$or ${ }^{99} \mathrm{Tc}$-(gluconate) complex interacted with the BioGel P-2 packed column such that the elution volumes of both were much greater than they should be. However, the two Tc species could be resolved

\footnotetext{
${ }^{1}$ Unfortunately, the authors do not provide details on when (how many elution volumes of effluent are collected before and after) the ${ }^{99} \mathrm{TcO}_{4}{ }^{-}$elutes from the G-10 column. The elution volume $\left(\mathrm{V}_{\mathrm{e}}\right)$, void volume $\left(\mathrm{V}_{0}\right)$, and interstitial volume $\left(\mathrm{V}_{\mathrm{i}}\right)$ of the G-10 packed column are necessary details to understand whether a solute species elutes simply as a function of size or whether there are unwanted chemical interactions between the solute and the column beads.

${ }^{2} \mathrm{P}-2$ is a polyacrylamide gel copolymer of acrylamide and N, N'-methylene-bis-acrylamide with a fractionation range 100 to 1800 daltons.
} 
(i.e., they eluted at different elution volumes). These two studies relied on radiocounting (NaI for gross gamma and liquid scintillation counting [LSC] for ${ }^{99} \mathrm{Tc}$ ) of the various effluents from the Dowex cation exchange columns and size exclusion columns. The LSC method is not exclusively separating ${ }^{99} \mathrm{Tc}$ from

all other potential beta emitters in the eluents from $\mathrm{AN}-107$ supernate or for that matter ${ }^{95 \mathrm{~m}} \mathrm{TcO}_{4}{ }^{-}$added to some of the mixed simple solutions. Thus, the radiocounting method also complicates definitive identification of the Tc species in the size exclusion effluents. Future studies using size exclusion chromatography should use ICP-MS to measure total ${ }^{99} \mathrm{Tc}$ and NMR to differentiate pertechnetate from other non-pertechnetate forms of Tc.

These suggested changes in ${ }^{99} \mathrm{Tc}$ measurement techniques should significantly improve the value of using size exclusion chromatography as a tool to identify ${ }^{99} \mathrm{Tc}$ species in DST supernates as long as the various eluents contain high enough ${ }^{99} \mathrm{Tc}$ total concentrations. It would appear that current ${ }^{99} \mathrm{Tc}$ detection limits for ICP-MS and NMR should be acceptable because they are comparable to or better than LSC.

\subsubsection{Spectroscopic Studies used to Determine Tc Speciation}

A third method used to explore Tc speciation uses spectroscopic measurements on both carefully synthesized pure Tc compounds and actual DST supernates using several instruments and techniques, including UV-Vis, NMR, and synchrotron-based X-ray absorption spectroscopy (XAS), both XANES and EXAFS. A number of studies have been reported where ${ }^{99} \mathrm{Tc}$-organic complexes have been synthesized and characterized in great detail in attempts to identify the ${ }^{99} \mathrm{Tc}$ speciation of the soluble non-pertechnetate species found in DST supernates. Schroeder et al. (2002, 2004), and Ashely et al. (2004) attempted to synthesize and characterize Tc complexes with the following ligands: EDTA, ethylenediamine-N,N'-diacetic acid (EDDA), IDA, nitrilotriacetic acid (NTA),

diethylenetriaminepentaacetic acid (DTPA), N-(2-hydroxyethyl)ethylenediaminetriacetic acid (HEDTA), oxalate, glycolate, citrate, gluconate, ethhylenediamine (en), diethylenetriamine (detn), and triethylenetetraamine (tetn). These preparations proved quite difficult, as the products were often not clean and required extensive chromatographic separation. XAS data that the authors were able to obtain indicated some similarity to structures in the literature, but often their synthesized products were more complex. The synthesized complexes also decomposed or oxidized when placed in caustic. The one exception to the above observations was a soluble Tc-gluconate complex that does form in base, but also will change over time to some other species.

Rapko et al. (2013b) were able to synthesize $\mathrm{Tc}(\mathrm{CO})_{3}\left(\mathrm{H}_{2} \mathrm{O}\right)_{3}{ }^{+}$and $\left[\mathrm{Tc}(\mathrm{CO})_{3} \text { gluconate }\right]^{2-}$ separately in alkaline solution and measured their NMR, FTIR, and UV spectra. Other key results of this work included the following:

- Many of the current synthesis procedures are not suitable for making high-milligram to gram quantities of these compounds needed for detailed studies.

- $\left[\mathrm{Tc}(\mathrm{CO})_{3}\left(\mathrm{H}_{2} \mathrm{O}\right)_{3}\right]^{+}$undergoes extensive hydrolysis at $\mathrm{pH}$ values above 6.8; thus, in tank-relevant conditions in the absence of organic complexing agents, the hydrolysis species $\left[\mathrm{Tc}(\mathrm{CO})_{3}(\mathrm{OH})_{\mathrm{n}}\right.$ $\left.\left(\mathrm{H}_{2} \mathrm{O}\right)_{\mathrm{m}}\right]^{1-\mathrm{n}}$ will be formed.

- These tricarbonyl hydrolysis species complicate and interfere with complexation with inorganic and organic ligands in the alkaline tank environment. 
Direct spectroscopic synchrotron XAS has been used in attempts to identify the ${ }^{99} \mathrm{Tc}$ species in DST supernates. The first attempts are documented by Blanchard et al. $(1996,1997)$, wherein XANES spectra were obtained for five DST supernates taken from three tanks. XANES is a technique that probes electronic transitions from an atomic core level to final states in the energy region of $50-100 \mathrm{eV}$ above the selected atomic core level ionization potential. $\mathrm{TcO}_{4}{ }^{-}$molecules exhibit a distinct hump in their XANES spectra below the Tc core level ionization potential, whereas lower-valence-state Tc molecules do not exhibit such a distinct hump. XANES studies of five DST supernates showed that in four of the samples most of the ${ }^{99} \mathrm{Tc}$ present did not show the characteristic pre-edge hump for pertechnetate. The four DST supernates that did not show a dominance of pertechnetate using XANES analysis were from tanks AN-107 (as received), SY-101 (after contacting the Reillex HPQ resin that selectively removes pertechnetate), SY-103 (after removal of cations $\left[{ }^{90} \mathrm{Sr}\right]$ ), and SY-103 (after contacting the Reillex HPQ resin that selectively removes pertechnetate).

Based on a comparison of the XANES spectra for the DST supernates to two Tc standards $(\mathrm{Tc}(0)$ metal and Tc(VII) pertechnetate solution) that had known oxidation states, Blanchard et al. (1997) felt that the ${ }^{99} \mathrm{Tc}$ in four of the five DST supernates were dominated by soluble Tc(IV) species, likely some Tc(IV)-organic species. Blanchard et al. (1997) properly warn that an XAS spectrum is the sum of the XAS spectra from all the different species of a given element that are present in a sample. If more than one species is present, care must be taken to account for this in analyzing the data, and having several known standards with known oxidation states is important in order to compare with the spectrum for an unknown. As mentioned previously, Blanchard et al. (1997) only had spectra for only two known standards: Tc metal, $\mathrm{Tc}(0)$, and pertechnetate, $\mathrm{Tc}(\mathrm{VII})$, so the interpretation was tentative and would have been improved with having a Tc(IV) standard.

The Tc XANES for the "as received" AN-107 sample and the SY-103 sample after removal of ${ }^{90} \mathrm{Sr}$ are reproduced in Figure 4.8. The spectra are very similar. The appearance of small shoulders for these two samples at the $\mathrm{TcO}_{4}{ }^{-}$pre-edge peak indicates the presence of $\mathrm{TcO}_{4}{ }^{-}$. The XANES spectra for DST supernate samples that were first contacted with Reillex HPQ resin are also nearly identical to each other and lack any sign of the pertechnetate-characteristic hump. Of course, the two supernates that were contacted first with the Reillex HPQ resin would be expected not to contain significant concentrations of pertechnetate. The similarity in XANES spectra indicates that the Tc species left in solution after removal of the $\mathrm{TcO}_{4}{ }^{-}$is the same for the two different tank supernates. Blanchard et al. (1997) also opine that if following removal of the $\mathrm{TcO}_{4}{ }^{-}$using Reillex HPQ resin that pertechnetate is reformed very slowly (i.e., reestablishment of equilibrium is kinetically limited), a linear combination of the Reillex HPQ resin contacted SY-103 XANES spectra and the $\mathrm{TcO}_{4}{ }^{-}$standard XANES spectra should fit the SY-103 XANES spectra and would indicate the difference in the amount of $\mathrm{TcO}_{4}{ }^{-}$between the two samples. Figure 4.9 shows this fit. The fit suggests that $22 \% \mathrm{TcO}_{4}{ }^{-}$is present in the $\mathrm{SY} 103$ supernate that had ${ }^{90} \mathrm{Sr}$ removed prior to analyses. A similar fit for as-received $\mathrm{AN}-107$ indicates that there is $38 \% \mathrm{TcO}_{4}{ }^{-}$present in AN-107 and 64\% non-pertechnetate species. Blanchard et al. (1997) felt that the non-pertechnetate species had ${ }^{99} \mathrm{Tc}$ present in the Tc(IV) oxidation state. 


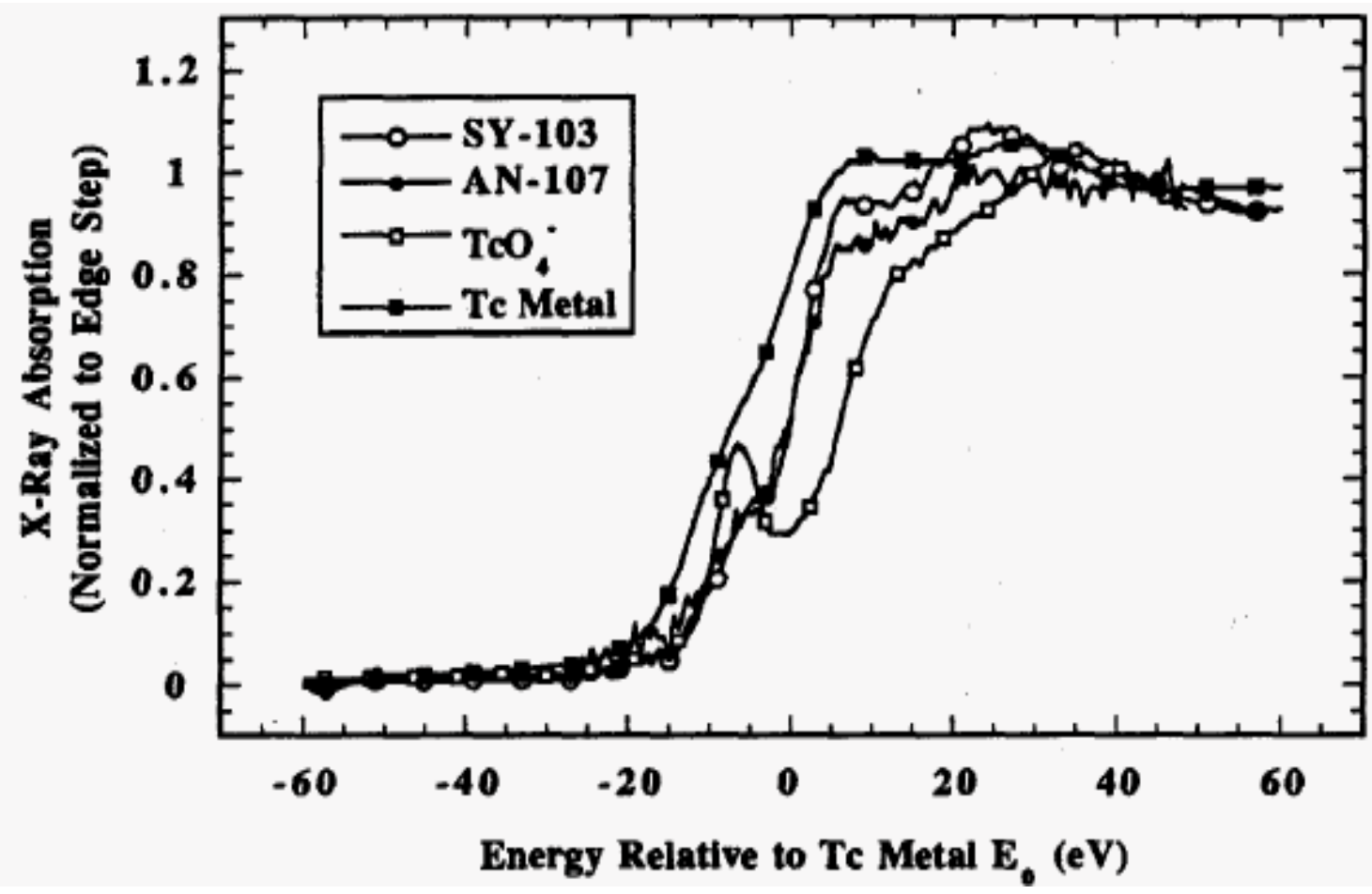

Figure 4.8. Comparison of XANES Spectra for AN-107 and SY-103 Supernates with Two Tc Standards



Figure 4.9. Comparison of XANES Spectra for SY-103 Supernates (contacted refers to removal of pertechnetate prior to analysis) 
The AW-101 supernate had a XANES spectrum with a significant pre-edge hump, similar to the pertechnetate standard XANES spectra, suggesting a predominance of pertechnetate in the supernate but also a small amount of non-pertechnetate (see Figure 4.10). Another XANES spectra comparison between SY-103 supernate that had been stored for an additional 4 months before analyses showed a

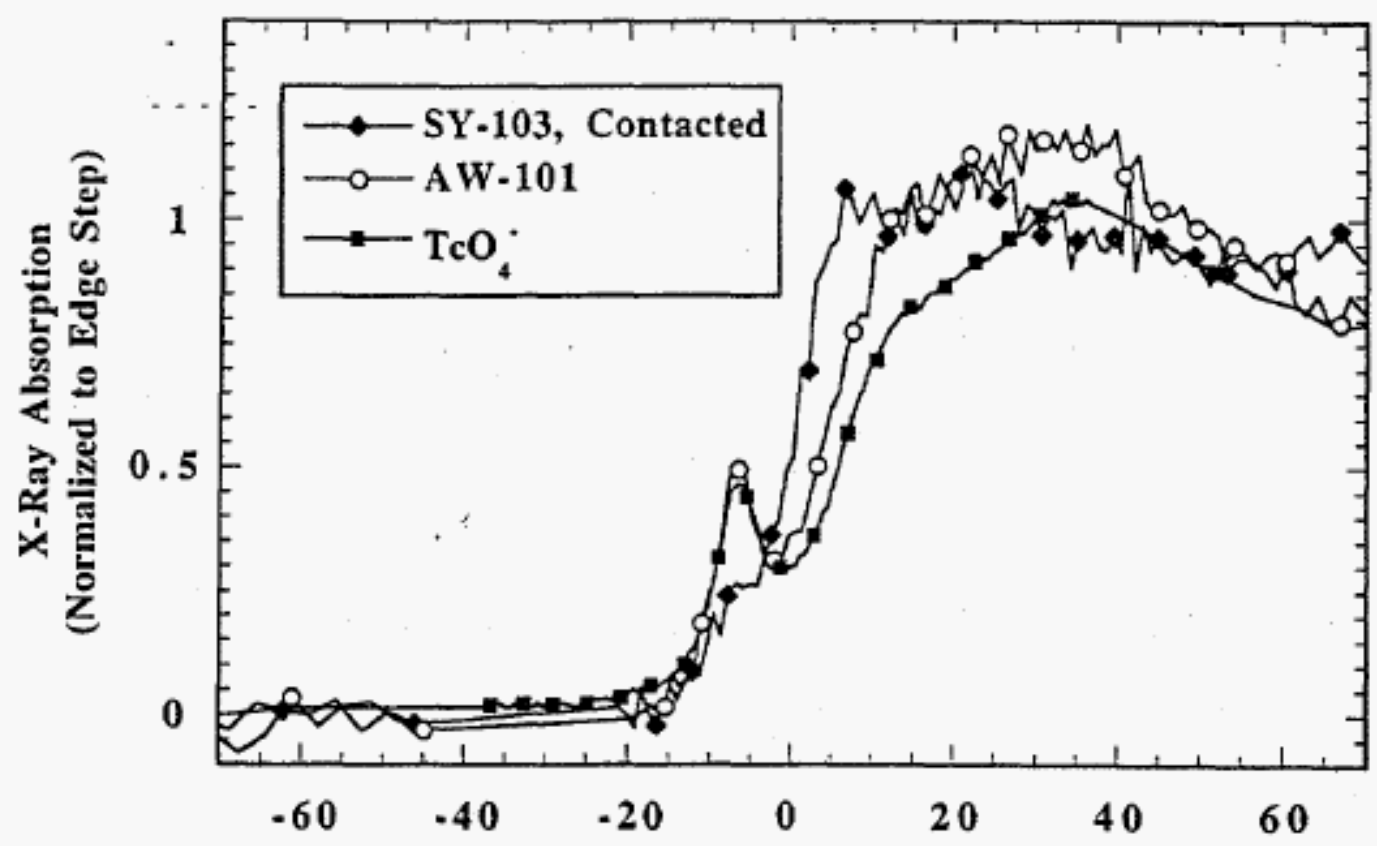

Figure 4.10. Comparison of XANES Spectra for AW-101 and SY-103 Supernates (contacted refers to removal of pertechnetate prior to analysis) with the Pertechnetate Standard

distinct in-growth of pertechnetate in comparison to the XANES spectra taken earlier. This shows that once a DST supernate sample is removed from the high-intensity radiation environment (along with potentially higher temperatures) inside the tank, some of the non-pertechnetate is re-oxidized to pertechnetate. This presents another challenge to identifying the speciation of the non-pertechnetate within the DSTs, mainly because the time between obtaining samples and completion of all processing and detailed characterization and analysis is often several months.

Later, after additional known Tc standards had their XANES spectra measured, other researchers took Blanchard's original DST supernate XANES spectra and compared them to the more robust standards spectra. By using detailed curve-fitting algorithms these other researchers concluded that the non-pertechnetate species shown in the Blanchard et al. $(1996,1997)$ reports (which concluded that the non-pertechnetate species had Tc(IV) oxidation state) are better matched to known standards that have an oxidation state of $\mathrm{Tc}(\mathrm{I})$. These revised XANES interpretations are presented next.

Shuh et al. (2003) and Lukens et al. (2004, 2006) compared the original XANES spectra for SY-101 and SY-103 supernates reported by Blanchard et al. $(1996,1997)$ to XANES spectra of Tc(IV)-gluconate complexes that they created. Although the XANES spectra of Tc(IV) gluconate and the SY tank supernates' spectra are superficially similar, the energies of their Tc absorption edges differ by $1.6 \mathrm{eV}$, an energy difference beyond the uncertainties in the raw data. More importantly, no combination of the XANES spectra for the known standards for Tc(IV) gluconate and $\mathrm{TcO}_{4}{ }^{-}$will fit the SY DST supernates' 
spectra. The authors conclude that not only are the SY DST supernates not Tc(IV) gluconate, they cannot be any kind of Tc(IV) alkoxide complex. The energies of the Tc-K edges of all known Tc(IV) alkoxide complexes and other Tc(IV) complexes with oxygen neighbors, including the solid $\mathrm{TcO}_{2} \cdot 2 \mathrm{H}_{2} \mathrm{O}$, fall within a narrow range around $5.5 \mathrm{eV}$ below the energy of the $\mathrm{TcO}_{4}{ }^{-}$absorption edge (Lukens et al. 2002). The Tc-K edge in the SY DST supernates occurs at 7.1 eV below the $\mathrm{TcO}_{4}{ }^{-}$absorption edge-a difference of $1.6 \mathrm{eV}$. Further, these researchers have shown that $\mathrm{Tc}(\mathrm{IV})$ gluconate is readily oxidized back to $\mathrm{TcO}_{4}{ }^{-}$ when exposed to air. Thus, based on both findings, Shuh and Lukens do not believe that the n-Tc species in the SY tank supernates is Tc(IV) alkoxide complexes. Shuh, Lukens, and co-workers next reviewed radiopharmaceutical literature and found that $\left[\mathrm{fac}-\mathrm{Tc}(\mathrm{CO})_{3}{ }^{+}\right]^{1}$ complexes can be prepared from $\mathrm{TcO}_{4}{ }^{-}$in alkaline solution containing low CO concentrations. DST waste tanks contain CO in their headspace gas at concentrations of 0.25 to $0.5 \mathrm{~mol} \% \mathrm{CO}$ (Johnson 1996). Thus fac-Tc(CO) ${ }_{3}{ }^{+}$could form in the Hanford waste tanks. These researchers then calculated theoretical XANES spectrum for a variety of lower-valent technetium complexes regardless of whether the ligands were present in Hanford DST waste.

Surprisingly, the best candidate theoretical spectrum that matched the DST supernate spectrum was the $\left[\mathrm{Tc}(\mathrm{CO})_{3}\left(\mathrm{H}_{2} \mathrm{O}\right)_{3}\right]^{+}$--- Tc(I)-carbonyl shown in Figure 4.11. This complex and derivatives in which the coordinated water molecules are replaced by other ligands have received considerable attention as ${ }^{99 \mathrm{~m}} \mathrm{Tc}$ radiopharmaceuticals. As mentioned, fac- $\left[\mathrm{Tc}(\mathrm{CO})_{3}\left(\mathrm{H}_{2} \mathrm{O}\right)_{3}\right]^{+}$can form in alkaline aqueous solution under conditions that are very similar to Hanford DST supernate waste that contains low CO concentrations.



Figure 4.11. Structure for the Tc(I) Tri-Carbonyl Fully Hydrated Cation

In other lab experiments, Shuh, Lukens, and co-workers synthesized both fac-Tc(CO) $)_{3}$ and Tc(IV)-gluconate and performed detailed NMR and EXAFS characterization studies to obtain good NMR and EXAFS information on these pure compounds. When Tc(IV) gluconate was mixed with CO for 5 minutes and then heated to $85^{\circ} \mathrm{C}$ in a closed NMR tube with air in the headspace, after 1 hour the sample contained a large amount of $\mathrm{TcO}_{4}{ }^{-}$as determined by ${ }^{99} \mathrm{Tc} \mathrm{NMR}$. After 18 hours at $85^{\circ} \mathrm{C}$, the solution was colorless and contained mainly $\mathrm{TcO}_{4}{ }^{-}$as determined by ${ }^{99} \mathrm{Tc} \mathrm{NMR}$. However, when gluconate was mixed with fac- $\mathrm{Tc}(\mathrm{CO})_{3}{ }^{+}$it did form a complex with fac-Tc(CO) ${ }_{3}{ }^{+}$, which was indicated by the presence of a new peak in the ${ }^{99} \mathrm{Tc}-\mathrm{NMR}$ spectrum at $-1240 \mathrm{ppm}$. This mixed solution was 0.1-M gluconate in 1-M NaOH and an unspecified amount of fac-Tc(CO) ${ }_{3}{ }^{+}$. In another study, fac- $\left[\mathrm{Tc}(\mathrm{CO})_{3}\left(\mathrm{H}_{2} \mathrm{O}\right)_{3}\right]^{+}$was mixed with an SY-101 simulant ${ }^{2}$ and both fac-Tc $(\mathrm{CO})_{3}\left(\mathrm{H}_{2} \mathrm{O}\right)(\mathrm{OH})^{0}$ and fac-Tc(CO) $)_{3}$ (gluconate $)^{2-}$ were observed. However, after one week, the only observable technetium species was fac- $\left[\mathrm{Tc}(\mathrm{CO})_{3}(\text { gluconate })\right]^{2-}$ and $\mathrm{TcO}_{4}{ }^{-}$based on detailed NMR measurements.

${ }^{1} \mathrm{fac}=$ When three identical ligands occupy one face of an octahedron, the isomer is said to be facial, or fac.

${ }^{2}$ SY-101 simulant: $3.78 \mathrm{M} \mathrm{NaOH}, 1.09 \mathrm{M} \mathrm{NaNO}_{2}, 0.42 \mathrm{M} \mathrm{Al}\left(\mathrm{NO}_{3}\right)_{2}, 0.058 \mathrm{M} \mathrm{NaF}, 0.037 \mathrm{M} \mathrm{Na}_{2} \mathrm{CO}_{3}, 0.034 \mathrm{M} \mathrm{KF}$, $0.031 \mathrm{M}$ iminodiacetic acid, $0.02 \mathrm{M} \mathrm{Na}_{2} \mathrm{HPO}_{4}, 0.013 \mathrm{M} \mathrm{Na}_{2}$-EDTA, $0.012 \mathrm{M}$ potassium gluconate, $0.005 \mathrm{M}$ sodium citrate, $0.005 \mathrm{M} \mathrm{Na}_{2} \mathrm{SO}_{4}, 0.004 \mathrm{M} \mathrm{Ca}\left(\mathrm{NO}_{3}\right)_{2}, 0.0005 \mathrm{M} \mathrm{Zn}\left(\mathrm{NO}_{3}\right)_{3}, 0.0002 \mathrm{M} \mathrm{Na}_{3} \mathrm{NTA}, 0.0002 \mathrm{M} \mathrm{Ni}\left(\mathrm{NO}_{3}\right)_{2}$, and $0.0002 \mathrm{M} \mathrm{Fe}\left(\mathrm{NO}_{3}\right)_{3}$. 
Their experiments demonstrate that fac- $\mathrm{Tc}(\mathrm{CO})_{3}$ species are stable in alkaline solutions approximating the composition of DST supernate. For comparison, alkaline solutions of Tc(IV) alkoxides are more air-sensitive, and will oxidize to $\mathrm{TcO}_{4}{ }^{-}$in less than a week if exposed to air. The results described above show that fac- $\mathrm{Tc}(\mathrm{CO})_{3}$ complexes are stable under conditions found in Hanford DSTs, but do not establish whether they are actually the non-pertechnetate species in the DST supernates.

As shown in Figure 4.12, the XANES spectra of the fac-Tc $(\mathrm{CO})_{3}$ complexes are very similar, if not identical, to those of the SY-101 and SY-103 non-pertechnetate species reported by Blanchard et al. (1996, 1997). The Tc K-edge energies of the XANES spectra of fac-Tc $(\mathrm{CO})_{3}$ complexes occur at $7.5 \mathrm{eV}$ below that of $\mathrm{TcO}_{4}^{-}$, in "excellent" agreement with the observed edge shift of $7.1 \mathrm{eV}$ for the non-pertechnetate species in SY DST supernates. Most convincing is the fact that the spectrum of the non-pertechnetate species in tank SY-103 can be fit using only the spectrum of fac- $\mathrm{Tc}(\mathrm{CO})_{3}(\text { gluconate })^{2-}$ and the spectrum of the non-pertechnetate species in tank SY-101 can be fit using the spectrum of fac- $\mathrm{Tc}(\mathrm{CO})_{3}(\text { gluconate })^{2-}$ containing $7 \% \mathrm{TcO}_{4}^{-}$, presumably due to oxidation.

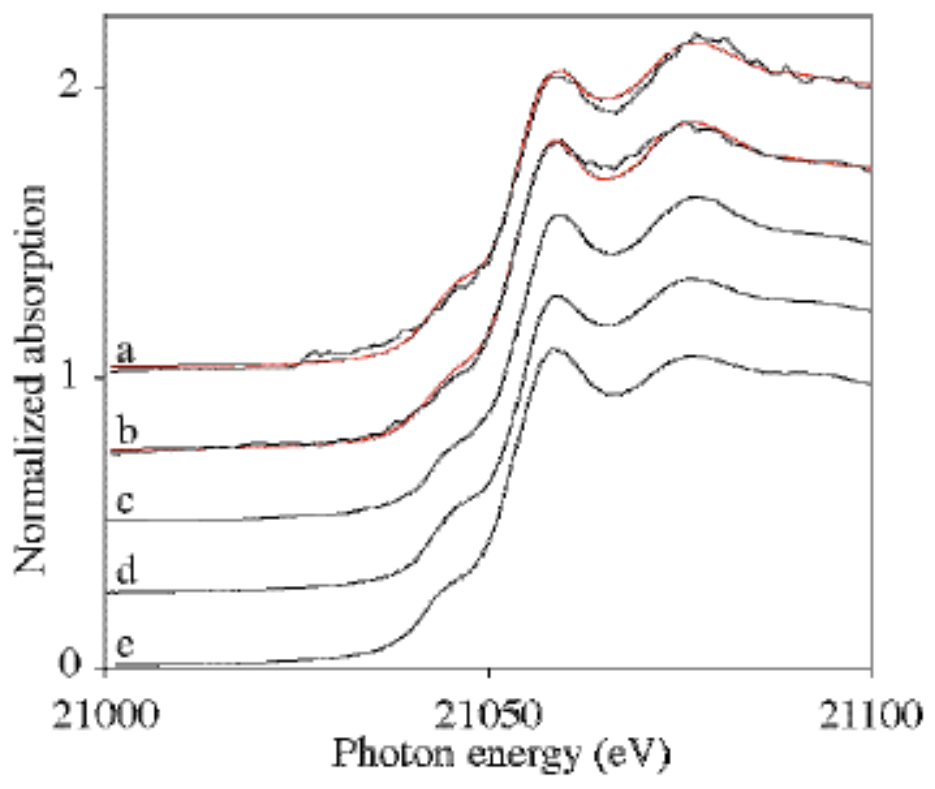

Figure 4.12. Tc K-edge XANES spectra of a) non-pertechnetate species in tank SY-103 (black) and $\mathrm{Tc}(\mathrm{CO})_{3}(\text { gluconate })^{2-}($ red $)$, b) non-pertechnetate species in tank SY-101 (black) and 93\% $\mathrm{Tc}(\mathrm{CO})_{3}$ (gluconate $)^{2-}$ with $7 \% \mathrm{TcO}_{4}^{-}(\mathrm{red})$, c) $\mathrm{Tc}(\mathrm{CO})_{3}(\text { gluconate })^{2-}$, d) $\mathrm{Tc}(\mathrm{CO})_{3}(\mathrm{OH})\left(\mathrm{H}_{2} \mathrm{O}\right)_{2}$, e) $\mathrm{Tc}(\mathrm{CO})_{3}\left(\mathrm{H}_{2} \mathrm{O}\right)_{3}{ }^{+}$. The spectra of the non-pertechnetate species in tanks SY-101 and SY-103 are from Blanchard et al. (1996, 1997).

Analogous Tc(I) dicarbonyl nitrosyl complexes, including $\mathrm{Tc}(\mathrm{CO})_{2}(\mathrm{NO})\left(\mathrm{H}_{2} \mathrm{O}\right)_{3}{ }^{2+}$, are known (Rattat et al. 2001). The $\mathrm{Tc}(\mathrm{CO})_{2}(\mathrm{NO})$ complexes are somewhat more stable than fac- $\mathrm{Tc}(\mathrm{CO})_{3}$ complexes and could be generated in Hanford tanks as a result of the radiolytic decomposition of nitrate and nitrite (Cook et al. 2001; Meisel et al. 2001). The XANES spectra of $\mathrm{Tc}(\mathrm{CO})_{2}(\mathrm{NO})$ [not available] and fac- $\mathrm{Tc}(\mathrm{CO})_{3}$ complexes would be similar. Given the probable similarity of the XANES spectra of the Tc(I) carbonyl complexes, assignment of the non-pertechnetate species observed in Hanford DST supernates to a particular species is not conclusive, although $\mathrm{Tc}(\mathrm{CO})_{3}(\text { gluconate })^{2-}$ provides an excellent fit to the observed XANES spectrum of the non-pertechnetate species in the SY-101 and SY-103 supernates. 
The fac- $\mathrm{Tc}(\mathrm{CO})_{3}$ complexes are not thermodynamically stable with respect to oxidation to $\mathrm{TcO}_{4}{ }^{-}$; however, they are kinetically inert due to their low-spin $d^{6}$ electronic structure. As a result, they will react slowly with potential oxidizing agents, such as oxygen. The kinetic inertness of these complexes also affects oxidation by strong oxidizers. Since fac- $\mathrm{Tc}(\mathrm{CO})_{3}$ complexes will react relatively slowly with strong oxidizers (although presumably much faster than they react with oxygen), the strong oxidizers will preferentially react with other Hanford tank compounds, such as nitrite and/or organic carbon molecules, that are present in much higher concentrations and are much more reactive than the presumed fac- $\mathrm{Tc}(\mathrm{CO})_{3}$ complexes.

In summary, based on the available information, Shuh, Lukens, and co-workers conclude that the problematic, non-pertechnetate species in the Hanford DST supernates can be tentatively identified as $\mathrm{Tc}(\mathrm{I})$ carbonyl complexes derived from either $\mathrm{Tc}(\mathrm{CO})_{3}{ }^{+}$or $\mathrm{Tc}(\mathrm{CO})_{2}(\mathrm{NO})^{2+}$. These positively charged complexes may further combine with organic, inorganic, or hydroxyl anions to attain charge neutrality.

\subsubsection{Correlation of Non-pertechnetate Percentages with Other DST Supernate Constituents}

Rapko et al. (2013a) attempted to establish chemically logical correlations between available DST analytes and the estimates of supernate-soluble non-pertechnetate. They used the DST supernate data from the TWINS database and tried to correlate variables with the percentage of non-pertechnetate shown in Table 4.9 in this report. The goal was to see if strong correlations could be found that would allow extrapolation and estimates of the non-pertechnetate percentages in supernates from other DSTs that have not been characterized for non-pertechnetate but have been characterized for other constituents. From the work of Rapko et al. (2013a), the only acceptable chemically based correlation with data from the TWINS database was that the fraction of non-pertechnetate present in characterized DSTs correlated with either of two closely related variables: 1) total dose experienced in the tank and 2) ${ }^{137} \mathrm{Cs}$ concentration in the tank supernatants. However, the observed inverse correlation is counterintuitive. One would expect that DST supernates with high doses/high ${ }^{137} \mathrm{Cs}$ concentrations to be excellent environments for radiolysis-induced reduction of components with concomitant formation of non-pertechnetate. After attempting to find chemically relevant correlations, Rapko et al. (2013a) realized that each variable for which correlations were sought had a broad range of variability in measured concentrations, and thus large uncertainty bars. The impact of such large uncertainty was often compounded by the relatively steep dependence of the percent non-pertechnetate on the variable in question. This led to situations that were described mathematically as a prediction of between $0 \%$ and $100 \%$ non-pertechnetate due to the uncertainty associated with the variable itself. The uncertainties in ${ }^{137} \mathrm{Cs}$ concentrations were relatively small and thus a correlation was found; unfortunately, the correlation was negative, which is counterintuitive. There was no correlation between the non-pertechnetate percentage and total soluble ${ }^{99} \mathrm{Tc}$ in the DST supernates for which non-pertechnetate estimates were available.

\subsection{Tc Recycle and Recovery in Off-gas Systems}

The second objective of this literature review was to discuss the anticipated fate of ${ }^{99} \mathrm{Tc}$ during glass melter operations, and its recycle and recovery from various off-gas units downstream of the melters. Finally there was a request to describe briefly ${ }^{99} \mathrm{Tc}$ removal options from LAW feed and off-gas 
condensates as an alternative to continuous recycle to the LAW melters. Section 5.0 presents the brief summary of reports containing such studies and notes key citations that can be read to gain more details.

Based on the current WTP process flow sheets, almost all of the ${ }^{99} \mathrm{Tc}$ in wastes retrieved from the Hanford tanks will remain in solution after various sludge washing and other processes are performed in the PT Facility to dissolve and separate the waste into the high-level and low-level fractions. This means that almost all of the ${ }^{99} \mathrm{Tc}$ will be found in the low-level portion of the liquid waste stream that is sent from the PT Facility to the LAW melter. Tc in LAW liquid waste forms species that are volatile at the high temperature in the LAW melter, causing most of it to partition to the off-gas systems and have low retention in the LAW glass. Depending on the composition of the LAW liquid waste stream, volatility studies on LAW simulants doped with ${ }^{99} \mathrm{Tc}$ in the pertechnetate form show widely different percentages to be volatile (<10\% to $~ 80 \%$; see Yanochko et al. 2012; Robbins and May 2013). Moreover, ${ }^{99} \mathrm{Tc}$ volatility is affected by other volatile and semivolatile constituents in the LAW feed that would also build up during recycling of condensed off-gases that are recycled back to the LAW melter, as discussed next.

The current River Protection Project WTP baseline approach to mitigate the low ${ }^{99}$ Tc retention in glass is to capture the volatile gases in off-gas condensate systems that capture and then condense the hot gases as an aqueous waste. The first system in the sequential LAW Facility off-gas system is a submerged bed scrubber (SBS) that condenses the gases and captures them in a liquid. Any gases that pass through the SBS are next treated in a wet electrostatic precipitator (WESP) that also condenses gases into a liquid waste stream. A third, caustic-based gas scrubber captures any residual exhaust gases that are not captured in the first two systems. ${ }^{1}$ In the current baseline for the LAW unit operations, these condensates are combined and sent back to the PT Facility evaporator or, should the PT Facility not be operational when the LAW Facility is melting glass, the condensates are routed either to the HLW melter or to the AW-102 DST for staging for the 242-A evaporator-two distinctly different current options. If routed to the PT Facility or the AW-102 DST/242-A evaporator, the condensates are concentrated by evaporation and then combined with new incoming LAW feed (see Figure 5.1).

The SBS-WESP combined condensate stream is a dilute salt solution with near neutral $\mathrm{pH}$, and will likely contain some insoluble glass-forming solids from melter carryover. One estimate of the chemical composition of this combined condensate waste stream (based on HTWOS $^{2}$ calculations) is documented in Robbins and May 2013 and Taylor-Pashow et al. (2014). These references suggest it will be a relatively high-volume waste stream (1.55 million gallons per year) with concentrations of ${ }^{99} \mathrm{Tc}$ (4.14 E-05 Ci/L [2.44 mg/L]), chloride (2.68 E-02 mole/L), fluoride (7.64 E-02 mole/L), nitrites (2.32 E-04 moles/L), nitrates (8.92 E-02 moles/L), sulfate (2.43 E-02 mole/L), and ammonium (8.33 E-02 mole/L), and low concentrations of ${ }^{137} \mathrm{Cs}(5.21 \mathrm{E}-06 \mathrm{Ci} / \mathrm{L})$. After being concentrated by evaporation and added to new LAW liquid waste after repeated recycles, the SBS/WESP condensates' ${ }^{99}$ Tc concentration will build up to some steady-state concentration until the Tc is captured in the LAW glass. The same will be true for the volatile halides and sulfate, which have deleterious effects on glass formation and evaporator corrosion. ${ }^{3}$

\footnotetext{
${ }^{1}$ This caustic scrubber produces a liquid waste that contains very little technetium and is pumped to the PT Facility, where it is combined with other condensate and sent to ETF (Yanochko and Corcoran 2012).

${ }^{2}$ A description of HTWOS and references to more details are provided in Appendix C.

${ }^{3}$ Prior experience in evaporation of another melter off-gas stream, the recycle stream at the Savannah River Site Defense Waste Processing Facility, unexpectedly caused deleterious impacts on evaporator scaling and formation of aluminosilicate solids before controls were implemented. Further, halides and sulfate are only marginally soluble in glass, and often dictate what the practical waste loading can be in glass (see McCabe et al. 2013).
} 


\section{Simplified LAW Off-gas System - Baseline WTP operations}

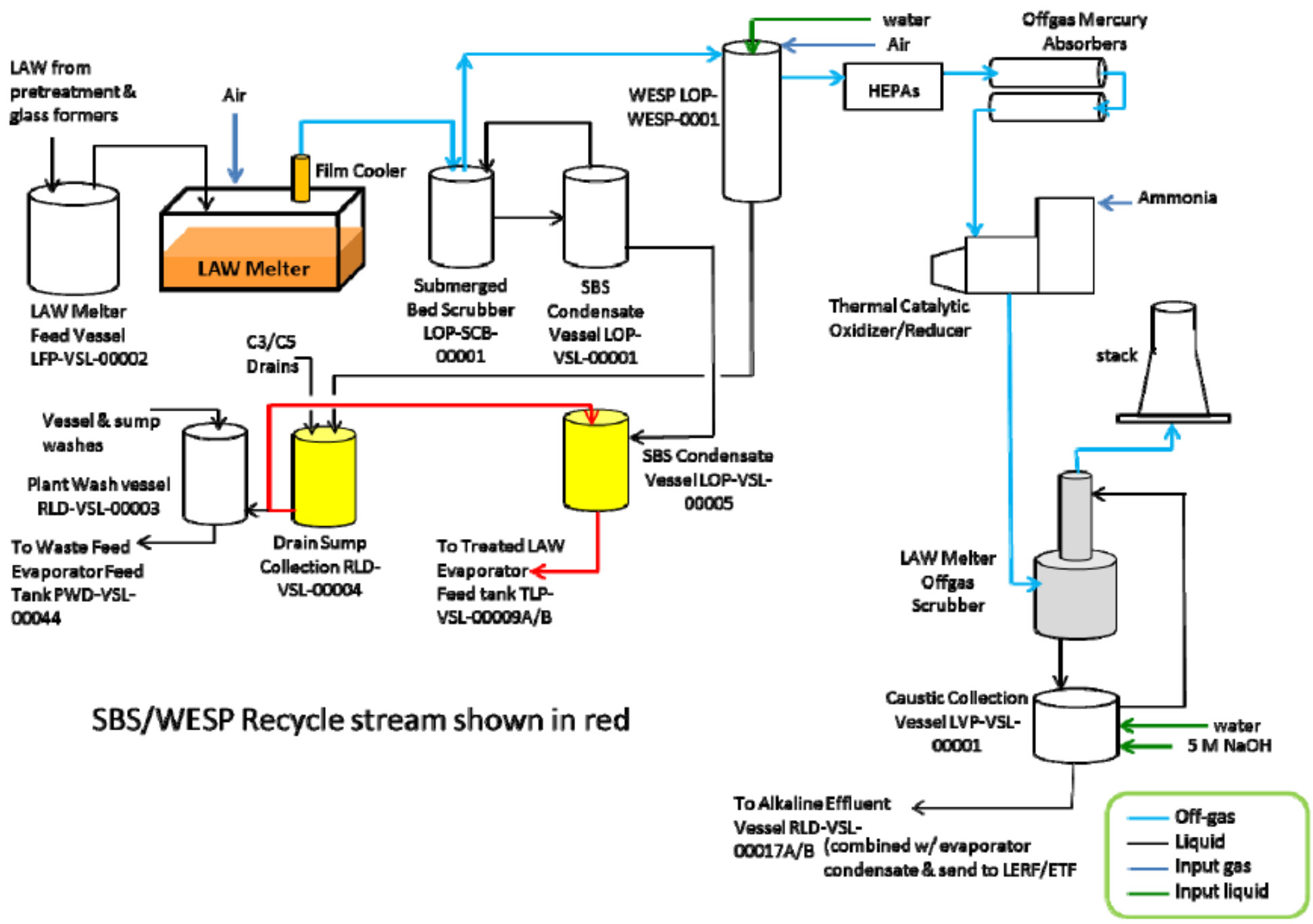

Figure 5.1. Simplified Off-gas System in Baseline WTP Unit Operations (taken from McCabe et al. 2013) 
Abramowitz et al. (2012) produced the first-ever data on the fate of Tc during recycle of condensates from key WTP unit operations (SBS, WESP, vacuum evaporator) into the LAW glass melter. They measured the distribution and fate of Tc throughout the vitrification system and recycle loop, and the extent of partitioning to secondary waste streams. Seven different LAW waste compositions (LAW from Hanford tanks AP-101, AN-102, AN-104, AN-105, AN-107, AZ-101, and AZ-102) were processed in nine, nominally 72-hour, continuous tests where glass was produced with feed that contained recycled off-gas condensate added to LAW simulant feed. All feeds were spiked with ${ }^{99 \mathrm{~m}}$ Tc (half-life 6.02 hours with a conveniently measured gamma emission) in the pertechnetate form. The nominal melter operating conditions used the DM10 melter at $1150^{\circ} \mathrm{C}$ glass pool temperature, added sugar reductant at a stoichiometric sugar ratio of 0.5 , and bubbled air through the glass pool at a rate to achieve a constant target glass production rate of $2250 \mathrm{~kg} / \mathrm{m}^{2}$ per day. In each test, a mass balance for Tc was obtained across the glass pool, the discharge glasses, throughout the SBS, WESP, and vacuum evaporators, and the WESP exhaust and evaporator overheads. In the WTP system, Tc can escape this "closed circuit" recycle loop via two routes: 1) in the off-gas stream exiting the WESP exhaust and 2) in the liquid condensate from the vacuum evaporator. The WESP exhaust effluent and vacuum evaporator condensates are disposed ultimately in non-glass waste forms. A schematic of the DM10 melter and continuous recycle testing system is shown in Figure 5.2 and a photograph showing the size of the key components is shown in Figure 5.3.

Key findings from this work include the following:

- With recycle, Tc retention in the glass product is increased by factors of at least 2 to 3 over the corresponding single-pass values for almost all glasses made with the seven LAW liquid waste compositions. For all but two LAW compositions, Tc retention in glass ranges from $68 \%$ to $84 \%$ of the total. In comparison, in 72 previously conducted single-pass DM10 tests (without recycle) the average Tc retention was $35.2 \%$.

- The increase in Tc retention in LAW glass was limited by holdup of material in the system, particularly in the WESP internals, the film cooler, and transition lines between the off-gas sequential train. Mobilization of the "held up" material to make it available for recycle would likely further increase the retention in glass.

- The Tc mass balance closure reached as high as $95 \%$ but averaged about $90 \%$. That is, on average $10 \%$ of the Tc was not accounted for during each of the nine continuous recycle tests.

- The fraction of feed Tc exiting the recycle loop through the evaporator overheads was less than $0.03 \%$ during normal operations and the fraction of feed Tc exiting the recycle loop through the WESP exhaust ranged from $0.01 \%$ to $0.5 \%$ during normal operations. However, the fraction of feed Tc exiting the recycle loop through the WESP exhaust was critically dependent on the performance of the WESP and increased to above $10 \%$ (i.e., by a factor of about 500 or more) when the WESP was not functioning. 


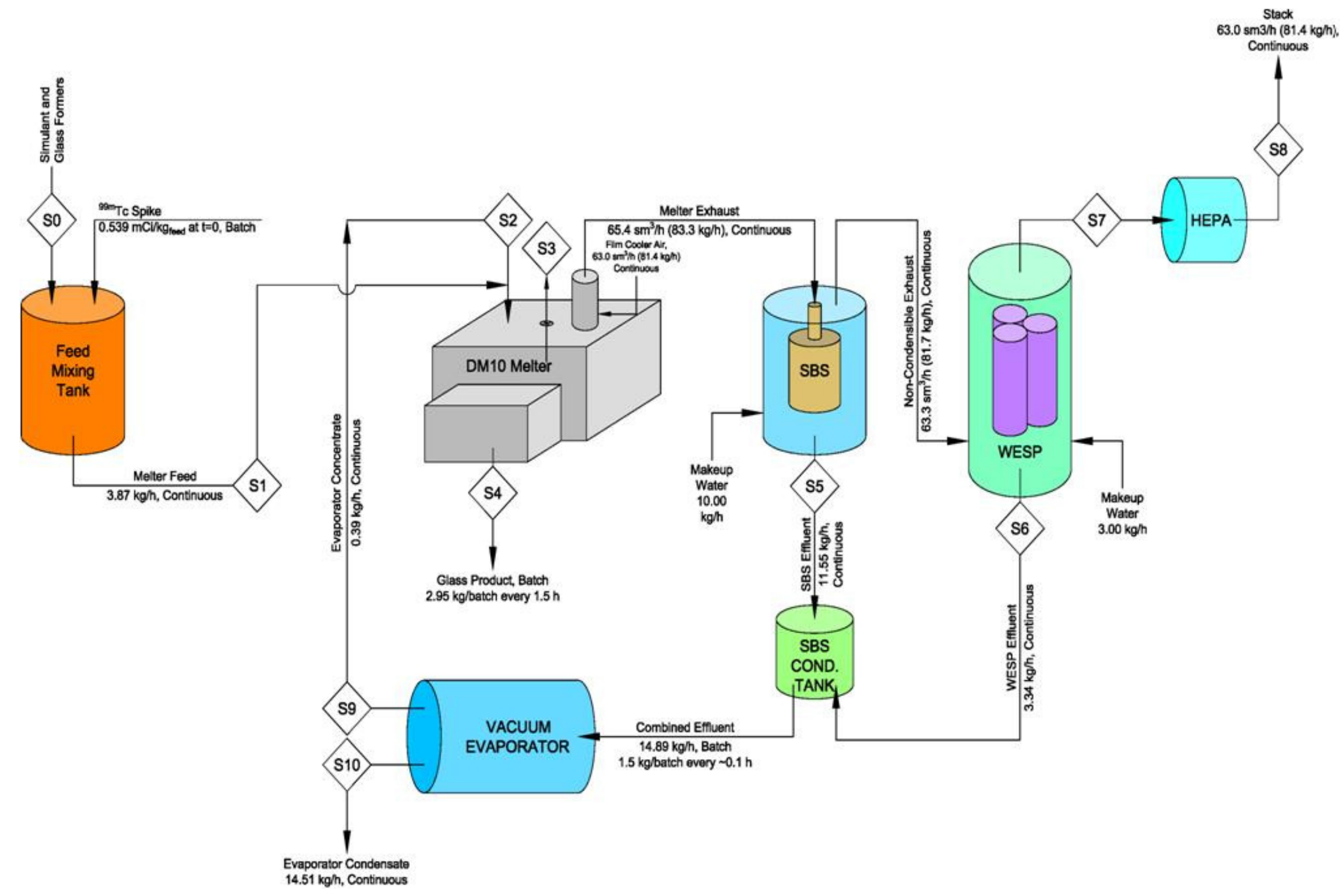

Figure 5.2. Schematic of the DM10 Melter and Continuous Recycle Testing Platform (from Ramsey 2012a). Diamonds with s\# represent sampling points for ${ }^{99 \mathrm{~m}} \mathrm{Tc}$ and other key constituents. 


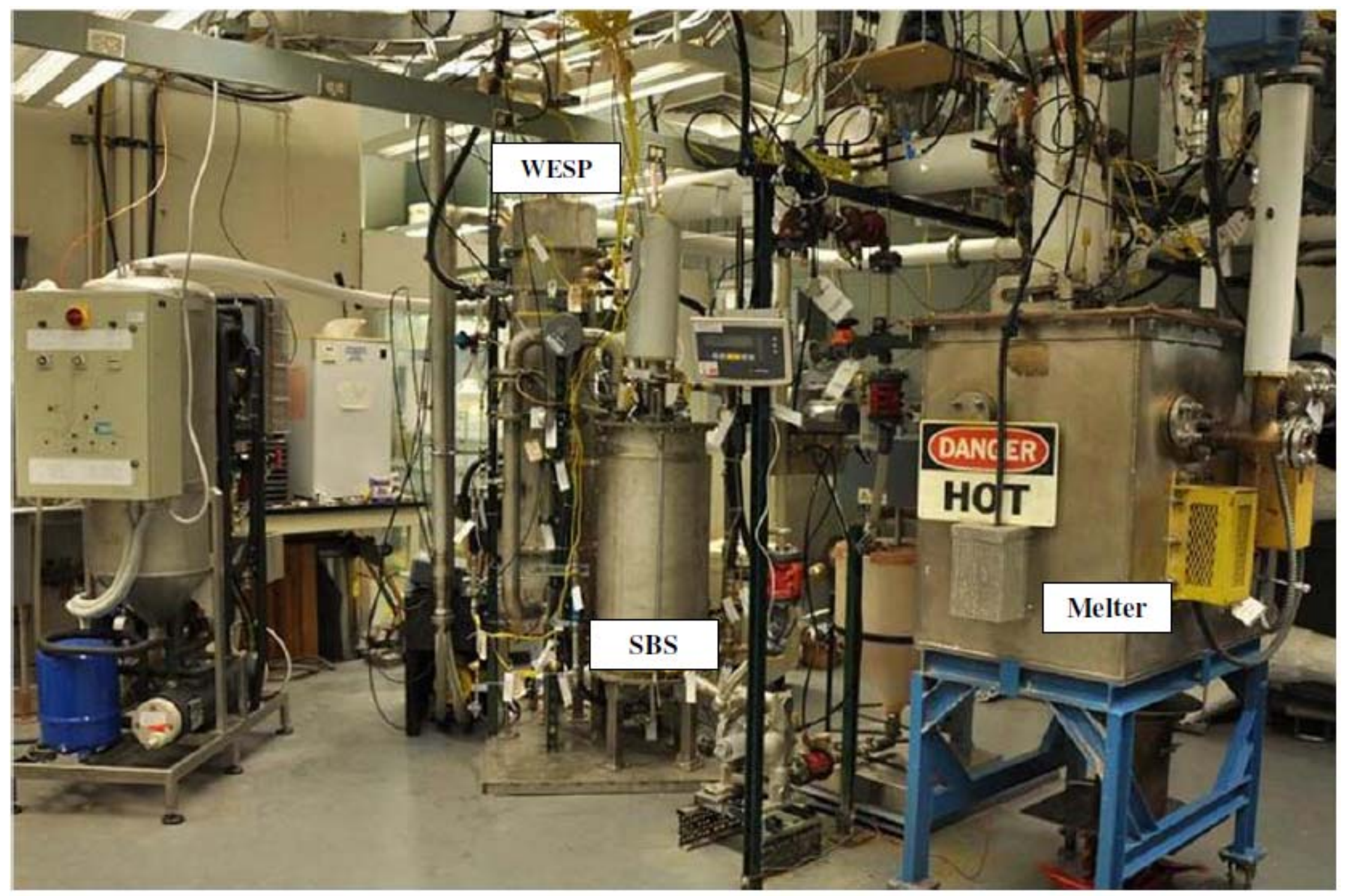

Figure 5.3. Photograph of the DM10 Melter and Continuous Off-gas Recycle Test Facility (from Ramsey 2012a) 
- While the measured technetium retention values for the LAW glass with recycle are much increased over the single-pass values (see Figure 5.4), they are significantly lower than previous assumptions and estimates used in WTP planning calculations. For example, the Mann et al. (2003) risk assessment supporting the evaluation of supplemental ILAW waste form technologies assumed "low," "best," and "high" estimates for the fraction of the Tc inventory bound in the LAW glass product of $90 \%, 99.9 \%$, and $100 \%$, respectively, with the "best estimate" value used for the baseline risk assessment calculations and the other two values used for sensitivity calculations.

- In view of the complexity of the recycle test system and the numerous samples and analyses that were required to complete the mass balance, the measured average Tc mass balance closure of about $90 \%$ is considered very good. For the previous once-through LAW tests, Tc mass balance closures were $97 \%$. However, the $10 \%$ recycle testing shortfall in Tc mass balance is significant with respect to the ability to measure retentions in glass nearing $100 \%$. Past performance assessments for the Hanford Site have assumed that LAW glass can capture between $95 \%$ and $99 \%$ of the ${ }^{99} \mathrm{Tc}$ such that the secondary waste stream would only have to accommodate a small ${ }^{99} \mathrm{Tc}$ inventory. If less ${ }^{99} \mathrm{Tc}$ can be incorporated into LAW glass, then the secondary waste forms must adequately incorporate more ${ }^{99} \mathrm{Tc}$ than currently planned. Further, any supplemental LAW waste form would have to accommodate larger quantities of ${ }^{99} \mathrm{Tc}$ also. Thus, the release performance of the secondary waste form (currently Cast Stone) and any supplemental LAW waste form would have to be shown to be very good to ensure groundwater protection.

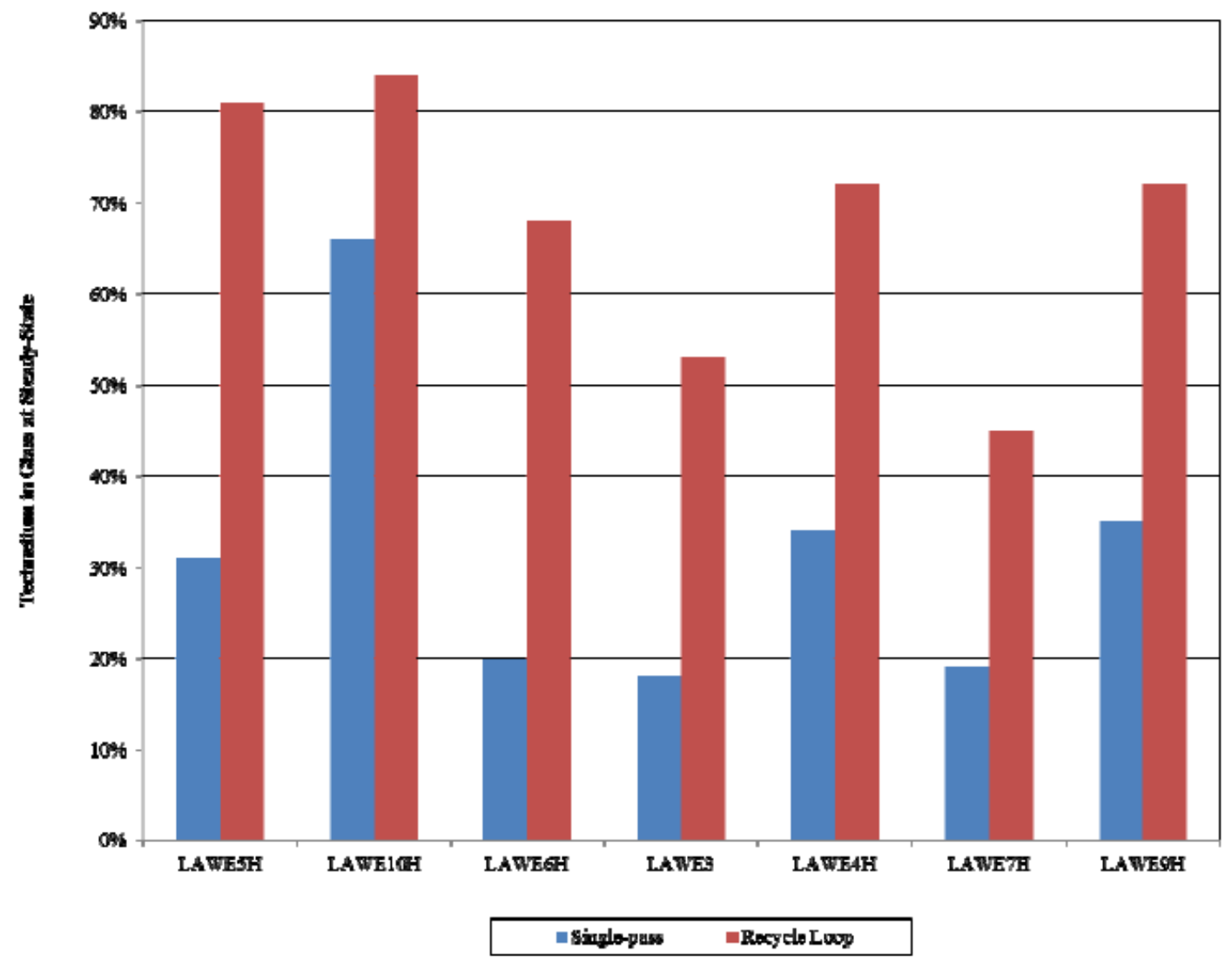

Figure 5.4. Comparison of Tc Retention in LAW Glass Between Single and Continuous Recycle of Off-gas Condensate (from Ramsey 2012a) 
The findings of Abramowitz et al. (2012) suggest that repeated recycling of the condensates from the off-gas treatment unit operations (SBS, WESP, and vacuum evaporator) does not incorporate $90 \%$ or more of the ${ }^{99} \mathrm{Tc}$ present in LAW liquid waste into LAW glass. This raises an issue with the current assumptions used in the latest IDF performance assessment (PA), supplemental waste risk assessment (RA), and TC\&WM EIS that $95 \%$ to $\sim 99.9 \%$ of the ${ }^{99} \mathrm{Tc}$ in LAW liquid can be incorporated into glass, which is considered the best performing waste form in regards to long-term release of the potentially mobile ${ }^{99}$ Tc. Other technical issues that surfaced from the results of the Abramowitz et al. (2012) continuous condensate recycle tests are documented in Ramsey (2012b).

Several reports have been published that describe alternative methods of treating the SBS-WESP condensates (which contain most of the ${ }^{99} \mathrm{Tc}$ after LAW liquid waste is fed through the LAW melter in each cycle). Essentially, the alternative methods would either send the SBS-WESP condensates off-site either with or without further treatment to remove the ${ }^{99} \mathrm{Tc}$ or would remove the ${ }^{99} \mathrm{Tc}$ from the condensates and then send the treated condensates to the Effluent Treatment Facility (ETF) on the Hanford Site. The ${ }^{99} \mathrm{Tc}$ removed from the condensates would be further treated (generally adsorbed, precipitated, directly encapsulated into a low-temperature waste form such as Cast Stone, or vitrified either through the LAW, HLW, or a separate melter). The ${ }^{99} \mathrm{Tc}$ removed from the SBS-WESP condensates after "solidification" could be sent off-site or disposed on-site. Details on the various alternative methods of removing the ${ }^{99} \mathrm{Tc}$ from the SBS-WESP condensates and treating and disposing the final ${ }^{99} \mathrm{Tc}$ waste are discussed in Yanochko and Corcoran (2012), Yanochko et al. (2012), Robbins and May (2013), McCabe et al. (2013), Adamson et al. (2014), and Taylor-Pashow et al. (2014). Each report discusses the advantages of not recycling the ${ }^{99}$ Tc-bearing SBS-WESP condensates to the PT Facility for recycle to the LAW melter. Many of these reports also offer cost and schedule estimates for the proposed alternatives. Nash et al. (2013) discuss removing ${ }^{99} \mathrm{Tc}$ directly from the LAW liquid waste before sending the treated LAW waste to the LAW melter or to another supplemental waste form. Removing the ${ }^{99} \mathrm{Tc}$ lessens some of the long-term performance issues for burial of non-glass waste forms in the IDF. Of course, the ${ }^{99} \mathrm{Tc}$ that is removed from the liquid LAW waste must be disposed in some solidified form at some disposal facility.

Regarding the speciation of ${ }^{99} \mathrm{Tc}$ in the off-gas and their condensates, several of the reports suggest that the LAW melter is expected to convert all the ${ }^{99} \mathrm{Tc}$ that volatilizes to the pertechnetate ion when the hot gases contact the water in the SBS and WESP condensers. However, the dissociation of the volatilized technetium species upon contact with water in the SBS and WESP has not been demonstrated to date. That said, the assumption seems reasonable given the likely oxidizing environment in the SBS and WESP condensers. Abramowitz et al. (2012) did not address any ${ }^{99} \mathrm{Tc}$ speciation issues because only the total ${ }^{99 \mathrm{~m}} \mathrm{Tc}$ activity could be measured.

Robbins and May (2013) show an estimate, presented in Table 5.1, for how the total ${ }^{99} \mathrm{Tc}$ presently in the 177 Hanford tanks distributes in the WTP glasses after completion of the entire vitrification campaign as shown in Table 5.1. The estimate is derived from the use of a HTWOS computer code. Based on HTWOS run MMR-13-008_Case-1-7.4-8.3r1-2013-04-04-at-02-39-53, all the tank waste is processed and separated into HLW and LAW fractions. Then all the treated tank waste is vitrified; the HLW portion in the WTP HLW Facility and the LAW in two LAW vitrification facilities. That is, all LAW is vitrified as opposed to another option where a supplemental waste form is chosen (and a different solidification facility built) to process a portion of the LAW. 
This final distribution of the total ${ }^{99} \mathrm{Tc}$ presently in the 177 Hanford storage tanks assumes that all the ${ }^{99} \mathrm{Tc}$ can be incorporated into glass, an assumption that is under review given the results of Abramowitz et al. (2012). The total ${ }^{99} \mathrm{Tc}$ shown in the last row of Table 5.1 agrees favorably with the two most recent BBI total ${ }^{99} \mathrm{Tc}$ inventory estimates shown in the bottom row of both Table 4.4 and Table 4.5.

Table 5.1. Estimated Distribution of All ${ }^{99} \mathrm{Tc}$ Currently in Hanford Tanks After Vitrification

\begin{tabular}{lcc}
\hline Estimated ${ }^{99}$ Tc Distribution & Curies & $\%$ of Total ${ }^{99} \mathrm{Tc}$ \\
\hline First off-gas condensate —recycled until incorporated in LAW glass & 7000 & $26.4 \%$ \\
First LAW glass plant product—captured in first cycle into LAW melter(s) & & \\
in first LAW plant & 4190 & $15.8 \%$ \\
Second off-gas condensate —recycled until incorporated in LAW glass & 8410 & $31.8 \%$ \\
Second LAW glass plant product—captured in first cycle into LAW & & \\
melter(s) in second LAW plant & 5410 & $20.4 \%$ \\
Total LAW in LAW glass & 25010 & $94.5 \%$ \\
HLW glass plant product & 1460 & $5.5 \%$ \\
Total ${ }^{99} \mathrm{Tc}$ & 26470 & $100 \%$ \\
\hline
\end{tabular}

\subsection{Tc Inventory in Other Hanford "Pools"}

Although the main focus of this review is to document the current inventory and distribution of ${ }^{99} \mathrm{Tc}$ in the Hanford storage tanks and to discuss the ${ }^{99} \mathrm{Tc}$ fate during retrieval, processing, and final disposal, there are other places on the Hanford Site where ${ }^{99} \mathrm{Tc}$ inventory exists. To get a complete picture of what has happened to the total ${ }^{99} \mathrm{Tc}$ created during nuclear fuel irradiation and its subsequent fate, a simple mass balance box model was created. A box was created for each type or place that ${ }^{99} \mathrm{Tc}$ has been disposed or currently resides, and attempts were made to assign a quantity to each box or ${ }^{99} \mathrm{Tc}$ "pool." The outcome of this mass balance exercise follows. This approach follows the spirit of EPA guidance for conducting remedial investigations (EPA 1988, p. 2-7). The guidance calls for development of a "conceptual site model" that includes known and suspected sources of contamination, types of contaminants and affected media, known and potential routes of migration, and known or potential human and environmental receptors. The stated purpose in the EPA (1988) guidance for developing and maintaining a conceptual site model is "to evaluate potential risks to human health and the environment" and to "assist in the identification of potential remedial technologies."

Figure 6.1 shows a schematic of the various "pools" or boxes in which ${ }^{99} \mathrm{Tc}$ distributes after production in the reactors used to produce plutonium. It also includes boxes for ${ }^{99} \mathrm{Tc}$ brought into the Hanford Reservation from off-site sources. Table 6.1 lists the curies of ${ }^{99} \mathrm{Tc}$ that are estimated to reside in each box or "pool" for those boxes where information is available. Many of the boxes have no values because data/estimates were not readily available. The table does capture the fate for the bulk of the ${ }^{99} \mathrm{Tc}$ generated at Hanford on a high-level view (amount produced, amount currently is storage tanks, amount released to the Hanford Site vadose zone, and amount shipped off-site with uranium). As shown in Table 6.1, the high-level ${ }^{99} \mathrm{Tc}$ mass balance is quite good; 32,600 Ci produced and 32,300 Ci accounted for. However, the partitioning of the "pool" of ${ }^{99} \mathrm{Tc}$ release to the vadose zone into the current boxes for "present in vadose zone," "present in aquifer sediments and groundwater," and ${ }^{99} \mathrm{Tc}$ that has "reached the Columbia River" can't be assigned estimates. These three "pools" are important for making site remediation decisions and site risk assessments but are not the main scope of the Tc Management 
Program that is funding this report. Appendix D provides some discussion and lists reports that discuss the complexities of making estimates for these three boxes (3A, 3B, and 3C in Table 6.1). An earlier estimate of where ${ }^{99} \mathrm{Tc}$ inventory resides or will reside in the future at the Hanford Site is found in Chapter 28 as Figure 28.1 of DOE/ORP 2010 and is reproduced herein as Figure 6.2, showing their estimated ${ }^{99} \mathrm{Tc}$ inventories on a $\log (\mathrm{Y}$-axis) bar chart. 




Figure 6.1. Schematic of the Distribution and Fate of ${ }^{99} \mathrm{Tc}$ Between the Various "Pools" 


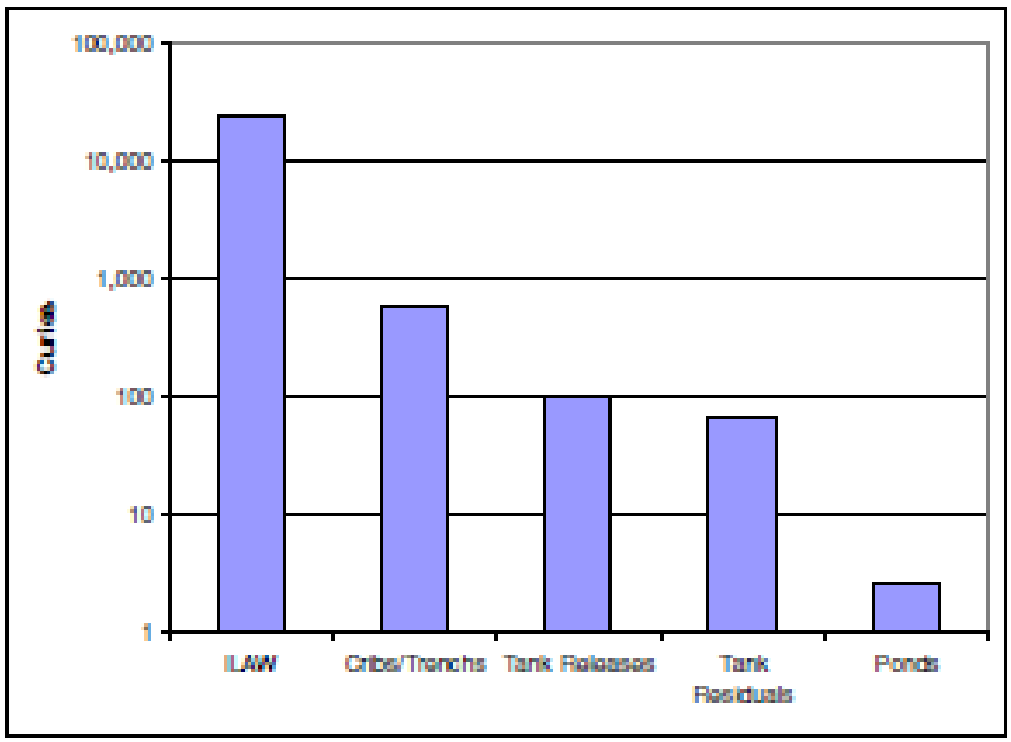

Figure 6.2. DOE/ORP 2010 Estimate of the Distribution of ${ }^{99} \mathrm{Tc}$ Between the Various "Pools"

Table 6.1. ${ }^{99} \mathrm{Tc}$ Distribution in Various "Pools" used to Calculate Mass Balance or Hanford Site ${ }^{99} \mathrm{Tc}$ Conceptual Model

\begin{tabular}{|c|c|c|c|c|}
\hline $\begin{array}{c}\begin{array}{c}\text { Box \# } \\
\text { (from } \\
\text { Figure 6.1) }\end{array} \\
\end{array}$ & Pool & Description & $\begin{array}{l}{ }^{99} \mathrm{Tc} \\
(\mathrm{Ci})\end{array}$ & Notes \\
\hline 1 & Fuel & $\begin{array}{l}\text { Fission product in } \\
\text { irradiated U/Th fuel rods }\end{array}$ & 32,600 & \\
\hline 2 & $\begin{array}{l}\text { Reprocessed Wastes } \\
\text { Generated }\end{array}$ & Fuel dissolution & 32,600 & $\begin{array}{l}\text { Three different processes } \\
\text { used }\end{array}$ \\
\hline 3 & $\begin{array}{l}\text { Liquid Wastes Disposed to } \\
\text { Ground }\end{array}$ & $\begin{array}{l}\text { Low-activity and lower } \\
\text { salt content wastes }\end{array}$ & 703 & $\begin{array}{l}\text { Soil Inventory Model } \\
\text { (SIM) tracked \& estimated }\end{array}$ \\
\hline 4 & $\begin{array}{l}\text { Solid Wastes Generated } \\
\text { during Fuel Reprocessing }\end{array}$ & $\begin{array}{l}\text { Misc. solid materials } \\
\text { likely not very } \\
\text { radioactive }\end{array}$ & $?$ & $\begin{array}{l}{ }^{99} \mathrm{Tc} \text { likely very low } \\
\text { because it remains soluble }\end{array}$ \\
\hline 5 & Wastes in Tanks & $\begin{array}{l}\text { Current inventory in all } \\
177 \text { storage tanks }\end{array}$ & 26,500 & $\begin{array}{l}\text { BBI model tracks this } \\
\text { estimate }\end{array}$ \\
\hline 6 & ${ }^{99} \mathrm{Tc}$ in $\mathrm{U}$ sent Off-site & & $\begin{array}{c}21.5 \% * 32,600 \\
=7000\end{array}$ & $\begin{array}{l}\text { HDW version } 5 \text { model } \\
\text { estimates } 20 \%-23 \% \text { went } \\
\text { off-site with reprocessed U }\end{array}$ \\
\hline 7 & $\begin{array}{l}\text { Waste Cascaded from } \\
\text { Tanks to Ground }\end{array}$ & & $\begin{array}{l}\text { Included in } \\
\text { Box \#3 }\end{array}$ & $\begin{array}{l}\text { SIM tracked and estimated; } \\
\text { combined with any direct } \\
\text { waste co-disposal by } \\
\text { disposal facility }\end{array}$ \\
\hline 8 & $\begin{array}{l}\text { Waste Released by SSTs } \\
\text { and Their Infrastructure }\end{array}$ & & $\begin{array}{l}\text { Included in } \\
\text { Box \#3 but } \\
\text { when parsed } \\
\text { out SST } \\
\text { release } \sim 100\end{array}$ & $\begin{array}{l}\text { SIM tracked but Tank } \\
\text { Farm Contractor and State } \\
\text { Ecology have updated } \\
\text { using a Formal Joint } \\
\text { Working Group }\end{array}$ \\
\hline
\end{tabular}




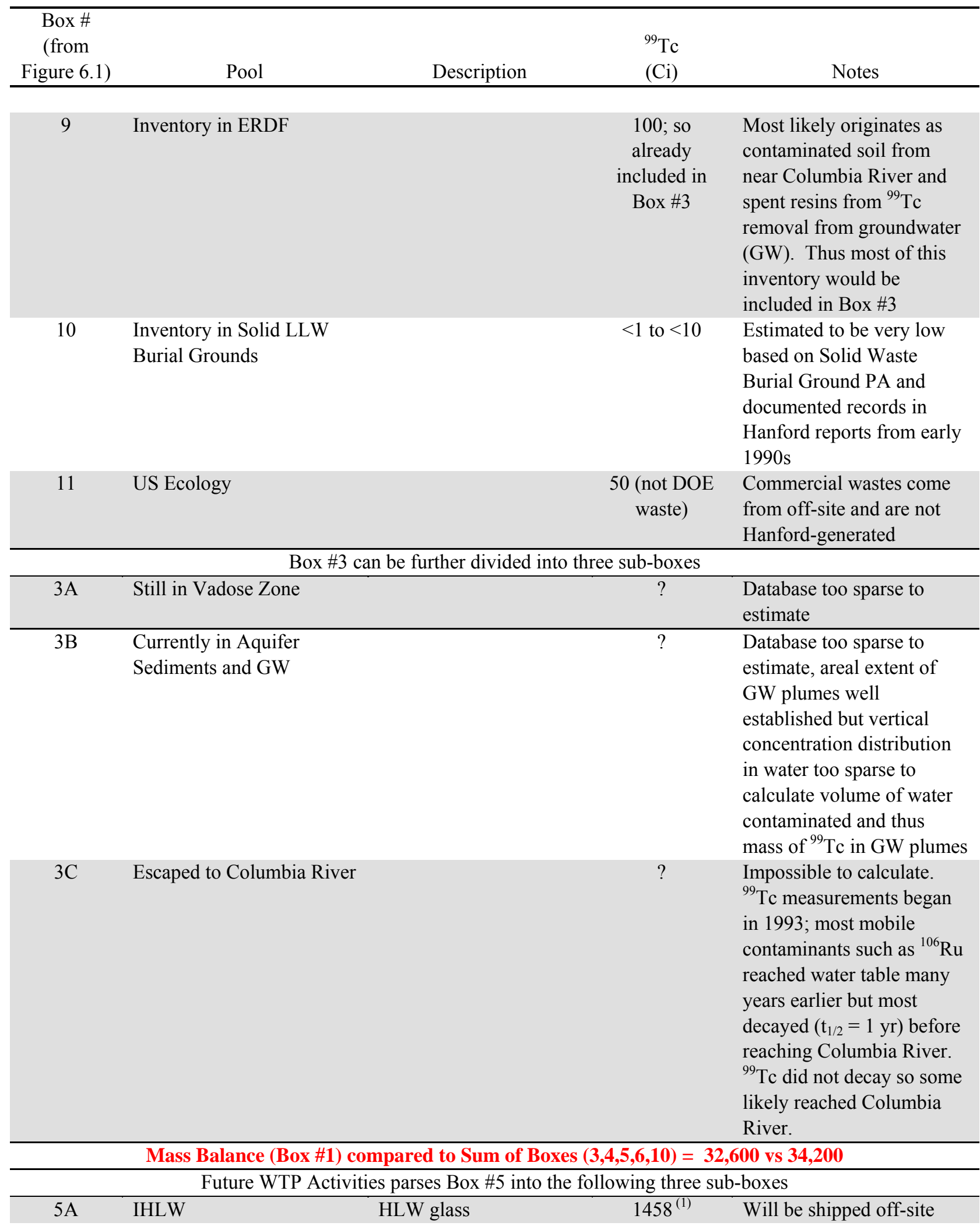




\begin{tabular}{|c|c|c|c|c|}
\hline $\begin{array}{l}\text { Box \# } \\
\text { (from } \\
\text { Figure 61) }\end{array}$ & Pool & Descrintion & $\begin{array}{l}{ }^{99} \mathrm{Tc} \\
\text { (Ci) }\end{array}$ & Notes \\
\hline $5 \mathrm{~B}$ & ILAW & $\begin{array}{l}\text { LAW glass or } \\
\text { supplemental waste } \\
\text { forms }\end{array}$ & $24,974^{(1)}$ & $\begin{array}{l}\text { Currently will stay on } \\
\text { Hanford Site; many other } \\
\text { possible scenarios } \\
\text { dependent on }{ }^{99} \mathrm{Tc} \text { removal } \\
\text { vs. off-gas condensate } \\
\text { recycle to LAW melter }\end{array}$ \\
\hline $5 \mathrm{C}$ & $\begin{array}{l}\text { Residual Sludge left in } \\
\text { Tanks }\end{array}$ & & $\begin{array}{l}68 \\
\text { (Appendix B } \\
\text { of DOE/ORP } \\
(2010))\end{array}$ & $\begin{array}{l}\text { Is tracked in HTWOS and } \\
\text { updated with real volume } \\
\text { and concentration data } \\
\text { when tank is closed }\end{array}$ \\
\hline \multicolumn{5}{|c|}{ Other Potential Future Activities (shipping solid wastes from small DOE site to Hanford for final burial) } \\
\hline 12 & $\begin{array}{l}\text { Potential Future Solid } \\
\text { Wastes }\end{array}$ & $\begin{array}{l}\text { Off-site DOE wastes } \\
\text { shipped to Hanford for } \\
\text { disposal }\end{array}$ & 1460 & $\begin{array}{l}\text { Per TC\&WM EIS } \\
\text { Appendix D, Table D-87; } \\
\text { uncertain fate; WA State } \\
\text { has legal court cases } \\
\text { underway to prohibit }\end{array}$ \\
\hline $\begin{array}{l}\text { (1) } \text { Sec } \\
\text { int } \\
\text { wh } \\
\text { equ }\end{array}$ & \multicolumn{4}{|c|}{$\begin{array}{l}\text { See Table 5.1. The Table } 5.1{ }^{99} \mathrm{Tc} \text { inventory values are for the scenario where all tank waste is vitrified } \\
\text { into glass in the HLW Facility and two LAW facilities. The Table } 5.1{ }^{99} \mathrm{Tc} \text { inventory sums to } 26,470 \mathrm{Ci} \text {, } \\
\text { which rounds to the current BBI value of } 26,500 \mathrm{Ci} \text {. We converted the sum of boxes } 5 \mathrm{~A}, 5 \mathrm{~B} \text {, and } 5 \mathrm{C} \text { to } \\
\text { equal } 26,500 \mathrm{Ci} \text {. }\end{array}$} \\
\hline
\end{tabular}

The main focus of the Tc Management Program is to improve the understanding of the fate of the ${ }^{99} \mathrm{Tc}$ currently stored in the 177 storage tanks at Hanford. Based on Box \#5 and discussions in Section 4.2, this accounts for 26, $500 \mathrm{Ci}$. One future scenario for the disposition of the ${ }^{99} \mathrm{Tc}$ in the tanks is discussed in Section 5.0 and specifically Table 5.1. In this scenario, all the waste is split into two fractions (HLW and LAW) in the WTP PT Facility and each sent to WTP melters that produce glass. Within Box \#5B, one can further split the ${ }^{99} \mathrm{Tc}$ inventory if other scenarios for LAW are chosen as briefly described in Section 5.0. One current discussion revolves around the fact that much of the ${ }^{99} \mathrm{Tc}$ present in LAW feed volatilizes upon entering the LAW melters and is captured in various off-gas treatment operations such that most of the ${ }^{99} \mathrm{Tc}$ is found in condensates from these off-gas units. Approaches for addressing the condensates are actively being discussed and many of the other tasks in the Tc Management Program are generating data to aid in the final decisions on how to address the off-gas condensates.

In summary, at a high level there is a good mass balance for how the ${ }^{99} \mathrm{Tc}$ produced at the Hanford Site is currently distributed. About $75 \%$ of the ${ }^{99} \mathrm{Tc}$ produced at Hanford currently resides in the 177 storage tanks, $\sim 21 \%$ was shipped off-site with reprocessed uranium that was recycled/purified for other uses, and $\sim 2 \%$ was released to the Hanford sediments. The fate of the $75 \%$ of the ${ }^{99} \mathrm{Tc}$ currently in the storage tanks is actively being discussed and several viable alternatives have been identified. 


\subsection{Summary and Conclusions}

A thorough understanding of the inventory for mobile contaminants is key to any performance or risk assessment for Hanford Site facilities because potential groundwater and river contamination levels are proportional to the amount of contaminants disposed at the Hanford Site, especially those capable of migrating from discharge and disposal sites. At the Hanford Site, some ${ }^{99} \mathrm{Tc}$ has been purposefully or accidently released in the wastes generated during irradiated fuel reprocessing. ${ }^{99} \mathrm{Tc}$ has been found to be quite mobile and some has reached the groundwater. Because the majority of the total ${ }^{99} \mathrm{Tc}$ produced at Hanford $(\sim 32,600 \mathrm{Ci})$ is currently stored in Hanford's 177 tanks $(\sim 26,500 \mathrm{Ci})$, there is a critical need for knowledge of the fate of this ${ }^{99} \mathrm{Tc}$ as it is removed from the tanks and processed into a final solid waste form. Based on current plans, the retrieved tank waste will be processed and solidified into glass, with a small amount of secondary wastes from the WTP being solidified as some other low-temperature waste form. Current flow sheets for the WTP process show most of the ${ }^{99} \mathrm{Tc}$ will be immobilized as LAW glass that will be disposed at the Hanford Site IDF; only a small fraction will be shipped off-site to a geologic repository with the IHLW. Past performance assessment studies, which focused on groundwater protection, have shown that ${ }^{99} \mathrm{Tc}$ would be the primary dose contributor to the IDF performance.

Based on this review of various technical reports and environmental impacts statements, the range in total curie inventory of ${ }^{99} \mathrm{Tc}$ produced at the Hanford Site as a consequence of irradiating fuel to produce plutonium is 31,000 to $34,000 \mathrm{Ci}$. This study's best estimate is that $\sim 32,600 \mathrm{Ci}$ of ${ }^{99} \mathrm{Tc}$ equates to $1922 \mathrm{~kg}$ of ${ }^{99} \mathrm{Tc}$. Some of this inventory was shipped off-site with uranium removed from the dissolved irradiated fuel and destined for purification for reuse in making fresh fuel rods or for other purposes. As mentioned, some of the ${ }^{99} \mathrm{Tc}$ has been purposefully or accidently released to the Hanford vadose zone in wastes generated during irradiated fuel reprocessing, but most of the ${ }^{99} \mathrm{Tc}$ remains in the Hanford storage tanks. The BBI is the current official estimate of the current contents (46 radionuclides and 25 chemicals) in SSTs and DSTs. The BBI data are stored in the TWINS database. A query of the TWINS database in late January 2014 and subsequent analysis of the data leads to the following observations. The best estimate of the total ${ }^{99} \mathrm{Tc}$ inventory in the storage tanks is $26,500 \mathrm{Ci}$. There is more total ${ }^{99} \mathrm{Tc}$ in the 28 DSTs $\left(1.51 \times 10^{4} \mathrm{Ci}\right)$ than in the 149 SSTs $(1.14 \times 104 \mathrm{Ci})$. The SSTs in $200-\mathrm{W}$ contain $8.11 \times 10^{3} \mathrm{Ci}$ and those in $200-\mathrm{E}$ contain $3.33 \times 10^{3} \mathrm{Ci}$ of ${ }^{99} \mathrm{Tc}$.

${ }^{99} \mathrm{Tc}$ present in three of the 200-W SST farms (TX, S, and SX) accounts for $54 \%$ of the ${ }^{99} \mathrm{Tc}$ in all SSTs (and $23.4 \%$ of the total ${ }^{99} \mathrm{Tc}$ tank inventory) and in 200 -E the BY SST farm contains $\sim 14 \%$ of the total ${ }^{99} \mathrm{Tc}$ in all SSTs (or $6 \%$ of the total ${ }^{99} \mathrm{Tc}$ tank inventory). The DSTs contain $57 \%$ of the total ${ }^{99} \mathrm{Tc}$ inventory in Hanford tanks, with the bulk $\left(1.33 \times 10^{4} \mathrm{Ci}\right)$ within four DST farms (AP, AN, AW, and AZ) in the 200-E Area.

A key issue addressed in this literature review was to estimate the amount of ${ }^{99} \mathrm{Tc}$ present as non-pertechnetate species because this species has been shown to be difficult to separate from treated liquid tank wastes, should ${ }^{99} \mathrm{Tc}$ removal prior to vitrification become the preferred path forward. Further, there are no data on how non-pertechnetate species will interact in the melters or whether they will partition into the glass similar to the pertechnetate form, which has been studied. First literature on the non-pertechnetate issue, including several companion documents authored by Rapko and colleagues, was reviewed to understand how the non-pertechnetate species were discovered. 
Numerous reports describe the use of organic-based resins that preferentially sequester pertechnetate anions out of Hanford liquid waste streams. Most of the studies used pertechnetate-specific resins called SuperLig 639 or Reillex HPQ, both highly selective to sequestering only the pertechnetate form of ${ }^{99} \mathrm{Tc}$. While processing DST supernates through columns packed with SuperLig 639, it was observed for some of the supernates that there was an immediate breakthrough of some of the ${ }^{99}$ Tc present.

A second methodology that identified the presence of non-pertechnetate species was batch sorption tests. For the batch tests, known amounts of SuperLig 639 or Reillex HPQ are contacted with actual Hanford DST supernatant liquids, usually at 100:1 (liquid volume to resin) for 4-day contacts. The batch slurry is then separated by centrifugation and/or filtration and the concentration of ${ }^{99} \mathrm{Tc}$ in the effluent is compared to the concentration in the influent using the traditional $K_{d}$ construct. The Tc $K_{d} S$ values for DST supernatants that were suspected to contain non-pertechnetate species were significantly lower than the $\mathrm{K}_{\mathrm{d}}$ values for DST supernatants that contained only the pertechnetate species. A third method used to explore Tc speciation used spectroscopic measurements on both carefully synthesized pure Tc compounds and actual DST supernates using several instruments and techniques including UV-Vis, NMR, and synchrotron based XAS, both XANES and EXAFS.

The conclusion from reviewing of all these studies was that the identity of the non-pertechnetate species has not been definitively determined. However, based on all the various investigations and detailed measurements, non-pertechnetate species in the Hanford DST supernates are tentatively identified as Tc(I) carbonyl complexes derived from either $\mathrm{Tc}(\mathrm{CO})_{3}{ }^{+}$or $\left[\mathrm{Tc}(\mathrm{CO})_{2}(\mathrm{NO})\right]^{2+}$ precursor molecules that may lead to final species such as $\left[\mathrm{Tc}(\mathrm{CO})_{3} \text { (gluconate) }\right]^{2-}$ as a result of the radiolytic decomposition of organics and nitrite/nitrate in the DSTs, which contain carbon monoxide in their head spaces as well as dissolved in the supernates. The XANES spectrum for "pure" $\left[\mathrm{Tc}(\mathrm{CO})_{3} \text { (gluconate) }\right]^{2-}$ provides an excellent fit to the observed XANES spectrum of the non-pertechnetate species in the SY-101 and SY-103 supernates.

A summary of the non-pertechnetate percentages in the supernates from DSTs that have had samples analyzed is shown in Table 7.1, which is based on an evaluation of Table 4.9. Table 7.1 shows the type of supernate waste in each DST, the ${ }^{99} \mathrm{Tc}$ inventory in each tank's supernate, the percentage of non-pertechnetate species in each tanks supernate, and the ${ }^{99} \mathrm{Tc}$ curies of non-pertechnetate. For a few of the DSTs, based on the similarity on the supernate waste type for some of the DSTs that have not been characterized for non-pertechnetate, an estimate of whether they might contain "high" (assumed to be $70 \%$ ) or "low" (assumed to be 10\%) non-pertechnetate is given. Then the non-pertechnetate ${ }^{99}$ Tc content is calculated, as shown in black type in the last column. For the DSTs that did have non-pertechnetate estimated by techniques described in Section 4.3, the non-pertechnetate ${ }^{99}$ Tc content is shown in colored type. The bottom rows of Table 7.1 show statistics on the total non-pertechnetate ${ }^{99}$ Tc inventory that has been characterized (this quantity is labeled as "confirmed” [963 Ci], the sum of "confirmed" and "estimated from similarity of waste types" [1160 Ci]). There are 10,900 Ci of ${ }^{99} \mathrm{Tc}$ in the supernate of the 28 DSTs, and an estimated 5370 of those curies cannot be categorized for non-pertechnetate content given that the supernate waste type is designated as NA (not assignable to one of the HDW conceptual model waste types). The uncategorizable DST ${ }^{99}$ Tc inventory represents $49 \%$ of the total ${ }^{99}$ Tc in DST supernates, or $36 \%$ of the total ${ }^{99}$ Tc in all phases of the DSTs, or $20.3 \%$ of the total Hanford tank BBI estimate for ${ }^{99} \mathrm{Tc}$. 
Table 7.1. Estimates of Non-pertechnetate ${ }^{99} \mathrm{Tc}$ Inventory in DST Supernates

\begin{tabular}{|c|c|c|c|c|}
\hline DST Tank & Waste Type & $\begin{array}{l}\text { supernate } \\
{ }^{99} \mathrm{Tc}(\mathrm{Ci})\end{array}$ & NPS \% & $\begin{array}{c}\text { non- }{ }^{99} \mathrm{Tc} \\
\mathrm{Ci}\end{array}$ \\
\hline 241-AN-101 & NA (Liquid) & $7.59 \mathrm{E}+01$ & high? & $5.31 \mathrm{E}+01$ \\
\hline 241-AN-102 & NA (Liquid) & $4.60 \mathrm{E}+02$ & 60 & $2.76 E+02$ \\
\hline 241-AN-103 & A2-SltSlr (Liquid) & $2.81 \mathrm{E}+02$ & 4 & $1.12 \mathrm{E}+01$ \\
\hline 241-AN-104 & A2-SltSlr (Liquid) & $4.62 \mathrm{E}+02$ & low? & $4.62 \mathrm{E}+01$ \\
\hline 241-AN-105 & A2-SltSlr (Liquid) & $5.88 \mathrm{E}+02$ & low? & $5.88 \mathrm{E}+01$ \\
\hline 241-AN-106 & NA (Liquid) & $1.31 \mathrm{E}+01$ & high? & $9.17 \mathrm{E}+00$ \\
\hline 241-AN-107 & A2-SltSlr (Liquid) & $3.03 E+02$ & 70 & $2.12 \mathrm{E}+02$ \\
\hline 241-AP-101 & NA (Liquid) & $7.24 \mathrm{E}+02$ & 0 & 0 \\
\hline 241-AP-102 & NA (Liquid) & $6.90 \mathrm{E}+02$ & $?$ & $?$ \\
\hline 241-AP-103 & NA (Liquid) & $9.21 \mathrm{E}+02$ & $?$ & $?$ \\
\hline 241-AP-104 & NA (Liquid) & $6.13 \mathrm{E}+01$ & 70 & $4.29 E+01$ \\
\hline 241-AP-105 & NA (Liquid) & $8.60 \mathrm{E}+02$ & $?$ & $?$ \\
\hline 241-AP-106 & NA (Liquid) & $3.68 \mathrm{E}+02$ & $?$ & $?$ \\
\hline 241-AP-107 & NA (Liquid) & $1.77 \mathrm{E}+02$ & $?$ & $?$ \\
\hline 241-AP-108 & NA (Liquid) & $6.65 \mathrm{E}+02$ & $?$ & $?$ \\
\hline 241-AW-101 & A2-SltSlr (Liquid) & $4.68 \mathrm{E}+02$ & 4 & $1.87 \mathrm{E}+01$ \\
\hline 241-AW-102 & NA (Liquid) & $3.21 \mathrm{E}+02$ & $?$ & $?$ \\
\hline 241-AW-103 & NA (Liquid) & $3.42 \mathrm{E}+02$ & $?$ & $?$ \\
\hline 241-AW-104 & NA (Liquid) & $5.67 \mathrm{E}+02$ & $?$ & $?$ \\
\hline 241-AW-105 & NA (Liquid) & $5.35 \mathrm{E}+00$ & $?$ & $?$ \\
\hline 241-AW-106 & NA Lower (Liquid) & $5.56 \mathrm{E}+01$ & $?$ & $?$ \\
\hline 241-AW-106 & NA Upper (Liquid) & $2.01 \mathrm{E}+02$ & $?$ & $?$ \\
\hline 241-AY-101 & NA Lower (Liquid) & $2.08 \mathrm{E}+01$ & $?$ & $?$ \\
\hline 241-AY-101 & NA Upper (Liquid) & $1.84 \mathrm{E}+01$ & $?$ & $?$ \\
\hline 241-AY-102 & NA (Liquid) & $1.58 \mathrm{E}+02$ & $?$ & $?$ \\
\hline 241-AZ-101 & NA (Liquid) & $1.18 \mathrm{E}+03$ & 0 & 0 \\
\hline 241-AZ-102 & NA (Liquid) & $3.14 \mathrm{E}+02$ & 4 & $1.26 \mathrm{E}+01$ \\
\hline 241-SY-101 & NA (Liquid) & $4.04 \mathrm{E}+01$ & 65 & $2.63 E+01$ \\
\hline 241-SY-102 & NA (Liquid) & $3.70 \mathrm{E}+01$ & high? & $2.59 \mathrm{E}+01$ \\
\hline \multirow[t]{3}{*}{ 241-SY-103 } & S2-SltSlr (Liquid) & $5.19 \mathrm{E}+02$ & 70 & $3.63 E+02$ \\
\hline & Total ${ }^{99} \mathrm{Tc}$ in Supernate $(\mathrm{Ci})$ & $1.09 \mathrm{E}+04$ & $\begin{array}{l}\text { Total "confirmed" } \\
\text { Non-pertech }(\mathrm{Ci})\end{array}$ & $9.63 E+02$ \\
\hline & $\begin{array}{l}\text { Total }{ }^{99} \mathrm{Tc} \text { Ci in DST } \\
\text { supernates with no info }\end{array}$ & $5.37 \mathrm{E}+03$ & $\begin{array}{l}\text { Total "Estimable" } \\
\text { Non-pertech }(\mathrm{Ci})\end{array}$ & $1.16 \mathrm{E}+03$ \\
\hline
\end{tabular}

Notes: AW-106 and AY-102 have two distinct layers of supernate within them that have different properties. Waste type NA = not assignable.

A2-salt slurry comes from the second 242-Evaporator campaign using AW-102 feed tank (1981-1988).

S2-salt slurry comes from the second 242-S Evaporator campaign using SY-102 feed tank (1977-1980).

Based on the current WTP process flow sheets, almost all of the ${ }^{99} \mathrm{Tc}$ in wastes retrieved from the Hanford tanks will remain in solution after various sludge washing and other processes are performed in the PT Facility to dissolve and separate the waste into the high-level and low-level fractions. This means that almost all of the ${ }^{99} \mathrm{Tc}$ will be found in the low-level portion of the liquid waste stream that is sent from the PT Facility to the LAW melter. Tc in LAW liquid waste forms species that are volatile 
(estimates are from $<10 \%$ to $80 \%$ volatile) at the high temperature in the LAW melter, causing most of it to partition to the off-gas systems. At least three off-gas unit operations (SBS, WESP, and caustic scrubber) are used to condense the hot gases back to a liquid waste stream. The current flow sheets for the WTP plan to continually recycle the condensates from the SBS and WESP units by mixing them with fresh LAW feed. The combined liquids will be sent back to the LAW melter. Based on mass balance principles, at some point the ${ }^{99} \mathrm{Tc}$ in the recycle LAW feed will reach a steady-state concentration wherein the mass of ${ }^{99} \mathrm{Tc}$ being retained in the LAW glass will be the same as the mass of ${ }^{99} \mathrm{Tc}$ the incoming recycled condensate and fresh LAW feed. Abramowitz et al. (2012) performed the first LAW off-gas condensate recycle testing of this concept using the DM10 melter available at the Catholic University of America Vitreous State Laboratory. They used seven different LAW simulants, each spiked with known amounts of ${ }^{99 \mathrm{~m}} \mathrm{Tc}$, a short-lived, gamma-emitting isotope of Tc. They performed a mass balance for the ${ }^{99 \mathrm{~m}} \mathrm{Tc}$ throughout all the DM-10 melter and off-gas condensate systems configured in the LAW continuous recycle loop. Key findings from this work include the following:

- With recycle, retention of Tc in the glass product is increased by factors of at least 2 to 3 over the corresponding single-pass values for almost all glasses made with the seven LAW liquid waste compositions. For all but two LAW compositions, Tc retention in glass ranged from $68 \%$ to $84 \%$ of the total. In comparison, in 72 previously conducted single-pass DM10 tests (without recycle) the average of $35.2 \%$ of Tc was incorporated into LAW glass.

- The increase in Tc retention in LAW glass was limited by holdup of material, including Tc in the system, particularly in the WESP internals, the film cooler, and transition lines between the off-gas sequential trains. Mobilization of the "held up" material to make it available for recycle back to the melter along with fresh LAW feed would likely further increase the retention in glass.

- While the measured Tc retention values for the LAW glass with recycle are much increased over the single-pass values, they are significantly lower than previous assumptions and estimates used in WTP planning calculations. For example, the Mann et al. (2003) risk assessment supporting the evaluation of supplemental ILAW waste form technologies assumed "low," "best," and "high" estimates for the fraction of the Tc inventory bound in the LAW glass product of $90 \%, 99.9 \%$, and $100 \%$, respectively, with the "best estimate" value used for the baseline risk assessment calculations and the other two values used for sensitivity calculations.

Regarding the speciation of ${ }^{99} \mathrm{Tc}$ in the off-gas and their condensates, several reports suggest that the ${ }^{99} \mathrm{Tc}$ volatilizes in the melter and when the hot gases contact the water in the SBS and WESP condensers, it becomes pertechnetate. However, the speciation of ${ }^{99} \mathrm{Tc}$ in off-gas condensates has not been explored to date. That said, the assumption seems reasonable given the likely oxidizing environment in the SBS and WESP condensers. Abramowitz et al. (2012) did not address any ${ }^{99} \mathrm{Tc}$ speciation issues because only the total ${ }^{99 \mathrm{~m}}$ Tc activity could be measured.

The findings of Abramowitz et al. (2012) - that repeated recycling the condensates from the off-gas treatment unit operations (SBS, WESP, and vacuum evaporator) does not incorporate $90 \%$ or more of the ${ }^{99} \mathrm{Tc}$ present in LAW liquid waste into LAW glass - raises an issue with the current assumptions used in the latest IDF PA, supplemental waste RA, and TC\&WM EIS that $90 \%$ to $\sim 99.9 \%$ of the ${ }^{99} \mathrm{Tc}$ in LAW liquid can be incorporated into glass, which is considered the best-performing waste form in regards to long-term release of the potentially mobile ${ }^{99} \mathrm{Tc}$. Therefore, several reports have been published that describe alternative methods of treating the SBS-WESP condensates (which contain most of the ${ }^{99} \mathrm{Tc}$ after LAW liquid waste is fed through the LAW melter in each cycle). Essentially, the alternative methods 
would either send the SBS-WESP condensates off-site either with or without further treatment to remove the ${ }^{99} \mathrm{Tc}$ or would remove the ${ }^{99} \mathrm{Tc}$ from the condensates and then send the treated condensates to the ETF on the Hanford Site. The ${ }^{99} \mathrm{Tc}$ removed from the condensates would be further treated (generally adsorbed, precipitated, directly encapsulated into a low-temperature waste form such as Cast Stone, or vitrified either through the LAW, HLW, or a separate melter). The ${ }^{99} \mathrm{Tc}$ removed from the SBS-WESP condensates after "solidification" could be sent off-site or disposed on-site. Several reports on alternative strategies for addressing the ${ }^{99} \mathrm{Tc}$ in off-gas condensates are briefly reviewed in this document.

The main focus of the Tc Management Program is to improve the understanding of the fate of the ${ }^{99}$ Tc currently stored in the 177 storage tanks at Hanford. Based on Box \#5 at the top of Table 6.1 and discussions in Section 4.2, this accounts for 26,500 Ci. At a high level there is a good mass balance for how the ${ }^{99} \mathrm{Tc}$ produced at the Hanford Site is currently distributed. About $80 \%$ of the ${ }^{99} \mathrm{Tc}$ produced at Hanford currently resides in the 177 storage tanks, $\sim 20 \%$ was shipped off-site with reprocessed uranium that was recycled/purified for other uses, and $\sim 2 \%$ was released to the Hanford sediments. The fate of the $80 \%$ of the ${ }^{99} \mathrm{Tc}$ currently in the storage tanks is actively being discussed and several viable alternatives have been identified. However, the partitioning of the "pool" of ${ }^{99} \mathrm{Tc}$ released to the vadose zone into "pools" for "present in vadose zone," "present in aquifer sediments and groundwater," and ${ }^{99} \mathrm{Tc}$ that has "reached the Columbia River" cannot be assigned estimates. The reasons that no technically defensible values of ${ }^{99} \mathrm{Tc}$ inventory can be assigned for these "pools" include lack of sufficient data on ${ }^{99} \mathrm{Tc}$ in the vadose zone, the complexity of the vadose zone hydrogeology (caused in part from the Ice Age catastrophic flood deposits), and lack of knowledge on the vertical distribution of ${ }^{99} \mathrm{Tc}$ in the aquifer plumes (most monitoring wells sample only the top 5 to 10 meters, and the aquifer is much thicker; where vertical distributions of groundwater contaminants have been measured there is large variability), and finally ${ }^{99} \mathrm{Tc}$ in groundwater has been monitored only since 1993 whereas most of the mobile contaminants were released in the mid 1940s through late 1970s. These three "pools" are important for making site remediation decisions and site risk assessments but are not the main scope of the Tc Management Program that is funding this report.

Final observations and recommendations for determining the amount and forms of non-pertechnetate in Hanford tank wastes from this report and the companion document (Rapko 2014) follow. Any proposed characterization of non-pertechnetate (n-Tc) in Hanford tank waste supernate must consider that no means of isolating or concentrating $\mathrm{n}-\mathrm{Tc}$ has been discovered (aside from evaporation-which also concentrates all other species present except water), although efforts in this area have been made (Schroeder and Ashley 2005). Therefore, any characterization must be made on the actual supernates, which contain around $10^{-5} \mathrm{M}$ technetium at their maximum concentration.

Unfortunately, there is no clear method to characterize n-Tc species in Hanford tank supernate or the resultant liquids from dissolving tank saltcake and sludges. Of the commonly used methods for inorganic compounds, UV-vis and vibrational spectroscopy are perhaps the most routine, but to date these methods have not provided any useful information or any characteristic signal that can be associated with the presence of n-Tc. To date, the only two methods that have given information as to the oxidation state and structural features of $\mathrm{n}-\mathrm{Tc}$ are XAS of one form or another and ${ }^{99} \mathrm{Tc}$ NMR. Unfortunately, XAS analysis is both time- and labor-intensive. Still, to the extent possible, continued analysis of new DST supernates for $\mathrm{n}$-Tc by XANES and/or EXAFS is recommended. Size exclusion chromatography may also have some merit on separating ${ }^{99} \mathrm{Tc}$ species from each other prior to analysis (in hopes of simplifying the sample matrix) by the recommended NMR and XAS methods. 


\subsection{References}

Abramowitz H, M Brandys, R Cecil, N D’Angelo, KS Matlack, IS Muller, IL Pegg, and RA Callow. 2012. Technetium Retention in WTP LAW Glass with Recycle Flow-Sheet: DM10 Melter Testing. RPP-54130, Rev. 0, Washington River Protection Solutions LLC, Richland, WA.

Adamson DJ, CA Nash, DJ McCabe, CL Crawford, and WR Wilmarth. 2014. Laboratory Evaporation of Hanford Waste Treatment Plant Low Activity Waste Off-Gas Condensate Simulant. SRNL-STI-2013-0071, Rev. 0, Savannah River National Laboratory, Aiken, SC.

Ashely KR, N Schroeder, JA Olivares, and B Scott. 2004. Identification of Non-Pertechnetate Species in Hanford Tank Waste, Their Synthesis, Characterization, and Fundamental Chemistry. Final Report September 15, 2001 through September 14, 2004. DE-FG07-01ER63281, Texas A\&M University-Commerce, Commerce, TX.

Bernard JG, E Bauer, MP Richards, JB Arterburn, and RM Chamberlin. 2001. "Catalytic Reduction of Pertechnetate (99TcO4-) in Simulated Alkaline Nuclear Wastes.” Radiochimica Acta 89(1):59-61. doi:10.1524/ract.2001.89.1.059.

Blanchard Jr. DL, DE Kurath, GR Golcar, and SD Conradson. 1996. Technetium Removal Column Flow Testing with Alkaline, High Salt, Radioactive Tank Waste. PNNL-11398, Pacific Northwest National Laboratory, Richland, WA.

Blanchard Jr. DL, GN Brown, SD Conradson, SK Fadeff, GR Golcar, NJ Hess, GS Klinger, and DE Kurath. 1997. Technetium in Alkaline, High-Salt, Radioactive Tank Waste Supernate: Preliminary Characterization and Removal. PNNL-1 1386, Pacific Northwest National Laboratory, Richland, Washington.

Blanchard Jr. DL, DE Kurath, and JR Bontha. 2000a. Small Column Testing of Superlig 639® for Removal of 99Tc from Hanford Tank Waste Envelope A (Tank 241-AW-101). PNWD-3004, Battelle-Pacific Northwest Division, Richland, WA.

Blanchard Jr. DL, DE Kurath, and BM Rapko. 2000b. Small Column Testing of Superlig® 639 for Removal of ${ }^{99}$ Tc from Hanford Tank Waste Envelope C (Tank 241-AN-107). PNWD-3028, Battelle-Pacific Northwest Division, Richland, WA.

Burgeson IE, DL Blanchard Jr., and JR Deschane. 2002. Small Column Testing of Superlig® 639 for Removing ${ }^{99}$ Tc from Hanford Tank Waste Envelope A (Tank 241-AP-101). PNWD-3222, Battelle-Pacific Northwest Division, Richland, WA.

Burgeson IE, DL Blanchard Jr., and JR Deschane. 2004a. Small Column Testing of Superlig ${ }^{\circledR} 639$ for Removing 99Tc from Hanford Tank Waste 241-AN-102 Supernate (Envelope C) Mixed with Tank 241-C-104 Solids (Envelope D) Wash and Permeate Solutions. PNWD-3252, Rev. 1, Battelle-Pacific Northwest Division, Richland, WA. 
Burgeson IE, DL Blanchard Jr., and JR Deschane. 2004b. Small Column Testing of Superlig ${ }^{\circledR} 639$ for Removing 99Tc from Hanford Tank Waste Envelope B (Tank 241-AZ-101). PNWD-3281, Battelle-Pacific Northwest Division, Richland, WA.

Burgeson IE, JR Deschane, and DL Blanchard. 2005. "Removal of Technetium from Hanford Tank Waste Supernates.” Separation Science and Technology 40(1-3):201-23.

Cook AR, N Dimitrijevic, BW Dreyfus, D Meisel, LA Curtiss, and DM Camaioni. 2001. "Reducing Radicals in Nitrate Solutions." The $\mathrm{NO}_{3}{ }^{2-}$ System Revisited." J. Phys. Chem. A. 105: 3658-3666.

Croff AG. 1980. ORIGEN2 - A Revised and Updated Version of the Oak Ridge Isotope Generation and Depletion Code. ORNL-5621, Oak Ridge National Laboratory, Oak Ridge, TN.

DOE. 1996. Tank Waste Remediation System, Hanford Site, Richland Washington Final Environmental Impact Statement (TWRS EIS). DOE/EIS-0189. U.S. Department of Energy, Richland, WA.

DOE. 1997. Final Waste Management Programmatic Environmental Impact Statement for Managing, Treatment, Storage, and Disposal of Radioactive and Hazardous Waste. DOE/EIS-0200-F. U.S. Department of Energy, Office of Environmental Management, Washington, D.C.

DOE. 2012. Final Tank Closure and Waste Management Environmental Impact Statement for the Hanford Site, Richland, Washington (TC \& WM EIS) DOE/EIS-0391. Office of River Protection, U.S. Department of Energy, Richland, WA. http://www.hanford.gov/page.cfm/FinalTCWMEIS.

DOE/ORP. 2010. RCRA Facility Investigation Report for Hanford Single-Shell Tank Waste Management-Tier 1 \& 2. DOE/ORP-2008-01 Rev. 1 Reissue, Office of River Protection, U.S. Department of Energy, Richland, WA.

Duncan JB, SE Kelly, RA Robbins, RD Adams, MA Thorson, and CC Haass. 2011. Technetium Sorption Media Review, RPP-RPT-50122, Washington River Protection Solutions, Richland, WA.

Egorov OB, MJ O’Hara, and JW Grate. 2004. “Microwave-Assisted Sample Treatment in a Fully Automated Flow-Based Instrument: Oxidation of Reduced Technetium Species in the Analysis of Total Technetium-99 in Caustic Aged Nuclear Waste Samples.” Analytical Chemistry 76:3869-3877.

Egorov OB, MJ O’Hara, and JW Grate. 2012. “Automated Radioanalytical System Incorporating Microwave-Assisted Sample Preparation, Chemical Separation, and Online Radiometric Detection for the Monitoring of Total ${ }^{99}$ Tc in Nuclear Waste Processing Streams." Analytical Chemistry 84:3090 -3098.

EPA. 1988. Guidance for Conducting Remedial Investigations and Feasibility Studies Under CERCLA, Interim Final. OSWER Directive 9355.3.3-01, U.S. Environmental Protection Agency, Washington, D.C.

Geeting JGH, RT Hallen, LK Jagoda, AP Poloski, RD Scheele, and DR Weier. 2003. Filtration, Washing, and Caustic Leaching of Hanford Tank AZ-101 Sludge. PNWD-3206, Rev. 1, WTP-RPT-043, Rev. 1, Battelle-Pacific Northwest Division, Richland, WA.

Gumprecht RO. 1968. Mathematical Basis of Computer Code RIBD. DUN-4136, Douglas United Nuclear, Inc., Richland, WA. 
Hassan NM, DJ McCabe, and WD King. 2000a. Small-Scale Ion Exchange Removal of Cesium and Technetium from Hanford Tank 241-AN-103. BNF-003-98-0146, Rev. 1, Westinghouse Savannah River Company, Aiken, SC.

Hassan NM, DJ McCabe, WD King, and ML Crowder. 2000b. Small-Scale Ion Exchange Removal of Cesium and Technetium from Hanford Tank 241-AN-102. BNF-003-98-0219, Westinghouse Savannah River Company, Aiken, SC.

Hassan NM, WD King, DJ McCabe, and ML Crowder. 2001a. Small-Scale Ion Exchange Removal of Cesium and Technetium Form Envelope B Hanford Tank 241-AZ-102. WSRC-TR-2000-00419, Rev. 0, Westinghouse Savannah River Company, Aiken, SC.

Hassan NM, WD King, DJ McCabe, LL Hamm, and ME Johnson. 2001b. Superlig® 639 Equilibrium Sorption Data for Technetium from Hanford Tank Waste Supernates. WSRC-MS-2001-00573, Westinghouse Savannah River Company, Aiken, SC.

Hassan NM, WD King, DJ McCabe, LL Hamm, and ME Johnson . 2002. "Superlig Equilibrium Sorption Data for Technetium from Hanford Tank Waste Supernates." Sol. Extr. Ion. Exch. 20:211-226.

Hassan NM, K Adu-Wusu, CA Nash, and JC Marra. 2003. Multiple Ion Exchange Column Tests for Technetium Removal from Hanford Tank Waste Supernate (U). WSRC-MS-2003-00789, Westinghouse Savannah River Company, Aiken, SC.

Higley BA and DE Place. 2005. Hanford Defined Waste Model - Revision 5.0. RPP-19822, Rev. 0-A, CH2M Hill Hanford Group, Inc., Richland, WA.

Johnson GD. 1996. Flammable Gas Program Report. WHC-SP-1193, Westinghouse Hanford Company, Richland, WA.

Jungfliesh FM and BC Simpson. 1993. Preliminary Estimate of Waste Inventories in Hanford Tanks through 1980. SD-WM-TI-057, Rev. 0a, Westinghouse Hanford Company, Richland, WA.

Kincaid CT, PW Eslinger, RL Aaberg, TB Miley, IC Nelson, DL Strenge and JC Evans, Jr. 2006. Inventory Data Package for Hanford Assessments. PNNL-15829, Rev. 0, Pacific Northwest National Laboratory, Richland, WA.

King WD, NM Hassan, and DJ McCabe. 2000. Intermediate-Scale Ion Exchange Removal of Cesium and Technetium from Hanford Tank 241-AN-102. Report No. WSRC-TR-2000-00420, Westinghouse Savannah River Company, Aiken, SC.

King WD, NM Hassan, DJ McCabe, LL Hamm, and ME Johnson. 2001. Technetium Removal from Hanford and Savannah River Site Actual Tank Waste Supernates with Superlig ${ }^{\circledR} 639$ Resin. WSRC-MS-2001-00760, Westinghouse Savannah River Co., Aiken, SC.

King WD, NM Hassan, DJ McCabe, LL Hamm, and ME Johnson. 2003. "Technetium Removal from Hanford and Savannah River Actual Tank Waste Supernates with Superlig ${ }^{\circledR} 639$ Resin." Sep. Sci. Tech. 38(12,13): 3093-3114. 
Kirkbride RA, GK Allen, PJ Certa, JA Lechlet, and S. Orcutt. 2005. Hanford Tank Waste Operations Simulator Model Data Package for the Development Run for the Refined Target Case. RPP-RPT-23412, Rev. 1, CH2M Hill Hanford Group, Inc., Richland, WA.

Krupka KM, WJ Deutsch, MJ Lindberg, KJ Cantrell, NJ Hess, HT Schaef, and BW Arey. 2004. Hanford Tanks 241-AY-102 and 241-BX-101: Sludge Composition and Contaminant Release Data. PNNL-14614, Pacific Northwest National Laboratory, Richland, WA. Full Publication (pdf)

Kupfer MJ, AL Boldt, BA Higley, KM Hodgson, LW Shelton, BC Simpson, RA Watrous, MD LeClair, GL Borsheim, RT Winward, RM Orme, NG Colton, SL Lambert, DE Place, and WW Schulz. 1997. Standard Inventories of Chemicals and Radionuclides in Hanford Site Tank Wastes. HNF-SD-WM-TI-740, Rev. 0, Lockheed Martin Hanford Corporation, Richland, WA.

Kupfer MJ, AL Boldt, KM Hodgson, LW Shelton, BC Simpson, RA Watrous, MD LeClair, GL Borsheim, RT Winward, BA Higley, RM Orme, NG Colton, SL Lambert, DE Place, and WW Schulz. 1999. Standard Inventories of Chemicals and Radionuclides in Hanford Site Tank Wastes. HNF-SD-WM-TI-740, Rev. 0C, Lockheed Martin Hanford Corporation, Richland, WA.

Kurath DE, DL Blanchard Jr., and JR Bontha. 2000. Ion Exchange Distribution Coefficients for 137Cs and 99Tc Removal from Hanford Tank Supernatants AW-101 (Envelope A) and AN-107 (Envelope C). PNWD-2467, Battelle-Pacific Northwest Division, Richland, WA.

Lindberg MJ and WJ Deutsch. 2003. Tank 241-AY-102 Data Report. PNNL-14344, Pacific Northwest National Laboratory, Richland, WA. Full Publication (pdf)

Lukens WW, JJ Bucher, NM Edelstein, and DK Shuh. 2001. "Radiolysis of $\mathrm{TcO}_{4}{ }^{-}$in Alkaline, Nitrate Solutions: Reduction by $\mathrm{NO}_{3}{ }^{2-}$." J. Phys. Chem. A 105:9611-9615.

Lukens WW, JJ Buchner, NM Edelstein, and DS Shuh. 2002. "Products of Pertechnetate Radiolysis in Highly Alkaline Solution: Structure of $\mathrm{TcO}_{2} \bullet \mathrm{H}_{2} \mathrm{O}$." Environ. Sci. Technol. 36:1124-1129.

Lukens WW, DK Shuh, NC Schroeder, and KR Ashley. 2004. "Identification of the Non-Pertechnetate Species in Hanford Waste Tanks, Tc(I)-Carbonyl Complexes." Environmental Science \& Technology 38:229-233.

Lukens WW, DK Shuh, NC Schroeder, and KR Ashley. 2006. "Behavior of Technetium in Alkaline Solution: Identification of Non-Pertechnetate Species in High-Level Nuclear Waste Tanks at the Hanford Reservation." ACS Symposium 943:302-317.

Mann FM, RJ Puigh, SH Finfrock, EJ Freeman, R Khaleel, DH Bacon, MP Bergeron, BP McGrail, SK Wurstner, K Burgard, WR Root, and P LaMont. 2001. Hanford Immobilized Low-Activity Tank Waste Performance Assessment: 2001 Version. DOE/ORP-2000-24, Rev. 0, Office of River Protection, U.S. Department of Energy, Richland, WA.

Mann FM, RJ Puigh, R Khaleel, S Finfrock, BP McGrail, DH Bacon, and RJ Serne. 2003. Risk Assessment Supporting the Decision on the Initial Selection of Supplemental ILAW Technologies. RPP-17675, Rev. 0, CH2M Hill Hanford Group, Inc., Richland, WA. 
McCabe DJ, NM Hassan, WD King, JL Steimke, MA Norato, LL Hamm, LN Oji, and ME Johnson. 2000. Comprehensive Scale Testing of the Ion Exchange Removal of Cesium and Technetium from Hanford Tank Wastes. WSRC-MS-2000-00499, CH2M Hill Hanford Group, Richland, WA.

McCabe DJ, WR Wilmarth, and CA Nash. 2013. Waste Treatment Technology Process Development Plan for Hanford Waste Treatment Plant Low Activity Waste Recycle. SRNL-STI-2013-00351, Rev. 0, Savannah River National Laboratory, Aiken, SC.

Meisel D, DM Camaioni, and TM Orlando. 2001. "Radiation and Chemistry in Nuclear Waste: The NOx System and Organic Aging. Nuclear Site Remediation: First Accomplishments of the Environmental Management Science Program.” American Chemical Society Symposium. 778: 342-361 Washington DC, edited by PG Eller and WR Heinemann.

Morgan LM, WW Schulz, MR Adams, and KW Owens. 1988. Summary of Single-Shell Tank Waste Characterization: 1985 to 1987. WHC-EP-0075, Westinghouse Hanford Company, Richland, WA.

Nash CA, MM Morse, DJ McCabe, LL Hamm, and FG Smith. 2013. Ion Exchange Column Tests Supporting Technetium Removal Resin Maturation. SRNL-STI-2013-00573, Rev. 1, Savannah River National Laboratory, Aiken, SC.

Nguyen DM. 2010. Guidelines for Updating Best-Basis Inventory. RPP-7625, Rev. 10, Washington River Protection Solutions LLC, Richland, WA.

Place DE. 2006. Best-Basis Inventory Process Requirements. RPP-7625, Rev. 6a, CH2M Hill Hanford Group, Inc., Richland, WA.

Puigh RJ and MI Wood. 2005. Inventory Data Package for the 2005 Integrated Disposal Facility Performance Assessment. RPP-20692, Rev. 1, CH2M Hill Company, Richland, WA.

Ramsey WG. 2012a. Tc/LAW Melter Recycle Demonstration Project Update: February 2012. RPP-RPT-51964, Rev. 0, Washington River Protection Solutions LLC, Richland, WA.

Ramsey WG. 2012b. Tc/LAW Melter Recycle Demonstration Project Summary: September 2012. RPP-RPT-53649, Rev. 1, Washington River Protection Solutions LLC, Richland, WA.

Rapko BM. 2014. Protocol for Identifying the Presence of and Understanding the Nature of Soluble, Non-pertechnetate Technetium in Hanford Tank Supernatants. PNNL-23180; EMSP-RPT-020, Pacific Northwest National Laboratory, Richland, WA. Full Publication (pdf)

Rapko BM, SA Bryan, JL Bryant, S Chatterjee, MK Edwards, JY Houchin, T Janik, TG Levitskaia, JM Peterson, RA Peterson, SI Sinkov, FN Smith, and R Wittman. 2013a. Development of a Chemistry-Based, Predictive Method for Determining the Amount of Non-Pertechnetate Technetium in the Hanford Tanks: FY2012 Progress Report. PNNL-22173, Pacific Northwest National Laboratory, Richland, WA. Full Publication (pdf)

Rapko BM, SA Bryan, S Chatterjee, MK Edwards, TG Levitskaia, JM Peterson, RA Peterson, and SI Sinkov. 2013b. Investigations into the Nature of Alkaline Soluble, Nor-Pertechnetate Technetium. PNNL-22957, Pacific Northwest National Laboratory, Richland, WA. Full Publication (pdf) 
Rattat D, AP Schubiger, HG Berke, H Schmalle, and R Alberto. 2001. "Dicarbonyl-Nitrosyl-Complexes of Rhenium (Re) and Technetium (Tc), a Potentially New Class of Compounds for the Direct Radiolabeling of Biomoledules." Cancer Biotherapy and Radiopharmaceuticals 16: 339-343.

Robbins RA and TH May. 2013. Submerged Bed Scrubber Condensate Technetium Removal and Disposal Preconceptual Engineering Study. RPP-RPT-55213, Rev. 0, Washington River Protection Solutions, LLC, Richland, WA.

Schroeder NC and KR Ashley. 2005. "Separation of Non-Pertechnetate Species from Hanford AN-107 Tank Waste." Journal of Radioanalytical and Nuclear Chemistry 263(3):567-73. doi: 10.1007/s10967-005-0625-9.

Schroeder NC, SD Radzinski, JR Ball, KR Ashley, SL Cobb, B Cutrell, JM Adams, C Johnson, and D Whitener. 1995. Technetium Partitioning for the Hanford Tank Waste Remediation System: Anion Exchange Studies for Partitioning Technetium from Synthetic DSSF and DSS Simulants and Actual Hanford Waste (101-SY and 103-SY) Using Reilliex-HPQ Resin. LA-UR-95-4440, Los Alamos National Laboratory, Los Alamos, NM.

Schroeder NC, DL Blanchard, Jr., and KR Ashley. 1998. Fundamental Chemistry, Characterization, and Separation of Technetium Complexes in Hanford Waste. EMSP-59990-98, Los Alamos National Laboratory, Los Alamos, NM.

Schroeder NC, SD Radzinski, KR Ashley, AP Truong, and GD Whitener. 2001. "Feed adjustment chemistry for Hanford 101-SY and 103-SY tank waste: Attempts to oxidize the non-pertechnetate species." Journal of Radioanalytical and Nuclear Chemistry 250:271-284.

Schroeder NC, KR Ashley, and DL Blanchard. 2002. Fundamental Chemistry, Characterization, and Separation of Technetium Complexes in Hanford Waste. DOE Project Number: 59990, Los Alamos National Laboratory, Los Alamos, NM.

Schroeder NC, JA Olivares, and KR Ashley. 2004. Identification of Non-Pertechnetate Species in Hanford Tank Waste, Their Synthesis, Characterization, and Fundamentals Chemistry. LA-UR-04-4277, Los Alamos National Laboratory, Los Alamos, NM.

Serne RJ, TE Jones, MJ Lindberg, HT Schaef, and KM Krupka. 2007. Laboratory Scale Bismuth Phosphate Extraction Process Simulation to Track Fate of Fission Products. PNNL-14120, Pacific Northwest National Laboratory, Richland, WA.

Shuh DK, NM Edelstein, CJ Burns, WW Lukens, JJ Bucher, MG Fickes, and BL Scott. 2001. Final Report: Research Program to Investigate The Fundamental Chemistry of Technetium 10/1/97-10/1/00. EMSP-60296, Lawrence Berkeley National Laboratory, Berkeley, CA.

Shuh DK, WW Lukens, and CJ Burns. 2003. Final Report, Research Program to Investigate the Fundamental Chemistry of Technetium--10/2000- 9/2003. LBNL-54240, Lawrence Berkeley National Laboratory, Berkeley, CA. 
Taylor-Pashow KM, CA Nash, CL Crawford, DJ McCabe, and WR Wilmarth. 2014. Laboratory Scoping Tests of Decontamination of Hanford Waste Treatment Plant Low Activity Waste Off-Gas Condensate Simulant. SRNL-STI-2013-00719, Rev. 0, Savannah River National Laboratory, Aiken, SC.

Watrous. RA. 2002. Activity of Fuel Batches Processed through Hanford Separations Plants, 1944 through 1989. RPP-13489, Rev. 0, CH2MHILL Hanford Group, Inc., Richland, WA.

Yanochko RM and C Corcoran. 2012. Waste Treatment and Immobilization Plant of Submerged Bed Scrubber Condensate Disposition Project. RPP-53982-FP, Rev. 0, Washington River Protection Solutions LLC, Richland, WA.

Yanochko RM, C Corcoran, GR Golcar, P Johnson, LM Nolan, and A Pajunen. 2012. Submerged Bed Scrubber Condensate Disposal Preconceptual Engineering Study. RPP-RPT-52321, Rev. 0, Washington River Protection Solutions LLC, Richland, WA. 


\section{Appendix A}

\section{Additional Outputs from TWINS 1-27-2014}





\section{Appendix A}

\section{Additional Outputs from TWINS 1-27-2014}

This appendix contains two large tables imported from Excel ${ }^{\circledR}$ that provide additional data on the ${ }^{99} \mathrm{Tc}$ inventory currently estimated to be each phase within each of the 177 Hanford storage tanks. The concentration of ${ }^{99} \mathrm{Tc}$ in each phase is also listed in Table A.1. Table A.2 is a ranking from the highest inventory tank to the lowest inventory tank. Note that double-shell tanks (DSTs) hold the top 15 positions for highest inventories and 20 of the top 25 positions for tanks. Three single-shell tanks (SSTs) in the SX tank farm and TX-113 and AX-101 have the top five ${ }^{99} \mathrm{Tc}$ inventories among the SSTs.

These rankings may have importance for retrieval risk assessment should there be fluid losses that reach the vadose zone outside the tanks. Another consideration is knowledge of which tanks are considered to have leaked fluids in the past and may not be structurally sound. Known and suspected SST leakers are identified in reports referenced in Appendix D.

The complete TWINS data query from January 27, 2014 in Excel format is available from the authors if desired. It has too many columns to be easily reproduced as Word ${ }^{\circledR}$ tables. 
Table A.1. ${ }^{99} \mathrm{Tc}$ Inventory, ${ }^{99} \mathrm{Tc}$ Concentration by Phase, and Phase Volumes in Each Tank

\begin{tabular}{|c|c|c|c|c|c|c|c|c|}
\hline Tank Name & Waste Phase & Waste Type & $\begin{array}{l}{ }^{99} \mathrm{Tc} \\
(\mathrm{Ci})\end{array}$ & Basis & $\begin{array}{l}\text { Density } \\
(\mathrm{g} / \mathrm{mL})\end{array}$ & $\begin{array}{c}\text { Volume } \\
(\mathrm{kL})\end{array}$ & Adjusted Conc. & Conc. Units \\
\hline 241-A-101 & $\begin{array}{l}\text { Saltcake } \\
\text { Interstitial } \\
\text { Liquid }\end{array}$ & $\begin{array}{l}\text { A1-SltCk } \\
\text { (Liquid) }\end{array}$ & $4.19 \mathrm{E}+01$ & $\mathrm{TS}$ & 1.49 & 148 & $2.83 \mathrm{E}-01$ & $\mu \mathrm{Ci} / \mathrm{mL}$ \\
\hline 241-A-101 & Saltcake Solid & $\begin{array}{l}\text { A1-SltCk } \\
\text { (Solid) }\end{array}$ & $1.86 \mathrm{E}+02$ & $\mathrm{TE}$ & 1.74 & 878 & $1.22 \mathrm{E}-01$ & $\mu \mathrm{Ci} / \mathrm{g}$ \\
\hline 241-A-101 & $\begin{array}{l}\text { Sludge (Liquid } \\
\text { \& Solid) }\end{array}$ & P2 (Solid) & $1.30 \mathrm{E}+00$ & $\mathrm{TE}$ & 1.61 & 11 & $7.36 \mathrm{E}-02$ & $\mu \mathrm{Ci} / \mathrm{g}$ \\
\hline 241-A-101 & Total & & $2.29 \mathrm{E}+02$ & $\mathrm{TS} / \mathrm{TE}$ & & & & \\
\hline 241-A-102 & $\begin{array}{l}\text { Saltcake } \\
\text { Interstitial } \\
\text { Liquid }\end{array}$ & $\begin{array}{l}\text { A1-SltCk } \\
\text { (Liquid) }\end{array}$ & $1.22 \mathrm{E}+01$ & $\mathrm{E}$ & 1.57 & 33 & $3.69 \mathrm{E}-01$ & $\mu \mathrm{Ci} / \mathrm{mL}$ \\
\hline 241-A-102 & Saltcake Solid & $\begin{array}{l}\text { A1-SltCk } \\
\text { (Solid) }\end{array}$ & $2.04 \mathrm{E}+01$ & $\mathrm{TE}$ & 1.7 & 106 & $1.13 \mathrm{E}-01$ & $\mu \mathrm{Ci} / \mathrm{g}$ \\
\hline 241-A-102 & Supernatant & $\begin{array}{l}\text { A1-SltCk } \\
\text { (Liquid) }\end{array}$ & $4.43 E+00$ & $\mathrm{E}$ & 1.57 & 12 & 3.69E-01 & $\mu \mathrm{Ci} / \mathrm{mL}$ \\
\hline 241-A-102 & Total & & $3.70 \mathrm{E}+01$ & $\mathrm{E} / \mathrm{TE}$ & & & & \\
\hline 241-A-103 & $\begin{array}{l}\text { Saltcake } \\
\text { Interstitial } \\
\text { Liquid }\end{array}$ & $\begin{array}{l}\text { A1-SltCk } \\
\text { (Liquid) }\end{array}$ & $8.06 \mathrm{E}+01$ & $\mathrm{E}$ & 1.51 & 338 & 2.38E-01 & $\mu \mathrm{Ci} / \mathrm{mL}$ \\
\hline 241-A-103 & Saltcake Solid & $\begin{array}{l}\text { A1-SltCk } \\
\text { (Solid) }\end{array}$ & $1.74 \mathrm{E}+02$ & $\mathrm{E}$ & 1.32 & 1071 & $1.23 \mathrm{E}-01$ & $\mu \mathrm{Ci} / \mathrm{g}$ \\
\hline 241-A-103 & $\begin{array}{l}\text { Sludge (Liquid } \\
\& \text { Solid) }\end{array}$ & AR (Solid) & 4.75E-01 & TE & 1.34 & 8 & $4.43 \mathrm{E}-02$ & $\mu \mathrm{Ci} / \mathrm{g}$ \\
\hline 241-A-103 & Supernatant & $\begin{array}{l}\text { A1-SltCk } \\
\text { (Liquid) }\end{array}$ & $4.05 \mathrm{E}+00$ & $\mathrm{E}$ & 1.51 & 17 & $2.38 \mathrm{E}-01$ & $\mu \mathrm{Ci} / \mathrm{mL}$ \\
\hline 241-A-103 & Total & & $2.59 \mathrm{E}+02$ & $\mathrm{E} / \mathrm{TE}$ & & & & \\
\hline 241-A-104 & Sludge Solid & AR (Solid) & $1.36 \mathrm{E}+01$ & $\mathrm{TE}$ & 0.95 & 102 & $1.41 \mathrm{E}-01$ & $\mu \mathrm{Ci} / \mathrm{g}$ \\
\hline 241-A-104 & Sludge Solid & P1 (Solid) & 4.99E-01 & TE & 0.95 & 4 & $1.32 \mathrm{E}-01$ & $\mu \mathrm{Ci} / \mathrm{g}$ \\
\hline 241-A-104 & Total & & $1.41 \mathrm{E}+01$ & $\mathrm{TE}$ & & & & \\
\hline 241-A-105 & Sludge Solid & P2 (Solid) & $2.82 \mathrm{E}+01$ & $\mathrm{TE}$ & 1.54 & 139 & $1.32 \mathrm{E}-01$ & $\mu \mathrm{Ci} / \mathrm{g}$ \\
\hline 241-A-105 & Total & & $2.82 \mathrm{E}+01$ & TE & & & & \\
\hline
\end{tabular}




\begin{tabular}{|c|c|c|c|c|c|c|c|c|}
\hline Tank Name & Waste Phase & Waste Type & $\begin{array}{l}{ }^{99} \mathrm{Tc} \\
(\mathrm{Ci})\end{array}$ & Basis & $\begin{array}{l}\text { Density } \\
(\mathrm{g} / \mathrm{mL})\end{array}$ & $\begin{array}{c}\text { Volume } \\
(\mathrm{kL})\end{array}$ & Adjusted Conc. & Conc. Units \\
\hline $241-A-106$ & Saltcake Solid & $\begin{array}{l}\text { A1-SltCk } \\
\text { (Solid) }\end{array}$ & $5.45 \mathrm{E}+01$ & $\bar{E}$ & 1.7 & 110 & $2.92 \mathrm{E}-01$ & $\mu \mathrm{Ci} / \mathrm{g}$ \\
\hline 241-A-106 & $\begin{array}{l}\text { Sludge (Liquid } \\
\text { \& Solid) }\end{array}$ & AR (Solid) & $3.92 \mathrm{E}+01$ & $\mathrm{E}$ & 1.7 & 79 & 2.92E-01 & $\mu \mathrm{Ci} / \mathrm{g}$ \\
\hline 241-A-106 & $\begin{array}{l}\text { Sludge (Liquid } \\
\text { \& Solid) }\end{array}$ & SRR (Solid) & $5.45 \mathrm{E}+01$ & $\mathrm{E}$ & 1.7 & 110 & $2.92 \mathrm{E}-01$ & $\mu \mathrm{Ci} / \mathrm{g}$ \\
\hline 241-A-106 & Total & & $1.48 \mathrm{E}+02$ & $\mathrm{E}$ & & & & \\
\hline 241-AN-101 & $\begin{array}{l}\text { Saltcake } \\
\text { Interstitial } \\
\text { Liquid }\end{array}$ & $\begin{array}{l}\text { A1-SltCk } \\
\text { (Liquid) }\end{array}$ & $7.39 \mathrm{E}+00$ & TS & 1.45 & 28 & $2.64 \mathrm{E}-01$ & $\mu \mathrm{Ci} / \mathrm{mL}$ \\
\hline 241-AN-101 & Saltcake Solid & $\begin{array}{l}\text { A1-SltCk } \\
\text { (Solid) }\end{array}$ & $1.52 \mathrm{E}+01$ & $\mathrm{TE}$ & 1.58 & 90 & $1.07 \mathrm{E}-01$ & $\mu \mathrm{Ci} / \mathrm{g}$ \\
\hline 241-AN-101 & $\begin{array}{l}\text { Sludge (Liquid } \\
\& \text { Solid) }\end{array}$ & CWP1 (Solid) & $1.92 \mathrm{E}+01$ & $\mathrm{E}$ & 1.68 & 326 & $3.50 \mathrm{E}-02$ & $\mu \mathrm{Ci} / \mathrm{g}$ \\
\hline 241-AN-101 & $\begin{array}{l}\text { Sludge (Liquid } \\
\& \text { Solid) }\end{array}$ & CWP2 (Solid) & $1.35 \mathrm{E}+01$ & $\mathrm{E}$ & 1.68 & 229 & $3.50 \mathrm{E}-02$ & $\mu \mathrm{Ci} / \mathrm{g}$ \\
\hline 241-AN-101 & $\begin{array}{l}\text { Sludge (Liquid } \\
\& \text { Solid) }\end{array}$ & CWZr1 (Solid) & $5.29 \mathrm{E}+00$ & $\mathrm{E}$ & 1.68 & 90 & $3.50 \mathrm{E}-02$ & $\mu \mathrm{Ci} / \mathrm{g}$ \\
\hline 241-AN-101 & $\begin{array}{l}\text { Sludge (Liquid } \\
\& \text { Solid) }\end{array}$ & HS (Solid) & $1.14 \mathrm{E}-02$ & $\mathrm{E}$ & 1.58 & 1 & $7.21 \mathrm{E}-03$ & $\mu \mathrm{Ci} / \mathrm{g}$ \\
\hline 241-AN-101 & $\begin{array}{l}\text { Sludge (Liquid } \\
\& \text { Solid) }\end{array}$ & NA (Sludge) & $7.88 \mathrm{E}+00$ & $\mathrm{E}$ & 1.68 & 134 & $3.50 \mathrm{E}-02$ & $\mu \mathrm{Ci} / \mathrm{g}$ \\
\hline 241-AN-101 & $\begin{array}{l}\text { Sludge (Liquid } \\
\& \text { Solid) }\end{array}$ & $\begin{array}{l}\text { NA C-104 } \\
\text { HHR }\end{array}$ & 5.63E-01 & $\mathrm{E}$ & 1.68 & 7 & 4.79E-02 & $\mu \mathrm{Ci} / \mathrm{g}$ \\
\hline 241-AN-101 & $\begin{array}{l}\text { Sludge (Liquid } \\
\& \text { Solid) }\end{array}$ & OWW3 (Solid) & $6.06 \mathrm{E}+00$ & $\mathrm{E}$ & 1.68 & 103 & $3.50 \mathrm{E}-02$ & $\mu \mathrm{Ci} / \mathrm{g}$ \\
\hline 241-AN-101 & $\begin{array}{l}\text { Sludge (Liquid } \\
\text { \& Solid) }\end{array}$ & TFeCN (Solid) & $4.13 \mathrm{E}+01$ & $\mathrm{E}$ & 1.6 & 266 & $9.71 \mathrm{E}-02$ & $\mu \mathrm{Ci} / \mathrm{g}$ \\
\hline 241-AN-101 & $\begin{array}{l}\text { Sludge (Liquid } \\
\text { \& Solid) }\end{array}$ & TH2 (Solid) & $4.70 \mathrm{E}+00$ & $\mathrm{E}$ & 1.68 & 80 & $3.50 \mathrm{E}-02$ & $\mu \mathrm{Ci} / \mathrm{g}$ \\
\hline 241-AN-101 & $\begin{array}{l}\text { Sludge } \\
\text { Interstitial } \\
\text { Liquid }\end{array}$ & $\begin{array}{l}\text { C-101 CWP1 } \\
\text { (Liquid) }\end{array}$ & $2.09 \mathrm{E}+00$ & $\mathrm{~S}$ & 1.16 & 52 & $4.02 \mathrm{E}-02$ & $\mu \mathrm{Ci} / \mathrm{mL}$ \\
\hline
\end{tabular}




\begin{tabular}{|c|c|c|c|c|c|c|c|c|}
\hline Tank Name & Waste Phase & Waste Type & $\begin{array}{l}{ }^{99} \mathrm{Tc} \\
(\mathrm{Ci})\end{array}$ & Basis & $\begin{array}{l}\text { Density } \\
(\mathrm{g} / \mathrm{mL})\end{array}$ & $\begin{array}{c}\text { Volume } \\
(\mathrm{kL})\end{array}$ & Adjusted Conc. & Conc. Units \\
\hline 241-AN-101 & $\begin{array}{l}\text { Sludge } \\
\text { Interstitial } \\
\text { Liquid }\end{array}$ & $\begin{array}{l}\text { C-101 TBP } \\
\text { (Liquid) }\end{array}$ & $1.96 \mathrm{E}+00$ & $\mathrm{~S}$ & 1.16 & 34 & $5.75 \mathrm{E}-02$ & $\mu \mathrm{Ci} / \mathrm{mL}$ \\
\hline 241-AN-101 & Sludge Solid & $\begin{array}{l}\text { C-101 CWP1 } \\
\text { (Solid) }\end{array}$ & $9.06 \mathrm{E}-02$ & $\mathrm{E}$ & 2.14 & 112 & $3.78 \mathrm{E}-04$ & $\mu \mathrm{Ci} / \mathrm{g}$ \\
\hline 241-AN-101 & Sludge Solid & $\begin{array}{l}\text { C-101 TBP } \\
\text { (Solid) }\end{array}$ & $2.96 \mathrm{E}-01$ & $\mathrm{E}$ & 2.14 & 75 & $1.85 \mathrm{E}-03$ & $\mu \mathrm{Ci} / \mathrm{g}$ \\
\hline 241-AN-101 & Supernatant & NA (Liquid) & $7.59 \mathrm{E}+01$ & $\mathrm{~S}$ & 1.17 & 1402 & $5.41 \mathrm{E}-02$ & $\mu \mathrm{Ci} / \mathrm{mL}$ \\
\hline 241-AN-101 & Total & & $2.01 \mathrm{E}+02$ & $\mathrm{~S} / \mathrm{E} / \mathrm{TS} / \mathrm{TE}$ & & & & \\
\hline 241-AN-102 & $\begin{array}{l}\text { Saltcake (Liquid } \\
\& \text { Solid) }\end{array}$ & $\begin{array}{l}\text { A2-SltSlr } \\
\text { (Solid) }\end{array}$ & $1.20 \mathrm{E}+02$ & E & 1.53 & 584 & $1.35 \mathrm{E}-01$ & $\mu \mathrm{Ci} / \mathrm{g}$ \\
\hline 241-AN-102 & Supernatant & NA (Liquid) & $4.60 \mathrm{E}+02$ & $\mathrm{~S}$ & 1.44 & 3475 & $1.32 \mathrm{E}-01$ & $\mu \mathrm{Ci} / \mathrm{mL}$ \\
\hline 241-AN-102 & Total & & $5.80 \mathrm{E}+02$ & $\mathrm{~S} / \mathrm{E}$ & & & & \\
\hline 241-AN-103 & $\begin{array}{l}\text { Saltcake (Liquid } \\
\& \text { Solid) }\end{array}$ & $\begin{array}{l}\text { A2-SltSlr } \\
\text { (Solid) }\end{array}$ & $4.00 \mathrm{E}+02$ & $\mathrm{~S}$ & 1.72 & 1638 & $1.42 \mathrm{E}-01$ & $\mu \mathrm{Ci} / \mathrm{g}$ \\
\hline 241-AN-103 & Supernatant & $\begin{array}{l}\text { A2-SltSlr } \\
\text { (Liquid) }\end{array}$ & $2.81 \mathrm{E}+02$ & $\mathrm{~S}$ & 1.48 & 1769 & $1.59 \mathrm{E}-01$ & $\mu \mathrm{Ci} / \mathrm{mL}$ \\
\hline 241-AN-103 & Total & & $6.81 \mathrm{E}+02$ & $\mathrm{~S}$ & & & & \\
\hline 241-AN-104 & $\begin{array}{l}\text { Saltcake (Liquid } \\
\& \text { Solid) }\end{array}$ & $\begin{array}{l}\text { A2-SltSlr } \\
\text { (Solid) }\end{array}$ & $3.32 \mathrm{E}+02$ & $\mathrm{~S}$ & 1.59 & 1566 & $1.33 \mathrm{E}-01$ & $\mu \mathrm{Ci} / \mathrm{g}$ \\
\hline 241-AN-104 & Supernatant & $\begin{array}{l}\text { A2-SltSlr } \\
\text { (Liquid) }\end{array}$ & $4.62 \mathrm{E}+02$ & $\mathrm{~S}$ & 1.4 & 2298 & $2.01 \mathrm{E}-01$ & $\mu \mathrm{Ci} / \mathrm{mL}$ \\
\hline 241-AN-104 & Total & & $7.94 \mathrm{E}+02$ & $\mathrm{~S}$ & & & & \\
\hline 241-AN-105 & $\begin{array}{l}\text { Saltcake (Liquid } \\
\& \text { Solid) }\end{array}$ & $\begin{array}{l}\text { A2-SltSlr } \\
\text { (Solid) }\end{array}$ & $5.34 \mathrm{E}+02$ & $\mathrm{~S}$ & 1.57 & 1925 & $1.77 \mathrm{E}-01$ & $\mu \mathrm{Ci} / \mathrm{g}$ \\
\hline 241-AN-105 & Supernatant & $\begin{array}{l}\text { A2-SltSlr } \\
\text { (Liquid) }\end{array}$ & $5.88 \mathrm{E}+02$ & $\mathrm{~S}$ & 1.42 & 2227 & $2.64 \mathrm{E}-01$ & $\mu \mathrm{Ci} / \mathrm{mL}$ \\
\hline 241-AN-105 & Total & & $1.12 \mathrm{E}+03$ & $\mathrm{~S}$ & & & & \\
\hline 241-AN-106 & $\begin{array}{l}\text { Saltcake (Liquid } \\
\& \text { Solid) }\end{array}$ & NA (SltCk) & $1.10 \mathrm{E}+01$ & $\mathrm{TE}$ & 1.58 & 65 & $1.07 \mathrm{E}-01$ & $\mu \mathrm{Ci} / \mathrm{g}$ \\
\hline 241-AN-106 & $\begin{array}{l}\text { Saltcake (Liquid } \\
\& \text { Solid) }\end{array}$ & $\begin{array}{l}\text { NA from C- } \\
110 \text { (Solids) }\end{array}$ & $3.62 \mathrm{E}-01$ & $\mathrm{E}$ & 1.56 & 30 & $7.73 \mathrm{E}-03$ & $\mu \mathrm{Ci} / \mathrm{g}$ \\
\hline 241-AN-106 & $\begin{array}{l}\text { Sludge (Liquid } \\
\& \text { Solid) }\end{array}$ & $\begin{array}{l}1 \mathrm{C} \text { from C-107 } \\
\text { (Solid) }\end{array}$ & $1.64 \mathrm{E}+01$ & $\mathrm{E}$ & 1.72 & 288 & $3.32 \mathrm{E}-02$ & $\mu \mathrm{Ci} / \mathrm{g}$ \\
\hline
\end{tabular}




\begin{tabular}{|c|c|c|c|c|c|c|c|c|}
\hline Tank Name & Waste Phase & Waste Type & $\begin{array}{l}{ }^{99} \mathrm{Tc} \\
(\mathrm{Ci})\end{array}$ & Basis & $\begin{array}{l}\text { Density } \\
(\mathrm{g} / \mathrm{mL})\end{array}$ & $\begin{array}{l}\text { Volume } \\
\text { (kL) }\end{array}$ & Adjusted Conc. & Conc. Units \\
\hline $241-\mathrm{AN}-106$ & $\begin{array}{l}\text { Sludge (Liquid } \\
\text { \& Solid) }\end{array}$ & $\begin{array}{l}1 \mathrm{C} \text { from C-108 } \\
\text { (Solid) }\end{array}$ & $9.56 \mathrm{E}-03$ & $\bar{E}$ & 1.71 & 1 & $3.99 \mathrm{E}-03$ & $\mu \mathrm{Ci} / \mathrm{g}$ \\
\hline 241-AN-106 & $\begin{array}{l}\text { Sludge (Liquid } \\
\text { \& Solid) }\end{array}$ & $\begin{array}{l}\text { 1C from C-109 } \\
\text { (Solids) }\end{array}$ & $3.33 \mathrm{E}-03$ & $\mathrm{E}$ & 1.71 & 5 & $3.67 \mathrm{E}-04$ & $\mu \mathrm{Ci} / \mathrm{g}$ \\
\hline 241-AN-106 & $\begin{array}{l}\text { Sludge (Liquid } \\
\text { \& Solid) }\end{array}$ & $\begin{array}{l}\text { CWP2 from C- } \\
107 \text { (Solid) }\end{array}$ & $3.59 \mathrm{E}+00$ & $\mathrm{E}$ & 1.72 & 63 & $3.31 \mathrm{E}-02$ & $\mu \mathrm{Ci} / \mathrm{g}$ \\
\hline 241-AN-106 & $\begin{array}{l}\text { Sludge (Liquid } \\
\text { \& Solid) }\end{array}$ & Garnet & $0.00 \mathrm{E}+00$ & $\mathrm{E}$ & 2.4 & 0 & $0.00 \mathrm{E}+00$ & $\mu \mathrm{Ci} / \mathrm{g}$ \\
\hline 241-AN-106 & $\begin{array}{l}\text { Sludge (Liquid } \\
\text { \& Solid) }\end{array}$ & NA (Sludge) & $8.59 \mathrm{E}+01$ & $\mathrm{E}$ & 1.71 & 903 & $5.56 \mathrm{E}-02$ & $\mu \mathrm{Ci} / \mathrm{g}$ \\
\hline 241-AN-106 & $\begin{array}{l}\text { Sludge (Liquid } \\
\text { \& Solid) }\end{array}$ & $\begin{array}{l}\text { SRR from C- } \\
107 \text { (Solid) }\end{array}$ & $1.37 \mathrm{E}+01$ & $\mathrm{E}$ & 1.72 & 239 & $3.32 \mathrm{E}-02$ & $\mu \mathrm{Ci} / \mathrm{g}$ \\
\hline 241-AN-106 & Supernatant & NA (Liquid) & $1.31 \mathrm{E}+01$ & $\mathrm{E}$ & 1.09 & 1163 & $1.13 \mathrm{E}-02$ & $\mu \mathrm{Ci} / \mathrm{mL}$ \\
\hline 241-AN-106 & Total & & $1.44 \mathrm{E}+02$ & $\mathrm{E} / \mathrm{TE}$ & & & & \\
\hline 241-AN-107 & $\begin{array}{l}\text { Saltcake (Liquid } \\
\text { \& Solid) }\end{array}$ & $\begin{array}{l}\text { A2-SltSlr } \\
\text { (Solid) }\end{array}$ & $1.31 \mathrm{E}+02$ & $\mathrm{E}$ & 1.48 & 912 & $9.72 \mathrm{E}-02$ & $\mu \mathrm{Ci} / \mathrm{g}$ \\
\hline 241-AN-107 & Supernatant & $\begin{array}{l}\text { A2-SltSlr } \\
\text { (Liquid) }\end{array}$ & $3.03 \mathrm{E}+02$ & $\mathrm{~S}$ & 1.42 & 3208 & $9.45 \mathrm{E}-02$ & $\mu \mathrm{Ci} / \mathrm{mL}$ \\
\hline 241-AN-107 & Total & & $4.34 \mathrm{E}+02$ & $\mathrm{~S} / \mathrm{E}$ & & & & \\
\hline 241-AP-101 & $\begin{array}{l}\text { Saltcake (Liquid } \\
\& \text { Solid) }\end{array}$ & NA (SltCk) & $3.12 \mathrm{E}+01$ & $\mathrm{E}$ & 1.61 & 126 & $1.54 \mathrm{E}-01$ & $\mu \mathrm{Ci} / \mathrm{g}$ \\
\hline 241-AP-101 & Supernatant & NA (Liquid) & $7.24 \mathrm{E}+02$ & $\mathrm{E}$ & 1.39 & 4555 & $1.59 \mathrm{E}-01$ & $\mu \mathrm{Ci} / \mathrm{mL}$ \\
\hline 241-AP-101 & Total & & $7.55 \mathrm{E}+02$ & $\mathrm{E}$ & & & & \\
\hline 241-AP-102 & $\begin{array}{l}\text { Sludge (Liquid } \\
\text { \& Solid) }\end{array}$ & NA (Sludge) & $1.34 \mathrm{E}+01$ & $\mathrm{E}$ & 1.73 & 105 & $7.36 \mathrm{E}-02$ & $\mu \mathrm{Ci} / \mathrm{g}$ \\
\hline 241-AP-102 & Supernatant & NA (Liquid) & $6.90 \mathrm{E}+02$ & $\mathrm{E}$ & 1.37 & 4212 & $1.64 \mathrm{E}-01$ & $\mu \mathrm{Ci} / \mathrm{mL}$ \\
\hline 241-AP-102 & Total & & $7.03 \mathrm{E}+02$ & $\mathrm{E}$ & & & & \\
\hline 241-AP-103 & $\begin{array}{l}\text { Saltcake (Liquid } \\
\text { \& Solid) }\end{array}$ & NA (SltCk) & $3.80 \mathrm{E}+01$ & TS & 1.5 & 198 & $1.28 \mathrm{E}-01$ & $\mu \mathrm{Ci} / \mathrm{g}$ \\
\hline 241-AP-103 & Supernatant & NA (Liquid) & $9.21 \mathrm{E}+02$ & $\mathrm{E}$ & 1.38 & 4487 & $2.05 \mathrm{E}-01$ & $\mu \mathrm{Ci} / \mathrm{mL}$ \\
\hline 241-AP-103 & Total & & $9.59 \mathrm{E}+02$ & $\mathrm{E} / \mathrm{TS}$ & & & & \\
\hline 241-AP-104 & $\begin{array}{l}\text { Saltcake (Liquid } \\
\text { \& Solid) }\end{array}$ & NA (SltCk) & $9.37 \mathrm{E}+01$ & $\mathrm{E}$ & 1.61 & 378 & $1.54 \mathrm{E}-01$ & $\mu \mathrm{Ci} / \mathrm{g}$ \\
\hline 241-AP-104 & Supernatant & NA (Liquid) & $6.13 \mathrm{E}+01$ & E & 1.18 & 1643 & $3.73 \mathrm{E}-02$ & $\mu \mathrm{Ci} / \mathrm{mL}$ \\
\hline
\end{tabular}




\begin{tabular}{|c|c|c|c|c|c|c|c|c|}
\hline Tank Name & Waste Phase & Waste Type & $\begin{array}{l}{ }^{99} \mathrm{Tc} \\
(\mathrm{Ci})\end{array}$ & Basis & $\begin{array}{l}\text { Density } \\
(\mathrm{g} / \mathrm{mL})\end{array}$ & $\begin{array}{c}\text { Volume } \\
\text { (kL) }\end{array}$ & Adjusted Conc. & Conc. Units \\
\hline 241-AP-104 & Total & & $1.55 \mathrm{E}+02$ & $\bar{E}$ & & & & \\
\hline 241-AP-105 & $\begin{array}{l}\text { Saltcake (Liquid } \\
\& \text { Solid) }\end{array}$ & $\begin{array}{l}\text { A2-SltSlr } \\
\text { (Solid) }\end{array}$ & $9.02 \mathrm{E}+01$ & TS & 1.61 & 396 & $1.42 \mathrm{E}-01$ & $\mu \mathrm{Ci} / \mathrm{g}$ \\
\hline 241-AP-105 & Supernatant & NA (Liquid) & $8.60 \mathrm{E}+02$ & $\mathrm{E}$ & 1.4 & 4321 & $1.99 \mathrm{E}-01$ & $\mu \mathrm{Ci} / \mathrm{mL}$ \\
\hline 241-AP-105 & Total & & $9.51 \mathrm{E}+02$ & $\mathrm{E} / \mathrm{TS}$ & & & & \\
\hline 241-AP-106 & Supernatant & NA (Liquid) & $3.68 \mathrm{E}+02$ & $\mathrm{E}$ & 1.21 & 4291 & $8.59 \mathrm{E}-02$ & $\mu \mathrm{Ci} / \mathrm{mL}$ \\
\hline 241-AP-106 & Total & & $3.68 \mathrm{E}+02$ & $\mathrm{E}$ & & & & \\
\hline 241-AP-107 & Supernatant & NA (Liquid) & $1.77 \mathrm{E}+02$ & $\mathrm{~S}$ & 1.21 & 1670 & $1.06 \mathrm{E}-01$ & $\mu \mathrm{Ci} / \mathrm{mL}$ \\
\hline 241-AP-107 & Total & & $1.77 \mathrm{E}+02$ & $\mathrm{~S}$ & & & & \\
\hline 241-AP-108 & $\begin{array}{l}\text { Saltcake (Liquid } \\
\text { \& Solid) }\end{array}$ & NA (SltCk) & $5.94 \mathrm{E}+01$ & $\mathrm{E}$ & 1.57 & 425 & $8.90 \mathrm{E}-02$ & $\mu \mathrm{Ci} / \mathrm{g}$ \\
\hline 241-AP-108 & Supernatant & NA (Liquid) & $6.65 \mathrm{E}+02$ & $\mathrm{E}$ & 1.42 & 4290 & $1.55 \mathrm{E}-01$ & $\mu \mathrm{Ci} / \mathrm{mL}$ \\
\hline 241-AP-108 & Total & & $7.24 \mathrm{E}+02$ & $\mathrm{E}$ & & & & \\
\hline 241-AW-101 & $\begin{array}{l}\text { Saltcake (Liquid } \\
\text { \& Solid) }\end{array}$ & $\begin{array}{l}\text { A2-SltSlr } \\
\text { (Solid) }\end{array}$ & $3.50 \mathrm{E}+02$ & $\mathrm{~S}$ & 1.59 & 1403 & $1.57 \mathrm{E}-01$ & $\mu \mathrm{Ci} / \mathrm{g}$ \\
\hline 241-AW-101 & Supernatant & $\begin{array}{l}\text { A2-SltSlr } \\
\text { (Liquid) }\end{array}$ & $4.68 \mathrm{E}+02$ & $\mathrm{~S}$ & 1.47 & 2770 & $1.69 \mathrm{E}-01$ & $\mu \mathrm{Ci} / \mathrm{mL}$ \\
\hline 241-AW-101 & Total & & $8.18 \mathrm{E}+02$ & $\mathrm{~S}$ & & & & \\
\hline 241-AW-102 & $\begin{array}{l}\text { Sludge (Liquid } \\
\text { \& Solid) }\end{array}$ & NA (Sludge) & 8.63E-02 & $\mathrm{TE}$ & 1.6 & 196 & $2.75 \mathrm{E}-04$ & $\mu \mathrm{Ci} / \mathrm{g}$ \\
\hline 241-AW-102 & Supernatant & NA (Liquid) & $3.21 \mathrm{E}+02$ & $\mathrm{E}$ & 1.22 & 3088 & $1.04 \mathrm{E}-01$ & $\mu \mathrm{Ci} / \mathrm{mL}$ \\
\hline 241-AW-102 & Total & & $3.21 \mathrm{E}+02$ & $\mathrm{E} / \mathrm{TE}$ & & & & \\
\hline 241-AW-103 & $\begin{array}{l}\text { Saltcake } \\
\text { Interstitial } \\
\text { Liquid }\end{array}$ & $\begin{array}{l}\text { A1-SltCk } \\
\text { (Liquid) }\end{array}$ & $9.04 \mathrm{E}+00$ & TS & 1.42 & 36 & $2.51 \mathrm{E}-01$ & $\mu \mathrm{Ci} / \mathrm{mL}$ \\
\hline 241-AW-103 & Saltcake Solid & $\begin{array}{l}\text { A1-SltCk } \\
\text { (Solid) }\end{array}$ & $4.45 \mathrm{E}+00$ & $\mathrm{~S}$ & 1.69 & 115 & $2.29 \mathrm{E}-02$ & $\mu \mathrm{Ci} / \mathrm{g}$ \\
\hline 241-AW-103 & $\begin{array}{l}\text { Sludge (Liquid } \\
\text { \& Solid) }\end{array}$ & CWZr2 (Solid) & $4.10 \mathrm{E}+01$ & $\mathrm{~S}$ & 1.47 & 1060 & $2.63 \mathrm{E}-02$ & $\mu \mathrm{Ci} / \mathrm{g}$ \\
\hline 241-AW-103 & Supernatant & NA (Liquid) & $3.42 \mathrm{E}+02$ & $\mathrm{E}$ & 1.24 & 2884 & $1.19 \mathrm{E}-01$ & $\mu \mathrm{Ci} / \mathrm{mL}$ \\
\hline 241-AW-103 & Total & & $3.97 \mathrm{E}+02$ & $\mathrm{~S} / \mathrm{E} / \mathrm{TS}$ & & & & \\
\hline 241-AW-104 & $\begin{array}{l}\text { Saltcake } \\
\text { Interstitial } \\
\text { Liquid }\end{array}$ & $\begin{array}{l}\text { A2-SltSlr } \\
\text { (Liquid) }\end{array}$ & $3.54 \mathrm{E}+01$ & TS & 1.45 & 142 & $2.49 \mathrm{E}-01$ & $\mu \mathrm{Ci} / \mathrm{mL}$ \\
\hline
\end{tabular}




\begin{tabular}{|c|c|c|c|c|c|c|c|c|}
\hline Tank Name & Waste Phase & Waste Type & $\begin{array}{l}{ }^{99} \mathrm{Tc} \\
(\mathrm{Ci})\end{array}$ & Basis & $\begin{array}{l}\text { Density } \\
(\mathrm{g} / \mathrm{mL})\end{array}$ & $\begin{array}{c}\text { Volume } \\
(\mathrm{kL})\end{array}$ & Adjusted Conc. & Conc. Units \\
\hline 241-AW-104 & Saltcake Solid & $\begin{array}{l}\text { A2-SltSlr } \\
\text { (Solid) }\end{array}$ & $1.37 \mathrm{E}+02$ & $\bar{E}$ & 1.6 & 451 & $1.90 \mathrm{E}-01$ & $\mu \mathrm{Ci} / \mathrm{g}$ \\
\hline 241-AW-104 & $\begin{array}{l}\text { Sludge } \\
\text { Interstitial } \\
\text { Liquid }\end{array}$ & PL2 (Liquid) & $1.98 \mathrm{E}+01$ & TS & 1.33 & 115 & $1.72 \mathrm{E}-01$ & $\mu \mathrm{Ci} / \mathrm{mL}$ \\
\hline 241-AW-104 & Sludge Solid & PL2 (Solid) & 4.26E-03 & $\mathrm{TE}$ & 1.28 & 255 & $1.31 \mathrm{E}-05$ & $\mu \mathrm{Ci} / \mathrm{g}$ \\
\hline 241-AW-104 & Supernatant & NA (Liquid) & $5.67 \mathrm{E}+02$ & $\mathrm{E}$ & 1.36 & 3070 & $1.85 \mathrm{E}-01$ & $\mu \mathrm{Ci} / \mathrm{mL}$ \\
\hline 241-AW-104 & Total & & $7.59 \mathrm{E}+02$ & $\mathrm{E} / \mathrm{TS} / \mathrm{TE}$ & & & & \\
\hline 241-AW-105 & $\begin{array}{l}\text { Sludge (Liquid } \\
\text { \& Solid) }\end{array}$ & CWZr2 (Solid) & $3.99 \mathrm{E}+00$ & TE & 1.33 & 841 & $3.57 \mathrm{E}-03$ & $\mu \mathrm{Ci} / \mathrm{g}$ \\
\hline 241-AW-105 & $\begin{array}{l}\text { Sludge (Liquid } \\
\text { \& Solid) }\end{array}$ & PL2 (Solid) & $2.11 \mathrm{E}-03$ & $\mathrm{TE}$ & 1.35 & 99 & $1.58 \mathrm{E}-05$ & $\mu \mathrm{Ci} / \mathrm{g}$ \\
\hline 241-AW-105 & Supernatant & NA (Liquid) & $5.35 \mathrm{E}+00$ & $\mathrm{TE}$ & 1.06 & 592 & $9.04 \mathrm{E}-03$ & $\mu \mathrm{Ci} / \mathrm{mL}$ \\
\hline 241-AW-105 & Total & & $9.35 \mathrm{E}+00$ & TE & & & & \\
\hline 241-AW-106 & $\begin{array}{l}\text { Saltcake (Liquid } \\
\text { \& Solid) }\end{array}$ & $\begin{array}{l}\text { A2-SltSlr } \\
\text { (Solid) }\end{array}$ & $3.36 \mathrm{E}+02$ & TS & 1.77 & 1001 & $1.90 \mathrm{E}-01$ & $\mu \mathrm{Ci} / \mathrm{g}$ \\
\hline 241-AW-106 & Supernatant & $\begin{array}{l}\text { NA Lower } \\
\text { (Liquid) }\end{array}$ & $5.56 \mathrm{E}+01$ & S & 1.4 & 285 & $1.95 \mathrm{E}-01$ & $\mu \mathrm{Ci} / \mathrm{mL}$ \\
\hline 241-AW-106 & Supernatant & $\begin{array}{l}\text { NA Upper } \\
\text { (Liquid) }\end{array}$ & $2.01 \mathrm{E}+02$ & $\mathrm{~S}$ & 1.24 & 3019 & $6.65 \mathrm{E}-02$ & $\mu \mathrm{Ci} / \mathrm{mL}$ \\
\hline 241-AW-106 & Total & & $5.93 \mathrm{E}+02$ & $\mathrm{~S} / \mathrm{TS}$ & & & & \\
\hline 241-AX-101 & $\begin{array}{l}\text { Saltcake } \\
\text { Interstitial } \\
\text { Liquid }\end{array}$ & $\begin{array}{l}\text { A1-SltCk } \\
\text { (Liquid) }\end{array}$ & $5.54 \mathrm{E}+01$ & TS & 1.53 & 178 & $3.12 \mathrm{E}-01$ & $\mu \mathrm{Ci} / \mathrm{mL}$ \\
\hline 241-AX-101 & Saltcake Solid & $\begin{array}{l}\text { A1-SltCk } \\
\text { (Solid) }\end{array}$ & $2.34 \mathrm{E}+02$ & TE & 1.73 & 1164 & $1.16 \mathrm{E}-01$ & $\mu \mathrm{Ci} / \mathrm{g}$ \\
\hline 241-AX-101 & $\begin{array}{l}\text { Sludge (Liquid } \\
\text { \& Solid) }\end{array}$ & SRR (Solid) & $3.55 \mathrm{E}-01$ & TE & 1.51 & 11 & $2.14 \mathrm{E}-02$ & $\mu \mathrm{Ci} / \mathrm{g}$ \\
\hline 241-AX-101 & Total & & $2.90 \mathrm{E}+02$ & TS/TE & & & & \\
\hline 241-AX-102 & $\begin{array}{l}\text { Saltcake (Liquid } \\
\& \text { Solid) }\end{array}$ & $\begin{array}{l}\text { A1-SltCk } \\
\text { (Solid) }\end{array}$ & $5.42 \mathrm{E}+00$ & S & 1.58 & 90 & $3.81 \mathrm{E}-02$ & $\mu \mathrm{Ci} / \mathrm{g}$ \\
\hline 241-AX-102 & $\begin{array}{l}\text { Sludge (Liquid } \\
\text { \& Solid) }\end{array}$ & B (Solid) & $8.80 \mathrm{E}-01$ & TE & 1.57 & 23 & 2.44E-02 & $\mu \mathrm{Ci} / \mathrm{g}$ \\
\hline 241-AX-102 & Total & & $6.30 \mathrm{E}+00$ & $\mathrm{~S} / \mathrm{TE}$ & & & & \\
\hline
\end{tabular}




\begin{tabular}{|c|c|c|c|c|c|c|c|c|}
\hline Tank Name & Waste Phase & Waste Type & $\begin{array}{l}{ }^{99} \mathrm{Tc} \\
(\mathrm{Ci})\end{array}$ & Basis & $\begin{array}{l}\text { Density } \\
(\mathrm{g} / \mathrm{mL})\end{array}$ & $\begin{array}{l}\text { Volume } \\
(\mathrm{kL})\end{array}$ & Adjusted Conc. & Conc. Units \\
\hline $241-\mathrm{AX}-103$ & $\begin{array}{l}\text { Saltcake } \\
\text { Interstitial } \\
\text { Liquid }\end{array}$ & $\begin{array}{l}\text { A1-SltCk } \\
\text { (Liquid) }\end{array}$ & $1.98 \mathrm{E}+01$ & $\mathrm{TS}$ & 1.45 & 75 & $2.64 \mathrm{E}-01$ & $\mu \mathrm{Ci} / \mathrm{mL}$ \\
\hline 241-AX-103 & Saltcake Solid & $\begin{array}{l}\text { A1-SltCk } \\
\text { (Solid) }\end{array}$ & $4.69 \mathrm{E}+01$ & $\mathrm{TE}$ & 1.61 & 298 & $9.78 \mathrm{E}-02$ & $\mu \mathrm{Ci} / \mathrm{g}$ \\
\hline 241-AX-103 & $\begin{array}{l}\text { Sludge (Liquid } \\
\text { \& Solid) }\end{array}$ & P2 (Solid) & $3.55 \mathrm{E}+00$ & $\mathrm{TE}$ & 1.61 & 30 & $7.36 \mathrm{E}-02$ & $\mu \mathrm{Ci} / \mathrm{g}$ \\
\hline 241-AX-103 & Total & & $7.03 \mathrm{E}+01$ & $\mathrm{TS} / \mathrm{TE}$ & & & & \\
\hline 241-AX-104 & Sludge Solid & P2 (Solid) & $2.06 \mathrm{E}+01$ & $\mathrm{~S}$ & 1.8 & 28 & $4.08 \mathrm{E}-01$ & $\mu \mathrm{Ci} / \mathrm{g}$ \\
\hline 241-AX-104 & Total & & $2.06 \mathrm{E}+01$ & $\mathrm{~S}$ & & & & \\
\hline 241-AY-101 & $\begin{array}{l}\text { Sludge } \\
\text { Interstitial } \\
\text { Liquid }\end{array}$ & NA (Liquid) & $2.54 \mathrm{E}+00$ & $\mathrm{~S}$ & 1.29 & 60 & 4.23E-02 & $\mu \mathrm{Ci} / \mathrm{mL}$ \\
\hline 241-AY-101 & Sludge Solid & NA (Sludge) & $1.37 \mathrm{E}+01$ & $\mathrm{E}$ & 1.87 & 338 & $2.17 \mathrm{E}-02$ & $\mu \mathrm{Ci} / \mathrm{g}$ \\
\hline 241-AY-101 & Supernatant & $\begin{array}{l}\text { NA Lower } \\
\text { (Liquid) }\end{array}$ & $2.08 \mathrm{E}+01$ & $\mathrm{~S}$ & 1.11 & 1247 & $1.67 \mathrm{E}-02$ & $\mu \mathrm{Ci} / \mathrm{mL}$ \\
\hline 241-AY-101 & Supernatant & $\begin{array}{l}\text { NA Upper } \\
\text { (Liquid) }\end{array}$ & $1.84 \mathrm{E}+01$ & $\mathrm{~S}$ & 1.06 & 1977 & $9.30 \mathrm{E}-03$ & $\mu \mathrm{Ci} / \mathrm{mL}$ \\
\hline 241-AY-101 & Total & & $5.55 \mathrm{E}+01$ & $\mathrm{~S} / \mathrm{E}$ & & & & \\
\hline 241-AY-102 & $\begin{array}{l}\text { Sludge } \\
\text { Interstitial } \\
\text { Liquid }\end{array}$ & BL (Liquid) & $1.54 \mathrm{E}+00$ & $\mathrm{~S}$ & 1.15 & 120 & $1.28 \mathrm{E}-02$ & $\mu \mathrm{Ci} / \mathrm{mL}$ \\
\hline 241-AY-102 & Sludge Solid & BL (Solid) & $3.81 \mathrm{E}+00$ & $\mathrm{~S}$ & 1.71 & 75 & $2.97 \mathrm{E}-02$ & $\mu \mathrm{Ci} / \mathrm{g}$ \\
\hline 241-AY-102 & Sludge Solid & NA (Sludge) & $1.91 \mathrm{E}+01$ & $\mathrm{~S}$ & 1.71 & 376 & $2.97 \mathrm{E}-02$ & $\mu \mathrm{Ci} / \mathrm{g}$ \\
\hline 241-AY-102 & Supernatant & NA (Liquid) & $1.58 \mathrm{E}+02$ & $\mathrm{E}$ & 1.36 & 2538 & $6.23 \mathrm{E}-02$ & $\mu \mathrm{Ci} / \mathrm{mL}$ \\
\hline 241-AY-102 & Total & & $1.82 \mathrm{E}+02$ & $\mathrm{~S} / \mathrm{E}$ & & & & \\
\hline 241-AZ-101 & $\begin{array}{l}\text { Sludge (Liquid } \\
\text { \& Solid) }\end{array}$ & NA (Sludge) & $7.73 \mathrm{E}+00$ & $\mathrm{E}$ & 1.59 & 30 & $1.62 \mathrm{E}-01$ & $\mu \mathrm{Ci} / \mathrm{g}$ \\
\hline 241-AZ-101 & $\begin{array}{l}\text { Sludge (Liquid } \\
\text { \& Solid) }\end{array}$ & P3AZ1 (Solid) & $4.30 \mathrm{E}+01$ & $\mathrm{E}$ & 1.59 & 167 & $1.62 \mathrm{E}-01$ & $\mu \mathrm{Ci} / \mathrm{g}$ \\
\hline 241-AZ-101 & Supernatant & NA (Liquid) & $1.18 \mathrm{E}+03$ & $\mathrm{~S}$ & 1.27 & 3019 & $3.92 \mathrm{E}-01$ & $\mu \mathrm{Ci} / \mathrm{mL}$ \\
\hline 241-AZ-101 & Total & & $1.23 \mathrm{E}+03$ & $\mathrm{~S} / \mathrm{E}$ & & & & \\
\hline 241-AZ-102 & $\begin{array}{l}\text { Sludge (Liquid } \\
\text { \& Solid) }\end{array}$ & NA (Sludge) & $1.75 \mathrm{E}+00$ & $\mathrm{E}$ & 1.41 & 8 & $1.55 \mathrm{E}-01$ & $\mu \mathrm{Ci} / \mathrm{g}$ \\
\hline
\end{tabular}




\begin{tabular}{|c|c|c|c|c|c|c|c|c|}
\hline Tank Name & Waste Phase & Waste Type & $\begin{array}{l}{ }^{99} \mathrm{Tc} \\
(\mathrm{Ci})\end{array}$ & Basis & $\begin{array}{l}\text { Density } \\
(\mathrm{g} / \mathrm{mL})\end{array}$ & $\begin{array}{c}\text { Volume } \\
(\mathrm{kL})\end{array}$ & Adjusted Conc. & Conc. Units \\
\hline $241-A Z-102$ & $\begin{array}{l}\text { Sludge (Liquid } \\
\text { \& Solid) }\end{array}$ & P3AZ2 (Solid) & $6.02 \mathrm{E}+01$ & $\bar{E}$ & 1.41 & 275 & $1.55 \mathrm{E}-01$ & $\mu \mathrm{Ci} / \mathrm{g}$ \\
\hline 241-AZ-102 & $\begin{array}{l}\text { Sludge (Liquid } \\
\text { \& Solid) }\end{array}$ & PL2 (Solid) & $3.28 \mathrm{E}+00$ & $\mathrm{E}$ & 1.41 & 15 & $1.55 \mathrm{E}-01$ & $\mu \mathrm{Ci} / \mathrm{g}$ \\
\hline 241-AZ-102 & $\begin{array}{l}\text { Sludge (Liquid } \\
\text { \& Solid) }\end{array}$ & SRR (Solid) & $2.15 \mathrm{E}+01$ & $\mathrm{E}$ & 1.41 & 98 & $1.55 \mathrm{E}-01$ & $\mu \mathrm{Ci} / \mathrm{g}$ \\
\hline 241-AZ-102 & Supernatant & NA (Liquid) & $3.14 \mathrm{E}+02$ & $\mathrm{~S}$ & 1.17 & 3356 & $9.36 \mathrm{E}-02$ & $\mu \mathrm{Ci} / \mathrm{mL}$ \\
\hline 241-AZ-102 & Total & & $4.01 \mathrm{E}+02$ & $\mathrm{~S} / \mathrm{E}$ & & & & \\
\hline 241-B-101 & $\begin{array}{l}\text { Saltcake } \\
\text { Interstitial } \\
\text { Liquid }\end{array}$ & $\begin{array}{l}\text { B-SltCk } \\
\text { (Liquid) }\end{array}$ & 4.80E-01 & $\mathrm{TE}$ & 1.53 & 73 & $6.57 \mathrm{E}-03$ & $\mu \mathrm{Ci} / \mathrm{mL}$ \\
\hline 241-B-101 & Saltcake Solid & $\begin{array}{l}\text { B-SltCk } \\
\text { (Solid) }\end{array}$ & 2.35E-01 & TE & 1.48 & 232 & $6.83 \mathrm{E}-04$ & $\mu \mathrm{Ci} / \mathrm{g}$ \\
\hline 241-B-101 & $\begin{array}{l}\text { Sludge (Liquid } \\
\& \text { Solid) }\end{array}$ & B (Solid) & 6.64E-01 & $\mathrm{TE}$ & 1.74 & 19 & $2.01 \mathrm{E}-02$ & $\mu \mathrm{Ci} / \mathrm{g}$ \\
\hline 241-B-101 & $\begin{array}{l}\text { Sludge (Liquid } \\
\& \text { Solid) }\end{array}$ & BL (Solid) & $4.26 \mathrm{E}-01$ & $\mathrm{TE}$ & 1.5 & 76 & $3.74 \mathrm{E}-03$ & $\mu \mathrm{Ci} / \mathrm{g}$ \\
\hline 241-B-101 & $\begin{array}{l}\text { Sludge (Liquid } \\
\text { \& Solid) }\end{array}$ & MW1 (Solid) & 2.04E-02 & TE & 1.8 & 11 & $1.03 \mathrm{E}-03$ & $\mu \mathrm{Ci} / \mathrm{g}$ \\
\hline 241-B-101 & Total & & $1.83 \mathrm{E}+00$ & $\mathrm{TE}$ & & & & \\
\hline 241-B-102 & $\begin{array}{l}\text { Saltcake } \\
\text { Interstitial } \\
\text { Liquid }\end{array}$ & $\begin{array}{l}\text { B-SltCk } \\
\text { (Liquid) }\end{array}$ & $8.20 \mathrm{E}-02$ & $\mathrm{TE}$ & 1.26 & 25 & $3.28 \mathrm{E}-03$ & $\mu \mathrm{Ci} / \mathrm{mL}$ \\
\hline 241-B-102 & Saltcake Solid & $\begin{array}{l}\text { B-SltCk } \\
\text { (Solid) }\end{array}$ & 8.37E-02 & TE & 1.72 & 81 & $6.01 \mathrm{E}-04$ & $\mu \mathrm{Ci} / \mathrm{g}$ \\
\hline 241-B-102 & Supernatant & $\begin{array}{l}\text { B-SltCk } \\
\text { (Liquid) }\end{array}$ & 4.92E-02 & TE & 1.26 & 15 & $3.28 \mathrm{E}-03$ & $\mu \mathrm{Ci} / \mathrm{mL}$ \\
\hline 241-B-102 & Total & & $2.15 \mathrm{E}-01$ & $\mathrm{TE}$ & & & & \\
\hline 241-B-103 & $\begin{array}{l}\text { Saltcake } \\
\text { Interstitial } \\
\text { Liquid }\end{array}$ & $\begin{array}{l}\text { B-SltCk } \\
\text { (Liquid) }\end{array}$ & $1.64 \mathrm{E}-01$ & $\mathrm{TE}$ & 1.26 & 50 & $3.28 \mathrm{E}-03$ & $\mu \mathrm{Ci} / \mathrm{mL}$ \\
\hline 241-B-103 & Saltcake Solid & $\begin{array}{l}\text { B-SltCk } \\
\text { (Solid) }\end{array}$ & $1.62 \mathrm{E}-01$ & TE & 1.72 & 157 & $6.01 \mathrm{E}-04$ & $\mu \mathrm{Ci} / \mathrm{g}$ \\
\hline
\end{tabular}




\begin{tabular}{|c|c|c|c|c|c|c|c|c|}
\hline Tank Name & Waste Phase & Waste Type & $\begin{array}{l}{ }^{99} \mathrm{Tc} \\
(\mathrm{Ci})\end{array}$ & Basis & $\begin{array}{l}\text { Density } \\
(\mathrm{g} / \mathrm{mL})\end{array}$ & $\begin{array}{c}\text { Volume } \\
(\mathrm{kL})\end{array}$ & Adjusted Conc. & Conc. Units \\
\hline 241-B-103 & $\begin{array}{l}\text { Sludge (Liquid } \\
\text { \& Solid) }\end{array}$ & MW1 (Solid) & $7.42 \mathrm{E}-03$ & $\mathrm{TE}$ & 1.8 & 4 & $1.03 \mathrm{E}-03$ & $\mu \mathrm{Ci} / \mathrm{g}$ \\
\hline 241-B-103 & Total & & $3.34 \mathrm{E}-01$ & $\mathrm{TE}$ & & & & \\
\hline 241-B-104 & $\begin{array}{l}\text { Saltcake } \\
\text { Interstitial } \\
\text { Liquid }\end{array}$ & $\begin{array}{l}\text { B-SltCk } \\
\text { (Liquid) }\end{array}$ & $1.80 \mathrm{E}-01$ & $\mathrm{TE}$ & 1.26 & 55 & $3.28 \mathrm{E}-03$ & $\mu \mathrm{Ci} / \mathrm{mL}$ \\
\hline 241-B-104 & Saltcake Solid & $\begin{array}{l}\text { B-SltCk } \\
\text { (Solid) }\end{array}$ & $1.43 \mathrm{E}-01$ & $\mathrm{TE}$ & 1.39 & 192 & $5.35 \mathrm{E}-04$ & $\mu \mathrm{Ci} / \mathrm{g}$ \\
\hline 241-B-104 & $\begin{array}{l}\text { Sludge (Liquid } \\
\text { \& Solid) }\end{array}$ & $1 \mathrm{C}$ (Solid) & $1.86 \mathrm{E}+01$ & TS & 1.39 & 473 & $2.82 \mathrm{E}-02$ & $\mu \mathrm{Ci} / \mathrm{g}$ \\
\hline 241-B-104 & $\begin{array}{l}\text { Sludge (Liquid } \\
\& \text { Solid) }\end{array}$ & 2C (Solid) & $1.50 \mathrm{E}-03$ & $\mathrm{TE}$ & 1.39 & 697 & $1.54 \mathrm{E}-06$ & $\mu \mathrm{Ci} / \mathrm{g}$ \\
\hline 241-B-104 & Total & & $1.89 \mathrm{E}+01$ & $\mathrm{TS} / \mathrm{TE}$ & & & & \\
\hline 241-B-105 & $\begin{array}{l}\text { Saltcake } \\
\text { Interstitial } \\
\text { Liquid }\end{array}$ & $\begin{array}{l}\text { B-SltCk } \\
\text { (Liquid) }\end{array}$ & $2.39 \mathrm{E}-01$ & $\mathrm{TE}$ & 1.26 & 73 & $3.28 \mathrm{E}-03$ & $\mu \mathrm{Ci} / \mathrm{mL}$ \\
\hline 241-B-105 & Saltcake Solid & $\begin{array}{l}\text { B-SltCk } \\
\text { (Solid) }\end{array}$ & $9.50 \mathrm{E}-01$ & $\mathrm{TE}$ & 1.72 & 919 & $6.01 \mathrm{E}-04$ & $\mu \mathrm{Ci} / \mathrm{g}$ \\
\hline 241-B-105 & $\begin{array}{l}\text { Sludge (Liquid } \\
\text { \& Solid) }\end{array}$ & 1C (Solid) & $1.56 \mathrm{E}+00$ & TS & 1.43 & 45 & $2.43 \mathrm{E}-02$ & $\mu \mathrm{Ci} / \mathrm{g}$ \\
\hline 241-B-105 & $\begin{array}{l}\text { Sludge (Liquid } \\
\text { \& Solid) }\end{array}$ & 2C (Solid) & $7.57 \mathrm{E}-05$ & $\mathrm{TE}$ & 1.28 & 61 & $9.70 \mathrm{E}-07$ & $\mu \mathrm{Ci} / \mathrm{g}$ \\
\hline 241-B-105 & Total & & $2.75 \mathrm{E}+00$ & $\mathrm{TS} / \mathrm{TE}$ & & & & \\
\hline 241-B-106 & $\begin{array}{l}\text { Sludge (Liquid } \\
\text { \& Solid) }\end{array}$ & 1C (Solid) & $5.30 \mathrm{E}+00$ & TS & 1.42 & 163 & $2.29 \mathrm{E}-02$ & $\mu \mathrm{Ci} / \mathrm{g}$ \\
\hline 241-B-106 & $\begin{array}{l}\text { Sludge (Liquid } \\
\text { \& Solid) }\end{array}$ & TBP (Solid) & 3.09E-01 & $\mathrm{TE}$ & 1.36 & 297 & $7.64 \mathrm{E}-04$ & $\mu \mathrm{Ci} / \mathrm{g}$ \\
\hline 241-B-106 & Supernatant & $\begin{array}{l}\text { B-SltCk } \\
\text { (Liquid) }\end{array}$ & $1.31 \mathrm{E}-02$ & $\mathrm{TE}$ & 1.26 & 4 & $3.28 \mathrm{E}-03$ & $\mu \mathrm{Ci} / \mathrm{mL}$ \\
\hline 241-B-106 & Total & & $5.62 \mathrm{E}+00$ & $\mathrm{TS} / \mathrm{TE}$ & & & & \\
\hline 241-B-107 & $\begin{array}{l}\text { Saltcake } \\
\text { Interstitial } \\
\text { Liquid } \\
\end{array}$ & $\begin{array}{l}\text { B-SltCk } \\
\text { (Liquid) }\end{array}$ & $3.33 \mathrm{E}-01$ & $\mathrm{TE}$ & 1.34 & 68 & $4.89 \mathrm{E}-03$ & $\mu \mathrm{Ci} / \mathrm{mL}$ \\
\hline
\end{tabular}




\begin{tabular}{|c|c|c|c|c|c|c|c|c|}
\hline Tank Name & Waste Phase & Waste Type & $\begin{array}{l}{ }^{99} \mathrm{Tc} \\
(\mathrm{Ci})\end{array}$ & Basis & $\begin{array}{l}\text { Density } \\
(\mathrm{g} / \mathrm{mL})\end{array}$ & $\begin{array}{c}\text { Volume } \\
(\mathrm{kL})\end{array}$ & Adjusted Conc. & Conc. Units \\
\hline 241-B-107 & Saltcake Solid & $\begin{array}{l}\text { B-SltCk } \\
\text { (Solid) }\end{array}$ & $2.47 \mathrm{E}-01$ & $\mathrm{TE}$ & 1.7 & 216 & $6.73 \mathrm{E}-04$ & $\mu \mathrm{Ci} / \mathrm{g}$ \\
\hline 241-B-107 & $\begin{array}{l}\text { Sludge (Liquid } \\
\& \text { Solid) }\end{array}$ & 1C (Solid) & $1.42 \mathrm{E}+01$ & TS & 1.63 & 285 & 3.07E-02 & $\mu \mathrm{Ci} / \mathrm{g}$ \\
\hline 241-B-107 & $\begin{array}{l}\text { Sludge (Liquid } \\
\& \text { Solid) }\end{array}$ & CWP2 (Solid) & $9.31 \mathrm{E}-03$ & $\mathrm{TE}$ & 1.68 & 42 & $1.32 \mathrm{E}-04$ & $\mu \mathrm{Ci} / \mathrm{g}$ \\
\hline 241-B-107 & Total & & $1.48 \mathrm{E}+01$ & TS/TE & & & & \\
\hline 241-B-108 & $\begin{array}{l}\text { Saltcake } \\
\text { Interstitial } \\
\text { Liquid }\end{array}$ & $\begin{array}{l}\text { B-SltCk } \\
\text { (Liquid) }\end{array}$ & $1.51 \mathrm{E}-01$ & TE & 1.38 & 42 & $3.60 \mathrm{E}-03$ & $\mu \mathrm{Ci} / \mathrm{mL}$ \\
\hline 241-B-108 & Saltcake Solid & $\begin{array}{l}\text { B-SltCk } \\
\text { (Solid) }\end{array}$ & $2.35 \mathrm{E}-01$ & TE & 1.72 & 204 & $6.70 \mathrm{E}-04$ & $\mu \mathrm{Ci} / \mathrm{g}$ \\
\hline 241-B-108 & $\begin{array}{l}\text { Sludge (Liquid } \\
\text { \& Solid) }\end{array}$ & CWP2 (Solid) & $3.10 \mathrm{E}-02$ & $\mathrm{TE}$ & 1.8 & 104 & $1.65 \mathrm{E}-04$ & $\mu \mathrm{Ci} / \mathrm{g}$ \\
\hline 241-B-108 & Total & & 4.17E-01 & $\mathrm{TE}$ & & & & \\
\hline 241-B-109 & $\begin{array}{l}\text { Saltcake } \\
\text { Interstitial } \\
\text { Liquid }\end{array}$ & $\begin{array}{l}\text { B-SltCk } \\
\text { (Liquid) }\end{array}$ & $1.34 \mathrm{E}-01$ & $\mathrm{TE}$ & 1.26 & 41 & $3.28 \mathrm{E}-03$ & $\mu \mathrm{Ci} / \mathrm{mL}$ \\
\hline 241-B-109 & Saltcake Solid & $\begin{array}{l}\text { B-SltCk } \\
\text { (Solid) }\end{array}$ & $2.87 \mathrm{E}-01$ & $\mathrm{TE}$ & 1.89 & 245 & $6.19 \mathrm{E}-04$ & $\mu \mathrm{Ci} / \mathrm{g}$ \\
\hline 241-B-109 & $\begin{array}{l}\text { Sludge (Liquid } \\
\text { \& Solid) }\end{array}$ & CWP2 (Solid) & 4.98E-02 & $\mathrm{TE}$ & 1.85 & 189 & $1.43 \mathrm{E}-04$ & $\mu \mathrm{Ci} / \mathrm{g}$ \\
\hline 241-B-109 & Total & & $4.71 \mathrm{E}-01$ & $\mathrm{TE}$ & & & & \\
\hline 241-B-110 & $\begin{array}{l}\text { Sludge (Liquid } \\
\& \text { Solid) }\end{array}$ & 2C (Solid) & $2.05 \mathrm{E}+01$ & $\mathrm{E}$ & 1.36 & 914 & $1.65 \mathrm{E}-02$ & $\mu \mathrm{Ci} / \mathrm{g}$ \\
\hline 241-B-110 & $\begin{array}{l}\text { Sludge (Liquid } \\
\text { \& Solid) }\end{array}$ & B (Solid) & $2.47 \mathrm{E}-01$ & $\mathrm{E}$ & 1.36 & 11 & $1.65 \mathrm{E}-02$ & $\mu \mathrm{Ci} / \mathrm{g}$ \\
\hline 241-B-110 & Supernatant & CSR (Liquid) & $5.76 \mathrm{E}-01$ & $\mathrm{TE}$ & 1.19 & 4 & $1.44 \mathrm{E}-01$ & $\mu \mathrm{Ci} / \mathrm{mL}$ \\
\hline 241-B-110 & Total & & $2.13 \mathrm{E}+01$ & $\mathrm{E} / \mathrm{TE}$ & & & & \\
\hline 241-B-111 & $\begin{array}{l}\text { Sludge (Liquid } \\
\text { \& Solid) }\end{array}$ & 2C (Solid) & $1.17 \mathrm{E}+02$ & S & 1.27 & 809 & $1.14 \mathrm{E}-01$ & $\mu \mathrm{Ci} / \mathrm{g}$ \\
\hline 241-B-111 & $\begin{array}{l}\text { Sludge (Liquid } \\
\text { \& Solid) }\end{array}$ & B (Solid) & $1.46 \mathrm{E}+01$ & $\mathrm{~S}$ & 1.27 & 101 & $1.14 \mathrm{E}-01$ & $\mu \mathrm{Ci} / \mathrm{g}$ \\
\hline 241-B-111 & Supernatant & CSR (Liquid) & $5.76 \mathrm{E}-01$ & $\mathrm{TE}$ & 1.19 & 4 & $1.44 \mathrm{E}-01$ & $\mu \mathrm{Ci} / \mathrm{mL}$ \\
\hline
\end{tabular}




\begin{tabular}{|c|c|c|c|c|c|c|c|c|}
\hline Tank Name & Waste Phase & Waste Type & $\begin{array}{l}{ }^{99} \mathrm{Tc} \\
(\mathrm{Ci})\end{array}$ & Basis & $\begin{array}{l}\text { Density } \\
(\mathrm{g} / \mathrm{mL})\end{array}$ & $\begin{array}{c}\text { Volume } \\
(\mathrm{kL})\end{array}$ & Adjusted Conc. & Conc. Units \\
\hline $241-B-111$ & Total & & $1.32 \mathrm{E}+02$ & $\mathrm{~S} / \mathrm{TE}$ & & & & \\
\hline 241-B-112 & $\begin{array}{l}\text { Saltcake } \\
\text { Interstitial } \\
\text { Liquid }\end{array}$ & $\begin{array}{l}\text { BY-SltCk } \\
\text { (Liquid) }\end{array}$ & $3.15 \mathrm{E}+00$ & $\mathrm{TE}$ & 1.51 & 16 & $1.97 \mathrm{E}-01$ & $\mu \mathrm{Ci} / \mathrm{mL}$ \\
\hline 241-B-112 & Saltcake Solid & $\begin{array}{l}\text { BY-SltCk } \\
\text { (Solid) }\end{array}$ & $3.83 \mathrm{E}+00$ & $\mathrm{TE}$ & 1.49 & 49 & $5.24 \mathrm{E}-02$ & $\mu \mathrm{Ci} / \mathrm{g}$ \\
\hline 241-B-112 & $\begin{array}{l}\text { Sludge (Liquid } \\
\text { \& Solid) }\end{array}$ & 2C (Solid) & $1.44 \mathrm{E}-04$ & $\mathrm{TE}$ & 1.49 & 56 & $1.73 \mathrm{E}-06$ & $\mu \mathrm{Ci} / \mathrm{g}$ \\
\hline 241-B-112 & Supernatant & $\begin{array}{l}\text { BY-SltCk } \\
\text { (Liquid) }\end{array}$ & $2.17 \mathrm{E}+00$ & $\mathrm{TE}$ & 1.51 & 11 & $1.97 \mathrm{E}-01$ & $\mu \mathrm{Ci} / \mathrm{mL}$ \\
\hline 241-B-112 & Total & & $9.15 \mathrm{E}+00$ & $\mathrm{TE}$ & & & & \\
\hline 241-B-201 & $\begin{array}{l}\text { Sludge (Liquid } \\
\& \text { Solid) }\end{array}$ & 224-1 (Solid) & $1.72 \mathrm{E}-06$ & TE & 1.26 & 111 & $1.23 \mathrm{E}-08$ & $\mu \mathrm{Ci} / \mathrm{g}$ \\
\hline 241-B-201 & Total & & $1.72 \mathrm{E}-06$ & $\mathrm{TE}$ & & & & \\
\hline 241-B-202 & $\begin{array}{l}\text { Sludge (Liquid } \\
\& \text { Solid) }\end{array}$ & 224-2 (Solid) & $6.85 \mathrm{E}-01$ & $\mathrm{~S}$ & 1.22 & 108 & $5.20 \mathrm{E}-03$ & $\mu \mathrm{Ci} / \mathrm{g}$ \\
\hline 241-B-202 & Total & & $6.85 \mathrm{E}-01$ & $\mathrm{~S}$ & & & & \\
\hline 241-B-203 & $\begin{array}{l}\text { Sludge (Liquid } \\
\& \text { Solid) }\end{array}$ & 224-2 (Solid) & 4.07E-06 & $\mathrm{TE}$ & 1.19 & 188 & $1.82 \mathrm{E}-08$ & $\mu \mathrm{Ci} / \mathrm{g}$ \\
\hline 241-B-203 & Supernatant & NA (Liquid) & $8.86 \mathrm{E}-08$ & $\mathrm{TE}$ & 1.05 & 2 & 4.43E-08 & $\mu \mathrm{Ci} / \mathrm{mL}$ \\
\hline 241-B-203 & Total & & $4.16 \mathrm{E}-06$ & $\mathrm{TE}$ & & & & \\
\hline 241-B-204 & $\begin{array}{l}\text { Sludge (Liquid } \\
\& \text { Solid) }\end{array}$ & 224-2 (Solid) & $3.72 \mathrm{E}-06$ & $\mathrm{TE}$ & 1.19 & 184 & $1.70 \mathrm{E}-08$ & $\mu \mathrm{Ci} / \mathrm{g}$ \\
\hline 241-B-204 & Supernatant & NA (Liquid) & $6.58 \mathrm{E}-08$ & TE & 1.05 & 3 & $2.19 \mathrm{E}-08$ & $\mu \mathrm{Ci} / \mathrm{mL}$ \\
\hline 241-B-204 & Total & & $3.79 \mathrm{E}-06$ & $\mathrm{TE}$ & & & & \\
\hline 241-BX-101 & $\begin{array}{l}\text { Sludge (Liquid } \\
\& \text { Solid) }\end{array}$ & BL (Solid) & $4.25 \mathrm{E}+00$ & $\mathrm{E}$ & 1.68 & 74 & $3.42 \mathrm{E}-02$ & $\mu \mathrm{Ci} / \mathrm{g}$ \\
\hline 241-BX-101 & $\begin{array}{l}\text { Sludge (Liquid } \\
\& \text { Solid) }\end{array}$ & CWP2 (Solid) & $2.70 \mathrm{E}+00$ & $\mathrm{E}$ & 1.68 & 47 & $3.42 \mathrm{E}-02$ & $\mu \mathrm{Ci} / \mathrm{g}$ \\
\hline 241-BX-101 & $\begin{array}{l}\text { Sludge (Liquid } \\
\text { \& Solid) }\end{array}$ & TBP (Solid) & $3.39 \mathrm{E}+00$ & $\mathrm{E}$ & 1.68 & 59 & $3.42 \mathrm{E}-02$ & $\mu \mathrm{Ci} / \mathrm{g}$ \\
\hline 241-BX-101 & Total & & $1.03 \mathrm{E}+01$ & E & & & & \\
\hline 241-BX-102 & Sludge Solid & CWP2 (Solid) & $1.80 \mathrm{E}-02$ & TE & 1.68 & 81 & $1.32 \mathrm{E}-04$ & $\mu \mathrm{Ci} / \mathrm{g}$ \\
\hline 241-BX-102 & Sludge Solid & DE (Solid) & $0.00 \mathrm{E}+00$ & $\mathrm{E}$ & 0.65 & 147 & $0.00 \mathrm{E}+00$ & $\mu \mathrm{Ci} / \mathrm{g}$ \\
\hline
\end{tabular}




\begin{tabular}{|c|c|c|c|c|c|c|c|c|}
\hline Tank Name & Waste Phase & Waste Type & $\begin{array}{l}{ }^{99} \mathrm{Tc} \\
(\mathrm{Ci})\end{array}$ & Basis & $\begin{array}{l}\text { Density } \\
(\mathrm{g} / \mathrm{mL})\end{array}$ & $\begin{array}{l}\text { Volume } \\
\text { (kL) }\end{array}$ & Adjusted Conc. & Conc. Units \\
\hline 241-BX-102 & Sludge Solid & TBP (Solid) & $1.01 \mathrm{E}-01$ & TE & 1.47 & 70 & $9.85 \mathrm{E}-04$ & $\mu \mathrm{Ci} / \mathrm{g}$ \\
\hline 241-BX-102 & Total & & 1.19E-01 & $\mathrm{E} / \mathrm{TE}$ & & & & \\
\hline 241-BX-103 & $\begin{array}{l}\text { Sludge (Liquid } \\
\text { \& Solid) }\end{array}$ & CWP2 (Solid) & 4.05E-02 & $\mathrm{TE}$ & 1.68 & 214 & $1.13 \mathrm{E}-04$ & $\mu \mathrm{Ci} / \mathrm{g}$ \\
\hline 241-BX-103 & $\begin{array}{l}\text { Sludge (Liquid } \\
\text { \& Solid) }\end{array}$ & TBP (Solid) & $3.10 \mathrm{E}-02$ & TE & 1.47 & 21 & $1.00 \mathrm{E}-03$ & $\mu \mathrm{Ci} / \mathrm{g}$ \\
\hline 241-BX-103 & Supernatant & $\begin{array}{l}\text { CWP2 } \\
\text { (Liquid) }\end{array}$ & $1.05 \mathrm{E}-02$ & TE & 1.07 & 50 & 2.09E-04 & $\mu \mathrm{Ci} / \mathrm{mL}$ \\
\hline 241-BX-103 & Total & & 8.19E-02 & $\mathrm{TE}$ & & & & \\
\hline 241-BX-104 & $\begin{array}{l}\text { Sludge (Liquid } \\
\text { \& Solid) }\end{array}$ & CWP2 (Solid) & $6.25 \mathrm{E}+00$ & $\mathrm{E}$ & 1.68 & 51 & 7.29E-02 & $\mu \mathrm{Ci} / \mathrm{g}$ \\
\hline 241-BX-104 & $\begin{array}{l}\text { Sludge (Liquid } \\
\text { \& Solid) }\end{array}$ & CWR1 (Solid) & $1.35 \mathrm{E}+01$ & $\mathrm{E}$ & 1.68 & 110 & 7.29E-02 & $\mu \mathrm{Ci} / \mathrm{g}$ \\
\hline 241-BX-104 & $\begin{array}{l}\text { Sludge (Liquid } \\
\text { \& Solid) }\end{array}$ & MW1 (Solid) & $1.90 \mathrm{E}+01$ & $\mathrm{E}$ & 1.68 & 155 & 7.29E-02 & $\mu \mathrm{Ci} / \mathrm{g}$ \\
\hline 241-BX-104 & $\begin{array}{l}\text { Sludge (Liquid } \\
\text { \& Solid) }\end{array}$ & TBP (Solid) & $6.49 \mathrm{E}+00$ & $\mathrm{E}$ & 1.68 & 53 & 7.29E-02 & $\mu \mathrm{Ci} / \mathrm{g}$ \\
\hline 241-BX-104 & Supernatant & $\begin{array}{l}\text { CWR1 } \\
\text { (Liquid) }\end{array}$ & $1.32 \mathrm{E}+00$ & $\mathrm{E}$ & 1.28 & 11 & $1.20 \mathrm{E}-01$ & $\mu \mathrm{Ci} / \mathrm{mL}$ \\
\hline 241-BX-104 & Total & & $4.65 \mathrm{E}+01$ & $\mathrm{E}$ & & & & \\
\hline 241-BX-105 & $\begin{array}{l}\text { Saltcake (Liquid } \\
\text { \& Solid) }\end{array}$ & $\begin{array}{l}\text { BY-SltCk } \\
\text { (Solid) }\end{array}$ & $2.24 \mathrm{E}+01$ & $\mathrm{E}$ & 1.69 & 94 & $1.41 \mathrm{E}-01$ & $\mu \mathrm{Ci} / \mathrm{g}$ \\
\hline 241-BX-105 & $\begin{array}{l}\text { Sludge (Liquid } \\
\text { \& Solid) }\end{array}$ & CWP2 (Solid) & $2.29 \mathrm{E}+01$ & $\mathrm{E}$ & 1.69 & 96 & $1.41 \mathrm{E}-01$ & $\mu \mathrm{Ci} / \mathrm{g}$ \\
\hline 241-BX-105 & $\begin{array}{l}\text { Sludge (Liquid } \\
\text { \& Solid) }\end{array}$ & MW1 (Solid) & $1.67 \mathrm{E}-02$ & TE & 1.8 & 9 & $1.03 \mathrm{E}-03$ & $\mu \mathrm{Ci} / \mathrm{g}$ \\
\hline 241-BX-105 & $\begin{array}{l}\text { Sludge (Liquid } \\
\text { \& Solid) }\end{array}$ & TBP (Solid) & $1.31 \mathrm{E}+01$ & $\mathrm{E}$ & 1.69 & 55 & $1.41 \mathrm{E}-01$ & $\mu \mathrm{Ci} / \mathrm{g}$ \\
\hline 241-BX-105 & Supernatant & $\begin{array}{l}\text { CWP2 } \\
\text { (Liquid) }\end{array}$ & $2.05 \mathrm{E}+00$ & $\mathrm{E}$ & 1.29 & 18 & $1.14 \mathrm{E}-01$ & $\mu \mathrm{Ci} / \mathrm{mL}$ \\
\hline 241-BX-105 & Total & & $6.04 \mathrm{E}+01$ & $\mathrm{E} / \mathrm{TE}$ & & & & \\
\hline 241-BX-106 & $\begin{array}{l}\text { Saltcake } \\
\text { Interstitial } \\
\text { Liquid }\end{array}$ & $\begin{array}{l}\text { BY-SltCk } \\
\text { (Liquid) }\end{array}$ & $4.92 \mathrm{E}+00$ & $\mathrm{TE}$ & 1.51 & 25 & $1.97 \mathrm{E}-01$ & $\mu \mathrm{Ci} / \mathrm{mL}$ \\
\hline
\end{tabular}




\begin{tabular}{|c|c|c|c|c|c|c|c|c|}
\hline Tank Name & Waste Phase & Waste Type & $\begin{array}{l}{ }^{99} \mathrm{Tc} \\
(\mathrm{Ci})\end{array}$ & Basis & $\begin{array}{l}\text { Density } \\
(\mathrm{g} / \mathrm{mL})\end{array}$ & $\begin{array}{c}\text { Volume } \\
(\mathrm{kL})\end{array}$ & Adjusted Conc. & Conc. Units \\
\hline $241-\mathrm{BX}-106$ & Saltcake Solid & $\begin{array}{l}\text { BY-SltCk } \\
\text { (Solid) }\end{array}$ & $7.04 \mathrm{E}+00$ & $\mathrm{TE}$ & 1.64 & 80 & $5.37 \mathrm{E}-02$ & $\mu \mathrm{Ci} / \mathrm{g}$ \\
\hline 241-BX-106 & $\begin{array}{l}\text { Sludge (Liquid } \\
\& \text { Solid) }\end{array}$ & CWP2 (Solid) & 4.04E-03 & $\mathrm{TE}$ & 1.64 & 18 & $1.37 \mathrm{E}-04$ & $\mu \mathrm{Ci} / \mathrm{g}$ \\
\hline 241-BX-106 & $\begin{array}{l}\text { Sludge (Liquid } \\
\text { \& Solid) }\end{array}$ & TBP (Solid) & $4.00 \mathrm{E}-02$ & $\mathrm{TE}$ & 1.64 & 20 & $1.22 \mathrm{E}-03$ & $\mu \mathrm{Ci} / \mathrm{g}$ \\
\hline 241-BX-106 & Total & & $1.20 \mathrm{E}+01$ & $\mathrm{TE}$ & & & & \\
\hline 241-BX-107 & $\begin{array}{l}\text { Sludge (Liquid } \\
\& \text { Solid) }\end{array}$ & 1C (Solid) & $6.98 \mathrm{E}+01$ & $\mathrm{~S}$ & 1.44 & 1313 & $3.69 \mathrm{E}-02$ & $\mu \mathrm{Ci} / \mathrm{g}$ \\
\hline 241-BX-107 & Total & & $6.98 \mathrm{E}+01$ & $\mathrm{~S}$ & & & & \\
\hline 241-BX-108 & $\begin{array}{l}\text { Sludge (Liquid } \\
\& \text { Solid) }\end{array}$ & 1C (Solid) & $2.38 \mathrm{E}+00$ & TS & 1.43 & 38 & $4.38 \mathrm{E}-02$ & $\mu \mathrm{Ci} / \mathrm{g}$ \\
\hline 241-BX-108 & $\begin{array}{l}\text { Sludge (Liquid } \\
\& \text { Solid) }\end{array}$ & TBP (Solid) & $1.96 \mathrm{E}-01$ & $\mathrm{TE}$ & 1.47 & 81 & $1.65 \mathrm{E}-03$ & $\mu \mathrm{Ci} / \mathrm{g}$ \\
\hline 241-BX-108 & Total & & $2.58 \mathrm{E}+00$ & $\mathrm{TS} / \mathrm{TE}$ & & & & \\
\hline 241-BX-109 & $\begin{array}{l}\text { Sludge (Liquid } \\
\text { \& Solid) }\end{array}$ & TBP (Solid) & $1.09 \mathrm{E}+00$ & $\mathrm{TE}$ & 1.52 & 730 & $9.83 \mathrm{E}-04$ & $\mu \mathrm{Ci} / \mathrm{g}$ \\
\hline 241-BX-109 & Total & & $1.09 \mathrm{E}+00$ & $\mathrm{TE}$ & & & & \\
\hline 241-BX-110 & $\begin{array}{l}\text { Saltcake } \\
\text { Interstitial } \\
\text { Liquid }\end{array}$ & $\begin{array}{l}\text { BY-SltCk } \\
\text { (Liquid) }\end{array}$ & $2.12 \mathrm{E}+01$ & $\mathrm{TE}$ & 1.44 & 129 & $1.64 \mathrm{E}-01$ & $\mu \mathrm{Ci} / \mathrm{mL}$ \\
\hline 241-BX-110 & Saltcake Solid & $\begin{array}{l}\text { BY-SltCk } \\
\text { (Solid) }\end{array}$ & $4.30 \mathrm{E}+01$ & $\mathrm{TE}$ & 1.79 & 433 & $5.55 \mathrm{E}-02$ & $\mu \mathrm{Ci} / \mathrm{g}$ \\
\hline 241-BX-110 & $\begin{array}{l}\text { Sludge (Liquid } \\
\text { \& Solid) }\end{array}$ & 1C (Solid) & $5.25 \mathrm{E}+00$ & TS & 1.43 & 151 & $2.43 \mathrm{E}-02$ & $\mu \mathrm{Ci} / \mathrm{g}$ \\
\hline 241-BX-110 & $\begin{array}{l}\text { Sludge (Liquid } \\
\text { \& Solid) }\end{array}$ & NA (Sludge) & $5.65 \mathrm{E}+00$ & $\mathrm{TS}$ & 1.79 & 94 & $3.36 \mathrm{E}-02$ & $\mu \mathrm{Ci} / \mathrm{g}$ \\
\hline 241-BX-110 & Supernatant & $\begin{array}{l}\text { BY-SltCk } \\
\text { (Liquid) }\end{array}$ & $8.20 \mathrm{E}-01$ & $\mathrm{TE}$ & 1.44 & 5 & $1.64 \mathrm{E}-01$ & $\mu \mathrm{Ci} / \mathrm{mL}$ \\
\hline 241-BX-110 & Total & & $7.59 \mathrm{E}+01$ & $\mathrm{TS} / \mathrm{TE}$ & & & & \\
\hline 241-BX-111 & $\begin{array}{l}\text { Saltcake } \\
\text { Interstitial } \\
\text { Liquid } \\
\end{array}$ & $\begin{array}{l}\text { BY-SltCk } \\
\text { (Liquid) }\end{array}$ & $9.28 \mathrm{E}+00$ & $\mathrm{TE}$ & 1.45 & 54 & $1.72 \mathrm{E}-01$ & $\mu \mathrm{Ci} / \mathrm{mL}$ \\
\hline
\end{tabular}




\begin{tabular}{|c|c|c|c|c|c|c|c|c|}
\hline Tank Name & Waste Phase & Waste Type & $\begin{array}{l}{ }^{99} \mathrm{Tc} \\
(\mathrm{Ci})\end{array}$ & Basis & $\begin{array}{l}\text { Density } \\
(\mathrm{g} / \mathrm{mL})\end{array}$ & $\begin{array}{c}\text { Volume } \\
(\mathrm{kL})\end{array}$ & Adjusted Conc. & Conc. Units \\
\hline 241-BX-111 & Saltcake Solid & $\begin{array}{l}\text { BY-SltCk } \\
\text { (Solid) }\end{array}$ & $5.76 \mathrm{E}+01$ & $\mathrm{TE}$ & 1.45 & 538 & $7.39 \mathrm{E}-02$ & $\mu \mathrm{Ci} / \mathrm{g}$ \\
\hline 241-BX-111 & $\begin{array}{l}\text { Sludge (Liquid } \\
\text { \& Solid) }\end{array}$ & 1C (Solid) & $4.20 \mathrm{E}+00$ & TS & 1.43 & 121 & $2.43 \mathrm{E}-02$ & $\mu \mathrm{Ci} / \mathrm{g}$ \\
\hline 241-BX-111 & Total & & $7.11 \mathrm{E}+01$ & $\mathrm{TS} / \mathrm{TE}$ & & & & \\
\hline 241-BX-112 & $\begin{array}{l}\text { Sludge (Liquid } \\
\& \text { Solid) }\end{array}$ & 1C (Solid) & $1.57 \mathrm{E}+01$ & $\mathrm{TS}$ & 1.31 & 617 & $1.94 \mathrm{E}-02$ & $\mu \mathrm{Ci} / \mathrm{g}$ \\
\hline 241-BX-112 & Supernatant & 1C2 (Liquid) & $2.04 \mathrm{E}-03$ & $\mathrm{TE}$ & 1.18 & 5 & $4.07 \mathrm{E}-04$ & $\mu \mathrm{Ci} / \mathrm{mL}$ \\
\hline 241-BX-112 & Total & & $1.57 \mathrm{E}+01$ & $\mathrm{TS} / \mathrm{TE}$ & & & & \\
\hline 241-BY-101 & $\begin{array}{l}\text { Saltcake } \\
\text { Interstitial } \\
\text { Liquid }\end{array}$ & $\begin{array}{l}\text { BY-SltCk } \\
\text { (Liquid) }\end{array}$ & $1.02 \mathrm{E}+01$ & $\mathrm{TE}$ & 1.51 & 52 & $1.97 \mathrm{E}-01$ & $\mu \mathrm{Ci} / \mathrm{mL}$ \\
\hline 241-BY-101 & Saltcake Solid & $\begin{array}{l}\text { BY-SltCk } \\
\text { (Solid) }\end{array}$ & $1.57 \mathrm{E}+02$ & $\mathrm{TE}$ & 1.87 & 1208 & $6.97 \mathrm{E}-02$ & $\mu \mathrm{Ci} / \mathrm{g}$ \\
\hline 241-BY-101 & $\begin{array}{l}\text { Sludge (Liquid } \\
\& \text { Solid) }\end{array}$ & PFeCN (Solid) & $1.94 \mathrm{E}-01$ & $\mathrm{TE}$ & 1.68 & 140 & $8.24 \mathrm{E}-04$ & $\mu \mathrm{Ci} / \mathrm{g}$ \\
\hline 241-BY-101 & Total & & $1.68 \mathrm{E}+02$ & $\mathrm{TE}$ & & & & \\
\hline 241-BY-102 & $\begin{array}{l}\text { Saltcake } \\
\text { Interstitial } \\
\text { Liquid }\end{array}$ & $\begin{array}{l}\text { BY-SltCk } \\
\text { (Liquid) }\end{array}$ & $2.74 \mathrm{E}+01$ & $\mathrm{TE}$ & 1.46 & 157 & $1.75 \mathrm{E}-01$ & $\mu \mathrm{Ci} / \mathrm{mL}$ \\
\hline 241-BY-102 & Saltcake Solid & $\begin{array}{l}\text { BY-SltCk } \\
\text { (Solid) }\end{array}$ & $9.01 \mathrm{E}+01$ & TE & 1.59 & 897 & $6.32 \mathrm{E}-02$ & $\mu \mathrm{Ci} / \mathrm{g}$ \\
\hline 241-BY-102 & Total & & $1.18 \mathrm{E}+02$ & $\mathrm{TE}$ & & & & \\
\hline 241-BY-103 & $\begin{array}{l}\text { Saltcake } \\
\text { Interstitial } \\
\text { Liquid }\end{array}$ & $\begin{array}{l}\text { BY-SltCk } \\
\text { (Liquid) }\end{array}$ & $2.30 \mathrm{E}+01$ & $\mathrm{TE}$ & 1.29 & 214 & $1.07 \mathrm{E}-01$ & $\mu \mathrm{Ci} / \mathrm{mL}$ \\
\hline 241-BY-103 & Saltcake Solid & $\begin{array}{l}\text { BY-SltCk } \\
\text { (Solid) }\end{array}$ & $1.55 \mathrm{E}+02$ & TE & 1.72 & 1316 & $6.86 \mathrm{E}-02$ & $\mu \mathrm{Ci} / \mathrm{g}$ \\
\hline 241-BY-103 & $\begin{array}{l}\text { Sludge (Liquid } \\
\text { \& Solid) }\end{array}$ & CWP2 (Solid) & 7.54E-03 & TE & 1.68 & 34 & $1.32 \mathrm{E}-04$ & $\mu \mathrm{Ci} / \mathrm{g}$ \\
\hline 241-BY-103 & Total & & $1.78 \mathrm{E}+02$ & $\mathrm{TE}$ & & & & \\
\hline 241-BY-104 & $\begin{array}{l}\text { Saltcake } \\
\text { Interstitial } \\
\text { Liquid }\end{array}$ & $\begin{array}{l}\text { BY-SltCk } \\
\text { (Liquid) }\end{array}$ & $2.87 \mathrm{E}+01$ & $\mathrm{TE}$ & 1.51 & 153 & $1.87 \mathrm{E}-01$ & $\mu \mathrm{Ci} / \mathrm{mL}$ \\
\hline
\end{tabular}




\begin{tabular}{|c|c|c|c|c|c|c|c|c|}
\hline Tank Name & Waste Phase & Waste Type & $\begin{array}{l}{ }^{99} \mathrm{Tc} \\
(\mathrm{Ci})\end{array}$ & Basis & $\begin{array}{l}\text { Density } \\
(\mathrm{g} / \mathrm{mL})\end{array}$ & $\begin{array}{l}\text { Volume } \\
\text { (kL) }\end{array}$ & Adjusted Conc. & Conc. Units \\
\hline $241-B Y-104$ & Saltcake Solid & $\begin{array}{l}\text { BY-SltCk } \\
\text { (Solid) }\end{array}$ & $1.43 \mathrm{E}+02$ & $\mathrm{TE}$ & 1.75 & 1208 & $6.75 \mathrm{E}-02$ & $\mu \mathrm{Ci} / \mathrm{g}$ \\
\hline 241-BY-104 & $\begin{array}{l}\text { Sludge (Liquid } \\
\text { \& Solid) }\end{array}$ & PFeCN (Solid) & $2.44 \mathrm{E}-01$ & $\mathrm{TE}$ & 1.64 & 172 & $8.65 \mathrm{E}-04$ & $\mu \mathrm{Ci} / \mathrm{g}$ \\
\hline 241-BY-104 & Total & & $1.72 \mathrm{E}+02$ & $\mathrm{TE}$ & & & & \\
\hline 241-BY-105 & $\begin{array}{l}\text { Saltcake } \\
\text { Interstitial } \\
\text { Liquid }\end{array}$ & $\begin{array}{l}\text { BY-SltCk } \\
\text { (Liquid) }\end{array}$ & $1.35 \mathrm{E}+01$ & $\mathrm{~S}$ & 1.44 & 159 & $8.48 \mathrm{E}-02$ & $\mu \mathrm{Ci} / \mathrm{mL}$ \\
\hline 241-BY-105 & Saltcake Solid & $\begin{array}{l}\text { BY-SltCk } \\
\text { (Solid) }\end{array}$ & $3.26 \mathrm{E}+01$ & $\mathrm{~S}$ & 1.85 & 1481 & $1.19 \mathrm{E}-02$ & $\mu \mathrm{Ci} / \mathrm{g}$ \\
\hline 241-BY-105 & $\begin{array}{l}\text { Sludge (Liquid } \\
\text { \& Solid) }\end{array}$ & PFeCN (Solid) & 2.30E-01 & $\mathrm{TE}$ & 1.68 & 151 & $9.08 \mathrm{E}-04$ & $\mu \mathrm{Ci} / \mathrm{g}$ \\
\hline 241-BY-105 & $\begin{array}{l}\text { Sludge (Liquid } \\
\text { \& Solid) }\end{array}$ & $\begin{array}{l}\text { Portland } \\
\text { Cement (Solid) }\end{array}$ & $0.00 \mathrm{E}+00$ & $\mathrm{E}$ & 1.9 & 30 & $0.00 \mathrm{E}+00$ & $\mu \mathrm{Ci} / \mathrm{g}$ \\
\hline 241-BY-105 & Total & & $4.63 \mathrm{E}+01$ & $\mathrm{~S} / \mathrm{E} / \mathrm{TE}$ & & & & \\
\hline 241-BY-106 & $\begin{array}{l}\text { Saltcake } \\
\text { Interstitial } \\
\text { Liquid }\end{array}$ & $\begin{array}{l}\text { BY-SltCk } \\
\text { (Liquid) }\end{array}$ & $1.78 \mathrm{E}+01$ & $\mathrm{TE}$ & 1.31 & 138 & $1.29 \mathrm{E}-01$ & $\mu \mathrm{Ci} / \mathrm{mL}$ \\
\hline 241-BY-106 & Saltcake Solid & $\begin{array}{l}\text { BY-SltCk } \\
\text { (Solid) }\end{array}$ & $1.54 \mathrm{E}+02$ & TE & 1.68 & 1365 & $6.72 \mathrm{E}-02$ & $\mu \mathrm{Ci} / \mathrm{g}$ \\
\hline 241-BY-106 & $\begin{array}{l}\text { Sludge (Liquid } \\
\text { \& Solid) }\end{array}$ & PFeCN (Solid) & $1.54 \mathrm{E}-01$ & $\mathrm{TE}$ & 1.68 & 120 & $7.65 \mathrm{E}-04$ & $\mu \mathrm{Ci} / \mathrm{g}$ \\
\hline 241-BY-106 & Total & & $1.72 \mathrm{E}+02$ & $\mathrm{TE}$ & & & & \\
\hline 241-BY-107 & $\begin{array}{l}\text { Saltcake } \\
\text { Interstitial } \\
\text { Liquid }\end{array}$ & $\begin{array}{l}\text { BY-SltCk } \\
\text { (Liquid) }\end{array}$ & $2.46 \mathrm{E}+01$ & $\mathrm{TE}$ & 1.46 & 135 & $1.82 \mathrm{E}-01$ & $\mu \mathrm{Ci} / \mathrm{mL}$ \\
\hline 241-BY-107 & Saltcake Solid & $\begin{array}{l}\text { BY-SltCk } \\
\text { (Solid) }\end{array}$ & $8.01 \mathrm{E}+01$ & $\mathrm{TE}$ & 1.72 & 835 & $5.58 \mathrm{E}-02$ & $\mu \mathrm{Ci} / \mathrm{g}$ \\
\hline 241-BY-107 & $\begin{array}{l}\text { Sludge (Liquid } \\
\text { \& Solid) }\end{array}$ & PFeCN (Solid) & $7.85 \mathrm{E}-02$ & $\mathrm{TE}$ & 1.78 & 58 & $7.61 \mathrm{E}-04$ & $\mu \mathrm{Ci} / \mathrm{g}$ \\
\hline 241-BY-107 & Total & & $1.05 \mathrm{E}+02$ & $\mathrm{TE}$ & & & & \\
\hline 241-BY-108 & $\begin{array}{l}\text { Saltcake } \\
\text { Interstitial } \\
\text { Liquid }\end{array}$ & $\begin{array}{l}\text { BY-SltCk } \\
\text { (Liquid) }\end{array}$ & $2.24 \mathrm{E}+01$ & $\mathrm{TE}$ & 1.33 & 103 & $2.17 \mathrm{E}-01$ & $\mu \mathrm{Ci} / \mathrm{mL}$ \\
\hline
\end{tabular}




\begin{tabular}{|c|c|c|c|c|c|c|c|c|}
\hline Tank Name & Waste Phase & Waste Type & $\begin{array}{l}{ }^{99} \mathrm{Tc} \\
(\mathrm{Ci})\end{array}$ & Basis & $\begin{array}{l}\text { Density } \\
(\mathrm{g} / \mathrm{mL})\end{array}$ & $\begin{array}{c}\text { Volume } \\
(\mathrm{kL})\end{array}$ & Adjusted Conc. & Conc. Units \\
\hline $241-B Y-108$ & Saltcake Solid & $\begin{array}{l}\text { BY-SltCk } \\
\text { (Solid) }\end{array}$ & $5.74 \mathrm{E}+01$ & $\mathrm{TE}$ & 1.5 & 587 & $6.52 \mathrm{E}-02$ & $\mu \mathrm{Ci} / \mathrm{g}$ \\
\hline 241-BY-108 & $\begin{array}{l}\text { Sludge (Liquid } \\
\text { \& Solid) }\end{array}$ & PFeCN (Solid) & $1.94 \mathrm{E}-01$ & $\mathrm{TE}$ & 1.53 & 151 & $8.41 \mathrm{E}-04$ & $\mu \mathrm{Ci} / \mathrm{g}$ \\
\hline 241-BY-108 & Total & & $8.00 \mathrm{E}+01$ & $\mathrm{TE}$ & & & & \\
\hline 241-BY-109 & $\begin{array}{l}\text { Saltcake } \\
\text { Interstitial } \\
\text { Liquid }\end{array}$ & $\begin{array}{l}\text { BY-SltCk } \\
\text { (Liquid) }\end{array}$ & $2.50 \mathrm{E}+01$ & $\mathrm{TE}$ & 1.5 & 146 & $1.71 \mathrm{E}-01$ & $\mu \mathrm{Ci} / \mathrm{mL}$ \\
\hline 241-BY-109 & Saltcake Solid & $\begin{array}{l}\text { BY-SltCk } \\
\text { (Solid) }\end{array}$ & $7.39 \mathrm{E}+01$ & TE & 1.71 & 851 & $5.08 \mathrm{E}-02$ & $\mu \mathrm{Ci} / \mathrm{g}$ \\
\hline 241-BY-109 & $\begin{array}{l}\text { Sludge (Liquid } \\
\text { \& Solid) }\end{array}$ & CWP2 (Solid) & $2.85 \mathrm{E}-02$ & $\mathrm{TE}$ & 2 & 89 & $1.60 \mathrm{E}-04$ & $\mu \mathrm{Ci} / \mathrm{g}$ \\
\hline 241-BY-109 & Total & & $9.89 \mathrm{E}+01$ & $\mathrm{TE}$ & & & & \\
\hline 241-BY-110 & $\begin{array}{l}\text { Saltcake } \\
\text { Interstitial } \\
\text { Liquid }\end{array}$ & $\begin{array}{l}\text { BY-SltCk } \\
\text { (Liquid) }\end{array}$ & $2.08 \mathrm{E}+01$ & $\mathrm{TE}$ & 1.44 & 99 & $2.10 \mathrm{E}-01$ & $\mu \mathrm{Ci} / \mathrm{mL}$ \\
\hline 241-BY-110 & Saltcake Solid & $\begin{array}{l}\text { BY-SltCk } \\
\text { (Solid) }\end{array}$ & $1.10 \mathrm{E}+02$ & TE & 1.54 & 1123 & $6.37 \mathrm{E}-02$ & $\mu \mathrm{Ci} / \mathrm{g}$ \\
\hline 241-BY-110 & $\begin{array}{l}\text { Sludge (Liquid } \\
\& \text { Solid) }\end{array}$ & PFeCN (Solid) & $2.56 \mathrm{E}-01$ & TE & 1.82 & 162 & 8.69E-04 & $\mu \mathrm{Ci} / \mathrm{g}$ \\
\hline 241-BY-110 & Total & & $1.31 \mathrm{E}+02$ & $\mathrm{TE}$ & & & & \\
\hline 241-BY-111 & $\begin{array}{l}\text { Saltcake } \\
\text { Interstitial } \\
\text { Liquid }\end{array}$ & $\begin{array}{l}\text { BY-SltCk } \\
\text { (Liquid) }\end{array}$ & $2.31 \mathrm{E}+01$ & $\mathrm{TE}$ & 1.42 & 145 & $1.59 \mathrm{E}-01$ & $\mu \mathrm{Ci} / \mathrm{mL}$ \\
\hline 241-BY-111 & Saltcake Solid & $\begin{array}{l}\text { BY-SltCk } \\
\text { (Solid) }\end{array}$ & $1.36 \mathrm{E}+02$ & $\mathrm{TE}$ & 1.7 & 1378 & $5.81 \mathrm{E}-02$ & $\mu \mathrm{Ci} / \mathrm{g}$ \\
\hline 241-BY-111 & Total & & $1.59 \mathrm{E}+02$ & $\mathrm{TE}$ & & & & \\
\hline 241-BY-112 & $\begin{array}{l}\text { Saltcake } \\
\text { Interstitial } \\
\text { Liquid }\end{array}$ & $\begin{array}{l}\text { BY-SltCk } \\
\text { (Liquid) }\end{array}$ & $1.45 \mathrm{E}+01$ & $\mathrm{TE}$ & 1.47 & 79 & $1.84 \mathrm{E}-01$ & $\mu \mathrm{Ci} / \mathrm{mL}$ \\
\hline 241-BY-112 & Saltcake Solid & $\begin{array}{l}\text { BY-SltCk } \\
\text { (Solid) }\end{array}$ & $1.10 \mathrm{E}+02$ & $\mathrm{TE}$ & 1.76 & 996 & $6.28 \mathrm{E}-02$ & $\mu \mathrm{Ci} / \mathrm{g}$ \\
\hline 241-BY-112 & $\begin{array}{l}\text { Sludge (Liquid } \\
\text { \& Solid) }\end{array}$ & MW2 (Solid) & $1.34 \mathrm{E}-02$ & TE & 1.85 & 8 & $9.04 \mathrm{E}-04$ & $\mu \mathrm{Ci} / \mathrm{g}$ \\
\hline
\end{tabular}




\begin{tabular}{|c|c|c|c|c|c|c|c|c|}
\hline Tank Name & Waste Phase & Waste Type & $\begin{array}{l}{ }^{99} \mathrm{Tc} \\
(\mathrm{Ci})\end{array}$ & Basis & $\begin{array}{l}\text { Density } \\
(\mathrm{g} / \mathrm{mL})\end{array}$ & $\begin{array}{c}\text { Volume } \\
(\mathrm{kL})\end{array}$ & Adjusted Conc. & Conc. Units \\
\hline $241-B Y-112$ & Total & & $1.25 \mathrm{E}+02$ & $\mathrm{TE}$ & & & & \\
\hline 241-C-101 & $\begin{array}{l}\text { Sludge (Liquid } \\
\& \text { Solid) }\end{array}$ & TBP (Solid) & 4.34E-02 & TE & 1.78 & 16 & $1.52 \mathrm{E}-03$ & $\mu \mathrm{Ci} / \mathrm{g}$ \\
\hline $241-\mathrm{C}-101$ & Supernatant & NA (Liquid) & $0.00 \mathrm{E}+00$ & $\mathrm{E}$ & 1 & 3 & $0.00 \mathrm{E}+00$ & $\mu \mathrm{Ci} / \mathrm{mL}$ \\
\hline $241-\mathrm{C}-101$ & Total & & 4.34E-02 & $\mathrm{E} / \mathrm{TE}$ & & & & \\
\hline 241-C-102 & $\begin{array}{l}\text { Sludge (Liquid } \\
\& \text { Solid) }\end{array}$ & CWP1 (Solid) & $5.50 \mathrm{E}-02$ & $\mathrm{TE}$ & 1.63 & 125 & $2.70 \mathrm{E}-04$ & $\mu \mathrm{Ci} / \mathrm{g}$ \\
\hline $241-C-102$ & $\begin{array}{l}\text { Sludge (Liquid } \\
\& \text { Solid) }\end{array}$ & CWP2 (Solid) & $1.90 \mathrm{E}-01$ & $\mathrm{TE}$ & 1.74 & 855 & $1.27 \mathrm{E}-04$ & $\mu \mathrm{Ci} / \mathrm{g}$ \\
\hline 241-C-102 & $\begin{array}{l}\text { Sludge (Liquid } \\
\& \text { Solid) }\end{array}$ & CWZr1 (Solid) & $3.37 \mathrm{E}-01$ & $\mathrm{TE}$ & 1.74 & 38 & $5.10 \mathrm{E}-03$ & $\mu \mathrm{Ci} / \mathrm{g}$ \\
\hline $241-C-102$ & $\begin{array}{l}\text { Sludge (Liquid } \\
\& \text { Solid) }\end{array}$ & MW1 (Solid) & $3.52 \mathrm{E}-02$ & $\mathrm{TE}$ & 1.8 & 19 & $1.03 \mathrm{E}-03$ & $\mu \mathrm{Ci} / \mathrm{g}$ \\
\hline 241-C-102 & $\begin{array}{l}\text { Sludge (Liquid } \\
\& \text { Solid) }\end{array}$ & TBP (Solid) & $8.83 \mathrm{E}-02$ & $\mathrm{TE}$ & 1.47 & 61 & $9.85 \mathrm{E}-04$ & $\mu \mathrm{Ci} / \mathrm{g}$ \\
\hline $241-\mathrm{C}-102$ & $\begin{array}{l}\text { Sludge (Liquid } \\
\& \text { Solid) }\end{array}$ & TH1 (Solid) & $1.81 \mathrm{E}-01$ & $\mathrm{TE}$ & 1.32 & 98 & $1.40 \mathrm{E}-03$ & $\mu \mathrm{Ci} / \mathrm{g}$ \\
\hline $241-\mathrm{C}-102$ & Total & & 8.87E-01 & $\mathrm{TE}$ & & & & \\
\hline $241-C-103$ & $\begin{array}{l}\text { Sludge (Liquid } \\
\& \text { Solid) }\end{array}$ & NA (Sludge) & 4.47E-02 & $\mathrm{S}$ & 1.61 & 8.64 & $3.22 \mathrm{E}-03$ & $\mu \mathrm{Ci} / \mathrm{g}$ \\
\hline 241-C-103 & Supernatant & NA (Liquid) & $6.02 \mathrm{E}-05$ & $\mathrm{~S}$ & 0.98 & 0.93 & $6.48 \mathrm{E}-05$ & $\mu \mathrm{Ci} / \mathrm{mL}$ \\
\hline 241-C-103 & Total & & 4.48E-02 & $\mathrm{S}$ & & & & \\
\hline 241-C-104 & $\begin{array}{l}\text { Sludge (Liquid } \\
\& \text { Solid) }\end{array}$ & NA (Sludge) & $1.73 \mathrm{E}-01$ & $\mathrm{~S}$ & 1.58 & 4 & 2.67E-02 & $\mu \mathrm{Ci} / \mathrm{g}$ \\
\hline 241-C-104 & Supernatant & NA (Liquid) & $0.00 \mathrm{E}+00$ & $\mathrm{E}$ & 1 & 2 & $0.00 \mathrm{E}+00$ & $\mu \mathrm{Ci} / \mathrm{mL}$ \\
\hline 241-C-104 & Total & & $1.73 \mathrm{E}-01$ & $\mathrm{~S} / \mathrm{E}$ & & & & \\
\hline 241-C-105 & $\begin{array}{l}\text { Sludge (Liquid } \\
\text { \& Solid) }\end{array}$ & CWP1 (Solid) & $7.32 \mathrm{E}+01$ & $\mathrm{E}$ & 1.55 & 450 & $1.05 \mathrm{E}-01$ & $\mu \mathrm{Ci} / \mathrm{g}$ \\
\hline $241-C-105$ & $\begin{array}{l}\text { Sludge (Liquid } \\
\& \text { Solid) }\end{array}$ & TBP (Solid) & $8.14 \mathrm{E}+00$ & $\mathrm{E}$ & 1.55 & 50 & $1.05 \mathrm{E}-01$ & $\mu \mathrm{Ci} / \mathrm{g}$ \\
\hline $241-C-105$ & Total & & $8.14 \mathrm{E}+01$ & $\mathrm{E}$ & & & & \\
\hline 241-C-106 & $\begin{array}{l}\text { Sludge (Liquid } \\
\& \text { Solid) }\end{array}$ & NA (Sludge) & $1.64 \mathrm{E}-01$ & S & 1.56 & 10.166 & $1.04 \mathrm{E}-02$ & $\mu \mathrm{Ci} / \mathrm{g}$ \\
\hline 241-C-106 & Supernatant & NA (Liquid) & $3.44 \mathrm{E}-06$ & $\mathrm{~S}$ & 1.02 & 0.322 & $1.07 \mathrm{E}-05$ & $\mu \mathrm{Ci} / \mathrm{mL}$ \\
\hline
\end{tabular}




\begin{tabular}{|c|c|c|c|c|c|c|c|c|}
\hline Tank Name & Waste Phase & Waste Type & $\begin{array}{l}{ }^{99} \mathrm{Tc} \\
(\mathrm{Ci})\end{array}$ & Basis & $\begin{array}{l}\text { Density } \\
(\mathrm{g} / \mathrm{mL})\end{array}$ & $\begin{array}{c}\text { Volume } \\
(\mathrm{kL})\end{array}$ & Adjusted Conc. & Conc. Units \\
\hline 241-C-106 & Total & & $1.64 \mathrm{E}-01$ & $\mathrm{~S}$ & & & & \\
\hline 241-C-107 & $\begin{array}{l}\text { Sludge (Liquid } \\
\& \text { Solid) }\end{array}$ & $1 \mathrm{C}$ (Solid) & $3.99 \mathrm{E}+00$ & $\mathrm{~S}$ & 1.55 & 99 & $2.60 \mathrm{E}-02$ & $\mu \mathrm{Ci} / \mathrm{g}$ \\
\hline 241-C-107 & Supernatant & Liquid (NA) & $5.61 \mathrm{E}-03$ & $\mathrm{E}$ & 1 & 33 & $1.70 \mathrm{E}-04$ & $\mu \mathrm{Ci} / \mathrm{mL}$ \\
\hline 241-C-107 & Total & & $4.00 \mathrm{E}+00$ & $\mathrm{~S} / \mathrm{E}$ & & & & \\
\hline 241-C-108 & $\begin{array}{l}\text { Sludge (Liquid } \\
\& \text { Solid) }\end{array}$ & NA (Solid) & $3.96 \mathrm{E}-02$ & $\mathrm{~S}$ & 2.09 & 10.5 & $1.80 \mathrm{E}-03$ & $\mu \mathrm{Ci} / \mathrm{g}$ \\
\hline 241-C-108 & Supernatant & NA (Liquid) & $0.00 \mathrm{E}+00$ & $\mathrm{E}$ & 1 & 0.7 & $0.00 \mathrm{E}+00$ & $\mu \mathrm{Ci} / \mathrm{mL}$ \\
\hline 241-C-108 & Total & & $3.96 \mathrm{E}-02$ & $\mathrm{~S} / \mathrm{E}$ & & & & \\
\hline 241-C-109 & $\begin{array}{l}\text { Sludge (Liquid } \\
\text { \& Solid) }\end{array}$ & 1C (Solid) & $7.50 \mathrm{E}-03$ & $\mathrm{~S}$ & 1.74 & 6.5 & $6.63 \mathrm{E}-04$ & $\mu \mathrm{Ci} / \mathrm{g}$ \\
\hline 241-C-109 & Total & & $7.50 \mathrm{E}-03$ & $\mathrm{~S}$ & & & & \\
\hline 241-C-110 & $\begin{array}{l}\text { Saltcake (Liquid } \\
\& \text { Solid) }\end{array}$ & NA (SltCk) & 5.77E-02 & $\mathrm{S}$ & 1.44 & 6.7 & $5.98 \mathrm{E}-03$ & $\mu \mathrm{Ci} / \mathrm{g}$ \\
\hline 241-C-110 & Total & & $5.77 \mathrm{E}-02$ & $\mathrm{~S}$ & & & & \\
\hline 241-C-111 & $\begin{array}{l}\text { Sludge (Liquid } \\
\& \text { Solid) }\end{array}$ & 1C (Solid) & $1.70 \mathrm{E}+00$ & $\mathrm{TS}$ & 1.43 & 49 & $2.43 \mathrm{E}-02$ & $\mu \mathrm{Ci} / \mathrm{g}$ \\
\hline 241-C-111 & $\begin{array}{l}\text { Sludge (Liquid } \\
\text { \& Solid) }\end{array}$ & CWP1 (Solid) & $1.11 \mathrm{E}-02$ & TE & 1.58 & 26 & $2.71 \mathrm{E}-04$ & $\mu \mathrm{Ci} / \mathrm{g}$ \\
\hline 241-C-111 & $\begin{array}{l}\text { Sludge (Liquid } \\
\text { \& Solid) }\end{array}$ & HS (Solid) & $1.94 \mathrm{E}-01$ & TE & 1.58 & 17 & $7.21 \mathrm{E}-03$ & $\mu \mathrm{Ci} / \mathrm{g}$ \\
\hline 241-C-111 & $\begin{array}{l}\text { Sludge (Liquid } \\
\& \text { Solid) }\end{array}$ & TFeCN (Solid) & $2.80 \mathrm{E}-01$ & $\mathrm{TE}$ & 1.58 & 40 & 4.42E-03 & $\mu \mathrm{Ci} / \mathrm{g}$ \\
\hline 241-C-111 & Total & & $2.19 \mathrm{E}+00$ & $\mathrm{TS} / \mathrm{TE}$ & & & & \\
\hline 241-C-112 & $\begin{array}{l}\text { Sludge (Liquid } \\
\text { \& Solid) }\end{array}$ & $1 \mathrm{C}$ (Solid) & $1.98 \mathrm{E}+00$ & TS & 1.43 & 57 & $2.43 \mathrm{E}-02$ & $\mu \mathrm{Ci} / \mathrm{g}$ \\
\hline 241-C-112 & $\begin{array}{l}\text { Sludge (Liquid } \\
\& \text { Solid) }\end{array}$ & CWP1 (Solid) & $7.61 \mathrm{E}+00$ & $\mathrm{~S}$ & 1.6 & 49 & $9.71 \mathrm{E}-02$ & $\mu \mathrm{Ci} / \mathrm{g}$ \\
\hline 241-C-112 & $\begin{array}{l}\text { Sludge (Liquid } \\
\& \text { Solid) }\end{array}$ & CWP2 (Solid) & $1.71 \mathrm{E}+00$ & S & 1.6 & 11 & $9.71 \mathrm{E}-02$ & $\mu \mathrm{Ci} / \mathrm{g}$ \\
\hline 241-C-112 & $\begin{array}{l}\text { Sludge (Liquid } \\
\text { \& Solid) }\end{array}$ & HS (Solid) & $6.21 \mathrm{E}-01$ & $\mathrm{~S}$ & 1.6 & 4 & $9.71 \mathrm{E}-02$ & $\mu \mathrm{Ci} / \mathrm{g}$ \\
\hline 241-C-112 & $\begin{array}{l}\text { Sludge (Liquid } \\
\& \text { Solid) }\end{array}$ & TFeCN (Solid) & $9.32 \mathrm{E}-01$ & S & 1.6 & 6 & $9.71 \mathrm{E}-02$ & $\mu \mathrm{Ci} / \mathrm{g}$ \\
\hline
\end{tabular}




\begin{tabular}{|c|c|c|c|c|c|c|c|c|}
\hline Tank Name & Waste Phase & Waste Type & $\begin{array}{l}{ }^{99} \mathrm{Tc} \\
(\mathrm{Ci})\end{array}$ & Basis & $\begin{array}{l}\text { Density } \\
(\mathrm{g} / \mathrm{mL})\end{array}$ & $\begin{array}{c}\text { Volume } \\
(\mathrm{kL})\end{array}$ & Adjusted Conc. & Conc. Units \\
\hline $241-C-112$ & Total & & $1.29 \mathrm{E}+01$ & $\mathrm{~S} / \mathrm{TS}$ & & & & \\
\hline 241-C-201 & Sludge Solid & HS (Solid) & 2.63E-03 & $\mathrm{E}$ & 1.75 & 0.537 & $2.80 \mathrm{E}-03$ & $\mu \mathrm{Ci} / \mathrm{g}$ \\
\hline 241-C-201 & Supernatant & NA (Liquid) & $0.00 \mathrm{E}+00$ & $\mathrm{E}$ & 1 & 0.007 & $0.00 \mathrm{E}+00$ & $\mu \mathrm{Ci} / \mathrm{mL}$ \\
\hline 241-C-201 & Total & & $2.63 \mathrm{E}-03$ & $\mathrm{E}$ & & & & \\
\hline 241-C-202 & $\begin{array}{l}\text { Sludge (Liquid } \\
\text { \& Solid) }\end{array}$ & HS (Solid) & $2.50 \mathrm{E}-03$ & $\mathrm{~S}$ & 1.75 & 0.548 & $2.61 \mathrm{E}-03$ & $\mu \mathrm{Ci} / \mathrm{g}$ \\
\hline 241-C-202 & Supernatant & NA (Liquid) & $0.00 \mathrm{E}+00$ & $\mathrm{E}$ & 1 & 0.009 & $0.00 \mathrm{E}+00$ & $\mu \mathrm{Ci} / \mathrm{mL}$ \\
\hline 241-C-202 & Total & & $2.50 \mathrm{E}-03$ & $\mathrm{~S} / \mathrm{E}$ & & & & \\
\hline 241-C-203 & $\begin{array}{l}\text { Sludge (Liquid } \\
\& \text { Solid) }\end{array}$ & HS (Solid) & $2.32 \mathrm{E}-03$ & $\mathrm{~S}$ & 1.93 & 0.476 & $2.53 \mathrm{E}-03$ & $\mu \mathrm{Ci} / \mathrm{g}$ \\
\hline 241-C-203 & Supernatant & NA (Liquid) & $0.00 \mathrm{E}+00$ & $\mathrm{E}$ & 1 & 0.048 & $0.00 \mathrm{E}+00$ & $\mu \mathrm{Ci} / \mathrm{mL}$ \\
\hline 241-C-203 & Total & & 2.32E-03 & $\mathrm{S} / \mathrm{E}$ & & & & \\
\hline 241-C-204 & $\begin{array}{l}\text { Sludge (Liquid } \\
\& \text { Solid) }\end{array}$ & HS (Solid) & $3.18 \mathrm{E}-03$ & $\mathrm{~S}$ & 1.77 & 0.507 & $3.54 \mathrm{E}-03$ & $\mu \mathrm{Ci} / \mathrm{g}$ \\
\hline 241-C-204 & Supernatant & NA (Liquid) & $0.00 \mathrm{E}+00$ & $\mathrm{E}$ & 1 & 0.011 & $0.00 \mathrm{E}+00$ & $\mu \mathrm{Ci} / \mathrm{mL}$ \\
\hline 241-C-204 & Total & & $3.18 \mathrm{E}-03$ & $\mathrm{~S} / \mathrm{E}$ & & & & \\
\hline 241-S-101 & $\begin{array}{l}\text { Saltcake } \\
\text { Interstitial } \\
\text { Liquid }\end{array}$ & $\begin{array}{l}\text { S1-SltCk } \\
\text { (Liquid) }\end{array}$ & $4.99 \mathrm{E}+00$ & S & 1.47 & 16 & $3.12 \mathrm{E}-01$ & $\mu \mathrm{Ci} / \mathrm{mL}$ \\
\hline 241-S-101 & $\begin{array}{l}\text { Saltcake } \\
\text { Interstitial } \\
\text { Liquid }\end{array}$ & $\begin{array}{l}\text { S2-SltSlr } \\
\text { (Liquid) }\end{array}$ & $3.43 \mathrm{E}+00$ & S & 1.47 & 11 & $3.12 \mathrm{E}-01$ & $\mu \mathrm{Ci} / \mathrm{mL}$ \\
\hline $241-S-101$ & Saltcake Solid & $\begin{array}{l}\text { S1-SltCk } \\
\text { (Solid) }\end{array}$ & $3.08 \mathrm{E}+01$ & TE & 1.56 & 246 & 8.03E-02 & $\mu \mathrm{Ci} / \mathrm{g}$ \\
\hline 241-S-101 & Saltcake Solid & $\begin{array}{l}\text { S2-SltSlr } \\
\text { (Solid) }\end{array}$ & $2.66 \mathrm{E}+01$ & $\mathrm{TE}$ & 1.56 & 169 & $1.01 \mathrm{E}-01$ & $\mu \mathrm{Ci} / \mathrm{g}$ \\
\hline 241-S-101 & $\begin{array}{l}\text { Sludge (Liquid } \\
\text { \& Solid) }\end{array}$ & NA (Sludge) & $4.02 \mathrm{E}+01$ & $\mathrm{E}$ & 1.7 & 890 & $2.66 \mathrm{E}-02$ & $\mu \mathrm{Ci} / \mathrm{g}$ \\
\hline 241-S-101 & Total & & $1.06 \mathrm{E}+02$ & $\mathrm{~S} / \mathrm{E} / \mathrm{TE}$ & & & & \\
\hline $241-S-102$ & $\begin{array}{l}\text { Saltcake (Liquid } \\
\text { \& Solid) }\end{array}$ & NA (SltCk) & $1.81 \mathrm{E}+01$ & $\mathrm{E}$ & 1.69 & 219 & $4.89 \mathrm{E}-02$ & $\mu \mathrm{Ci} / \mathrm{g}$ \\
\hline 241-S-102 & $\begin{array}{l}\text { Sludge (Liquid } \\
\& \text { Solid) }\end{array}$ & R1 (Solid) & $1.85 \mathrm{E}+00$ & $\mathrm{TE}$ & 1.88 & 71 & $1.39 \mathrm{E}-02$ & $\mu \mathrm{Ci} / \mathrm{g}$ \\
\hline 241-S-102 & Supernatant & NA (Liquid) & $0.00 \mathrm{E}+00$ & $\mathrm{E}$ & 1 & 9 & $0.00 \mathrm{E}+00$ & $\mu \mathrm{Ci} / \mathrm{mL}$ \\
\hline
\end{tabular}




\begin{tabular}{|c|c|c|c|c|c|c|c|c|}
\hline Tank Name & Waste Phase & Waste Type & $\begin{array}{l}{ }^{99} \mathrm{Tc} \\
(\mathrm{Ci})\end{array}$ & Basis & $\begin{array}{l}\text { Density } \\
(\mathrm{g} / \mathrm{mL})\end{array}$ & $\begin{array}{c}\text { Volume } \\
(\mathrm{kL})\end{array}$ & Adjusted Conc. & Conc. Units \\
\hline $241-S-102$ & Total & & $2.00 \mathrm{E}+01$ & $\mathrm{E} / \mathrm{TE}$ & & & & \\
\hline $241-S-103$ & $\begin{array}{l}\text { Saltcake } \\
\text { Interstitial } \\
\text { Liquid }\end{array}$ & $\begin{array}{l}\text { S1-SltCk } \\
\text { (Liquid) }\end{array}$ & $3.02 \mathrm{E}+01$ & TS & 1.45 & 116 & $2.60 \mathrm{E}-01$ & $\mu \mathrm{Ci} / \mathrm{mL}$ \\
\hline 241-S-103 & $\begin{array}{l}\text { Saltcake } \\
\text { Interstitial } \\
\text { Liquid }\end{array}$ & $\begin{array}{l}\text { S2-SltSlr } \\
\text { (Liquid) }\end{array}$ & $2.47 \mathrm{E}+01$ & $\mathrm{TS}$ & 1.45 & 95 & $2.60 \mathrm{E}-01$ & $\mu \mathrm{Ci} / \mathrm{mL}$ \\
\hline $241-S-103$ & Saltcake Solid & $\begin{array}{l}\text { S1-SltCk } \\
\text { (Solid) }\end{array}$ & $5.68 \mathrm{E}+01$ & $\mathrm{TE}$ & 1.68 & 347 & $9.74 \mathrm{E}-02$ & $\mu \mathrm{Ci} / \mathrm{g}$ \\
\hline 241-S-103 & Saltcake Solid & $\begin{array}{l}\text { S2-SltSlr } \\
\text { (Solid) }\end{array}$ & $5.57 \mathrm{E}+01$ & TE & 1.63 & 300 & $1.14 \mathrm{E}-01$ & $\mu \mathrm{Ci} / \mathrm{g}$ \\
\hline $241-S-103$ & $\begin{array}{l}\text { Sludge (Liquid } \\
\& \text { Solid) }\end{array}$ & R1 (Solid) & $8.30 \mathrm{E}-01$ & TE & 1.77 & 34 & $1.38 \mathrm{E}-02$ & $\mu \mathrm{Ci} / \mathrm{g}$ \\
\hline $241-S-103$ & Supernatant & $\begin{array}{l}\text { S2-SltSlr } \\
\text { (Liquid) }\end{array}$ & $1.04 \mathrm{E}+00$ & TS & 1.45 & 4 & $2.60 \mathrm{E}-01$ & $\mu \mathrm{Ci} / \mathrm{mL}$ \\
\hline $241-S-103$ & Total & & $1.69 \mathrm{E}+02$ & $\mathrm{TS} / \mathrm{TE}$ & & & & \\
\hline 241-S-104 & $\begin{array}{l}\text { Saltcake } \\
\text { Interstitial } \\
\text { Liquid }\end{array}$ & $\begin{array}{l}\text { R-SltCk } \\
\text { (Liquid) }\end{array}$ & $1.19 \mathrm{E}+01$ & TE & 1.37 & 139 & $8.55 \mathrm{E}-02$ & $\mu \mathrm{Ci} / \mathrm{mL}$ \\
\hline 241-S-104 & Saltcake Solid & $\begin{array}{l}\text { R-SltCk } \\
\text { (Solid) }\end{array}$ & $1.86 \mathrm{E}+01$ & $\mathrm{~S}$ & 1.64 & 451 & $2.52 \mathrm{E}-02$ & $\mu \mathrm{Ci} / \mathrm{g}$ \\
\hline 241-S-104 & $\begin{array}{l}\text { Sludge (Liquid } \\
\& \text { Solid) }\end{array}$ & CWR1 (Solid) & $3.76 \mathrm{E}+00$ & $\mathrm{~S}$ & 1.8 & 91 & $2.30 \mathrm{E}-02$ & $\mu \mathrm{Ci} / \mathrm{g}$ \\
\hline 241-S-104 & $\begin{array}{l}\text { Sludge (Liquid } \\
\& \text { Solid) }\end{array}$ & R1 (Solid) & $1.69 \mathrm{E}+01$ & $\mathrm{~S}$ & 1.77 & 409 & $2.34 \mathrm{E}-02$ & $\mu \mathrm{Ci} / \mathrm{g}$ \\
\hline 241-S-104 & Total & & $5.12 \mathrm{E}+01$ & $\mathrm{~S} / \mathrm{TE}$ & & & & \\
\hline 241-S-105 & $\begin{array}{l}\text { Saltcake } \\
\text { Interstitial } \\
\text { Liquid }\end{array}$ & $\begin{array}{l}\text { S1-SltCk } \\
\text { (Liquid) }\end{array}$ & $4.14 \mathrm{E}+01$ & TS & 1.45 & 157 & 2.64E-01 & $\mu \mathrm{Ci} / \mathrm{mL}$ \\
\hline 241-S-105 & Saltcake Solid & $\begin{array}{l}\text { S1-SltCk } \\
\text { (Solid) }\end{array}$ & $3.10 \mathrm{E}+02$ & $\mathrm{TE}$ & 1.68 & 1371 & $1.35 \mathrm{E}-01$ & $\mu \mathrm{Ci} / \mathrm{g}$ \\
\hline 241-S-105 & $\begin{array}{l}\text { Sludge (Liquid } \\
\text { \& Solid) }\end{array}$ & R1 (Solid) & $1.95 \mathrm{E}-01$ & $\mathrm{TE}$ & 1.77 & 8 & $1.38 \mathrm{E}-02$ & $\mu \mathrm{Ci} / \mathrm{g}$ \\
\hline 241-S-105 & Total & & $3.52 \mathrm{E}+02$ & TS/TE & & & & \\
\hline
\end{tabular}




\begin{tabular}{|c|c|c|c|c|c|c|c|c|}
\hline Tank Name & Waste Phase & Waste Type & $\begin{array}{l}{ }^{99} \mathrm{Tc} \\
(\mathrm{Ci})\end{array}$ & Basis & $\begin{array}{l}\text { Density } \\
(\mathrm{g} / \mathrm{mL})\end{array}$ & $\begin{array}{c}\text { Volume } \\
(\mathrm{kL})\end{array}$ & Adjusted Conc. & Conc. Units \\
\hline $241-S-106$ & $\begin{array}{l}\text { Saltcake } \\
\text { Interstitial } \\
\text { Liquid }\end{array}$ & $\begin{array}{l}\text { S1-SltCk } \\
\text { (Liquid) }\end{array}$ & $2.32 \mathrm{E}+01$ & TS & 1.43 & 99 & $2.34 \mathrm{E}-01$ & $\mu \mathrm{Ci} / \mathrm{mL}$ \\
\hline 241-S-106 & Saltcake Solid & $\begin{array}{l}\text { S1-SltCk } \\
\text { (Solid) }\end{array}$ & $2.62 \mathrm{E}+02$ & TE & 1.74 & 1624 & $9.28 \mathrm{E}-02$ & $\mu \mathrm{Ci} / \mathrm{g}$ \\
\hline 241-S-106 & Total & & $2.85 \mathrm{E}+02$ & $\mathrm{TS} / \mathrm{TE}$ & & & & \\
\hline 241-S-107 & Saltcake Solid & $\begin{array}{l}\text { S1-SltCk } \\
\text { (Solid) }\end{array}$ & $7.61 \mathrm{E}+00$ & $\mathrm{TE}$ & 1.57 & 63 & 7.69E-02 & $\mu \mathrm{Ci} / \mathrm{g}$ \\
\hline 241-S-107 & Saltcake Solid & $\begin{array}{l}\text { S2-SltSlr } \\
\text { (Solid) }\end{array}$ & $4.54 \mathrm{E}+00$ & TE & 1.57 & 30 & $9.65 \mathrm{E}-02$ & $\mu \mathrm{Ci} / \mathrm{g}$ \\
\hline 241-S-107 & Saltcake Solid & $\begin{array}{l}\text { T2-SltCk } \\
\text { (Solid) }\end{array}$ & $4.13 \mathrm{E}+00$ & $\mathrm{TE}$ & 1.57 & 52 & $5.06 \mathrm{E}-02$ & $\mu \mathrm{Ci} / \mathrm{g}$ \\
\hline 241-S-107 & $\begin{array}{l}\text { Sludge (Liquid } \\
\& \text { Solid) }\end{array}$ & CWR1 (Solid) & $2.09 \mathrm{E}+00$ & TS & 1.8 & 447 & $2.60 \mathrm{E}-03$ & $\mu \mathrm{Ci} / \mathrm{g}$ \\
\hline 241-S-107 & $\begin{array}{l}\text { Sludge (Liquid } \\
\text { \& Solid) }\end{array}$ & CWR2 (Solid) & $1.18 \mathrm{E}-01$ & $\mathrm{TE}$ & 1.8 & 211 & $3.11 \mathrm{E}-04$ & $\mu \mathrm{Ci} / \mathrm{g}$ \\
\hline 241-S-107 & $\begin{array}{l}\text { Sludge (Liquid } \\
\& \text { Solid) }\end{array}$ & CWZr1 (Solid) & $2.16 \mathrm{E}+00$ & TE & 1.8 & 91 & $1.32 \mathrm{E}-02$ & $\mu \mathrm{Ci} / \mathrm{g}$ \\
\hline 241-S-107 & $\begin{array}{l}\text { Sludge (Liquid } \\
\& \text { Solid) }\end{array}$ & R1 (Solid) & $9.94 \mathrm{E}+00$ & TE & 1.8 & 462 & $1.20 \mathrm{E}-02$ & $\mu \mathrm{Ci} / \mathrm{g}$ \\
\hline 241-S-107 & Total & & $3.06 \mathrm{E}+01$ & $\mathrm{TS} / \mathrm{TE}$ & & & & \\
\hline 241-S-108 & $\begin{array}{l}\text { Saltcake } \\
\text { Interstitial } \\
\text { Liquid }\end{array}$ & $\begin{array}{l}\text { S1-SltCk } \\
\text { (Liquid) }\end{array}$ & $8.18 \mathrm{E}+00$ & TS & 1.45 & 31 & $2.64 \mathrm{E}-01$ & $\mu \mathrm{Ci} / \mathrm{mL}$ \\
\hline 241-S-108 & Saltcake Solid & $\begin{array}{l}\text { S1-SltCk } \\
\text { (Solid) }\end{array}$ & $3.32 \mathrm{E}+02$ & TE & 1.68 & 2032 & $9.74 \mathrm{E}-02$ & $\mu \mathrm{Ci} / \mathrm{g}$ \\
\hline 241-S-108 & $\begin{array}{l}\text { Sludge (Liquid } \\
\& \text { Solid) }\end{array}$ & R1 (Solid) & 4.64E-01 & TE & 1.77 & 19 & $1.38 \mathrm{E}-02$ & $\mu \mathrm{Ci} / \mathrm{g}$ \\
\hline 241-S-108 & Total & & $3.41 \mathrm{E}+02$ & $\mathrm{TS} / \mathrm{TE}$ & & & & \\
\hline 241-S-109 & $\begin{array}{l}\text { Saltcake } \\
\text { Interstitial } \\
\text { Liquid }\end{array}$ & $\begin{array}{l}\text { S1-SltCk } \\
\text { (Liquid) }\end{array}$ & $1.58 \mathrm{E}+01$ & TS & 1.49 & 63 & $2.50 \mathrm{E}-01$ & $\mu \mathrm{Ci} / \mathrm{mL}$ \\
\hline 241-S-109 & Saltcake Solid & $\begin{array}{l}\text { S1-SltCk } \\
\text { (Solid) }\end{array}$ & $4.01 \mathrm{E}+02$ & $\mathrm{TE}$ & 1.66 & 1905 & $1.27 \mathrm{E}-01$ & $\mu \mathrm{Ci} / \mathrm{g}$ \\
\hline
\end{tabular}




\begin{tabular}{|c|c|c|c|c|c|c|c|c|}
\hline Tank Name & Waste Phase & Waste Type & $\begin{array}{l}{ }^{99} \mathrm{Tc} \\
(\mathrm{Ci})\end{array}$ & Basis & $\begin{array}{l}\text { Density } \\
(\mathrm{g} / \mathrm{mL})\end{array}$ & $\begin{array}{c}\text { Volume } \\
(\mathrm{kL})\end{array}$ & Adjusted Conc. & Conc. Units \\
\hline $241-S-109$ & $\begin{array}{l}\text { Sludge (Liquid } \\
\text { \& Solid) }\end{array}$ & R1 (Solid) & $1.20 \mathrm{E}+00$ & $\mathrm{TE}$ & 1.77 & 49 & $1.38 \mathrm{E}-02$ & $\mu \mathrm{Ci} / \mathrm{g}$ \\
\hline 241-S-109 & Total & & $4.18 \mathrm{E}+02$ & TS/TE & & & & \\
\hline 241-S-110 & $\begin{array}{l}\text { Saltcake } \\
\text { Interstitial } \\
\text { Liquid }\end{array}$ & $\begin{array}{l}\text { S1-Sltck } \\
\text { (Liquid) }\end{array}$ & $2.98 \mathrm{E}+01$ & TS & 1.43 & 115 & $2.59 \mathrm{E}-01$ & $\mu \mathrm{Ci} / \mathrm{mL}$ \\
\hline 241-S-110 & Saltcake Solid & $\begin{array}{l}\text { S1-Sltck } \\
\text { (Solid) }\end{array}$ & $2.00 \mathrm{E}+02$ & TE & 1.65 & 994 & $1.22 \mathrm{E}-01$ & $\mu \mathrm{Ci} / \mathrm{g}$ \\
\hline 241-S-110 & $\begin{array}{l}\text { Sludge (Liquid } \\
\text { \& Solid) }\end{array}$ & CWR1 (Solid) & $3.58 \mathrm{E}-01$ & TS & 1.77 & 76 & $2.66 \mathrm{E}-03$ & $\mu \mathrm{Ci} / \mathrm{g}$ \\
\hline 241-S-110 & $\begin{array}{l}\text { Sludge (Liquid } \\
\text { \& Solid) }\end{array}$ & R1 (Solid) & $6.23 \mathrm{E}+00$ & TE & 1.77 & 288 & $1.22 \mathrm{E}-02$ & $\mu \mathrm{Ci} / \mathrm{g}$ \\
\hline $241-S-110$ & Total & & $2.37 \mathrm{E}+02$ & TS/TE & & & & \\
\hline 241-S-111 & $\begin{array}{l}\text { Saltcake } \\
\text { Interstitial } \\
\text { Liquid }\end{array}$ & $\begin{array}{l}\text { S1-SltCk } \\
\text { (Liquid) }\end{array}$ & $3.15 \mathrm{E}+01$ & TS & 1.45 & 124 & $2.54 \mathrm{E}-01$ & $\mu \mathrm{Ci} / \mathrm{mL}$ \\
\hline 241-S-111 & Saltcake Solid & $\begin{array}{l}\text { S1-SltCk } \\
\text { (Solid) }\end{array}$ & $1.56 \mathrm{E}+02$ & TE & 1.53 & 1028 & $9.90 \mathrm{E}-02$ & $\mu \mathrm{Ci} / \mathrm{g}$ \\
\hline 241-S-111 & $\begin{array}{l}\text { Sludge (Liquid } \\
\& \text { Solid) }\end{array}$ & CWR1 (Solid) & $1.98 \mathrm{E}-01$ & $\mathrm{TS}$ & 1.67 & 38 & $3.13 \mathrm{E}-03$ & $\mu \mathrm{Ci} / \mathrm{g}$ \\
\hline 241-S-111 & $\begin{array}{l}\text { Sludge (Liquid } \\
\& \text { Solid) }\end{array}$ & R1 (Solid) & $4.98 \mathrm{E}+00$ & $\mathrm{TE}$ & 1.67 & 207 & $1.44 \mathrm{E}-02$ & $\mu \mathrm{Ci} / \mathrm{g}$ \\
\hline 241-S-111 & Total & & $1.92 \mathrm{E}+02$ & TS/TE & & & & \\
\hline 241-S-112 & $\begin{array}{l}\text { Sludge (Liquid } \\
\text { \& Solid) }\end{array}$ & R1 (Solid) & $1.37 \mathrm{E}-01$ & $\mathrm{~S}$ & 1.9 & 8.574 & 8.39E-03 & $\mu \mathrm{Ci} / \mathrm{g}$ \\
\hline $241-\mathrm{S}-112$ & Supernatant & NA (liquid) & $0.00 \mathrm{E}+00$ & $\mathrm{E}$ & 1.27 & 0.469 & $0.00 \mathrm{E}+00$ & $\mu \mathrm{Ci} / \mathrm{mL}$ \\
\hline 241-S-112 & Total & & $1.37 \mathrm{E}-01$ & $\mathrm{~S} / \mathrm{E}$ & & & & \\
\hline 241-SX-101 & $\begin{array}{l}\text { Saltcake } \\
\text { Interstitial } \\
\text { Liquid }\end{array}$ & $\begin{array}{l}\text { R-SltCk } \\
\text { (Liquid) }\end{array}$ & $4.29 \mathrm{E}+00$ & $\mathrm{TE}$ & 1.48 & 41 & $1.05 \mathrm{E}-01$ & $\mu \mathrm{Ci} / \mathrm{mL}$ \\
\hline 241-SX-101 & $\begin{array}{l}\text { Saltcake } \\
\text { Interstitial } \\
\text { Liquid }\end{array}$ & $\begin{array}{l}\text { S1-SltCk } \\
\text { (Liquid) }\end{array}$ & $6.74 \mathrm{E}+00$ & TS & 1.48 & 25 & $2.70 \mathrm{E}-01$ & $\mu \mathrm{Ci} / \mathrm{mL}$ \\
\hline
\end{tabular}




\begin{tabular}{|c|c|c|c|c|c|c|c|c|}
\hline Tank Name & Waste Phase & Waste Type & $\begin{array}{l}{ }^{99} \mathrm{Tc} \\
(\mathrm{Ci})\end{array}$ & Basis & $\begin{array}{l}\text { Density } \\
(\mathrm{g} / \mathrm{mL})\end{array}$ & $\begin{array}{c}\text { Volume } \\
(\mathrm{kL})\end{array}$ & Adjusted Conc. & Conc. Units \\
\hline 241-SX-101 & $\begin{array}{l}\text { Saltcake } \\
\text { Interstitial } \\
\text { Liquid }\end{array}$ & $\begin{array}{l}\text { S2-SltSlr } \\
\text { (Liquid) }\end{array}$ & $3.77 \mathrm{E}+00$ & $\mathrm{TS}$ & 1.48 & 14 & $2.70 \mathrm{E}-01$ & $\mu \mathrm{Ci} / \mathrm{mL}$ \\
\hline 241-SX-101 & Saltcake Solid & $\begin{array}{l}\text { R-SltCk } \\
\text { (Solid) }\end{array}$ & $4.81 \mathrm{E}+01$ & $\mathrm{TE}$ & 1.69 & 497 & $5.73 \mathrm{E}-02$ & $\mu \mathrm{Ci} / \mathrm{g}$ \\
\hline 241-SX-101 & Saltcake Solid & $\begin{array}{l}\text { S1-SltCk } \\
\text { (Solid) }\end{array}$ & $5.19 \mathrm{E}+01$ & $\mathrm{TE}$ & 1.69 & 296 & $1.04 \mathrm{E}-01$ & $\mu \mathrm{Ci} / \mathrm{g}$ \\
\hline 241-SX-101 & Saltcake Solid & $\begin{array}{l}\text { S2-SltSlr } \\
\text { (Solid) }\end{array}$ & $3.66 \mathrm{E}+01$ & $\mathrm{TE}$ & 1.69 & 166 & $1.30 \mathrm{E}-01$ & $\mu \mathrm{Ci} / \mathrm{g}$ \\
\hline 241-SX-101 & $\begin{array}{l}\text { Sludge (Liquid } \\
\text { \& Solid) }\end{array}$ & R1 (Solid) & $1.22 \mathrm{E}+01$ & $\mathrm{TE}$ & 1.69 & 545 & $1.33 \mathrm{E}-02$ & $\mu \mathrm{Ci} / \mathrm{g}$ \\
\hline 241-SX-101 & Total & & $1.64 \mathrm{E}+02$ & $\mathrm{TS} / \mathrm{TE}$ & & & & \\
\hline 241-SX-102 & $\begin{array}{l}\text { Saltcake } \\
\text { Interstitial } \\
\text { Liquid }\end{array}$ & $\begin{array}{l}\text { S1-SltCk } \\
\text { (Liquid) }\end{array}$ & $2.85 \mathrm{E}+01$ & $\mathrm{TS}$ & 1.46 & 105 & $2.71 \mathrm{E}-01$ & $\mu \mathrm{Ci} / \mathrm{mL}$ \\
\hline 241-SX-102 & $\begin{array}{l}\text { Saltcake } \\
\text { Interstitial } \\
\text { Liquid }\end{array}$ & $\begin{array}{l}\text { S2-SltSlr } \\
\text { (Liquid) }\end{array}$ & $2.98 \mathrm{E}+00$ & $\mathrm{TS}$ & 1.46 & 11 & $2.71 \mathrm{E}-01$ & $\mu \mathrm{Ci} / \mathrm{mL}$ \\
\hline 241-SX-102 & Saltcake Solid & $\begin{array}{l}\text { S1-SltCk } \\
\text { (Solid) }\end{array}$ & $1.29 \mathrm{E}+02$ & $\mathrm{TE}$ & 1.72 & 875 & $8.58 \mathrm{E}-02$ & $\mu \mathrm{Ci} / \mathrm{g}$ \\
\hline 241-SX-102 & Saltcake Solid & $\begin{array}{l}\text { S2-SltSlr } \\
\text { (Solid) }\end{array}$ & $1.70 \mathrm{E}+01$ & $\mathrm{TE}$ & 1.72 & 92 & $1.08 \mathrm{E}-01$ & $\mu \mathrm{Ci} / \mathrm{g}$ \\
\hline 241-SX-102 & $\begin{array}{l}\text { Sludge (Liquid } \\
\text { \& Solid) }\end{array}$ & R1 (Solid) & $3.95 \mathrm{E}+00$ & $\mathrm{TE}$ & 1.72 & 209 & $1.10 \mathrm{E}-02$ & $\mu \mathrm{Ci} / \mathrm{g}$ \\
\hline 241-SX-102 & Total & & $1.82 \mathrm{E}+02$ & $\mathrm{TS} / \mathrm{TE}$ & & & & \\
\hline 241-SX-103 & $\begin{array}{l}\text { Saltcake } \\
\text { Interstitial } \\
\text { Liquid }\end{array}$ & $\begin{array}{l}\text { R-SltCk } \\
\text { (Liquid) }\end{array}$ & $2.40 \mathrm{E}+00$ & $\mathrm{TE}$ & 1.47 & 22 & $1.09 \mathrm{E}-01$ & $\mu \mathrm{Ci} / \mathrm{mL}$ \\
\hline 241-SX-103 & $\begin{array}{l}\text { Saltcake } \\
\text { Interstitial } \\
\text { Liquid }\end{array}$ & $\begin{array}{l}\text { S1-SltCk } \\
\text { (Liquid) }\end{array}$ & $2.64 \mathrm{E}+01$ & $\mathrm{TS}$ & 1.47 & 94 & $2.81 \mathrm{E}-01$ & $\mu \mathrm{Ci} / \mathrm{mL}$ \\
\hline 241-SX-103 & Saltcake Solid & $\begin{array}{l}\text { R-SltCk } \\
\text { (Solid) }\end{array}$ & $6.40 \mathrm{E}+00$ & $\mathrm{TE}$ & 1.72 & 77 & $4.83 \mathrm{E}-02$ & $\mu \mathrm{Ci} / \mathrm{g}$ \\
\hline
\end{tabular}




\begin{tabular}{|c|c|c|c|c|c|c|c|c|}
\hline Tank Name & Waste Phase & Waste Type & $\begin{array}{l}{ }^{99} \mathrm{Tc} \\
(\mathrm{Ci})\end{array}$ & Basis & $\begin{array}{l}\text { Density } \\
(\mathrm{g} / \mathrm{mL})\end{array}$ & $\begin{array}{c}\text { Volume } \\
(\mathrm{kL})\end{array}$ & Adjusted Conc. & Conc. Units \\
\hline $241-S X-103$ & Saltcake Solid & $\begin{array}{l}\text { S1-Sltck } \\
\text { (Solid) }\end{array}$ & $2.39 \mathrm{E}+02$ & $\mathrm{TE}$ & 1.72 & 1439 & $9.65 \mathrm{E}-02$ & $\mu \mathrm{Ci} / \mathrm{g}$ \\
\hline 241-SX-103 & $\begin{array}{l}\text { Sludge (Liquid } \\
\text { \& Solid) }\end{array}$ & R1 (Solid) & $7.71 \mathrm{E}+00$ & $\mathrm{TE}$ & 1.88 & 294 & $1.39 \mathrm{E}-02$ & $\mu \mathrm{Ci} / \mathrm{g}$ \\
\hline 241-SX-103 & Total & & $2.82 \mathrm{E}+02$ & TS/TE & & & & \\
\hline 241-SX-104 & $\begin{array}{l}\text { Saltcake } \\
\text { Interstitial } \\
\text { Liquid }\end{array}$ & $\begin{array}{l}\text { R-SltCk } \\
\text { (Liquid) }\end{array}$ & $1.90 \mathrm{E}+00$ & $\mathrm{TE}$ & 1.47 & 17 & $1.12 \mathrm{E}-01$ & $\mu \mathrm{Ci} / \mathrm{mL}$ \\
\hline 241-SX-104 & $\begin{array}{l}\text { Saltcake } \\
\text { Interstitial } \\
\text { Liquid }\end{array}$ & $\begin{array}{l}\text { S1-SltCk } \\
\text { (Liquid) }\end{array}$ & $3.19 \mathrm{E}+01$ & TS & 1.47 & 111 & $2.87 \mathrm{E}-01$ & $\mu \mathrm{Ci} / \mathrm{mL}$ \\
\hline 241-SX-104 & Saltcake Solid & $\begin{array}{l}\text { R-SltCk } \\
\text { (Solid) }\end{array}$ & $1.44 \mathrm{E}+01$ & $\mathrm{TE}$ & 1.72 & 142 & $5.90 \mathrm{E}-02$ & $\mu \mathrm{Ci} / \mathrm{g}$ \\
\hline 241-SX-104 & Saltcake Solid & $\begin{array}{l}\text { S1-SltCk } \\
\text { (Solid) }\end{array}$ & $1.48 \mathrm{E}+02$ & $\mathrm{TE}$ & 1.68 & 903 & $9.74 \mathrm{E}-02$ & $\mu \mathrm{Ci} / \mathrm{g}$ \\
\hline 241-SX-104 & $\begin{array}{l}\text { Sludge (Liquid } \\
\& \text { Solid) }\end{array}$ & R1 (Solid) & $1.26 \mathrm{E}+01$ & $\mathrm{TE}$ & 1.77 & 515 & $1.38 \mathrm{E}-02$ & $\mu \mathrm{Ci} / \mathrm{g}$ \\
\hline 241-SX-104 & Total & & $2.09 \mathrm{E}+02$ & $\mathrm{TS} / \mathrm{TE}$ & & & & \\
\hline 241-SX-105 & $\begin{array}{l}\text { Saltcake } \\
\text { Interstitial } \\
\text { Liquid }\end{array}$ & $\begin{array}{l}\text { S1-SltCk } \\
\text { (Liquid) }\end{array}$ & $3.69 \mathrm{E}+01$ & TS & 1.47 & 123 & $3.00 \mathrm{E}-01$ & $\mu \mathrm{Ci} / \mathrm{mL}$ \\
\hline 241-SX-105 & Saltcake Solid & $\begin{array}{l}\text { S1-SltCk } \\
\text { (Solid) }\end{array}$ & $1.53 \mathrm{E}+02$ & $\mathrm{TE}$ & 1.64 & 1061 & $8.78 \mathrm{E}-02$ & $\mu \mathrm{Ci} / \mathrm{g}$ \\
\hline 241-SX-105 & $\begin{array}{l}\text { Sludge (Liquid } \\
\text { \& Solid) }\end{array}$ & R1 (Solid) & $4.36 \mathrm{E}+00$ & $\mathrm{TE}$ & 1.67 & 189 & $1.38 \mathrm{E}-02$ & $\mu \mathrm{Ci} / \mathrm{g}$ \\
\hline 241-SX-105 & $\begin{array}{l}\text { Sludge (Liquid } \\
\& \text { Solid) }\end{array}$ & R2 (Solid) & $3.10 \mathrm{E}+00$ & $\mathrm{TE}$ & 1.67 & 49 & $3.79 \mathrm{E}-02$ & $\mu \mathrm{Ci} / \mathrm{g}$ \\
\hline 241-SX-105 & Total & & $1.97 \mathrm{E}+02$ & $\mathrm{TS} / \mathrm{TE}$ & & & & \\
\hline 241-SX-106 & $\begin{array}{l}\text { Saltcake } \\
\text { Interstitial } \\
\text { Liquid }\end{array}$ & $\begin{array}{l}\text { S1-SltCk } \\
\text { (Liquid) }\end{array}$ & $6.30 \mathrm{E}+00$ & TS & 1.29 & 27 & 2.33E-01 & $\mu \mathrm{Ci} / \mathrm{mL}$ \\
\hline 241-SX-106 & $\begin{array}{l}\text { Saltcake } \\
\text { Interstitial } \\
\text { Liquid }\end{array}$ & $\begin{array}{l}\text { S2-SltSlr } \\
\text { (Liquid) }\end{array}$ & $2.85 \mathrm{E}+01$ & TS & 1.29 & 122 & $2.33 \mathrm{E}-01$ & $\mu \mathrm{Ci} / \mathrm{mL}$ \\
\hline
\end{tabular}




\begin{tabular}{|c|c|c|c|c|c|c|c|c|}
\hline Tank Name & Waste Phase & Waste Type & $\begin{array}{l}{ }^{99} \mathrm{Tc} \\
(\mathrm{Ci})\end{array}$ & Basis & $\begin{array}{l}\text { Density } \\
(\mathrm{g} / \mathrm{mL})\end{array}$ & $\begin{array}{c}\text { Volume } \\
(\mathrm{kL})\end{array}$ & Adjusted Conc. & Conc. Units \\
\hline 241-SX-106 & Saltcake Solid & $\begin{array}{l}\text { S1-SltCk } \\
\text { (Solid) }\end{array}$ & $3.36 \mathrm{E}+01$ & $\mathrm{TE}$ & 1.61 & 245 & $8.52 \mathrm{E}-02$ & $\mu \mathrm{Ci} / \mathrm{g}$ \\
\hline 241-SX-106 & Saltcake Solid & $\begin{array}{l}\text { S2-SltSlr } \\
\text { (Solid) }\end{array}$ & $1.90 \mathrm{E}+02$ & $\mathrm{TE}$ & 1.61 & 1107 & $1.07 \mathrm{E}-01$ & $\mu \mathrm{Ci} / \mathrm{g}$ \\
\hline 241-SX-106 & Total & & $2.59 \mathrm{E}+02$ & TS/TE & & & & \\
\hline 241-SX-107 & $\begin{array}{l}\text { Sludge (Liquid } \\
\text { \& Solid) }\end{array}$ & R1 (Solid) & $5.84 \mathrm{E}+00$ & $\mathrm{TE}$ & 1.77 & 239 & $1.38 \mathrm{E}-02$ & $\mu \mathrm{Ci} / \mathrm{g}$ \\
\hline 241-SX-107 & $\begin{array}{l}\text { Sludge (Liquid } \\
\text { \& Solid) }\end{array}$ & R2 (Solid) & $7.85 \mathrm{E}+00$ & $\mathrm{TE}$ & 1.77 & 117 & $3.79 \mathrm{E}-02$ & $\mu \mathrm{Ci} / \mathrm{g}$ \\
\hline 241-SX-107 & Total & & $1.37 \mathrm{E}+01$ & $\mathrm{TE}$ & & & & \\
\hline 241-SX-108 & Sludge Solid & R1 (Solid) & $5.76 \mathrm{E}+00$ & $\mathrm{TE}$ & 1.77 & 186 & $1.75 \mathrm{E}-02$ & $\mu \mathrm{Ci} / \mathrm{g}$ \\
\hline 241-SX-108 & Sludge Solid & R2 (Solid) & $8.00 \mathrm{E}+00$ & $\mathrm{TE}$ & 1.77 & 94 & $4.81 \mathrm{E}-02$ & $\mu \mathrm{Ci} / \mathrm{g}$ \\
\hline 241-SX-108 & Total & & $1.38 \mathrm{E}+01$ & $\mathrm{TE}$ & & & & \\
\hline 241-SX-109 & Saltcake Solid & $\begin{array}{l}\text { R-SltCk } \\
\text { (Solid) }\end{array}$ & $6.72 \mathrm{E}+01$ & TE & 1.72 & 662 & $5.90 \mathrm{E}-02$ & $\mu \mathrm{Ci} / \mathrm{g}$ \\
\hline 241-SX-109 & Sludge Solid & R1 (Solid) & $4.15 \mathrm{E}+00$ & TE & 1.77 & 170 & $1.38 \mathrm{E}-02$ & $\mu \mathrm{Ci} / \mathrm{g}$ \\
\hline 241-SX-109 & Sludge Solid & R2 (Solid) & $5.44 \mathrm{E}+00$ & $\mathrm{TE}$ & 1.77 & 81 & $3.79 \mathrm{E}-02$ & $\mu \mathrm{Ci} / \mathrm{g}$ \\
\hline 241-SX-109 & Total & & $7.68 \mathrm{E}+01$ & $\mathrm{TE}$ & & & & \\
\hline 241-SX-110 & Saltcake Solid & $\begin{array}{l}\text { R-SltCk } \\
\text { (Solid) }\end{array}$ & $2.84 \mathrm{E}+00$ & TE & 1.72 & 28 & $5.90 \mathrm{E}-02$ & $\mu \mathrm{Ci} / \mathrm{g}$ \\
\hline 241-SX-110 & Sludge Solid & R2 (Solid) & $1.24 \mathrm{E}+01$ & $\mathrm{TE}$ & 1.77 & 184 & 3.79E-02 & $\mu \mathrm{Ci} / \mathrm{g}$ \\
\hline 241-SX-110 & Total & & $1.52 \mathrm{E}+01$ & $\mathrm{TE}$ & & & & \\
\hline 241-SX-111 & Saltcake Solid & $\begin{array}{l}\text { R-SltCk } \\
\text { (Solid) }\end{array}$ & $6.80 \mathrm{E}+00$ & $\mathrm{TE}$ & 1.72 & 67 & $5.90 \mathrm{E}-02$ & $\mu \mathrm{Ci} / \mathrm{g}$ \\
\hline 241-SX-111 & $\begin{array}{l}\text { Sludge (Liquid } \\
\text { \& Solid) }\end{array}$ & R1 (Solid) & $4.01 \mathrm{E}+00$ & TE & 1.77 & 164 & $1.38 \mathrm{E}-02$ & $\mu \mathrm{Ci} / \mathrm{g}$ \\
\hline 241-SX-111 & $\begin{array}{l}\text { Sludge (Liquid } \\
\text { \& Solid) }\end{array}$ & R2 (Solid) & $1.38 \mathrm{E}+01$ & TE & 1.77 & 205 & 3.79E-02 & $\mu \mathrm{Ci} / \mathrm{g}$ \\
\hline 241-SX-111 & Total & & $2.46 \mathrm{E}+01$ & TE & & & & \\
\hline 241-SX-112 & $\begin{array}{l}\text { Sludge (Liquid } \\
\& \text { Solid) }\end{array}$ & R1 (Solid) & $3.52 \mathrm{E}+00$ & $\mathrm{TE}$ & 1.77 & 144 & $1.38 \mathrm{E}-02$ & $\mu \mathrm{Ci} / \mathrm{g}$ \\
\hline 241-SX-112 & $\begin{array}{l}\text { Sludge (Liquid } \\
\text { \& Solid) }\end{array}$ & R2 (Solid) & $9.33 \mathrm{E}+00$ & TE & 1.77 & 139 & $3.79 \mathrm{E}-02$ & $\mu \mathrm{Ci} / \mathrm{g}$ \\
\hline 241-SX-112 & Total & & $1.28 \mathrm{E}+01$ & TE & & & & \\
\hline
\end{tabular}




\begin{tabular}{|c|c|c|c|c|c|c|c|c|}
\hline Tank Name & Waste Phase & Waste Type & $\begin{array}{l}{ }^{99} \mathrm{Tc} \\
(\mathrm{Ci})\end{array}$ & Basis & $\begin{array}{l}\text { Density } \\
(\mathrm{g} / \mathrm{mL})\end{array}$ & $\begin{array}{c}\text { Volume } \\
(\mathrm{kL})\end{array}$ & Adjusted Conc. & Conc. Units \\
\hline 241-SX-113 & Sludge Solid & DE (Solid) & $1.36 \mathrm{E}+00$ & $\mathrm{TE}$ & 1.43 & 64 & $1.48 \mathrm{E}-02$ & $\mu \mathrm{Ci} / \mathrm{g}$ \\
\hline 241-SX-113 & Sludge Solid & R1 (Solid) & $1.95 \mathrm{E}-01$ & $\mathrm{TE}$ & 1.43 & 8 & $1.71 \mathrm{E}-02$ & $\mu \mathrm{Ci} / \mathrm{g}$ \\
\hline 241-SX-113 & Total & & $1.55 \mathrm{E}+00$ & $\mathrm{TE}$ & & & & \\
\hline 241-SX-114 & $\begin{array}{l}\text { Saltcake } \\
\text { Interstitial } \\
\text { Liquid }\end{array}$ & $\begin{array}{l}\text { R-SltCk } \\
\text { (Liquid) }\end{array}$ & $2.60 \mathrm{E}+00$ & $\mathrm{TE}$ & 1.5 & 26 & $1.00 \mathrm{E}-01$ & $\mu \mathrm{Ci} / \mathrm{mL}$ \\
\hline 241-SX-114 & Saltcake Solid & $\begin{array}{l}\text { R-SltCk } \\
\text { (Solid) }\end{array}$ & $8.52 \mathrm{E}+00$ & $\mathrm{TE}$ & 1.72 & 84 & $5.90 \mathrm{E}-02$ & $\mu \mathrm{Ci} / \mathrm{g}$ \\
\hline 241-SX-114 & $\begin{array}{l}\text { Sludge (Liquid } \\
\text { \& Solid) }\end{array}$ & R1 (Solid) & $7.28 \mathrm{E}+00$ & $\mathrm{TE}$ & 1.77 & 298 & $1.38 \mathrm{E}-02$ & $\mu \mathrm{Ci} / \mathrm{g}$ \\
\hline 241-SX-114 & $\begin{array}{l}\text { Sludge (Liquid } \\
\& \text { Solid) }\end{array}$ & R2 (Solid) & $1.21 \mathrm{E}+01$ & $\mathrm{TE}$ & 1.77 & 180 & $3.79 \mathrm{E}-02$ & $\mu \mathrm{Ci} / \mathrm{g}$ \\
\hline 241-SX-114 & Total & & $3.05 \mathrm{E}+01$ & $\mathrm{TE}$ & & & & \\
\hline 241-SX-115 & Sludge Solid & R2 (Solid) & $1.25 \mathrm{E}+00$ & $\mathrm{TE}$ & 1.77 & 16 & 4.41E-02 & $\mu \mathrm{Ci} / \mathrm{g}$ \\
\hline 241-SX-115 & Total & & $1.25 \mathrm{E}+00$ & $\mathrm{TE}$ & & & & \\
\hline 241-SY-101 & $\begin{array}{l}\text { Saltcake (Liquid } \\
\text { \& Solid) }\end{array}$ & $\begin{array}{l}\text { S2-SltSlr } \\
\text { (Solid) }\end{array}$ & $2.58 \mathrm{E}+02$ & $\mathrm{~S}$ & 1.66 & 878 & $1.77 \mathrm{E}-01$ & $\mu \mathrm{Ci} / \mathrm{g}$ \\
\hline 241-SY-101 & Supernatant & NA (Liquid) & $4.04 \mathrm{E}+01$ & $\mathrm{E}$ & 1.13 & 3246 & $1.25 \mathrm{E}-02$ & $\mu \mathrm{Ci} / \mathrm{mL}$ \\
\hline 241-SY-101 & Total & & $2.98 \mathrm{E}+02$ & $\mathrm{~S} / \mathrm{E}$ & & & & \\
\hline 241-SY-102 & $\begin{array}{l}\text { Sludge } \\
\text { Interstitial } \\
\text { Liquid }\end{array}$ & NA (Liquid) & $1.79 \mathrm{E}+01$ & $\mathrm{E}$ & 1.28 & 151 & $1.18 \mathrm{E}-01$ & $\mu \mathrm{Ci} / \mathrm{mL}$ \\
\hline 241-SY-102 & $\begin{array}{l}\text { Sludge } \\
\text { Interstitial } \\
\text { Liquid }\end{array}$ & Z (Liquid) & $1.58 \mathrm{E}+01$ & $\mathrm{~S}$ & 1.36 & 82 & $1.93 \mathrm{E}-01$ & $\mu \mathrm{Ci} / \mathrm{mL}$ \\
\hline 241-SY-102 & Sludge Solid & NA (Sludge) & $1.12 \mathrm{E}+02$ & $\mathrm{E}$ & 1.65 & 336 & $2.02 \mathrm{E}-01$ & $\mu \mathrm{Ci} / \mathrm{g}$ \\
\hline 241-SY-102 & Sludge Solid & Z (Solid) & $6.10 \mathrm{E}+01$ & $\mathrm{~S}$ & 1.65 & 183 & $2.02 \mathrm{E}-01$ & $\mu \mathrm{Ci} / \mathrm{g}$ \\
\hline 241-SY-102 & Supernatant & NA (Liquid) & $3.70 \mathrm{E}+01$ & $\mathrm{E}$ & 1.15 & 1382 & $2.67 \mathrm{E}-02$ & $\mu \mathrm{Ci} / \mathrm{mL}$ \\
\hline 241-SY-102 & Total & & $2.44 \mathrm{E}+02$ & $\mathrm{~S} / \mathrm{E}$ & & & & \\
\hline 241-SY-103 & $\begin{array}{l}\text { Saltcake (Liquid } \\
\text { \& Solid) }\end{array}$ & $\begin{array}{l}\text { S2-SltSlr } \\
\text { (Solid) }\end{array}$ & $4.92 \mathrm{E}+02$ & $\mathrm{~S}$ & 1.67 & 1258 & $2.34 \mathrm{E}-01$ & $\mu \mathrm{Ci} / \mathrm{g}$ \\
\hline 241-SY-103 & Supernatant & $\begin{array}{l}\text { S2-SltSlr } \\
\text { (Liquid) }\end{array}$ & $5.19 \mathrm{E}+02$ & $\mathrm{E}$ & 1.49 & 1444 & $3.59 \mathrm{E}-01$ & $\mu \mathrm{Ci} / \mathrm{mL}$ \\
\hline 241-SY-103 & Total & & $1.01 \mathrm{E}+03$ & $\mathrm{~S} / \mathrm{E}$ & & & & \\
\hline
\end{tabular}




\begin{tabular}{|c|c|c|c|c|c|c|c|c|}
\hline Tank Name & Waste Phase & Waste Type & $\begin{array}{l}{ }^{99} \mathrm{Tc} \\
(\mathrm{Ci})\end{array}$ & Basis & $\begin{array}{l}\text { Density } \\
(\mathrm{g} / \mathrm{mL})\end{array}$ & $\begin{array}{c}\text { Volume } \\
(\mathrm{kL})\end{array}$ & Adjusted Conc. & Conc. Units \\
\hline $241-\mathrm{T}-101$ & $\begin{array}{l}\text { Saltcake } \\
\text { Interstitial } \\
\text { Liquid }\end{array}$ & $\begin{array}{l}\text { T2-SltCk } \\
\text { (Liquid) }\end{array}$ & $1.50 \mathrm{E}+01$ & TS & 1.45 & 57 & $2.64 \mathrm{E}-01$ & $\mu \mathrm{Ci} / \mathrm{mL}$ \\
\hline 241-T-101 & Saltcake Solid & $\begin{array}{l}\text { T2-SltCk } \\
\text { (Solid) }\end{array}$ & $1.93 \mathrm{E}+01$ & TE & 1.64 & 179 & $6.58 \mathrm{E}-02$ & $\mu \mathrm{Ci} / \mathrm{g}$ \\
\hline $241-\mathrm{T}-101$ & $\begin{array}{l}\text { Sludge (Liquid } \\
\& \text { Solid) }\end{array}$ & CWR2 (Solid) & $4.58 \mathrm{E}-02$ & $\mathrm{TE}$ & 1.46 & 140 & $2.24 \mathrm{E}-04$ & $\mu \mathrm{Ci} / \mathrm{g}$ \\
\hline 241-T-101 & Total & & $3.44 \mathrm{E}+01$ & $\mathrm{TS} / \mathrm{TE}$ & & & & \\
\hline 241-T-102 & $\begin{array}{l}\text { Sludge (Liquid } \\
\& \text { Solid) }\end{array}$ & CWP2 (Solid) & $1.49 \mathrm{E}+00$ & $\mathrm{~S}$ & 1.79 & 64 & $1.30 \mathrm{E}-02$ & $\mu \mathrm{Ci} / \mathrm{g}$ \\
\hline 241-T-102 & $\begin{array}{l}\text { Sludge (Liquid } \\
\text { \& Solid) }\end{array}$ & MW2 (Solid) & $1.34 \mathrm{E}-02$ & $\mathrm{TE}$ & 1.85 & 8 & $9.04 \mathrm{E}-04$ & $\mu \mathrm{Ci} / \mathrm{g}$ \\
\hline 241-T-102 & Supernatant & CSR (Liquid) & $5.63 \mathrm{E}+00$ & TE & 1.14 & 48 & $1.17 \mathrm{E}-01$ & $\mu \mathrm{Ci} / \mathrm{mL}$ \\
\hline 241-T-102 & Total & & $7.13 \mathrm{E}+00$ & $\mathrm{~S} / \mathrm{TE}$ & & & & \\
\hline $241-\mathrm{T}-103$ & $\begin{array}{l}\text { Sludge (Liquid } \\
\text { \& Solid) }\end{array}$ & CWP2 (Solid) & $1.42 \mathrm{E}-02$ & $\mathrm{TE}$ & 1.68 & 64 & $1.32 \mathrm{E}-04$ & $\mu \mathrm{Ci} / \mathrm{g}$ \\
\hline 241-T-103 & $\begin{array}{l}\text { Sludge (Liquid } \\
\& \text { Solid) }\end{array}$ & CWR1 (Solid) & $1.00 \mathrm{E}-01$ & TS & 1.8 & 19 & $2.93 \mathrm{E}-03$ & $\mu \mathrm{Ci} / \mathrm{g}$ \\
\hline 241-T-103 & $\begin{array}{l}\text { Sludge (Liquid } \\
\& \text { Solid) }\end{array}$ & MW2 (Solid) & $6.69 \mathrm{E}-03$ & TE & 1.85 & 4 & $9.04 \mathrm{E}-04$ & $\mu \mathrm{Ci} / \mathrm{g}$ \\
\hline $241-\mathrm{T}-103$ & Supernatant & CSR (Liquid) & $2.16 \mathrm{E}+00$ & $\mathrm{TE}$ & 1.19 & 15 & $1.44 \mathrm{E}-01$ & $\mu \mathrm{Ci} / \mathrm{mL}$ \\
\hline $241-\mathrm{T}-103$ & Total & & $2.28 \mathrm{E}+00$ & $\mathrm{TS} / \mathrm{TE}$ & & & & \\
\hline 241-T-104 & $\begin{array}{l}\text { Sludge (Liquid } \\
\& \text { Solid) }\end{array}$ & $1 \mathrm{C}$ (Solid) & $9.74 \mathrm{E}-01$ & $\mathrm{~S}$ & 1.29 & 1199 & $6.30 \mathrm{E}-04$ & $\mu \mathrm{Ci} / \mathrm{g}$ \\
\hline 241-T-104 & Total & & $9.74 \mathrm{E}-01$ & $\mathrm{~S} / \mathrm{E}$ & & & & \\
\hline $241-\mathrm{T}-105$ & $\begin{array}{l}\text { Sludge (Liquid } \\
\text { \& Solid) }\end{array}$ & 1C (Solid) & $2.14 \mathrm{E}+00$ & $\mathrm{~S}$ & 1.32 & 6 & $2.70 \mathrm{E}-01$ & $\mu \mathrm{Ci} / \mathrm{g}$ \\
\hline 241-T-105 & $\begin{array}{l}\text { Sludge (Liquid } \\
\& \text { Solid) }\end{array}$ & 2C (Solid) & $5.55 \mathrm{E}-04$ & $\mathrm{TE}$ & 1.51 & 273 & $1.35 \mathrm{E}-06$ & $\mu \mathrm{Ci} / \mathrm{g}$ \\
\hline $241-\mathrm{T}-105$ & $\begin{array}{l}\text { Sludge (Liquid } \\
\& \text { Solid) }\end{array}$ & CWR1 (Solid) & $3.28 \mathrm{E}+01$ & $\mathrm{~S}$ & 1.32 & 92 & $2.70 \mathrm{E}-01$ & $\mu \mathrm{Ci} / \mathrm{g}$ \\
\hline 241-T-105 & Total & & $3.50 \mathrm{E}+01$ & $\mathrm{~S} / \mathrm{TE}$ & & & & \\
\hline 241-T-106 & $\begin{array}{l}\text { Sludge (Liquid } \\
\text { \& Solid) }\end{array}$ & 1C (Solid) & $2.66 \mathrm{E}+00$ & TS & 1.43 & 38 & $4.90 \mathrm{E}-02$ & $\mu \mathrm{Ci} / \mathrm{g}$ \\
\hline
\end{tabular}




\begin{tabular}{|c|c|c|c|c|c|c|c|c|}
\hline Tank Name & Waste Phase & Waste Type & $\begin{array}{l}{ }^{99} \mathrm{Tc} \\
(\mathrm{Ci})\end{array}$ & Basis & $\begin{array}{l}\text { Density } \\
(\mathrm{g} / \mathrm{mL})\end{array}$ & $\begin{array}{l}\text { Volume } \\
(\mathrm{kL})\end{array}$ & Adjusted Conc. & Conc. Units \\
\hline 241-T-106 & $\begin{array}{l}\text { Sludge (Liquid } \\
\& \text { Solid) }\end{array}$ & CWR1 (Solid) & $1.75 \mathrm{E}-01$ & $\mathrm{TS}$ & 1.8 & 34 & $2.86 \mathrm{E}-03$ & $\mu \mathrm{Ci} / \mathrm{g}$ \\
\hline 241-T-106 & $\begin{array}{l}\text { Sludge (Liquid } \\
\text { \& Solid) }\end{array}$ & CWR2 (Solid) & $6.15 \mathrm{E}-03$ & $\mathrm{TE}$ & 1.46 & 10 & $4.22 \mathrm{E}-04$ & $\mu \mathrm{Ci} / \mathrm{g}$ \\
\hline 241-T-106 & Total & & $2.85 \mathrm{E}+00$ & TS/TE & & & & \\
\hline 241-T-107 & $\begin{array}{l}\text { Sludge (Liquid } \\
\& \text { Solid) }\end{array}$ & 1C (Solid) & $4.12 \mathrm{E}+01$ & $\mathrm{~S}$ & 1.56 & 559 & 4.73E-02 & $\mu \mathrm{Ci} / \mathrm{g}$ \\
\hline 241-T-107 & $\begin{array}{l}\text { Sludge (Liquid } \\
\text { \& Solid) }\end{array}$ & CWP2 (Solid) & $2.36 \mathrm{E}+00$ & $\mathrm{~S}$ & 1.56 & 32 & 4.73E-02 & $\mu \mathrm{Ci} / \mathrm{g}$ \\
\hline 241-T-107 & $\begin{array}{l}\text { Sludge (Liquid } \\
\& \text { Solid) }\end{array}$ & TBP (Solid) & $4.72 \mathrm{E}+00$ & $\mathrm{~S}$ & 1.56 & 64 & 4.73E-02 & $\mu \mathrm{Ci} / \mathrm{g}$ \\
\hline 241-T-107 & Total & & $4.83 \mathrm{E}+01$ & $\mathrm{~S}$ & & & & \\
\hline 241-T-108 & $\begin{array}{l}\text { Saltcake } \\
\text { Interstitial } \\
\text { Liquid }\end{array}$ & $\begin{array}{l}\text { T1-SltCk } \\
\text { (Liquid) }\end{array}$ & $3.28 \mathrm{E}-02$ & $\mathrm{TE}$ & 1.26 & 10 & $3.28 \mathrm{E}-03$ & $\mu \mathrm{Ci} / \mathrm{mL}$ \\
\hline 241-T-108 & Saltcake Solid & $\begin{array}{l}\text { T1-SltCk } \\
\text { (Solid) }\end{array}$ & 4.40E-02 & $\mathrm{TE}$ & 1.72 & 30 & $8.54 \mathrm{E}-04$ & $\mu \mathrm{Ci} / \mathrm{g}$ \\
\hline 241-T-108 & $\begin{array}{l}\text { Sludge (Liquid } \\
\& \text { Solid) }\end{array}$ & 1C (Solid) & $6.95 \mathrm{E}-01$ & TS & 1.43 & 20 & $2.43 \mathrm{E}-02$ & $\mu \mathrm{Ci} / \mathrm{g}$ \\
\hline 241-T-108 & Total & & 7.72E-01 & $\mathrm{TS} / \mathrm{TE}$ & & & & \\
\hline 241-T-109 & $\begin{array}{l}\text { Saltcake } \\
\text { Interstitial } \\
\text { Liquid }\end{array}$ & $\begin{array}{l}\text { T1-SltCk } \\
\text { (Liquid) }\end{array}$ & $1.25 \mathrm{E}-01$ & $\mathrm{TE}$ & 1.26 & 38 & $3.28 \mathrm{E}-03$ & $\mu \mathrm{Ci} / \mathrm{mL}$ \\
\hline 241-T-109 & Saltcake Solid & $\begin{array}{l}\text { T1-SltCk } \\
\text { (Solid) }\end{array}$ & $1.77 \mathrm{E}-01$ & TE & 1.72 & 197 & $5.24 \mathrm{E}-04$ & $\mu \mathrm{Ci} / \mathrm{g}$ \\
\hline 241-T-109 & Total & & $3.02 \mathrm{E}-01$ & $\mathrm{TE}$ & & & & \\
\hline 241-T-110 & $\begin{array}{l}\text { Sludge (Liquid } \\
\text { \& Solid) }\end{array}$ & 224-2 (Solid) & 8.49E-07 & $\mathrm{TE}$ & 1.25 & 37 & $1.84 \mathrm{E}-08$ & $\mu \mathrm{Ci} / \mathrm{g}$ \\
\hline $241-\mathrm{T}-110$ & $\begin{array}{l}\text { Sludge (Liquid } \\
\text { \& Solid) }\end{array}$ & 2C (Solid) & $1.21 \mathrm{E}-03$ & $\mathrm{TE}$ & 1.25 & 1360 & 7.09E-07 & $\mu \mathrm{Ci} / \mathrm{g}$ \\
\hline $241-\mathrm{T}-110$ & Supernatant & 2C1 (Liquid) & $9.02 \mathrm{E}-06$ & $\mathrm{TE}$ & 1.05 & 3 & $3.01 \mathrm{E}-06$ & $\mu \mathrm{Ci} / \mathrm{mL}$ \\
\hline $241-\mathrm{T}-110$ & Total & & $1.22 \mathrm{E}-03$ & $\mathrm{TE}$ & & & & \\
\hline 241-T-111 & $\begin{array}{l}\text { Sludge (Liquid } \\
\text { \& Solid) }\end{array}$ & 224-2 (Solid) & $8.87 \mathrm{E}+00$ & $\mathrm{~S}$ & 1.24 & 904 & 7.92E-03 & $\mu \mathrm{Ci} / \mathrm{g}$ \\
\hline
\end{tabular}




\begin{tabular}{|c|c|c|c|c|c|c|c|c|}
\hline Tank Name & Waste Phase & Waste Type & $\begin{array}{l}{ }^{99} \mathrm{Tc} \\
(\mathrm{Ci})\end{array}$ & Basis & $\begin{array}{l}\text { Density } \\
(\mathrm{g} / \mathrm{mL})\end{array}$ & $\begin{array}{c}\text { Volume } \\
(\mathrm{kL})\end{array}$ & Adjusted Conc. & Conc. Units \\
\hline $241-T-111$ & $\begin{array}{l}\text { Sludge (Liquid } \\
\& \text { Solid) }\end{array}$ & 2C (Solid) & $7.73 \mathrm{E}+00$ & $\mathrm{~S}$ & 1.24 & 787 & $7.92 \mathrm{E}-03$ & $\mu \mathrm{Ci} / \mathrm{g}$ \\
\hline 241-T-111 & Total & & $1.66 \mathrm{E}+01$ & S & & & & \\
\hline 241-T-112 & $\begin{array}{l}\text { Sludge (Liquid } \\
\text { \& Solid) }\end{array}$ & 224-2 (Solid) & $2.28 \mathrm{E}-06$ & $\mathrm{TE}$ & 1.28 & 91 & $1.96 \mathrm{E}-08$ & $\mu \mathrm{Ci} / \mathrm{g}$ \\
\hline 241-T-112 & $\begin{array}{l}\text { Sludge (Liquid } \\
\& \text { Solid) }\end{array}$ & 2C (Solid) & $1.31 \mathrm{E}-04$ & TE & 1.28 & 135 & $7.56 \mathrm{E}-07$ & $\mu \mathrm{Ci} / \mathrm{g}$ \\
\hline $241-\mathrm{T}-112$ & Supernatant & NA (Liquid) & $2.12 \mathrm{E}+00$ & $\mathrm{E}$ & 1.1 & 27 & $7.87 \mathrm{E}-02$ & $\mu \mathrm{Ci} / \mathrm{mL}$ \\
\hline 241-T-112 & Total & & $2.12 \mathrm{E}+00$ & $\mathrm{E} / \mathrm{TE}$ & & & & \\
\hline 241-T-201 & $\begin{array}{l}\text { Sludge (Liquid } \\
\& \text { Solid) }\end{array}$ & 224-1 (Solid) & $1.57 \mathrm{E}-06$ & TE & 1.31 & 107 & $1.12 \mathrm{E}-08$ & $\mu \mathrm{Ci} / \mathrm{g}$ \\
\hline 241-T-201 & Supernatant & 224-1 (Liquid) & $1.81 \mathrm{E}-07$ & $\mathrm{TE}$ & 1.06 & 8 & $2.27 \mathrm{E}-08$ & $\mu \mathrm{Ci} / \mathrm{mL}$ \\
\hline 241-T-201 & Total & & $1.75 \mathrm{E}-06$ & $\mathrm{TE}$ & & & & \\
\hline 241-T-202 & $\begin{array}{l}\text { Sludge (Liquid } \\
\text { \& Solid) }\end{array}$ & 224-2 (Solid) & $1.65 \mathrm{E}-06$ & TE & 1.18 & 77 & $1.81 \mathrm{E}-08$ & $\mu \mathrm{Ci} / \mathrm{g}$ \\
\hline 241-T-202 & Total & & $1.65 \mathrm{E}-06$ & TE & & & & \\
\hline 241-T-203 & $\begin{array}{l}\text { Sludge (Liquid } \\
\& \text { Solid) }\end{array}$ & 224-2 (Solid) & $2.96 \mathrm{E}-06$ & TE & 1.22 & 136 & $1.78 \mathrm{E}-08$ & $\mu \mathrm{Ci} / \mathrm{g}$ \\
\hline 241-T-203 & Total & & $2.96 \mathrm{E}-06$ & TE & & & & \\
\hline 241-T-204 & $\begin{array}{l}\text { Sludge (Liquid } \\
\& \text { Solid) }\end{array}$ & 224-2 (Solid) & $3.00 \mathrm{E}-06$ & TE & 1.18 & 136 & $1.87 \mathrm{E}-08$ & $\mu \mathrm{Ci} / \mathrm{g}$ \\
\hline 241-T-204 & Total & & $3.00 \mathrm{E}-06$ & TE & & & & \\
\hline 241-TX-101 & $\begin{array}{l}\text { Saltcake } \\
\text { Interstitial } \\
\text { Liquid }\end{array}$ & $\begin{array}{l}\text { T2-SltCk } \\
\text { (Liquid) }\end{array}$ & $3.17 \mathrm{E}+00$ & TS & 1.45 & 12 & $2.64 \mathrm{E}-01$ & $\mu \mathrm{Ci} / \mathrm{mL}$ \\
\hline 241-TX-101 & Saltcake Solid & $\begin{array}{l}\text { T2-SltCk } \\
\text { (Solid) }\end{array}$ & $4.21 \mathrm{E}+00$ & $\mathrm{TE}$ & 1.64 & 39 & $6.58 \mathrm{E}-02$ & $\mu \mathrm{Ci} / \mathrm{g}$ \\
\hline 241-TX-101 & $\begin{array}{l}\text { Sludge (Liquid } \\
\text { \& Solid) }\end{array}$ & MW2 (Solid) & $1.84 \mathrm{E}-02$ & TE & 1.85 & 11 & $9.04 \mathrm{E}-04$ & $\mu \mathrm{Ci} / \mathrm{g}$ \\
\hline 241-TX-101 & $\begin{array}{l}\text { Sludge (Liquid } \\
\text { \& Solid) }\end{array}$ & R1 (Solid) & $6.47 \mathrm{E}+00$ & TE & 1.77 & 265 & $1.38 \mathrm{E}-02$ & $\mu \mathrm{Ci} / \mathrm{g}$ \\
\hline 241-TX-101 & $\begin{array}{l}\text { Sludge (Liquid } \\
\text { \& Solid) }\end{array}$ & Z (Solid) & $0.00 \mathrm{E}+00$ & TE & 1.76 & 1 & $0.00 \mathrm{E}+00$ & $\mu \mathrm{Ci} / \mathrm{g}$ \\
\hline 241-TX-101 & Total & & $1.39 \mathrm{E}+01$ & TS/TE & & & & \\
\hline
\end{tabular}




\begin{tabular}{|c|c|c|c|c|c|c|c|c|}
\hline Tank Name & Waste Phase & Waste Type & $\begin{array}{l}{ }^{99} \mathrm{Tc} \\
(\mathrm{Ci})\end{array}$ & Basis & $\begin{array}{l}\text { Density } \\
(\mathrm{g} / \mathrm{mL})\end{array}$ & $\begin{array}{l}\text { Volume } \\
(\mathrm{kL})\end{array}$ & Adjusted Conc. & Conc. Units \\
\hline $241-\mathrm{TX}-102$ & $\begin{array}{l}\text { Saltcake } \\
\text { Interstitial } \\
\text { Liquid }\end{array}$ & $\begin{array}{l}\text { T2-SltCk } \\
\text { (Liquid) }\end{array}$ & $3.19 \mathrm{E}+01$ & $\mathrm{TS}$ & 1.45 & 121 & $2.64 \mathrm{E}-01$ & $\mu \mathrm{Ci} / \mathrm{mL}$ \\
\hline 241-TX-102 & Saltcake Solid & $\begin{array}{l}\text { T2-SltCk } \\
\text { (Solid) }\end{array}$ & $7.47 \mathrm{E}+01$ & $\mathrm{TE}$ & 1.64 & 692 & $6.58 \mathrm{E}-02$ & $\mu \mathrm{Ci} / \mathrm{g}$ \\
\hline 241-TX-102 & $\begin{array}{l}\text { Sludge (Liquid } \\
\& \text { Solid) }\end{array}$ & MW2 (Solid) & $1.34 \mathrm{E}-02$ & $\mathrm{TE}$ & 1.85 & 8 & $9.04 \mathrm{E}-04$ & $\mu \mathrm{Ci} / \mathrm{g}$ \\
\hline 241-TX-102 & Total & & $1.07 \mathrm{E}+02$ & TS/TE & & & & \\
\hline 241-TX-103 & $\begin{array}{l}\text { Saltcake } \\
\text { Interstitial } \\
\text { Liquid }\end{array}$ & $\begin{array}{l}\text { T1-SltCk } \\
\text { (Liquid) }\end{array}$ & $9.84 \mathrm{E}-03$ & $\mathrm{TE}$ & 1.26 & 3 & $3.28 \mathrm{E}-03$ & $\mu \mathrm{Ci} / \mathrm{mL}$ \\
\hline 241-TX-103 & $\begin{array}{l}\text { Saltcake } \\
\text { Interstitial } \\
\text { Liquid }\end{array}$ & $\begin{array}{l}\text { T2-SltCk } \\
\text { (Liquid) }\end{array}$ & $2.16 \mathrm{E}+01$ & TS & 1.45 & 82 & $2.64 \mathrm{E}-01$ & $\mu \mathrm{Ci} / \mathrm{mL}$ \\
\hline 241-TX-103 & Saltcake Solid & $\begin{array}{l}\text { T1-SltCk } \\
\text { (Solid) }\end{array}$ & $1.19 \mathrm{E}-02$ & $\mathrm{TE}$ & 1.72 & 9 & 7.69E-04 & $\mu \mathrm{Ci} / \mathrm{g}$ \\
\hline 241-TX-103 & Saltcake Solid & $\begin{array}{l}\text { T2-SltCk } \\
\text { (Solid) }\end{array}$ & $4.90 \mathrm{E}+01$ & $\mathrm{TE}$ & 1.64 & 454 & $6.58 \mathrm{E}-02$ & $\mu \mathrm{Ci} / \mathrm{g}$ \\
\hline 241-TX-103 & Total & & $7.07 \mathrm{E}+01$ & $\mathrm{TS} / \mathrm{TE}$ & & & & \\
\hline 241-TX-104 & $\begin{array}{l}\text { Saltcake } \\
\text { Interstitial } \\
\text { Liquid }\end{array}$ & $\begin{array}{l}\text { T2-SltCk } \\
\text { (Liquid) }\end{array}$ & $7.43 \mathrm{E}+00$ & TS & 1.44 & 30 & $2.48 \mathrm{E}-01$ & $\mu \mathrm{Ci} / \mathrm{mL}$ \\
\hline 241-TX-104 & Saltcake Solid & $\begin{array}{l}\text { T2-SltCk } \\
\text { (Solid) }\end{array}$ & $7.58 \mathrm{E}+00$ & $\mathrm{TE}$ & 1.62 & 93 & $5.03 \mathrm{E}-02$ & $\mu \mathrm{Ci} / \mathrm{g}$ \\
\hline 241-TX-104 & $\begin{array}{l}\text { Sludge (Liquid } \\
\& \text { Solid) }\end{array}$ & R1 (Solid) & $2.43 \mathrm{E}+00$ & $\mathrm{TE}$ & 1.89 & 130 & $9.89 \mathrm{E}-03$ & $\mu \mathrm{Ci} / \mathrm{g}$ \\
\hline 241-TX-104 & Supernatant & $\begin{array}{l}\text { T2-SltCk } \\
\text { (Liquid) }\end{array}$ & $2.23 \mathrm{E}+00$ & TS & 1.44 & 9 & $2.48 \mathrm{E}-01$ & $\mu \mathrm{Ci} / \mathrm{mL}$ \\
\hline 241-TX-104 & Total & & $1.97 \mathrm{E}+01$ & $\mathrm{TS} / \mathrm{TE}$ & & & & \\
\hline 241-TX-105 & $\begin{array}{l}\text { Saltcake } \\
\text { Interstitial } \\
\text { Liquid }\end{array}$ & $\begin{array}{l}\text { T2-SltCk } \\
\text { (Liquid) }\end{array}$ & $2.64 \mathrm{E}+01$ & TS & 1.45 & 100 & 2.64E-01 & $\mu \mathrm{Ci} / \mathrm{mL}$ \\
\hline 241-TX-105 & Saltcake Solid & $\begin{array}{l}\text { T2-SltCk } \\
\text { (Solid) }\end{array}$ & $2.18 \mathrm{E}+02$ & $\mathrm{TE}$ & 1.64 & 2020 & $6.58 \mathrm{E}-02$ & $\mu \mathrm{Ci} / \mathrm{g}$ \\
\hline
\end{tabular}




\begin{tabular}{|c|c|c|c|c|c|c|c|c|}
\hline Tank Name & Waste Phase & Waste Type & $\begin{array}{l}{ }^{99} \mathrm{Tc} \\
(\mathrm{Ci})\end{array}$ & Basis & $\begin{array}{l}\text { Density } \\
(\mathrm{g} / \mathrm{mL})\end{array}$ & $\begin{array}{c}\text { Volume } \\
(\mathrm{kL})\end{array}$ & Adjusted Conc. & Conc. Units \\
\hline 241-TX-105 & $\begin{array}{l}\text { Sludge (Liquid } \\
\text { \& Solid) }\end{array}$ & MW2 (Solid) & $5.18 \mathrm{E}-02$ & $\mathrm{TE}$ & 1.85 & 31 & $9.04 \mathrm{E}-04$ & $\mu \mathrm{Ci} / \mathrm{g}$ \\
\hline 241-TX-105 & $\begin{array}{l}\text { Sludge (Liquid } \\
\text { \& Solid) }\end{array}$ & Z (Solid) & $0.00 \mathrm{E}+00$ & $\mathrm{TE}$ & 1.76 & 11 & $0.00 \mathrm{E}+00$ & $\mu \mathrm{Ci} / \mathrm{g}$ \\
\hline 241-TX-105 & Total & & $2.44 \mathrm{E}+02$ & $\mathrm{TS} / \mathrm{TE}$ & & & & \\
\hline 241-TX-106 & $\begin{array}{l}\text { Saltcake } \\
\text { Interstitial } \\
\text { Liquid }\end{array}$ & $\begin{array}{l}\text { T2-SltCk } \\
\text { (Liquid) }\end{array}$ & $4.01 \mathrm{E}+01$ & $\mathrm{TS}$ & 1.45 & 152 & $2.64 \mathrm{E}-01$ & $\mu \mathrm{Ci} / \mathrm{mL}$ \\
\hline 241-TX-106 & Saltcake Solid & $\begin{array}{l}\text { T2-SltCk } \\
\text { (Solid) }\end{array}$ & $1.24 \mathrm{E}+02$ & $\mathrm{TE}$ & 1.64 & 1147 & $6.58 \mathrm{E}-02$ & $\mu \mathrm{Ci} / \mathrm{g}$ \\
\hline 241-TX-106 & $\begin{array}{l}\text { Sludge (Liquid } \\
\text { \& Solid) }\end{array}$ & MW2 (Solid) & $6.69 \mathrm{E}-03$ & $\mathrm{TE}$ & 1.85 & 4 & $9.04 \mathrm{E}-04$ & $\mu \mathrm{Ci} / \mathrm{g}$ \\
\hline 241-TX-106 & $\begin{array}{l}\text { Sludge (Liquid } \\
\& \text { Solid) }\end{array}$ & R1 (Solid) & $3.66 \mathrm{E}-01$ & $\mathrm{TE}$ & 1.77 & 15 & $1.38 \mathrm{E}-02$ & $\mu \mathrm{Ci} / \mathrm{g}$ \\
\hline 241-TX-106 & Total & & $1.64 \mathrm{E}+02$ & $\mathrm{TS} / \mathrm{TE}$ & & & & \\
\hline 241-TX-107 & $\begin{array}{l}\text { Saltcake } \\
\text { Interstitial } \\
\text { Liquid }\end{array}$ & $\begin{array}{l}\text { R-SltCk } \\
\text { (Liquid) }\end{array}$ & 7.00E-01 & $\mathrm{TE}$ & 1.5 & 7 & $1.00 \mathrm{E}-01$ & $\mu \mathrm{Ci} / \mathrm{mL}$ \\
\hline 241-TX-107 & $\begin{array}{l}\text { Saltcake } \\
\text { Interstitial } \\
\text { Liquid }\end{array}$ & $\begin{array}{l}\text { T2-SltCk } \\
\text { (Liquid) }\end{array}$ & $5.02 \mathrm{E}+00$ & TS & 1.45 & 19 & $2.64 \mathrm{E}-01$ & $\mu \mathrm{Ci} / \mathrm{mL}$ \\
\hline 241-TX-107 & Saltcake Solid & $\begin{array}{l}\text { R-SltCk } \\
\text { (Solid) }\end{array}$ & $2.44 \mathrm{E}+00$ & $\mathrm{TE}$ & 1.72 & 24 & $5.90 \mathrm{E}-02$ & $\mu \mathrm{Ci} / \mathrm{g}$ \\
\hline 241-TX-107 & Saltcake Solid & $\begin{array}{l}\text { T2-SltCk } \\
\text { (Solid) }\end{array}$ & $8.59 \mathrm{E}+00$ & TE & 1.94 & 62 & 7.14E-02 & $\mu \mathrm{Ci} / \mathrm{g}$ \\
\hline 241-TX-107 & Total & & $1.67 \mathrm{E}+01$ & $\mathrm{TS} / \mathrm{TE}$ & & & & \\
\hline 241-TX-108 & $\begin{array}{l}\text { Saltcake } \\
\text { Interstitial } \\
\text { Liquid }\end{array}$ & $\begin{array}{l}\text { T2-SltCk } \\
\text { (Liquid) }\end{array}$ & $1.06 \mathrm{E}+01$ & $\mathrm{TS}$ & 1.45 & 40 & 2.64E-01 & $\mu \mathrm{Ci} / \mathrm{mL}$ \\
\hline 241-TX-108 & Saltcake Solid & $\begin{array}{l}\text { T2-SltCk } \\
\text { (Solid) }\end{array}$ & $4.48 \mathrm{E}+01$ & $\mathrm{TE}$ & 1.64 & 415 & $6.58 \mathrm{E}-02$ & $\mu \mathrm{Ci} / \mathrm{g}$ \\
\hline 241-TX-108 & $\begin{array}{l}\text { Sludge (Liquid } \\
\text { \& Solid) }\end{array}$ & MW2 (Solid) & $1.34 \mathrm{E}-02$ & $\mathrm{TE}$ & 1.85 & 8 & $9.04 \mathrm{E}-04$ & $\mu \mathrm{Ci} / \mathrm{g}$ \\
\hline
\end{tabular}




\begin{tabular}{|c|c|c|c|c|c|c|c|c|}
\hline Tank Name & Waste Phase & Waste Type & $\begin{array}{l}{ }^{99} \mathrm{Tc} \\
(\mathrm{Ci})\end{array}$ & Basis & $\begin{array}{l}\text { Density } \\
(\mathrm{g} / \mathrm{mL})\end{array}$ & $\begin{array}{c}\text { Volume } \\
(\mathrm{kL})\end{array}$ & Adjusted Conc. & Conc. Units \\
\hline $241-\mathrm{TX}-108$ & $\begin{array}{l}\text { Sludge (Liquid } \\
\text { \& Solid) }\end{array}$ & TBP (Solid) & $2.17 \mathrm{E}-02$ & $\mathrm{TE}$ & 1.47 & 15 & $9.85 \mathrm{E}-04$ & $\mu \mathrm{Ci} / \mathrm{g}$ \\
\hline 241-TX-108 & Total & & $5.54 \mathrm{E}+01$ & $\mathrm{TS} / \mathrm{TE}$ & & & & \\
\hline 241-TX-109 & $\begin{array}{l}\text { Sludge (Liquid } \\
\text { \& Solid) }\end{array}$ & 1C (Solid) & $4.65 \mathrm{E}+01$ & $\mathrm{TS}$ & 1.43 & 1339 & $2.43 \mathrm{E}-02$ & $\mu \mathrm{Ci} / \mathrm{g}$ \\
\hline 241-TX-109 & $\begin{array}{l}\text { Sludge (Liquid } \\
\text { \& Solid) }\end{array}$ & Z (Solid) & $0.00 \mathrm{E}+00$ & $\mathrm{TE}$ & 1.76 & 19 & $0.00 \mathrm{E}+00$ & $\mu \mathrm{Ci} / \mathrm{g}$ \\
\hline 241-TX-109 & Total & & $4.65 \mathrm{E}+01$ & $\mathrm{TS} / \mathrm{TE}$ & & & & \\
\hline 241-TX-110 & $\begin{array}{l}\text { Saltcake } \\
\text { Interstitial } \\
\text { Liquid }\end{array}$ & $\begin{array}{l}\text { T2-SltCk } \\
\text { (Liquid) }\end{array}$ & $1.29 \mathrm{E}+01$ & $\mathrm{TS}$ & 1.45 & 49 & 2.64E-01 & $\mu \mathrm{Ci} / \mathrm{mL}$ \\
\hline 241-TX-110 & Saltcake Solid & $\begin{array}{l}\text { T2-SltCk } \\
\text { (Solid) }\end{array}$ & $1.70 \mathrm{E}+02$ & $\mathrm{TE}$ & 1.64 & 1580 & $6.58 \mathrm{E}-02$ & $\mu \mathrm{Ci} / \mathrm{g}$ \\
\hline 241-TX-110 & $\begin{array}{l}\text { Sludge (Liquid } \\
\& \text { Solid) }\end{array}$ & 1C (Solid) & $4.86 \mathrm{E}+00$ & TS & 1.43 & 140 & $2.43 \mathrm{E}-02$ & $\mu \mathrm{Ci} / \mathrm{g}$ \\
\hline 241-TX-110 & Total & & $1.88 \mathrm{E}+02$ & $\mathrm{TS} / \mathrm{TE}$ & & & & \\
\hline 241-TX-111 & $\begin{array}{l}\text { Saltcake } \\
\text { Interstitial } \\
\text { Liquid }\end{array}$ & $\begin{array}{l}\text { T2-SltCk } \\
\text { (Liquid) }\end{array}$ & $6.34 \mathrm{E}+00$ & $\mathrm{TS}$ & 1.45 & 24 & $2.64 \mathrm{E}-01$ & $\mu \mathrm{Ci} / \mathrm{mL}$ \\
\hline 241-TX-111 & Saltcake Solid & $\begin{array}{l}\text { T2-SltCk } \\
\text { (Solid) }\end{array}$ & $1.29 \mathrm{E}+02$ & TE & 1.64 & 1194 & $6.58 \mathrm{E}-02$ & $\mu \mathrm{Ci} / \mathrm{g}$ \\
\hline 241-TX-111 & $\begin{array}{l}\text { Sludge (Liquid } \\
\& \text { Solid) }\end{array}$ & 1C (Solid) & $5.66 \mathrm{E}+00$ & TS & 1.43 & 163 & $2.43 \mathrm{E}-02$ & $\mu \mathrm{Ci} / \mathrm{g}$ \\
\hline 241-TX-111 & Total & & $1.41 \mathrm{E}+02$ & $\mathrm{TS} / \mathrm{TE}$ & & & & \\
\hline 241-TX-112 & $\begin{array}{l}\text { Saltcake } \\
\text { Interstitial } \\
\text { Liquid }\end{array}$ & $\begin{array}{l}\text { T1-SltCk } \\
\text { (Liquid) }\end{array}$ & 4.92E-02 & $\mathrm{TE}$ & 1.26 & 15 & $3.28 \mathrm{E}-03$ & $\mu \mathrm{Ci} / \mathrm{mL}$ \\
\hline 241-TX-112 & $\begin{array}{l}\text { Saltcake } \\
\text { Interstitial } \\
\text { Liquid }\end{array}$ & $\begin{array}{l}\text { T2-SltCk } \\
\text { (Liquid) }\end{array}$ & $2.46 \mathrm{E}+01$ & $\mathrm{TS}$ & 1.45 & 93 & $2.64 \mathrm{E}-01$ & $\mu \mathrm{Ci} / \mathrm{mL}$ \\
\hline 241-TX-112 & Saltcake Solid & $\begin{array}{l}\text { T1-SltCk } \\
\text { (Solid) }\end{array}$ & $9.92 \mathrm{E}-02$ & $\mathrm{TE}$ & 1.72 & 75 & 7.69E-04 & $\mu \mathrm{Ci} / \mathrm{g}$ \\
\hline 241-TX-112 & Saltcake Solid & $\begin{array}{l}\text { T2-SltCk } \\
\text { (Solid) }\end{array}$ & $2.39 \mathrm{E}+02$ & TE & 1.64 & 2215 & $6.58 \mathrm{E}-02$ & $\mu \mathrm{Ci} / \mathrm{g}$ \\
\hline
\end{tabular}




\begin{tabular}{|c|c|c|c|c|c|c|c|c|}
\hline Tank Name & Waste Phase & Waste Type & $\begin{array}{l}{ }^{99} \mathrm{Tc} \\
(\mathrm{Ci})\end{array}$ & Basis & $\begin{array}{l}\text { Density } \\
(\mathrm{g} / \mathrm{mL})\end{array}$ & $\begin{array}{c}\text { Volume } \\
(\mathrm{kL})\end{array}$ & Adjusted Conc. & Conc. Units \\
\hline 241-TX-112 & Total & & $2.64 \mathrm{E}+02$ & $\mathrm{TS} / \mathrm{TE}$ & & & & \\
\hline 241-TX-113 & $\begin{array}{l}\text { Saltcake } \\
\text { Interstitial } \\
\text { Liquid }\end{array}$ & $\begin{array}{l}\text { T2-SltCk } \\
\text { (Liquid) }\end{array}$ & $5.28 \mathrm{E}+00$ & $\mathrm{TS}$ & 1.45 & 20 & $2.64 \mathrm{E}-01$ & $\mu \mathrm{Ci} / \mathrm{mL}$ \\
\hline 241-TX-113 & Saltcake Solid & $\begin{array}{l}\text { T2-SltCk } \\
\text { (Solid) }\end{array}$ & $2.79 \mathrm{E}+02$ & TE & 1.64 & 2045 & $8.31 \mathrm{E}-02$ & $\mu \mathrm{Ci} / \mathrm{g}$ \\
\hline 241-TX-113 & $\begin{array}{l}\text { Sludge (Liquid } \\
\text { \& Solid) }\end{array}$ & 1C (Solid) & $1.22 \mathrm{E}+01$ & $\mathrm{TS}$ & 1.43 & 351 & $2.43 \mathrm{E}-02$ & $\mu \mathrm{Ci} / \mathrm{g}$ \\
\hline 241-TX-113 & Total & & $2.96 \mathrm{E}+02$ & $\mathrm{TS} / \mathrm{TE}$ & & & & \\
\hline 241-TX-114 & $\begin{array}{l}\text { Saltcake } \\
\text { Interstitial } \\
\text { Liquid }\end{array}$ & $\begin{array}{l}\text { T1-SltCk } \\
\text { (Liquid) }\end{array}$ & $1.51 \mathrm{E}-01$ & $\mathrm{TE}$ & 1.26 & 46 & $3.28 \mathrm{E}-03$ & $\mu \mathrm{Ci} / \mathrm{mL}$ \\
\hline 241-TX-114 & $\begin{array}{l}\text { Saltcake } \\
\text { Interstitial } \\
\text { Liquid }\end{array}$ & $\begin{array}{l}\text { T2-SltCk } \\
\text { (Liquid) }\end{array}$ & $7.39 \mathrm{E}+00$ & $\mathrm{TS}$ & 1.45 & 28 & $2.64 \mathrm{E}-01$ & $\mu \mathrm{Ci} / \mathrm{mL}$ \\
\hline 241-TX-114 & Saltcake Solid & $\begin{array}{l}\text { T1-SltCk } \\
\text { (Solid) }\end{array}$ & 2.29E-01 & $\mathrm{TE}$ & 1.72 & 173 & 7.69E-04 & $\mu \mathrm{Ci} / \mathrm{g}$ \\
\hline 241-TX-114 & Saltcake Solid & $\begin{array}{l}\text { T2-SltCk } \\
\text { (Solid) }\end{array}$ & $1.89 \mathrm{E}+02$ & $\mathrm{TE}$ & 1.64 & 1750 & $6.58 \mathrm{E}-02$ & $\mu \mathrm{Ci} / \mathrm{g}$ \\
\hline 241-TX-114 & $\begin{array}{l}\text { Sludge (Liquid } \\
\text { \& Solid) }\end{array}$ & 1C (Solid) & $5.21 \mathrm{E}-01$ & TS & 1.43 & 15 & $2.43 \mathrm{E}-02$ & $\mu \mathrm{Ci} / \mathrm{g}$ \\
\hline 241-TX-114 & Total & & $1.97 \mathrm{E}+02$ & $\mathrm{TS} / \mathrm{TE}$ & & & & \\
\hline 241-TX-115 & $\begin{array}{l}\text { Saltcake } \\
\text { Interstitial } \\
\text { Liquid }\end{array}$ & $\begin{array}{l}\text { T2-SltCk } \\
\text { (Liquid) }\end{array}$ & $2.72 \mathrm{E}+01$ & $\mathrm{TS}$ & 1.45 & 103 & $2.64 \mathrm{E}-01$ & $\mu \mathrm{Ci} / \mathrm{mL}$ \\
\hline 241-TX-115 & Saltcake Solid & $\begin{array}{l}\text { T2-SltCk } \\
\text { (Solid) }\end{array}$ & $2.12 \mathrm{E}+02$ & $\mathrm{TE}$ & 1.64 & 1960 & $6.58 \mathrm{E}-02$ & $\mu \mathrm{Ci} / \mathrm{g}$ \\
\hline 241-TX-115 & $\begin{array}{l}\text { Sludge (Liquid } \\
\text { \& Solid) }\end{array}$ & TBP (Solid) & 4.34E-02 & $\mathrm{TE}$ & 1.47 & 30 & $9.85 \mathrm{E}-04$ & $\mu \mathrm{Ci} / \mathrm{g}$ \\
\hline 241-TX-115 & Total & & $2.39 \mathrm{E}+02$ & $\mathrm{TS} / \mathrm{TE}$ & & & & \\
\hline 241-TX-116 & $\begin{array}{l}\text { Saltcake } \\
\text { Interstitial } \\
\text { Liquid }\end{array}$ & $\begin{array}{l}\text { T1-SltCk } \\
\text { (Liquid) }\end{array}$ & $5.88 \mathrm{E}-01$ & $\mathrm{TE}$ & 1.39 & 113 & $5.20 \mathrm{E}-03$ & $\mu \mathrm{Ci} / \mathrm{mL}$ \\
\hline
\end{tabular}




\begin{tabular}{|c|c|c|c|c|c|c|c|c|}
\hline Tank Name & Waste Phase & Waste Type & $\begin{array}{l}{ }^{99} \mathrm{Tc} \\
(\mathrm{Ci})\end{array}$ & Basis & $\begin{array}{l}\text { Density } \\
(\mathrm{g} / \mathrm{mL})\end{array}$ & $\begin{array}{c}\text { Volume } \\
(\mathrm{kL})\end{array}$ & Adjusted Conc. & Conc. Units \\
\hline $241-\mathrm{TX}-116$ & Saltcake Solid & $\begin{array}{l}\text { T1-SltCk } \\
\text { (Solid) }\end{array}$ & $1.56 \mathrm{E}+00$ & $\mathrm{TE}$ & 1.72 & 977 & $9.29 \mathrm{E}-04$ & $\mu \mathrm{Ci} / \mathrm{g}$ \\
\hline 241-TX-116 & Saltcake Solid & $\begin{array}{l}\text { T2-SltCk } \\
\text { (Solid) }\end{array}$ & $9.96 \mathrm{E}+01$ & TE & 1.64 & 926 & $6.56 \mathrm{E}-02$ & $\mu \mathrm{Ci} / \mathrm{g}$ \\
\hline 241-TX-116 & $\begin{array}{l}\text { Sludge (Liquid } \\
\text { \& Solid) }\end{array}$ & DE (Solid) & $5.40 \mathrm{E}+01$ & TS & 1.6 & 248 & $1.36 \mathrm{E}-01$ & $\mu \mathrm{Ci} / \mathrm{g}$ \\
\hline 241-TX-116 & Total & & $1.56 \mathrm{E}+02$ & $\mathrm{TS} / \mathrm{TE}$ & & & & \\
\hline 241-TX-117 & $\begin{array}{l}\text { Saltcake } \\
\text { Interstitial } \\
\text { Liquid }\end{array}$ & $\begin{array}{l}\text { T1-SltCk } \\
\text { (Liquid) }\end{array}$ & $1.57 \mathrm{E}-01$ & TE & 1.26 & 48 & $3.28 \mathrm{E}-03$ & $\mu \mathrm{Ci} / \mathrm{mL}$ \\
\hline 241-TX-117 & Saltcake Solid & $\begin{array}{l}\text { T1-SltCk } \\
\text { (Solid) }\end{array}$ & $8.28 \mathrm{E}-01$ & TE & 1.72 & 626 & 7.69E-04 & $\mu \mathrm{Ci} / \mathrm{g}$ \\
\hline 241-TX-117 & Saltcake Solid & $\begin{array}{l}\text { T2-SltCk } \\
\text { (Solid) }\end{array}$ & $1.71 \mathrm{E}+02$ & $\mathrm{TE}$ & 1.64 & 1585 & $6.58 \mathrm{E}-02$ & $\mu \mathrm{Ci} / \mathrm{g}$ \\
\hline 241-TX-117 & $\begin{array}{l}\text { Sludge (Liquid } \\
\text { \& Solid) }\end{array}$ & DE (Solid) & $2.40 \mathrm{E}+01$ & TS & 1.58 & 110 & $1.38 \mathrm{E}-01$ & $\mu \mathrm{Ci} / \mathrm{g}$ \\
\hline 241-TX-117 & Total & & $1.96 \mathrm{E}+02$ & TS/TE & & & & \\
\hline 241-TX-118 & $\begin{array}{l}\text { Saltcake } \\
\text { Interstitial } \\
\text { Liquid }\end{array}$ & $\begin{array}{l}\text { T2-SltCk } \\
\text { (Liquid) }\end{array}$ & $3.67 \mathrm{E}+01$ & $\mathrm{TS}$ & 1.45 & 139 & $2.64 \mathrm{E}-01$ & $\mu \mathrm{Ci} / \mathrm{mL}$ \\
\hline 241-TX-118 & Saltcake Solid & NA (SltCk) & $9.40 \mathrm{E}+00$ & $\mathrm{TE}$ & 1.54 & 125 & $4.88 \mathrm{E}-02$ & $\mu \mathrm{Ci} / \mathrm{g}$ \\
\hline 241-TX-118 & Saltcake Solid & $\begin{array}{l}\text { T2-SltCk } \\
\text { (Solid) }\end{array}$ & $6.15 \mathrm{E}+01$ & $\mathrm{TE}$ & 1.77 & 671 & $5.18 \mathrm{E}-02$ & $\mu \mathrm{Ci} / \mathrm{g}$ \\
\hline 241-TX-118 & Total & & $1.08 \mathrm{E}+02$ & $\mathrm{TS} / \mathrm{TE}$ & & & & \\
\hline 241-TY-101 & $\begin{array}{l}\text { Saltcake } \\
\text { Interstitial } \\
\text { Liquid }\end{array}$ & $\begin{array}{l}\text { T1-SltCk } \\
\text { (Liquid) }\end{array}$ & 4.92E-02 & TE & 1.26 & 15 & $3.28 \mathrm{E}-03$ & $\mu \mathrm{Ci} / \mathrm{mL}$ \\
\hline 241-TY-101 & Saltcake Solid & $\begin{array}{l}\text { T1-SltCk } \\
\text { (Solid) }\end{array}$ & $1.92 \mathrm{E}+00$ & $\mathrm{E}$ & 1.64 & 159 & 7.36E-03 & $\mu \mathrm{Ci} / \mathrm{g}$ \\
\hline 241-TY-101 & $\begin{array}{l}\text { Sludge (Liquid } \\
\text { \& Solid) }\end{array}$ & $\begin{array}{l}1 \mathrm{CFeCN} \\
\text { (Solid) }\end{array}$ & $3.30 \mathrm{E}+00$ & $\mathrm{E}$ & 1.64 & 273 & 7.36E-03 & $\mu \mathrm{Ci} / \mathrm{g}$ \\
\hline 241-TY-101 & Total & & $5.26 \mathrm{E}+00$ & $\mathrm{E} / \mathrm{TE}$ & & & & \\
\hline
\end{tabular}




\begin{tabular}{|c|c|c|c|c|c|c|c|c|}
\hline Tank Name & Waste Phase & Waste Type & $\begin{array}{l}{ }^{99} \mathrm{Tc} \\
(\mathrm{Ci})\end{array}$ & Basis & $\begin{array}{l}\text { Density } \\
(\mathrm{g} / \mathrm{mL})\end{array}$ & $\begin{array}{l}\text { Volume } \\
(\mathrm{kL})\end{array}$ & Adjusted Conc. & Conc. Units \\
\hline $241-\mathrm{TY}-102$ & $\begin{array}{l}\text { Saltcake } \\
\text { Interstitial } \\
\text { Liquid }\end{array}$ & $\begin{array}{l}\text { T1-SltCk } \\
\text { (Liquid) }\end{array}$ & $9.51 \mathrm{E}-02$ & $\mathrm{TE}$ & 1.26 & 29 & $3.28 \mathrm{E}-03$ & $\mu \mathrm{Ci} / \mathrm{mL}$ \\
\hline 241-TY-102 & $\begin{array}{l}\text { Saltcake } \\
\text { Interstitial } \\
\text { Liquid }\end{array}$ & $\begin{array}{l}\text { T2-SltCk } \\
\text { (Liquid) }\end{array}$ & $8.98 \mathrm{E}+00$ & TS & 1.45 & 34 & $2.64 \mathrm{E}-01$ & $\mu \mathrm{Ci} / \mathrm{mL}$ \\
\hline 241-TY-102 & Saltcake Solid & $\begin{array}{l}\text { T1-SltCk } \\
\text { (Solid) }\end{array}$ & $1.33 \mathrm{E}-01$ & $\mathrm{E}$ & 1.88 & 90 & $7.88 \mathrm{E}-04$ & $\mu \mathrm{Ci} / \mathrm{g}$ \\
\hline 241-TY-102 & Saltcake Solid & $\begin{array}{l}\text { T2-SltCk } \\
\text { (Solid) }\end{array}$ & $1.61 \mathrm{E}-01$ & $\mathrm{E}$ & 1.88 & 109 & $7.88 \mathrm{E}-04$ & $\mu \mathrm{Ci} / \mathrm{g}$ \\
\hline 241-TY-102 & Total & & $9.37 \mathrm{E}+00$ & $\mathrm{E} / \mathrm{TS} / \mathrm{TE}$ & & & & \\
\hline 241-TY-103 & $\begin{array}{l}\text { Saltcake } \\
\text { Interstitial } \\
\text { Liquid }\end{array}$ & $\begin{array}{l}\text { T2-SltCk } \\
\text { (Liquid) }\end{array}$ & $1.19 \mathrm{E}+01$ & TS & 1.45 & 45 & $2.64 \mathrm{E}-01$ & $\mu \mathrm{Ci} / \mathrm{mL}$ \\
\hline 241-TY-103 & Saltcake Solid & $\begin{array}{l}\text { T2-SltCk } \\
\text { (Solid) }\end{array}$ & $4.22 \mathrm{E}+00$ & $\mathrm{E}$ & 1.7 & 150 & $1.65 \mathrm{E}-02$ & $\mu \mathrm{Ci} / \mathrm{g}$ \\
\hline 241-TY-103 & $\begin{array}{l}\text { Sludge (Liquid } \\
\text { \& Solid) }\end{array}$ & $\begin{array}{l}1 \mathrm{CFeCN} \\
\text { (Solid) }\end{array}$ & $4.78 \mathrm{E}+00$ & $\mathrm{E}$ & 1.7 & 170 & $1.65 \mathrm{E}-02$ & $\mu \mathrm{Ci} / \mathrm{g}$ \\
\hline 241-TY-103 & $\begin{array}{l}\text { Sludge (Liquid } \\
\& \text { Solid) }\end{array}$ & TBP (Solid) & $6.18 \mathrm{E}+00$ & $\mathrm{E}$ & 1.7 & 220 & $1.65 \mathrm{E}-02$ & $\mu \mathrm{Ci} / \mathrm{g}$ \\
\hline 241-TY-103 & Total & & $2.71 \mathrm{E}+01$ & E/TS & & & & \\
\hline 241-TY-104 & $\begin{array}{l}\text { Sludge (Liquid } \\
\& \text { Solid) }\end{array}$ & $\begin{array}{l}1 \mathrm{CFeCN} \\
\text { (Solid) }\end{array}$ & $6.02 \mathrm{E}+00$ & $\mathrm{E}$ & 1.65 & 114 & $3.20 \mathrm{E}-02$ & $\mu \mathrm{Ci} / \mathrm{g}$ \\
\hline 241-TY-104 & $\begin{array}{l}\text { Sludge (Liquid } \\
\text { \& Solid) }\end{array}$ & TBP (Solid) & $2.59 \mathrm{E}+00$ & $\mathrm{E}$ & 1.65 & 49 & $3.20 \mathrm{E}-02$ & $\mu \mathrm{Ci} / \mathrm{g}$ \\
\hline 241-TY-104 & Supernatant & DW (Liquid) & $2.55 \mathrm{E}-01$ & $\mathrm{E}$ & 1.18 & 5 & $5.11 \mathrm{E}-02$ & $\mu \mathrm{Ci} / \mathrm{mL}$ \\
\hline 241-TY-104 & Total & & $8.86 \mathrm{E}+00$ & $\mathrm{E}$ & & & & \\
\hline 241-TY-105 & $\begin{array}{l}\text { Sludge (Liquid } \\
\text { \& Solid) }\end{array}$ & TBP (Solid) & $4.40 \mathrm{E}+01$ & $\mathrm{E}$ & 1.53 & 874 & $3.29 \mathrm{E}-02$ & $\mu \mathrm{Ci} / \mathrm{g}$ \\
\hline 241-TY-105 & Total & & $4.40 \mathrm{E}+01$ & $\mathrm{E}$ & & & & \\
\hline 241-TY-106 & $\begin{array}{l}\text { Sludge (Liquid } \\
\text { \& Solid) }\end{array}$ & DE (Solid) & $8.18 \mathrm{E}-01$ & S & 1.4 & 47 & $1.24 \mathrm{E}-02$ & $\mu \mathrm{Ci} / \mathrm{g}$ \\
\hline 241-TY-106 & $\begin{array}{l}\text { Sludge (Liquid } \\
\text { \& Solid) }\end{array}$ & TBP (Solid) & 2.61E-01 & S & 1.4 & 15 & $1.24 \mathrm{E}-02$ & $\mu \mathrm{Ci} / \mathrm{g}$ \\
\hline
\end{tabular}




\begin{tabular}{|c|c|c|c|c|c|c|c|c|}
\hline Tank Name & Waste Phase & Waste Type & $\begin{array}{l}{ }^{99} \mathrm{Tc} \\
(\mathrm{Ci})\end{array}$ & Basis & $\begin{array}{l}\text { Density } \\
(\mathrm{g} / \mathrm{mL})\end{array}$ & $\begin{array}{c}\text { Volume } \\
(\mathrm{kL})\end{array}$ & Adjusted Conc. & Conc. Units \\
\hline 241-TY-106 & Total & & $1.08 \mathrm{E}+00$ & $\bar{S}$ & & & & \\
\hline 241-U-101 & $\begin{array}{l}\text { Sludge (Liquid } \\
\text { \& Solid) }\end{array}$ & R1 (Solid) & $1.93 \mathrm{E}+00$ & $\mathrm{TE}$ & 1.77 & 87 & $1.25 \mathrm{E}-02$ & $\mu \mathrm{Ci} / \mathrm{g}$ \\
\hline 241-U-101 & Total & & $1.93 \mathrm{E}+00$ & TE & & & & \\
\hline 241-U-102 & $\begin{array}{l}\text { Saltcake } \\
\text { Interstitial } \\
\text { Liquid }\end{array}$ & $\begin{array}{l}\text { T2-SltCk } \\
\text { (Liquid) }\end{array}$ & $3.25 \mathrm{E}+01$ & TS & 1.48 & 117 & $2.78 \mathrm{E}-01$ & $\mu \mathrm{Ci} / \mathrm{mL}$ \\
\hline 241-U-102 & Saltcake Solid & $\begin{array}{l}\text { S2-SltSlr } \\
\text { (Solid) }\end{array}$ & $5.90 \mathrm{E}+01$ & TE & 1.68 & 307 & $1.14 \mathrm{E}-01$ & $\mu \mathrm{Ci} / \mathrm{g}$ \\
\hline 241-U-102 & Saltcake Solid & $\begin{array}{l}\text { T2-SltCk } \\
\text { (Solid) }\end{array}$ & $6.51 \mathrm{E}+01$ & TE & 1.68 & 647 & $5.99 \mathrm{E}-02$ & $\mu \mathrm{Ci} / \mathrm{g}$ \\
\hline 241-U-102 & $\begin{array}{l}\text { Sludge (Liquid } \\
\text { \& Solid) }\end{array}$ & R1 (Solid) & $3.98 \mathrm{E}+00$ & $\mathrm{TE}$ & 1.77 & 163 & $1.38 \mathrm{E}-02$ & $\mu \mathrm{Ci} / \mathrm{g}$ \\
\hline 241-U-102 & Supernatant & $\begin{array}{l}\text { T2-SltCk } \\
\text { (Liquid) }\end{array}$ & $1.11 \mathrm{E}+00$ & TS & 1.48 & 4 & $2.78 \mathrm{E}-01$ & $\mu \mathrm{Ci} / \mathrm{mL}$ \\
\hline 241-U-102 & Total & & $1.62 \mathrm{E}+02$ & $\mathrm{TS} / \mathrm{TE}$ & & & & \\
\hline 241-U-103 & $\begin{array}{l}\text { Saltcake } \\
\text { Interstitial } \\
\text { Liquid }\end{array}$ & $\begin{array}{l}\text { S1-SltCk } \\
\text { (Liquid) }\end{array}$ & $3.07 \mathrm{E}+01$ & TS & 1.44 & 119 & $2.58 \mathrm{E}-01$ & $\mu \mathrm{Ci} / \mathrm{mL}$ \\
\hline 241-U-103 & Saltcake Solid & $\begin{array}{l}\text { S1-SltCk } \\
\text { (Solid) }\end{array}$ & $1.32 \mathrm{E}+02$ & TE & 1.72 & 891 & $8.60 \mathrm{E}-02$ & $\mu \mathrm{Ci} / \mathrm{g}$ \\
\hline 241-U-103 & Saltcake Solid & $\begin{array}{l}\text { S2-SltSlr } \\
\text { (Solid) }\end{array}$ & $6.60 \mathrm{E}+01$ & TE & 1.72 & 356 & $1.08 \mathrm{E}-01$ & $\mu \mathrm{Ci} / \mathrm{g}$ \\
\hline 241-U-103 & $\begin{array}{l}\text { Sludge (Liquid } \\
\& \text { Solid) }\end{array}$ & R1 (Solid) & 7.49E-01 & TE & 1.9 & 42 & $9.38 \mathrm{E}-03$ & $\mu \mathrm{Ci} / \mathrm{g}$ \\
\hline 241-U-103 & Supernatant & $\begin{array}{l}\text { S1-SltCk } \\
\text { (Liquid) }\end{array}$ & $5.16 \mathrm{E}-01$ & TS & 1.44 & 2 & $2.58 \mathrm{E}-01$ & $\mu \mathrm{Ci} / \mathrm{mL}$ \\
\hline 241-U-103 & Total & & $2.30 \mathrm{E}+02$ & TS/TE & & & & \\
\hline 241-U-104 & $\begin{array}{l}\text { Sludge (Liquid } \\
\text { \& Solid) }\end{array}$ & DE (Solid) & $7.21 \mathrm{E}-01$ & $\mathrm{TE}$ & 1.11 & 201 & $3.23 \mathrm{E}-03$ & $\mu \mathrm{Ci} / \mathrm{g}$ \\
\hline 241-U-104 & $\begin{array}{l}\text { Sludge (Liquid } \\
\& \text { Solid) }\end{array}$ & MW2 (Solid) & $6.69 \mathrm{E}-03$ & $\mathrm{TE}$ & 1.85 & 4 & $9.04 \mathrm{E}-04$ & $\mu \mathrm{Ci} / \mathrm{g}$ \\
\hline 241-U-104 & Total & & $7.28 \mathrm{E}-01$ & $\mathrm{TE}$ & & & & \\
\hline
\end{tabular}




\begin{tabular}{|c|c|c|c|c|c|c|c|c|}
\hline Tank Name & Waste Phase & Waste Type & $\begin{array}{l}{ }^{99} \mathrm{Tc} \\
(\mathrm{Ci})\end{array}$ & Basis & $\begin{array}{l}\text { Density } \\
(\mathrm{g} / \mathrm{mL})\end{array}$ & $\begin{array}{c}\text { Volume } \\
(\mathrm{kL})\end{array}$ & Adjusted Conc. & Conc. Units \\
\hline 241-U-105 & $\begin{array}{l}\text { Saltcake } \\
\text { Interstitial } \\
\text { Liquid }\end{array}$ & $\begin{array}{l}\text { S2-SltSlr } \\
\text { (Liquid) }\end{array}$ & $3.28 \mathrm{E}+01$ & TS & 1.46 & 130 & $2.53 \mathrm{E}-01$ & $\mu \mathrm{Ci} / \mathrm{mL}$ \\
\hline $241-U-105$ & $\begin{array}{l}\text { Saltcake } \\
\text { Interstitial } \\
\text { Liquid }\end{array}$ & $\begin{array}{l}\text { T2-SltCk } \\
\text { (Liquid) }\end{array}$ & $8.84 \mathrm{E}+00$ & TS & 1.46 & 35 & $2.53 \mathrm{E}-01$ & $\mu \mathrm{Ci} / \mathrm{mL}$ \\
\hline 241-U-105 & Saltcake Solid & $\begin{array}{l}\text { S2-SltSlr } \\
\text { (Solid) }\end{array}$ & $1.76 \mathrm{E}+02$ & $\mathrm{TE}$ & 1.7 & 827 & $1.25 \mathrm{E}-01$ & $\mu \mathrm{Ci} / \mathrm{g}$ \\
\hline 241-U-105 & Saltcake Solid & $\begin{array}{l}\text { T2-SltCk } \\
\text { (Solid) }\end{array}$ & $2.49 \mathrm{E}+01$ & $\mathrm{TE}$ & 1.7 & 223 & $6.57 \mathrm{E}-02$ & $\mu \mathrm{Ci} / \mathrm{g}$ \\
\hline 241-U-105 & $\begin{array}{l}\text { Sludge (Liquid } \\
\text { \& Solid) }\end{array}$ & CWR1 (Solid) & $6.20 \mathrm{E}-01$ & $\mathrm{TS}$ & 1.7 & 121 & $3.01 \mathrm{E}-03$ & $\mu \mathrm{Ci} / \mathrm{g}$ \\
\hline 241-U-105 & Total & & $2.43 \mathrm{E}+02$ & TS/TE & & & & \\
\hline 241-U-106 & $\begin{array}{l}\text { Saltcake } \\
\text { Interstitial } \\
\text { Liquid }\end{array}$ & $\begin{array}{l}\text { S1-SltCk } \\
\text { (Liquid) }\end{array}$ & $3.79 \mathrm{E}+01$ & TS & 1.34 & 154 & $2.46 \mathrm{E}-01$ & $\mu \mathrm{Ci} / \mathrm{mL}$ \\
\hline 241-U-106 & Saltcake Solid & $\begin{array}{l}\text { S1-SltCk } \\
\text { (Solid) }\end{array}$ & $6.59 \mathrm{E}+01$ & TE & 1.62 & 484 & $8.40 \mathrm{E}-02$ & $\mu \mathrm{Ci} / \mathrm{g}$ \\
\hline 241-U-106 & Supernatant & $\begin{array}{l}\text { S1-SltCk } \\
\text { (Liquid) }\end{array}$ & $1.48 \mathrm{E}+00$ & TS & 1.34 & 6 & $2.46 \mathrm{E}-01$ & $\mu \mathrm{Ci} / \mathrm{mL}$ \\
\hline 241-U-106 & Total & & $1.05 \mathrm{E}+02$ & $\mathrm{TS} / \mathrm{TE}$ & & & & \\
\hline 241-U-107 & $\begin{array}{l}\text { Saltcake } \\
\text { Interstitial } \\
\text { Liquid }\end{array}$ & $\begin{array}{l}\text { S2-SltSlr } \\
\text { (Liquid) }\end{array}$ & $3.66 \mathrm{E}+01$ & $\mathrm{~S}$ & 1.43 & 105 & $3.49 \mathrm{E}-01$ & $\mu \mathrm{Ci} / \mathrm{mL}$ \\
\hline 241-U-107 & $\begin{array}{l}\text { Saltcake } \\
\text { Interstitial } \\
\text { Liquid }\end{array}$ & $\begin{array}{l}\text { T2-SltCk } \\
\text { (Liquid) }\end{array}$ & $1.74 \mathrm{E}+00$ & $\mathrm{~S}$ & 1.43 & 5 & 3.49E-01 & $\mu \mathrm{Ci} / \mathrm{mL}$ \\
\hline 241-U-107 & Saltcake Solid & $\begin{array}{l}\text { S2-SltSlr } \\
\text { (Solid) }\end{array}$ & $1.92 \mathrm{E}+02$ & $\mathrm{TE}$ & 1.77 & 902 & $1.20 \mathrm{E}-01$ & $\mu \mathrm{Ci} / \mathrm{g}$ \\
\hline 241-U-107 & Saltcake Solid & $\begin{array}{l}\text { T2-SltCk } \\
\text { (Solid) }\end{array}$ & $4.90 \mathrm{E}+00$ & $\mathrm{TE}$ & 1.77 & 44 & $6.29 \mathrm{E}-02$ & $\mu \mathrm{Ci} / \mathrm{g}$ \\
\hline 241-U-107 & $\begin{array}{l}\text { Sludge (Liquid } \\
\text { \& Solid) }\end{array}$ & CWR1 (Solid) & 3.01E-01 & TS & 1.8 & 57 & $2.93 \mathrm{E}-03$ & $\mu \mathrm{Ci} / \mathrm{g}$ \\
\hline $241-\mathrm{U}-107$ & Total & & $2.35 \mathrm{E}+02$ & $\mathrm{~S} / \mathrm{TS} / \mathrm{TE}$ & & & & \\
\hline
\end{tabular}




\begin{tabular}{|c|c|c|c|c|c|c|c|c|}
\hline Tank Name & Waste Phase & Waste Type & $\begin{array}{l}{ }^{99} \mathrm{Tc} \\
(\mathrm{Ci})\end{array}$ & Basis & $\begin{array}{l}\text { Density } \\
(\mathrm{g} / \mathrm{mL})\end{array}$ & $\begin{array}{c}\text { Volume } \\
(\mathrm{kL})\end{array}$ & Adjusted Conc. & Conc. Units \\
\hline $241-U-108$ & $\begin{array}{l}\text { Saltcake } \\
\text { Interstitial } \\
\text { Liquid }\end{array}$ & $\begin{array}{l}\text { S1-SltCk } \\
\text { (Liquid) }\end{array}$ & $2.16 \mathrm{E}+01$ & $\mathrm{TS}$ & 1.4 & 86 & $2.51 \mathrm{E}-01$ & $\mu \mathrm{Ci} / \mathrm{mL}$ \\
\hline $241-\mathrm{U}-108$ & $\begin{array}{l}\text { Saltcake } \\
\text { Interstitial } \\
\text { Liquid }\end{array}$ & $\begin{array}{l}\text { S2-SltSlr } \\
\text { (Liquid) }\end{array}$ & $1.73 \mathrm{E}+01$ & TS & 1.4 & 69 & $2.51 \mathrm{E}-01$ & $\mu \mathrm{Ci} / \mathrm{mL}$ \\
\hline 241-U-108 & Saltcake Solid & $\begin{array}{l}\text { S1-SltCk } \\
\text { (Solid) }\end{array}$ & $1.21 \mathrm{E}+02$ & $\mathrm{TE}$ & 1.73 & 766 & $9.11 \mathrm{E}-02$ & $\mu \mathrm{Ci} / \mathrm{g}$ \\
\hline $241-\mathrm{U}-108$ & Saltcake Solid & $\begin{array}{l}\text { S2-SltS1r } \\
\text { (Solid) }\end{array}$ & $1.21 \mathrm{E}+02$ & $\mathrm{TE}$ & 1.73 & 610 & $1.14 \mathrm{E}-01$ & $\mu \mathrm{Ci} / \mathrm{g}$ \\
\hline 241-U-108 & $\begin{array}{l}\text { Sludge (Liquid } \\
\text { \& Solid) }\end{array}$ & CWR2 (Solid) & $3.60 \mathrm{E}-02$ & $\mathrm{TE}$ & 1.46 & 110 & $2.24 \mathrm{E}-04$ & $\mu \mathrm{Ci} / \mathrm{g}$ \\
\hline $241-\mathrm{U}-108$ & Total & & $2.80 \mathrm{E}+02$ & $\mathrm{TS} / \mathrm{TE}$ & & & & \\
\hline 241-U-109 & $\begin{array}{l}\text { Saltcake } \\
\text { Interstitial } \\
\text { Liquid }\end{array}$ & $\begin{array}{l}\text { S1-SltCk } \\
\text { (Liquid) }\end{array}$ & $3.55 \mathrm{E}+01$ & TS & 1.47 & 137 & $2.59 \mathrm{E}-01$ & $\mu \mathrm{Ci} / \mathrm{mL}$ \\
\hline 241-U-109 & Saltcake Solid & $\begin{array}{l}\text { S1-SltCk } \\
\text { (Solid) }\end{array}$ & $1.02 \mathrm{E}+02$ & $\mathrm{TE}$ & 1.67 & 600 & $1.02 \mathrm{E}-01$ & $\mu \mathrm{Ci} / \mathrm{g}$ \\
\hline 241-U-109 & Saltcake Solid & $\begin{array}{l}\text { S2-SltSlr } \\
\text { (Solid) }\end{array}$ & $1.09 \mathrm{E}+02$ & $\mathrm{TE}$ & 1.67 & 512 & $1.28 \mathrm{E}-01$ & $\mu \mathrm{Ci} / \mathrm{g}$ \\
\hline 241-U-109 & $\begin{array}{l}\text { Sludge (Liquid } \\
\text { \& Solid) }\end{array}$ & CWR1 (Solid) & $5.29 \mathrm{E}-01$ & $\mathrm{TS}$ & 1.71 & 103 & $3.00 \mathrm{E}-03$ & $\mu \mathrm{Ci} / \mathrm{g}$ \\
\hline 241-U-109 & Total & & $2.47 \mathrm{E}+02$ & $\mathrm{TS} / \mathrm{TE}$ & & & & \\
\hline $241-\mathrm{U}-110$ & $\begin{array}{l}\text { Sludge (Liquid } \\
\text { \& Solid) }\end{array}$ & 1C (Solid) & $5.48 \mathrm{E}+00$ & TS & 1.43 & 120 & $3.19 \mathrm{E}-02$ & $\mu \mathrm{Ci} / \mathrm{g}$ \\
\hline $241-\mathrm{U}-110$ & $\begin{array}{l}\text { Sludge (Liquid } \\
\text { \& Solid) }\end{array}$ & CWR1 (Solid) & $5.03 \mathrm{E}-01$ & $\mathrm{~S}$ & 1.8 & 149 & $1.87 \mathrm{E}-03$ & $\mu \mathrm{Ci} / \mathrm{g}$ \\
\hline $241-\mathrm{U}-110$ & $\begin{array}{l}\text { Sludge (Liquid } \\
\text { \& Solid) }\end{array}$ & R1 (Solid) & $5.01 \mathrm{E}+00$ & $\mathrm{~S}$ & 1.77 & 396 & $7.15 \mathrm{E}-03$ & $\mu \mathrm{Ci} / \mathrm{g}$ \\
\hline 241-U-110 & Total & & $1.10 \mathrm{E}+01$ & $\mathrm{~S} / \mathrm{TS}$ & & & & \\
\hline 241-U-111 & $\begin{array}{l}\text { Saltcake } \\
\text { Interstitial } \\
\text { Liquid } \\
\end{array}$ & $\begin{array}{l}\text { S1-SltCk } \\
\text { (Liquid) }\end{array}$ & $9.73 \mathrm{E}+00$ & TS & 1.4 & 41 & $2.37 \mathrm{E}-01$ & $\mu \mathrm{Ci} / \mathrm{mL}$ \\
\hline
\end{tabular}




\begin{tabular}{|c|c|c|c|c|c|c|c|c|}
\hline Tank Name & Waste Phase & Waste Type & $\begin{array}{l}{ }^{99} \mathrm{Tc} \\
(\mathrm{Ci})\end{array}$ & Basis & $\begin{array}{l}\text { Density } \\
(\mathrm{g} / \mathrm{mL})\end{array}$ & $\begin{array}{c}\text { Volume } \\
(\mathrm{kL})\end{array}$ & Adjusted Conc. & Conc. Units \\
\hline 241-U-111 & $\begin{array}{l}\text { Saltcake } \\
\text { Interstitial } \\
\text { Liquid }\end{array}$ & $\begin{array}{l}\text { S2-SltSlr } \\
\text { (Liquid) }\end{array}$ & $1.71 \mathrm{E}+01$ & $\mathrm{TS}$ & 1.4 & 72 & $2.37 \mathrm{E}-01$ & $\mu \mathrm{Ci} / \mathrm{mL}$ \\
\hline 241-U-111 & Saltcake Solid & $\begin{array}{l}\text { S1-SltCk } \\
\text { (Solid) }\end{array}$ & $3.73 \mathrm{E}+01$ & TE & 1.68 & 228 & $9.74 \mathrm{E}-02$ & $\mu \mathrm{Ci} / \mathrm{g}$ \\
\hline 241-U-111 & Saltcake Solid & $\begin{array}{l}\text { S2-SltSlr } \\
\text { (Solid) }\end{array}$ & $7.45 \mathrm{E}+01$ & $\mathrm{TE}$ & 1.63 & 401 & $1.14 \mathrm{E}-01$ & $\mu \mathrm{Ci} / \mathrm{g}$ \\
\hline 241-U-111 & $\begin{array}{l}\text { Sludge (Liquid } \\
\& \text { Solid) }\end{array}$ & 1C (Solid) & $1.70 \mathrm{E}+00$ & TS & 1.43 & 49 & $2.43 \mathrm{E}-02$ & $\mu \mathrm{Ci} / \mathrm{g}$ \\
\hline 241-U-111 & $\begin{array}{l}\text { Sludge (Liquid } \\
\& \text { Solid) }\end{array}$ & R1 (Solid) & $1.20 \mathrm{E}+00$ & TE & 1.77 & 49 & $1.38 \mathrm{E}-02$ & $\mu \mathrm{Ci} / \mathrm{g}$ \\
\hline 241-U-111 & Total & & $1.42 \mathrm{E}+02$ & $\mathrm{TS} / \mathrm{TE}$ & & & & \\
\hline 241-U-112 & $\begin{array}{l}\text { Sludge (Liquid } \\
\& \text { Solid) }\end{array}$ & 1C (Solid) & $1.63 \mathrm{E}+00$ & TS & 1.43 & 47 & 2.43E-02 & $\mu \mathrm{Ci} / \mathrm{g}$ \\
\hline 241-U-112 & $\begin{array}{l}\text { Sludge (Liquid } \\
\& \text { Solid) }\end{array}$ & CWR1 (Solid) & $3.10 \mathrm{E}-01$ & TS & 1.86 & 58 & $2.87 \mathrm{E}-03$ & $\mu \mathrm{Ci} / \mathrm{g}$ \\
\hline 241-U-112 & $\begin{array}{l}\text { Sludge (Liquid } \\
\& \text { Solid) }\end{array}$ & R1 (Solid) & $1.65 \mathrm{E}+00$ & TE & 1.86 & 67 & $1.32 \mathrm{E}-02$ & $\mu \mathrm{Ci} / \mathrm{g}$ \\
\hline 241-U-112 & Total & & $3.59 \mathrm{E}+00$ & TS/TE & & & & \\
\hline 241-U-201 & $\begin{array}{l}\text { Sludge (Liquid } \\
\& \text { Solid) }\end{array}$ & CWR1 (Solid) & $4.86 \mathrm{E}-02$ & $\mathrm{~S}$ & 1.63 & 11 & $2.71 \mathrm{E}-03$ & $\mu \mathrm{Ci} / \mathrm{g}$ \\
\hline 241-U-201 & Supernatant & $\begin{array}{l}\text { CWR1 } \\
\text { (Liquid) }\end{array}$ & 7.32E-02 & $\mathrm{S}$ & 1.26 & 4 & $1.83 \mathrm{E}-02$ & $\mu \mathrm{Ci} / \mathrm{mL}$ \\
\hline 241-U-201 & Total & & $1.22 \mathrm{E}-01$ & $\mathrm{~S}$ & & & & \\
\hline 241-U-202 & $\begin{array}{l}\text { Sludge (Liquid } \\
\& \text { Solid) }\end{array}$ & CWR1 (Solid) & $4.01 \mathrm{E}-02$ & S & 1.51 & 10 & $2.66 \mathrm{E}-03$ & $\mu \mathrm{Ci} / \mathrm{g}$ \\
\hline 241-U-202 & Supernatant & $\begin{array}{l}\text { CWR1 } \\
\text { (Liquid) }\end{array}$ & $6.95 \mathrm{E}-02$ & $\mathrm{~S}$ & 1.28 & 4 & $1.74 \mathrm{E}-02$ & $\mu \mathrm{Ci} / \mathrm{mL}$ \\
\hline 241-U-202 & Total & & $1.10 \mathrm{E}-01$ & S & & & & \\
\hline 241-U-203 & $\begin{array}{l}\text { Sludge (Liquid } \\
\& \text { Solid) }\end{array}$ & CWR1 (Solid) & $3.54 \mathrm{E}-02$ & S & 1.59 & 9 & $2.48 \mathrm{E}-03$ & $\mu \mathrm{Ci} / \mathrm{g}$ \\
\hline 241-U-203 & Supernatant & $\begin{array}{l}\text { CWR1 } \\
\text { (Liquid) }\end{array}$ & $6.40 \mathrm{E}-02$ & $\mathrm{~S}$ & 1.28 & 4 & $1.60 \mathrm{E}-02$ & $\mu \mathrm{Ci} / \mathrm{mL}$ \\
\hline 241-U-203 & Total & & $9.94 \mathrm{E}-02$ & S & & & & \\
\hline
\end{tabular}




\begin{tabular}{|c|c|c|c|c|c|c|c|c|}
\hline Tank Name & Waste Phase & Waste Type & $\begin{array}{l}{ }^{99} \mathrm{Tc} \\
(\mathrm{Ci})\end{array}$ & Basis & $\begin{array}{l}\text { Density } \\
(\mathrm{g} / \mathrm{mL})\end{array}$ & $\begin{array}{c}\text { Volume } \\
(\mathrm{kL})\end{array}$ & Adjusted Conc. & Conc. Units \\
\hline $241-U-204$ & $\begin{array}{l}\text { Sludge (Liquid } \\
\text { \& Solid) }\end{array}$ & CWR1 (Solid) & $1.64 \mathrm{E}-02$ & $\mathrm{~S}$ & 1.47 & 7 & $1.59 \mathrm{E}-03$ & $\mu \mathrm{Ci} / \mathrm{g}$ \\
\hline 241-U-204 & Supernatant & $\begin{array}{l}\text { CWR1 } \\
\text { (Liquid) }\end{array}$ & $1.92 \mathrm{E}-02$ & $\mathrm{~S}$ & 1.11 & 4 & $4.80 \mathrm{E}-03$ & $\mu \mathrm{Ci} / \mathrm{mL}$ \\
\hline 241-U-204 & Total & & $3.56 \mathrm{E}-02$ & $\mathrm{~S}$ & & & & \\
\hline
\end{tabular}

Table A.2. Hanford Tank Ranking by Total ${ }^{99} \mathrm{Tc}$ Inventory

\begin{tabular}{|c|c|c|c|c|c|c|c|c|c|c|c|}
\hline $\begin{array}{l}\text { Number } \\
\text { Ranking }\end{array}$ & Tank & $\begin{array}{l}{ }^{99} \mathrm{Tc} \\
(\mathrm{Ci})\end{array}$ & $\begin{array}{l}\text { Number } \\
\text { Ranking }\end{array}$ & Tank & $\begin{array}{l}{ }^{99} \mathrm{Tc} \\
(\mathrm{Ci})\end{array}$ & $\begin{array}{l}\text { Number } \\
\text { Ranking }\end{array}$ & Tank & $\begin{array}{l}{ }^{99} \mathrm{Tc} \\
(\mathrm{Ci})\end{array}$ & $\begin{array}{l}\text { Number } \\
\text { Ranking }\end{array}$ & Tank & $\begin{array}{l}{ }^{99} \mathrm{Tc} \\
(\mathrm{Ci})\end{array}$ \\
\hline 1 & AZ-101 & $1.23 \mathrm{E}+03$ & 46 & S-111 & $1.92 \mathrm{E}+02$ & 91 & BY-105 & $4.63 \mathrm{E}+01$ & 136 & U-101 & $1.93 \mathrm{E}+00$ \\
\hline 2 & AN-105 & $1.12 \mathrm{E}+03$ & 47 & TX-110 & $1.88 \mathrm{E}+02$ & 92 & TY-105 & $4.40 \mathrm{E}+01$ & 137 & B-101 & $1.83 \mathrm{E}+00$ \\
\hline 3 & SY-103 & $1.01 \mathrm{E}+03$ & 48 & AY-102 & $1.82 \mathrm{E}+02$ & 93 & A-102 & $3.70 \mathrm{E}+01$ & 138 & SX-113 & $1.55 \mathrm{E}+00$ \\
\hline 4 & AP-103 & $9.59 \mathrm{E}+02$ & 49 & SX-102 & $1.82 \mathrm{E}+02$ & 94 & $\mathrm{~T}-105$ & $3.50 \mathrm{E}+01$ & 139 & SX-115 & $1.25 \mathrm{E}+00$ \\
\hline 5 & AP-105 & $9.51 \mathrm{E}+02$ & 50 & BY-103 & $1.78 \mathrm{E}+02$ & 95 & $\mathrm{~T}-101$ & $3.44 \mathrm{E}+01$ & 140 & BX-109 & $1.09 \mathrm{E}+00$ \\
\hline 6 & AW-101 & $8.18 \mathrm{E}+02$ & 51 & AP-107 & $1.77 \mathrm{E}+02$ & 96 & S-107 & $3.06 \mathrm{E}+01$ & 141 & TY-106 & $1.08 \mathrm{E}+00$ \\
\hline 7 & AN-104 & $7.94 \mathrm{E}+02$ & 52 & BY-104 & $1.72 \mathrm{E}+02$ & 97 & SX-114 & $3.05 \mathrm{E}+01$ & 142 & $\mathrm{~T}-104$ & $9.74 \mathrm{E}-01$ \\
\hline 8 & AW-104 & $7.59 \mathrm{E}+02$ & 53 & BY-106 & $1.72 \mathrm{E}+02$ & 98 & A-105 & $2.82 \mathrm{E}+01$ & 143 & C-102 & 8.87E-01 \\
\hline 9 & AP-101 & $7.55 \mathrm{E}+02$ & 54 & S-103 & $1.69 \mathrm{E}+02$ & 99 & TY-103 & $2.71 \mathrm{E}+01$ & 144 & T-108 & $7.72 \mathrm{E}-01$ \\
\hline 10 & AP-108 & $7.24 \mathrm{E}+02$ & 55 & BY-101 & $1.68 \mathrm{E}+02$ & 100 & SX-111 & $2.46 \mathrm{E}+01$ & 145 & U-104 & $7.28 \mathrm{E}-01$ \\
\hline 11 & AP-102 & $7.03 E+02$ & 56 & SX-101 & $1.64 \mathrm{E}+02$ & 101 & B-110 & $2.13 \mathrm{E}+01$ & 146 & B-202 & $6.85 \mathrm{E}-01$ \\
\hline 12 & AN-103 & $6.81 \mathrm{E}+02$ & 57 & TX-106 & $1.64 \mathrm{E}+02$ & 102 & AX-104 & $2.06 \mathrm{E}+01$ & 147 & B-109 & $4.71 \mathrm{E}-01$ \\
\hline 13 & AW-106 & $5.93 E+02$ & 58 & U-102 & $1.62 \mathrm{E}+02$ & 103 & S-102 & $2.00 \mathrm{E}+01$ & 148 & B-108 & 4.17E-01 \\
\hline 14 & AN-102 & $5.80 \mathrm{E}+02$ & 59 & BY-111 & $1.59 \mathrm{E}+02$ & 104 & TX-104 & $1.97 \mathrm{E}+01$ & 149 & B-103 & $3.34 \mathrm{E}-01$ \\
\hline 15 & AN-107 & $4.34 \mathrm{E}+02$ & 60 & TX-116 & $1.56 \mathrm{E}+02$ & 105 & B-104 & $1.89 \mathrm{E}+01$ & 150 & T-109 & $3.02 \mathrm{E}-01$ \\
\hline 16 & S-109 & $4.18 \mathrm{E}+02$ & 61 & AP-104 & $1.55 \mathrm{E}+02$ & 106 & TX-107 & $1.67 \mathrm{E}+01$ & 151 & B-102 & $2.15 \mathrm{E}-01$ \\
\hline 17 & AZ-102 & $4.01 E+02$ & 62 & A-106 & $1.48 \mathrm{E}+02$ & 107 & $\mathrm{~T}-111$ & $1.66 \mathrm{E}+01$ & 152 & C-104 & $1.73 \mathrm{E}-01$ \\
\hline 18 & AW-103 & $3.97 \mathrm{E}+02$ & 63 & AN-106 & $1.44 \mathrm{E}+02$ & 108 & BX-112 & $1.57 \mathrm{E}+01$ & 153 & C-106 & $1.64 \mathrm{E}-01$ \\
\hline 19 & AP-106 & $3.68 \mathrm{E}+02$ & 64 & U-111 & $1.42 \mathrm{E}+02$ & 109 & SX-110 & $1.52 \mathrm{E}+01$ & 154 & S-112 & $1.37 \mathrm{E}-01$ \\
\hline 20 & S-105 & $3.52 \mathrm{E}+02$ & 65 & TX-111 & $1.41 \mathrm{E}+02$ & 110 & B-107 & $1.48 \mathrm{E}+01$ & 155 & U-201 & $1.22 \mathrm{E}-01$ \\
\hline 21 & S-108 & $3.41 \mathrm{E}+02$ & 66 & B-111 & $1.32 \mathrm{E}+02$ & 111 & A-104 & $1.41 \mathrm{E}+01$ & 156 & BX-102 & 1.19E-01 \\
\hline 22 & AW-102 & $3.21 \mathrm{E}+02$ & 67 & BY-110 & $1.31 \mathrm{E}+02$ & 112 & TX-101 & $1.39 \mathrm{E}+01$ & 157 & U-202 & $1.10 \mathrm{E}-01$ \\
\hline 23 & SY-101 & $2.98 \mathrm{E}+02$ & 68 & BY-112 & $1.25 \mathrm{E}+02$ & 113 & SX-108 & $1.38 \mathrm{E}+01$ & 158 & U-203 & $9.94 \mathrm{E}-02$ \\
\hline 24 & TX-113 & $2.96 \mathrm{E}+02$ & 69 & BY-102 & $1.18 \mathrm{E}+02$ & 114 & SX-107 & $1.37 \mathrm{E}+01$ & 159 & BX-103 & $8.19 \mathrm{E}-02$ \\
\hline
\end{tabular}




\begin{tabular}{|c|c|c|c|c|c|c|c|c|c|c|c|}
\hline $\begin{array}{l}\text { Number } \\
\text { Ranking }\end{array}$ & Tank & $\begin{array}{l}{ }^{99} \mathrm{Tc} \\
(\mathrm{Ci})\end{array}$ & $\begin{array}{l}\text { Number } \\
\text { Ranking }\end{array}$ & Tank & $\begin{array}{l}{ }^{99} \mathrm{Tc} \\
(\mathrm{Ci})\end{array}$ & $\begin{array}{l}\text { Number } \\
\text { Ranking }\end{array}$ & Tank & $\begin{array}{l}{ }^{99} \mathrm{Tc} \\
(\mathrm{Ci})\end{array}$ & $\begin{array}{l}\text { Number } \\
\text { Ranking }\end{array}$ & Tank & $\begin{array}{l}{ }^{99} \mathrm{Tc} \\
(\mathrm{Ci})\end{array}$ \\
\hline 25 & AX-101 & $2.90 \mathrm{E}+02$ & 70 & TX-118 & $1.08 \mathrm{E}+02$ & 115 & C-112 & $1.29 \mathrm{E}+01$ & 160 & C-110 & $5.77 \mathrm{E}-02$ \\
\hline 26 & S-106 & $2.85 \mathrm{E}+02$ & 71 & TX-102 & $1.07 \mathrm{E}+02$ & 116 & SX-112 & $1.28 \mathrm{E}+01$ & 161 & C-103 & 4.48E-02 \\
\hline 27 & SX-103 & $2.82 \mathrm{E}+02$ & 72 & S-101 & $1.06 \mathrm{E}+02$ & 117 & BX-106 & $1.20 \mathrm{E}+01$ & 162 & C-101 & 4.34E-02 \\
\hline 28 & U-108 & $2.80 \mathrm{E}+02$ & 73 & BY-107 & $1.05 \mathrm{E}+02$ & 118 & U-110 & $1.10 \mathrm{E}+01$ & 163 & C-108 & $3.96 \mathrm{E}-02$ \\
\hline 29 & TX-112 & $2.64 \mathrm{E}+02$ & 74 & U-106 & $1.05 \mathrm{E}+02$ & 119 & BX-101 & $1.03 \mathrm{E}+01$ & 164 & U-204 & $3.56 \mathrm{E}-02$ \\
\hline 30 & A-103 & $2.59 \mathrm{E}+02$ & 75 & BY-109 & $9.89 \mathrm{E}+01$ & 120 & TY-102 & $9.37 \mathrm{E}+00$ & 165 & C-109 & $7.50 \mathrm{E}-03$ \\
\hline 31 & SX-106 & $2.59 \mathrm{E}+02$ & 76 & C-105 & $8.14 \mathrm{E}+01$ & 121 & AW-105 & $9.35 \mathrm{E}+00$ & 166 & C-204 & $3.18 \mathrm{E}-03$ \\
\hline 32 & U-109 & $2.47 \mathrm{E}+02$ & 77 & BY-108 & $8.00 \mathrm{E}+01$ & 122 & B-112 & $9.15 \mathrm{E}+00$ & 167 & C-201 & $2.63 \mathrm{E}-03$ \\
\hline 33 & SY-102 & $2.44 \mathrm{E}+02$ & 78 & SX-109 & $7.68 \mathrm{E}+01$ & 123 & TY-104 & $8.86 \mathrm{E}+00$ & 168 & C-202 & $2.50 \mathrm{E}-03$ \\
\hline 34 & TX-105 & $2.44 \mathrm{E}+02$ & 79 & BX-110 & $7.59 \mathrm{E}+01$ & 124 & $\mathrm{~T}-102$ & $7.13 \mathrm{E}+00$ & 169 & C-203 & $2.32 \mathrm{E}-03$ \\
\hline 35 & U-105 & $2.43 \mathrm{E}+02$ & 80 & BX-111 & $7.11 \mathrm{E}+01$ & 125 & AX-102 & $6.30 \mathrm{E}+00$ & 170 & $\mathrm{~T}-110$ & $1.22 \mathrm{E}-03$ \\
\hline 36 & TX-115 & $2.39 \mathrm{E}+02$ & 81 & TX-103 & $7.07 \mathrm{E}+01$ & 126 & B-106 & $5.62 \mathrm{E}+00$ & 171 & B-203 & 4.16E-06 \\
\hline 37 & S-110 & $2.37 \mathrm{E}+02$ & 82 & AX-103 & $7.03 \mathrm{E}+01$ & 127 & TY-101 & $5.26 \mathrm{E}+00$ & 172 & B-204 & $3.79 \mathrm{E}-06$ \\
\hline 38 & U-107 & $2.35 \mathrm{E}+02$ & 83 & BX-107 & $6.98 \mathrm{E}+01$ & 128 & C-107 & $4.00 \mathrm{E}+00$ & 173 & $\mathrm{~T}-204$ & $3.00 \mathrm{E}-06$ \\
\hline 39 & U-103 & $2.30 \mathrm{E}+02$ & 84 & BX-105 & $6.04 \mathrm{E}+01$ & 129 & U-112 & $3.59 \mathrm{E}+00$ & 174 & $\mathrm{~T}-203$ & $2.96 \mathrm{E}-06$ \\
\hline 40 & A-101 & $2.29 \mathrm{E}+02$ & 85 & AY-101 & $5.55 \mathrm{E}+01$ & 130 & $\mathrm{~T}-106$ & $2.85 \mathrm{E}+00$ & 175 & $\mathrm{~T}-201$ & $1.75 \mathrm{E}-06$ \\
\hline 41 & SX-104 & $2.09 \mathrm{E}+02$ & 86 & TX-108 & $5.54 \mathrm{E}+01$ & 131 & B-105 & $2.75 \mathrm{E}+00$ & 176 & B-201 & $1.72 \mathrm{E}-06$ \\
\hline 42 & AN-101 & $2.01 \mathrm{E}+02$ & 87 & S-104 & $5.12 \mathrm{E}+01$ & 132 & BX-108 & $2.58 \mathrm{E}+00$ & 177 & $\mathrm{~T}-202$ & $1.65 \mathrm{E}-06$ \\
\hline 43 & SX-105 & $1.97 \mathrm{E}+02$ & 88 & $\mathrm{~T}-107$ & $4.83 \mathrm{E}+01$ & 133 & $\mathrm{~T}-103$ & $2.28 \mathrm{E}+00$ & Overall ${ }^{\mathrm{s}}$ & Tc inventory & $2.65 \mathrm{E}+04$ \\
\hline 44 & TX-114 & $1.97 \mathrm{E}+02$ & 89 & BX-104 & $4.65 \mathrm{E}+01$ & 134 & C-111 & $2.19 \mathrm{E}+00$ & & & \\
\hline 45 & TX-117 & $1.96 \mathrm{E}+02$ & 90 & TX-109 & $4.65 \mathrm{E}+01$ & 135 & $\mathrm{~T}-112$ & $2.12 \mathrm{E}+00$ & & & \\
\hline
\end{tabular}




\section{Appendix B}

Listing of Reports on Characterization of Residual Sludge in SSTs That Have Been Retrieved 



\section{Appendix B}

\section{Listing of Reports on Characterization of Residual Sludge in SSTs That Have Been Retrieved}

This appendix lists all the reports generated by Pacific Northwest National Laboratory staff on the characterization of residual sludges from single-shell tanks (SSTs) that have had most of their contents removed by various sluicing techniques. A summary of findings on ${ }^{99} \mathrm{Tc}$ is provided.

Some key results found in the reports germane to the fate of ${ }^{99} \mathrm{Tc}$ follow. The percentage of $\mathrm{Tc}$ that dissolved from residual sludge from tanks 241-C-103, 241- C-106, 241-C-202, and 241-C-203 ranged from approximately $6 \%$ to $10 \%$. Solid phase characterization results for leached sludges indicate that the recalcitrant forms of Tc are associated with iron oxides. X-ray absorption near edge structure (XANES) analysis of Tc in residual sludge indicates that Tc occurs in Fe oxide particles in their lower, less-soluble oxidation state [Tc(IV)]. Identifying the exact form of the Tc has been challenging. This is because Tc occurs at trace concentrations and the residual sludges are chemically complex assemblages of crystalline and amorphous solids that likely contain contaminants less as discrete phases and more as co-precipitates within oxide phases of the major components (Al, Si, Fe, etc.). Results from some of PNNL's early work using selective extractions suggested that significant fractions of Tc were typically co-precipitated at trace concentrations in Fe oxide phases that could not be identified unambiguously. Leachants used in these studies include DI water, a $\mathrm{Ca}(\mathrm{OH})_{2}$ saturated solution, and a calcite $\left(\mathrm{CaCO}_{3}\right)$ saturated solution. The aqueous leaching experiments were conducted using both single-contact experiments and sequential-contact experiments. The single-contact experiments typically included 1-day and 1-month contact periods. Additional sequential-contact experiments typically included six stages in which the leachate solution was replaced with fresh leachant after each contact period. The contact periods were typically 1 day for the first five stages and 30 days for the sixth stage. All the leach tests were conducted at a solution to solid ratio of approximately 100.

In the tank residual waste samples analyzed to date, no Tc was ever detected in any of the numerous Al oxyhydroxide particles analyzed by scanning electron microscopy-energy dispersive X-ray spectrometry. Recently published quantum-mechanical modeling of ${ }^{99} \mathrm{Tc}$ incorporation into hematite indicates that incorporation of small amounts of Tc(IV) (up to at least $2.6 \mathrm{wt} \%$ ) is energetically feasible whereas incorporation of pertechnetate $\left(\mathrm{TcO}_{4}{ }^{-}\right)$was unfavorable. ${ }^{1}$

Two archived sludges from tanks that have not been retrieved were also characterized (AY-102 and $\mathrm{BX}-101)$. A key finding of these tests is that ${ }^{99} \mathrm{Tc}$ is not completely water leachable and mobile from tank AY-102. Only $25 \%$ of the ${ }^{99} \mathrm{Tc}$ in AY-102 sludge is water leachable, whereas for tank BX-101 all of the ${ }^{99} \mathrm{Tc}$ is water leachable. Finally, the drainable liquid from tank AY-102 sludge was tested using the XANES technique to determine redox state of the dissolved technetium. Technetium in the drainable liquid from AY-102 sludge was shown by XANES analysis to be either in the oxidized pertechnetate $[\mathrm{Tc}(\mathrm{VII})]$ or a $\mathrm{Tc}(\mathrm{V})$ valence state soluble species, but not as reduced $\mathrm{Tc}(\mathrm{IV})$ species. Presumably the XANES analyst was aware of work on double-shell tank (DST) supernates that suggests that a soluble

\footnotetext{
${ }^{1}$ Skomurski FN, KM Rosso, KM Krupka, and BP McGrail. 2010. "Technetium incorporation into hematite $\left(\alpha-\mathrm{Fe}_{2} \mathrm{O}_{3}\right)$.” Environ. Sci. Technol. 44(15): 5855-5861.
} 
non-pertechnetate form of ${ }^{99} \mathrm{Tc}$ is present with an assumed $\mathrm{Tc}(\mathrm{I})$ valence state. The analyst was Dr. Wayne Lukens, who also has performed much of the XANES studies on model non-pertechnetate species to aid in efforts to determine the ${ }^{99} \mathrm{Tc}$ species in DST supernates. No supernates from AY-102 have been characterized for non-pertechnetate, and based on the available information on what waste type constitutes the AY-102 supernate, this study could not provide any insight on whether AY-102 supernate might contain non-pertechnetate species.

Here is the list of publications. The technical reports have embedded links to pdf files.

- $\quad$ Cantrell KJ, W Um, BD Williams, ME Bowden, BN Gartman, WW Lukens, EC Buck, and EJ Mausolf. 2014. "Chemical Stabilization of Hanford Tank Residual Waste." Journal of Nuclear Materials 446(1-3):246-256. doi:10.1016/j.jnucmat.2013.10.060 Abstract $\mid$ Details JOURNAL ARTICLE

- $\quad$ Cantrell KJ, KC Carroll, EC Buck, D Neiner, and KN Geiszler. 2013. "Single-Pass Flow-Through Test Elucidation of Weathering Behavior and Evaluation of Contaminant Release Models for Hanford Tank Residual Radioactive Waste." Applied Geochemistry 28:119-127. doi:10.1016/j.apgeochem.2012.09.004 Abstract $\mid$ Details JOURNAL ARTICLE

- Cantrell KJ, SM Heald, BW Arey, and MJ Lindberg. 2011. "Inhibited Release of Mobile Contaminants from Hanford Tank Residual Waste.” In Waste Management 2011: Global Achievements and Challenges in Waste Management, February 27-March 3, 2011, Phoenix, Arizona, p. Paper No. 11447. WM Symposia, Tucson, AZ. Abstract $\mid$ Details CONFERENCE PAPER

- Cantrell KJ, WJ Deutsch, and MJ Lindberg. 2011. "Thermodynamic Model for Uranium Release from Hanford Site Tank Residual Waste.” Environmental Science \& Technology 45(4):1473-1480. doi:10.1021/es1038968 Abstract $\mid \underline{\text { Details JOURNAL ARTICLE }}$

- $\quad$ Deutsch WJ, KJ Cantrell, KM Krupka, MJ Lindberg, and RJ Serne. 2011. "Hanford tank residual waste - contaminant source terms and release models." Applied Geochemistry 26(9-10):1681-1693. doi:10.1016/j.apgeochem.2011.04.025

- $\quad$ Cantrell KJ, KM Krupka, KN Geiszler, BW Arey, and HT Schaef. 2010. Hanford Site Tank 241-C-108 Residual Waste Contaminant Release Models and Supporting Data. PNNL-19425, Pacific Northwest National Laboratory, Richland, WA.

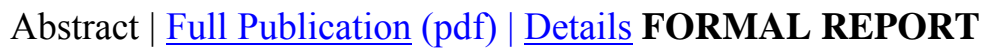

- $\quad$ Krupka KM, KJ Cantrell, HT Schaef, BW Arey, SM Heald, WJ Deutsch, and MJ Lindberg. 2010. "Characterizing Solids in Residual Wastes from Single-Shell Tanks at the Hanford Site." Radwaste Solutions 17(2):64-75.

- $\quad$ Cantrell KJ, KM Krupka, WJ Deutsch, and MJ Lindberg. 2009. "Contaminant Release from Residual Waste in Single Shell Tanks at the Hanford Site, Washington, USA - 9276." In WM 2009 Waste Management for the Nuclear Renaissance, March 1-5, 2009, Phoenix, Arizona. WM Symposia Inc., Tempe, AZ. 
- $\quad$ Krupka KM, KJ Cantrell, HT Schaef, BW Arey, SM Heald, WJ Deutsch, and MJ Lindberg. 2009. "Characterization of Solids in Residual Wastes from Single-Shell Tanks at the Hanford Site, Washington, USA - 9277." In WM2009 Waste Management for the Nuclear Renaissance, March 1-5, 2009, Phoenix, Arizona. WM Symposia Inc., Tempe, AZ.

- $\quad$ Cantrell KJ, KM Krupka, KN Geiszler, MJ Lindberg, BW Arey, and HT Schaef. 2008. Hanford Tank 241-S-112 Residual Waste Composition and Leach Test Data. PNNL-17593, Pacific Northwest National Laboratory, Richland, WA. Abstract $\mid$ Full Publication (pdf) | Details FORMAL REPORT

- $\quad$ Cantrell KJ, KM Krupka, WJ Deutsch, MJ Lindberg, HT Schaef, KN Geiszler, and BW Arey. 2008. Hanford Tank 241-C-103 Residual Waste Contaminant Release Models and Supporting Data. PNNL-16738, Pacific Northwest National Laboratory, Richland, WA. Abstract $\mid$ Full Publication (pdf) $\mid$ Details FORMAL REPORT

- $\quad$ Cantrell KJ, KM Krupka, WJ Deutsch, MJ Lindberg, HT Schaef, KN Geiszler, and BW Arey. 2008. Hanford Tank 241-C-103 Residual Waste Contaminant Release Models and Supporting Data. PNNL-16738, Pacific Northwest National Laboratory, Richland, WA.

- $\quad$ Deutsch WJ, KJ Cantrell, RJ Serne, and EM Pierce. 2008. “Appendix D: Contaminant Release from Residual Waste in Closed Single Shell Tanks and Other Waste Forms Associated with the Tanks." In The Resource Conservation and Recovery Act Facility Investigation (RFI) Report for Hanford Single-Shell Tank Waste Management Areas, DOE/ORP-2008-01 Revision 0, vol. Tier 2, ed. FM Mann. Office of River Protection, U.S. Department of Energy, Richland, WA. Abstract $\mid \underline{\text { Details BOOK CHAPTER }}$

- Deutsch WJ. 2008. "Contaminant Release from Residual Waste in Closed Single-Shell Tanks and Other Waste Forms Associated with the Tanks." Chapter 19 in The Resource Conservation and Recovery Act Facility Investigation (RFI) Report for Hanford Single-Shell Tank Waste Management Areas, DOE/ORP-2008-01 Revision 0, vol. Tier 1, ed. FM Mann, pp. 19-1 - 19-14. Office of River Protection, U.S. Department of Energy, Richland, WA.

Abstract $\mid \underline{\text { Details BOOK CHAPTER }}$

- $\quad$ Deutsch WJ, KJ Cantrell, and KM Krupka. 2007. Contaminant Release Data Package for Residual Waste in Single-Shell Hanford Tanks. PNNL-16748, Pacific Northwest National Laboratory, Richland, WA.

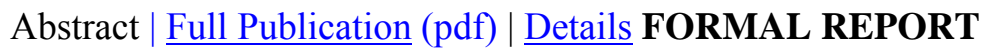

- $\quad$ Deutsch WJ, KM Krupka, MJ Lindberg, KJ Cantrell, CF Brown, and HT Schaef. 2007. Hanford Tank 241-C-106: Residual Waste Contaminant Release Model and Supporting Data. PNNL-15187 Rev. 1, Pacific Northwest National Laboratory, Richland, WA.

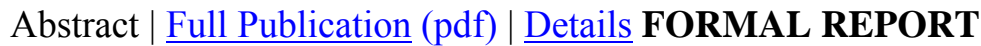

- $\quad$ Deutsch WJ, KM Krupka, MJ Lindberg, KJ Cantrell, CF Brown, and HT Schaef. 2007. Hanford Tanks 241-C-203 and 241 C 204: Residual Waste Contaminant Release Model and Supporting Data. PNNL-14903 Rev. 1, Pacific Northwest National Laboratory, Richland, WA.

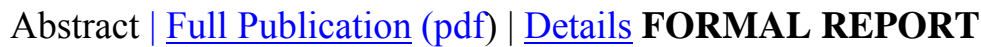


- $\quad$ Deutsch WJ, KM Krupka, MJ Lindberg, KJ Cantrell, CF Brown, SV Mattigod, HT Schaef, and BW Arey. 2007. Hanford Tanks 241-C-202 and 241-C-203 Residual Waste Contaminant Release Models and Supporting Data. PNNL-16229, Pacific Northwest National Laboratory, Richland, WA.

Abstract $\mid$ Full Publication (PDF) | Details FORMAL REPORT

- $\quad$ Krupka KM, WJ Deutsch, HT Schaef, BW Arey, SM Heald, MJ Lindberg, and KJ Cantrell. 2007. "Characterization of Solids in Residual Wastes from Underground Storage Tanks at the Hanford Site, Washington, U.S.A.” In 30th International Symposium on Scientific Basis for Nuclear Waste Management, Boston, November 27 - December 1, 2006. Materials Research Society Symposium Proceedings, vol. 985, ed. DE Dunn, C Poinssot, and B Begg, pp. 473-482. Materials Research Society, Warrendale, PA. Abstract $\mid$ Details CONFERENCE PAPER

- Cantrell KJ, KM Krupka, WJ Deutsch, and MJ Lindberg. 2006. "Residual Waste from Hanford Tanks 241-C-203 and 241-C-204. 2. Contaminant Release Model." Environmental Science and Technology 40(12):3755-3761 + supporting info. doi:10.1021/es0511568 Abstract $\mid$ Details JOURNAL ARTICLE

- $\quad$ Deutsch WJ, KM Krupka, MJ Lindberg, KJ Cantrell, CF Brown, and HT Schaef. 2006. Hanford Tank 241-C-106: Impact of Cement Reactions on Release of Contaminants from Residual Waste. PNNL-15544, Pacific Northwest National Laboratory, Richland, WA.

Abstract $\mid$ Full Publication (pdf) | Details FORMAL REPORT

- $\quad$ Krupka KM, HT Schaef, BW Arey, SM Heald, WJ Deutsch, MJ Lindberg, and KJ Cantrell. 2006. "Residual Waste from Hanford Tanks 241-C-203 and 241-C-204. I. Solids Characterization." Environmental Science and Technology 40(12):3749-3754, and sup. info. file. Abstract $\mid$ Details JOURNAL ARTICLE

- $\quad$ Lindberg MJ and WJ Deutsch. 2006. Comparison of Sludge Digestion Methods for High Organic Hanford Tank 241-C-204. PNNL-16140, Pacific Northwest National Laboratory, Richland, WA.

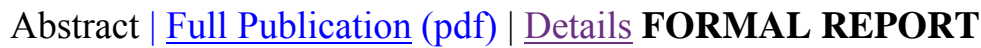

- $\quad$ Deutsch WJ, KM Krupka, KJ Cantrell, CF Brown, MJ Lindberg, HT Schaef, SM Heald, BW Arey, and RK Kukkadapu. 2005. Advances in Geochemical Testing of Key Contaminants in Residual Hanford Tank Waste. PNNL-15372, Pacific Northwest National Laboratory, Richland, WA.

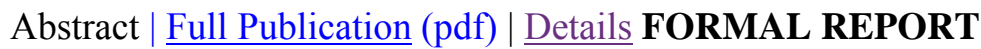

- $\quad$ Krupka KM, WJ Deutsch, MJ Lindberg, KJ Cantrell, NJ Hess, HT Schaef, and BW Arey. 2004. Hanford Tanks 241-AY-102 and 241-BX-101: Sludge Composition and Contaminant Release Data. PNNL-14614, Pacific Northwest National Laboratory, Richland, WA.

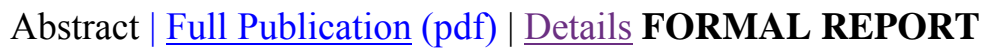

- $\quad$ Lindberg MJ and WJ Deutsch. 2003. Tank 241-AY-102 Data Report. PNNL-14344, Pacific Northwest National Laboratory, Richland, WA.

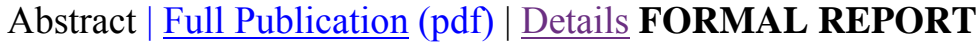


Appendix C

Description of the HTWOS Computer Code 



\section{Appendix C}

\section{Description of the HTWOS Computer Code}

\section{C.1 Code Description}

This appendix briefly describes the Hanford Tank Waste Operations Simulator (HTWOS) computer code and references. The HTWOS is a model/computer code that begins with an inventory in each Hanford storage tank and simulates its future form and location by applying a series of assumptions regarding the waste's retrieval out of the tanks, its pretreatment, and its final immobilization.

This model of future tank waste disposition relies on the best basis inventory (BBI) of the current estimates of each storage tank's waste inventory and volume and the processes that will be used to retrieve the waste from the tanks, the processes that will be used to separate it into high-level and low-activity fractions, and finally the processes that will be used to create the final waste form. The HTWOS model provides estimates of the primary waste form's inventory and volume of waste generated as well as the same for any secondary waste streams and secondary waste forms that are generated. Finally, HTWOS provides an estimate of the tank residual for each tank and an estimate of tank retrieval losses (volumes and composition). As additional tanks are retrieved, the predicted residual inventories left in tanks are replaced by measured values. The predicted inventory is determined by multiplying the volume of waste assumed to be left in the tanks after retrieval by the assumed residual waste concentration.

Essentially, HTWOS is a large mass balance bookkeeping-like computer code. The HTWOS model relies on the design of chemical separations, solidification, and vitrification processes as documented in the detailed flow sheets and designs for the Hanford Tank Waste Treatment and Immobilization Plant (WTP) and the other tank waste treatment options. These various treatment processes are modeled in sufficient detail to provide estimates of process operation, of interactions or recycle between unit operations, and of quantities of primary waste products and composition of secondary waste streams. The model adheres to physical constraints inherent to the equipment and safety limitations as well as the programmatic constraints from current plans or business strategies.

Of course, the estimates are highly dependent on knowledge of the numerous processes involved with waste retrieval from the tanks, waste partitioning during pretreatment, and final waste form generation. To date, numerous scenarios for the fate of current tank waste have been produced that model waste movement from Hanford's single- and double-shell tanks to its final disposition including high-level waste (HLW) glass, low-activity waste (LAW) glass, bulk vitrification glass, supplemental low-temperature LAW waste forms such as Cast Stone, contact-handled and remote-handled transuranic waste, tank retrieval losses, tank residuals, and all secondary waste streams (gaseous, liquid, and solid). McCabe et al. (2013) as well as other Hanford technical staff caution that the HTWOS model does not account for chemical speciation or solubility constraints, so that the fate of each contaminant and other constituents may not be as accurately predicted as it would be with codes that include detailed thermodynamic constraints of solubility. Further, HTWOS does not currently account for carryover of the insoluble solids (which appear to be largely glass-formers) into melter off-gas systems. 
Given these cautions, HTWOS has been actively used to estimate the volumes and contaminant inventories in any waste form contemplated to date - as long as process details are available or assumptions are carefully documented. This allows estimates of waste volumes and inventories to be generated for wastes destined for disposal on-site and for wastes that will be sent off-site. HTWOS has been used to evaluate the impacts of off-gas condensate recycle to the LAW melters and the benefits of Tc removal from the off-gas condensates prior to recycling condensates back to LAW melters. HTWOS runs have been produced for LAW glass feed and off-gas condensate stream compositions based on weekly batches over the 25-year River Protection Project mission for the primary LAW Facility. For each week's batch, the HTWOS model has provided batch volume and kg-moles of radionuclide and chemical constituents with radionuclides decayed from the HTWOS starting reference date to the batch date as described in Robbins and May (2013).

HTWOS has also been used to predict the composition of LAW and secondary waste streams for weekly waste processing through WTP so that both weekly and extreme high and low LAW and secondary waste simulant compositions could be prepared for use in various low-temperature waste form formulation and performance testing activities (see Westsik et al. 2013 and Russell et al. 2013 for examples).

Three documents that describe the HTWOS architecture and details are Belsher et al. (2012), Kirkbride et al. (2005), and Naiknimbalkar (2005). Figure C.1 displays the processes/facilities and their relationships that are part of the HTWOS mass balance and "fate" model. The diagram was taken from DOE/ORP 2010, Appendix B, but redrawn here to improve legibility.

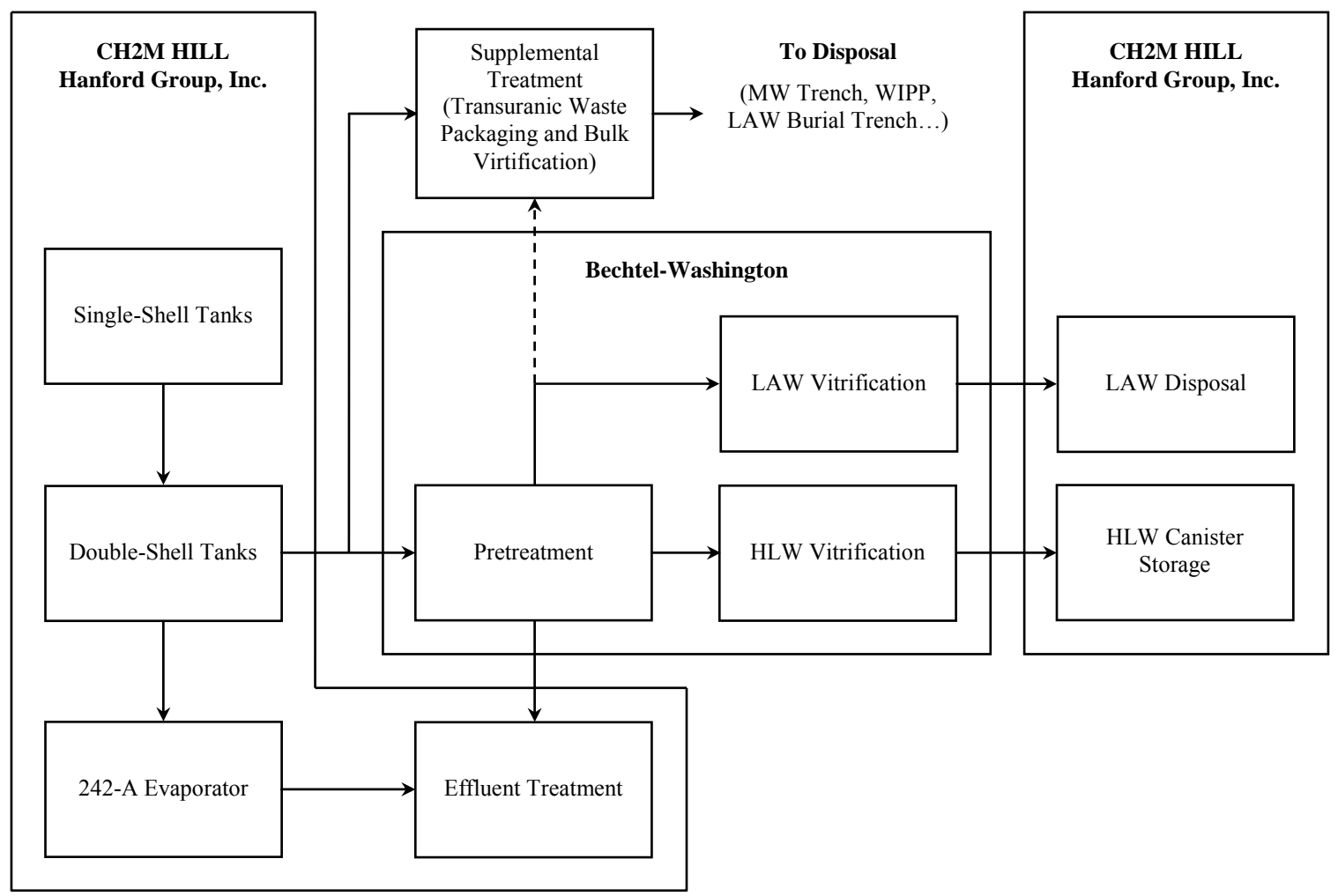

Figure C.1. Schematic of the Systems/Facilities and Waste Flow Included in HTWOS (redrawn from DOE/ORP 2010) 


\section{C.2 References}

Belsher JD, PA Empey, TM Hohl, RA Kirkbride, JS Ritari, EB West, LM Bergmann, and MN Wells. 2012. Hanford Tank Waste Operations Simulator (HTWOS) Version 7.4 Model Design Document. RPP-17152, Rev. 7, Washington River Protection Solutions, Richland, WA.

DOE/ORP. 2010. RCRA Facility Investigation Report for Hanford Single-Shell Tank Waste Management-Tier 1 \& 2. DOE/ORP-2008-01, Rev. 1 Reissue, Office of River Protection, U.S. Department of Energy, Richland, WA.

Kirkbride RA, GK Allen, PJ Certa, JA Lechelt, and SL Orcutt. 2005. Hanford Tank Waste Operations Simulator Model Data Package for the Development Run for the Refined Data Case. RPP-RPT-23412, Rev. 1, CH2M HILL Hanford Group, Inc., Richland, WA.

McCabe DJ, WR Wilmarth, and CA Nash. 2013. Waste Treatment Technology Process Development Plan for Hanford Waste Treatment Plant Low Activity Waste Recycle. SRNL-STI-2013-00351, Rev. 0, Savannah River National Laboratory, Aiken, SC.

Naiknimbalkar AN. 2005. Configuration Management Plan for Hanford Tank Waste Operations Simulator Flowsheet Modeling. RPP-7630, Rev. 4, CH2M Hill Hanford Group, Inc., Richland, WA.

Robbins RA and TH May. 2013. Submerged Bed Scrubber Condensate Technetium Removal and Disposal Preconceptual Engineering Study. RPP-RPT-55213, Rev. 0, Washington River Protection Solutions, LLC, Richland, WA.

Russell RL, JH Westsik, Jr, DJ Swanberg, RE Eibling, A Cozzi, MJ Lindberg, GB Josephson, and DE Rinehart. 2013. Letter Report: LAW Simulant Development for Cast Stone Screening Test. PNNL-22352, Pacific Northwest National Laboratory, Richland, WA. Full Publication (pdf)

Westsik Jr., JH, GF Piepel, MJ Lindberg, PG Heasler, TM Mercier, RL Russell, AD Cozzi, WE Daniel, RE Eibling, EK Hansen, MR Reigal, and DJ Swanberg. 2013. Supplemental Immobilization of Hanford Low-Activity Waste: Cast Stone Screening Tests. PNNL-22747 and SRNL-STI-2013-00465 Rev. 0, Pacific Northwest National Laboratory, Richland, WA and Savannah River National Laboratory, Aiken, $\mathrm{SC}$. 

Appendix D

Discussion and List of Resources for ${ }^{99} \mathrm{Tc}$ in Hanford Mass Balance "Pools" 



\section{Appendix D}

\section{Discussion and List of Resources for ${ }^{99} \mathrm{Tc}$ in Hanford Mass Balance "Pools"}

This appendix briefly describes some of the efforts and processes used to estimate the ${ }^{99} \mathrm{Tc}$ inventories that have been released to the Hanford vadose zone. Figure D.1 is a schematic showing the entire Hanford irradiated fuel separations process and where each waste stream was sent. Efforts have been expended to estimate both the release of ${ }^{99} \mathrm{Tc}$ from single-shell tanks (SSTs) and ${ }^{99} \mathrm{Tc}$ purposefully released to the now-inactive cribs, trenches, and ponds. Much effort has been placed on developing conceptual models for key contaminants for three regions in the Central Plateau and for the 300 Area. However, the 300 Area does not contain a significant inventory of ${ }^{99} \mathrm{Tc}$, rather the key contaminant is uranium. Thus, the conceptual model and mass balance studies performed in the 300 Area are not discussed here.



Figure D.1. Schematic of the Hanford Separations Process and Fate of the Wastes Produced

\section{D.1 Conceptual Models for Central Plateau Sub-regions}

The three areas in the Central Plateau for which contaminant conceptual models and inventories have been generated are the B-Complex in 200-E Area and the T-Complex, and to a lesser extent the S-Complex in 200-W Area. The key objective of these efforts was to evaluate available data pertaining to the boxes in Table 6.1, which evaluate releases to the ground (Box \#3 in the table) and more specifically to determine the inventories in the three sub-boxes, 3A, 3B, and 3CA-inventory still in the vadose zone, inventory presently in the aquifer, and inventory that may have escaped to the Columbia River. 
Conceptual models identify the most likely sources (disposal facilities or SSTs) and hypothesize the migration pathways by which contaminants reached the water table at evaluated locations.

Conceptual models attempt to estimate the activity of key mobile contaminants such as ${ }^{99} \mathrm{Tc}$ that still remain in the vadose zone (from ground surface to the water table; with the deep vadose zone portion highlighted) and within the current groundwater plumes. The methodology used to create conceptual models starts with review and assembly of pertinent background information on the suspected facilities that received the wastes. Key background information includes locations of the facilities, periods of operation, volumes of waste disposed, types of waste streams disposed, and total masses of constituents released to the vadose zone sediments.

The second step is to assemble the available data on the distribution (vertical and lateral) of the key contaminants and species that control the mobility of the contaminants in the vadose zone sediments. Plots of the available data for localized subregions when available are superimposed on cross-sections of the stratigraphy, and available field surveys (gamma logs and soil resistivity) are used to help construct models of the lateral and vertical extent of the key contaminants within the vadose zone. A similar effort is then performed using the available groundwater monitoring data to develop time-series contaminant plume maps. Using a three-dimensional aquifer conceptual model with $10 \mathrm{~m}$ by $10 \mathrm{~m}$ grid cells and the aquifer thicknesses for each year from the geologic conceptual model, the mass of selected contaminants is calculated. The masses within the annually averaged groundwater plumes are then calculated and compared to evaluate whether mass has been increasing or decreasing over the last decade and where the mass appears to be entering the water table. The shapes of the time series groundwater plumes are used to reveal the net direction of flow of the groundwater. The vadose zone contaminant distribution data and groundwater data are then combined to create integrated conceptual models on where the bulk of the contaminants remain, where they enter the water table, and how the groundwater plumes have migrated over time. The estimated masses of contaminants remaining in the vadose zone and currently present in the groundwater plumes are compared to the estimates of the total masses disposed or released to the subsurface since the beginning of waste disposal activities. These mass-balance estimates provide baseline information on two key issues:

1. How well has the mass (and thus distribution in the vadose zone and aquifer) of the contaminant been identified?

2. Can the contaminant mass distribution in the deep vadose zone and aquifer be used to project future risks and guide the selection of remediation alternatives?

Figure D.2 is an example (from the draft S-Complex conceptual site model (CSM) report) schematic of the "pools" or boxes in which contaminant mass data or estimates are needed and the logic flow of input information. The B-Complex conceptual model has been the most successful effort because this region has the most data and a relatively shallow aquifer below the key vadose zone sources and a detailed report is available:

- Serne RJ, BN Bjornstad, JM Keller, PD Thorne, DC Lanigan, JN Christensen, and GS Thomas. 2010. Conceptual Models for Migration of Key Groundwater Contaminants Through the Vadose Zone and Into the Upper Unconfined Aquifer Below the B-Complex. PNNL-19277, Pacific Northwest National Laboratory, Richland, WA. | Full Publication (pdf) 


\section{Mass Balance Approach for the SX-Complex}

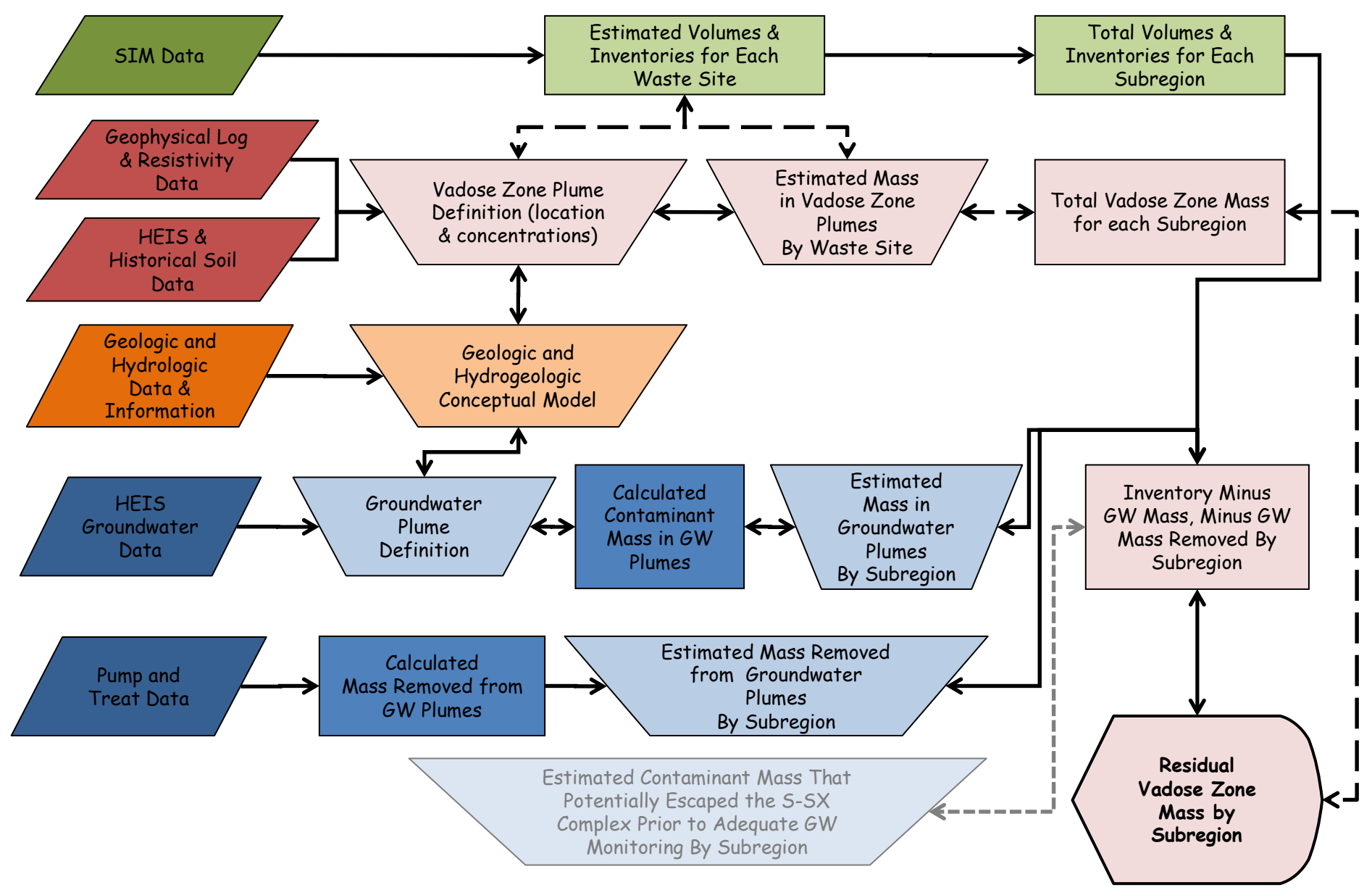

Figure D.2. Schematic of Inputs Used and Mass "Pools" Used or Calculated to Develop Conceptual Models for Contaminant Fate 
A brief summary of the findings from the B-Complex report follows. The B-Complex contains three major crib and trench disposal sites and three SST farms that have released nearly 346 million liters of waste liquids containing $145 \mathrm{Ci}$ of ${ }^{99} \mathrm{Tc}$. After a thorough review of available vadose zone sediment and pore water data, groundwater plume information, field gamma logging results, and field electrical resistivity information, conceptual models were developed for which waste sites have been the significant sources of the contaminants in the groundwater. This included estimating the masses of these contaminants remaining in the vadose zone and currently present in the groundwater in comparison to the totals released. This allowed mass balance calculations to be made on how consistent our knowledge is on the deep vadose zone and groundwater distribution of contaminants. Strengths and weaknesses of the conceptual models are discussed as well as implications on future groundwater and deep vadose zone remediation alternatives.

The hypothesized conceptual models attribute the source of most of the ${ }^{99} \mathrm{Tc}$ currently in the groundwater to the BY Cribs. Mass-balance estimates suggest that there are much larger masses of ${ }^{99} \mathrm{Tc}$ remaining in the deep vadose zone within $\sim 20 \mathrm{ft}$ of the water table than is currently in the groundwater plumes below the B-Complex. This hypothesis needs to be carefully considered before future remediation efforts are chosen. The masses of these contaminants in the groundwater plumes have been increasing over the last decade, and the groundwater plumes are migrating to the northwest toward the Gable Gap. The groundwater flow rate appears to fluctuate in response to seasonal changes in hydraulic gradient. The flux of contaminants out of the deep vadose zone from the three proposed sources also appears to be transient such that the evolution of the contaminant plumes is transient.

The available vadose zone sediment characterization data show that high concentrations of ${ }^{99} \mathrm{Tc}$ reside deep in the vadose zone below the BY Cribs within both the Hanford formation $\mathrm{H} 2$ and the Cold Creek Unit $\left(\mathrm{CCU}_{\mathrm{z}}\right)$ sediments. In the region of the BY Cribs, the fine-grained $\mathrm{CCU}_{\mathrm{z}}$ subunit is absent to very thin (1 to $1.5 \mathrm{ft}$ thick). It appears that water (steady-state natural recharge or transient natural or human-induced) that is fluxing through these deep sediments is carrying the ${ }^{99} \mathrm{Tc}$ down to the water table. Concentrations of ${ }^{99} \mathrm{Tc}$ in the sediments below the BY Cribs range from 120 to $200 \mathrm{pCi} / \mathrm{g}$ within $90 \mathrm{ft}$ of the water table. Residual ${ }^{99} \mathrm{Tc}$ concentrations in deep vadose zone sediments at all other boreholes within or proximal to other inactive disposal facilities in the B-Complex in the same geologic units are at least one order of magnitude lower. However, at two new boreholes (299-E33-343 and E33-345) far from the footprints of waste disposal facilities, water-extractable ${ }^{99} \mathrm{Tc}$ also reaches concentrations of $230 \mathrm{pCi} / \mathrm{g}$ in the $\mathrm{CCU}_{\mathrm{z}}$ unit. Based on the available deep vadose zone sediment samples from below the BY Cribs' footprint and the assumption that the areas under all eight BY Cribs have similar ${ }^{99} \mathrm{Tc}$ concentrations, the deep vadose zone inventory below the BY Cribs is estimated to be up to $55 \mathrm{Ci}$. No other deep vadose zone region, for which sediment data are available, calculates to have ${ }^{99} \mathrm{Tc}$ activity greater than $4 \mathrm{Ci}$. Based on the high volume of waste disposed of at the BY Cribs compared to any other facility in the B-Complex, the lack of or thin manifestation of the $\mathrm{CCU}_{z}$ lateral spreading layer, and the observed high concentrations of ${ }^{99} \mathrm{Tc}$ in the deep vadose zone, the BY Cribs are considered the most important source for the ${ }^{99} \mathrm{Tc}$ currently within the groundwater plume below the B-Complex and the plume's extension out north of Gable Gap.

Time series groundwater plumes also show that the BY Cribs are the location where the high groundwater concentrations for ${ }^{99} \mathrm{Tc}$ originate. The recent time series groundwater plume maps also show a second location near the new borehole 299-E33-343 where a small ${ }^{99} \mathrm{Tc}$ "hot spot" has formed. This coincides with the occurrence of high concentrations of both ${ }^{99} \mathrm{Tc}$ and uranium in the $\mathrm{CCU}_{\mathrm{z}}$ sediments, 
which are only $\sim 16 \mathrm{ft}$ above the water table at this location. The source of this secondary elevated ${ }^{99} \mathrm{Tc}$ mass has not been absolutely determined. The simplest hypothesis is that the ${ }^{99} \mathrm{Tc}$ originated from the tank BX-102 overfill event. The BX-102 fluids then spread laterally with a vertical component driven by gravity. Gravity and the stratigraphic dip of the vadose zone sediments have managed to transport the technetium into the very moist $\mathrm{CCU}_{\mathrm{z}}$ sediments, where it and uranium from BX-102 migrate east all the way to 299-E33-345.

Once the ${ }^{99} \mathrm{Tc}$ enters the water table at the two designated locations, it appears to be migrating toward the northwest and out of the B-Complex into the Gable Gap region. Given the fact that ${ }^{99} \mathrm{Tc}$ exhibits little to no sorptive tendencies with all Hanford Site sediments, its ultimate fate will be continued migration with the regional groundwater to the northwest out of the B-Complex with little to no retardation. The leading edge of the ${ }^{99} \mathrm{Tc} 900 \mathrm{pCi} / \mathrm{L}$ isopleth is moving toward the northwest and near the Gable Gap advanced $\sim 920 \mathrm{ft}$ between 2000 and 2009 . However, the ${ }^{99} \mathrm{Tc}$ secondary plume farther north and east of Gable Gap, likely a remnant from earlier times, is moving more slowly $(900 \mathrm{pCi} / \mathrm{L}$ isopleth has advanced to the north only $\sim 350 \mathrm{ft}$ in the same period), suggesting that dispersion and dilution to concentrations well below the drinking water standard are occurring far inland from the Columbia River.

The conceptual model for both ${ }^{99} \mathrm{Tc}$ and uranium suggests that significant amounts continue to migrate through the deep vadose zone into the groundwater. The total activity of ${ }^{99} \mathrm{Tc}$ currently in the B-Complex groundwater plume is estimated at $6.06 \mathrm{Ci}$, which represents no more than $5 \%$ of the total activity of ${ }^{99} \mathrm{Tc}$ released to the subsurface below the B-Complex. The conceptual models cannot assess how much of the ${ }^{99} \mathrm{Tc}$ may have migrated out of the B-Complex region before regular groundwater monitoring was performed (i.e., before 1993, when ${ }^{99} \mathrm{Tc}$ measurements commenced). Thus, some of the difference between the mass balance estimates ( $\sim 65$ out of $145 \mathrm{Ci}$ have been accounted for in the proposed ${ }^{99} \mathrm{Tc}$ conceptual model) may have "escaped" the region in past groundwater. The mass balance estimates show that the sum of ${ }^{99} \mathrm{Tc}$ activity deep below the BY Cribs and in the $\mathrm{CCU}_{z}$ sediments below wells E33-343 over to E33-345 are much larger (3.4 to $20.9 \mathrm{Ci}$ ) than the estimated activity of ${ }^{99} \mathrm{Tc}$ currently in the groundwater plume directly below B-Complex $(0.76 \mathrm{Ci})$. Succinctly, there is from 8 to 30 times more ${ }^{99} \mathrm{Tc}$ in the deep vadose sediments than is currently present in the ${ }^{99} \mathrm{Tc}$ groundwater plume directly below the B-Complex. These ${ }^{99} \mathrm{Tc}$ estimates are speculative because of sparser data availability for the deep vadose zone sediments ${ }^{99} \mathrm{Tc}$ concentrations and uncertainty in the lateral spreading area with high ${ }^{99} \mathrm{Tc}$ concentrations below BY Crib footprints. Future fate and transport modeling can be used to assess risks associated with these estimates currently in the deep vadose zone and to predict the timing for deep vadose zone ${ }^{99} \mathrm{Tc}$ to reach the water table.

Similar preliminary conceptual models for the T-Complex and S-Complex have been developed but remain unpublished pending further vadose zone contaminant characterization. Table D.1 shows the overall volumes of liquid waste released to the vadose zone and the total ${ }^{99} \mathrm{Tc}$ inventory in the wastes that were released. 
Table D.1. Comparison of Total Volumes Released to Ground and ${ }^{99} \mathrm{Tc}$ Inventory in the Disposed Liquid Wastes by Central Plateau Region

\begin{tabular}{ccc}
\hline & $\begin{array}{c}\text { Total Volume of Liquid Waste } \\
\text { Released } \\
(\mathrm{ML})\end{array}$ & $\begin{array}{c}\text { Total }{ }^{99} \text { Tc Inventory in Waste } \\
\text { Region }\end{array}$ \\
\hline B-Complex & 346 & 145 \\
S-Complex & 460 & 35 \\
T-Complex & 725 & 50 \\
\hline No CSMs have been generated for A-Complex, C-Complex, or U-Complex \\
\hline
\end{tabular}

\section{D.2 Releases of ${ }^{99} \mathrm{Tc}$ from SSTs and Their Infrastructure}

Perhaps of more interest to staff dealing strictly with Hanford tank farm issues is the status of SST leaks and infrastructure (piping, junction boxes, etc.) release of liquids to the subsurface and the possibility of leaks during retrieval. Finally, there is the issue of residual sludge left in the bottoms of tanks after retrieval. The current reference that tabulates the status of SST integrity, the timing of past releases of fluids, and the estimated release volumes is a series of status reports generally called the Hanlon reports (e.g., Hanlon 2006), which are updated when significant new evaluations have been made. A second resource is Field and Jones 2006, which revisited the timing of past releases and the estimated release volumes. Field and Jones (2006) release volume estimates are identical to those used in the current version of the Soil Inventory Model (SIM) (Corbin et al. 2005). Attempts to revisit and improve the understanding of past SST releases to the subsurface have been ongoing. A formal protocol (see Figure D.3) is in place to revisit the past estimates for the volume, timing of the release, type of waste released (chemical composition), and total inventory of key mobile contaminants. Essentially, a team of tank farm contractor experts, staff from the Office of River Protection, and the two regulators (Washington State Department of Ecology and Environmental Protection Agency-Richland Field Office) convene and evaluate all available data and then produce a consensus document.

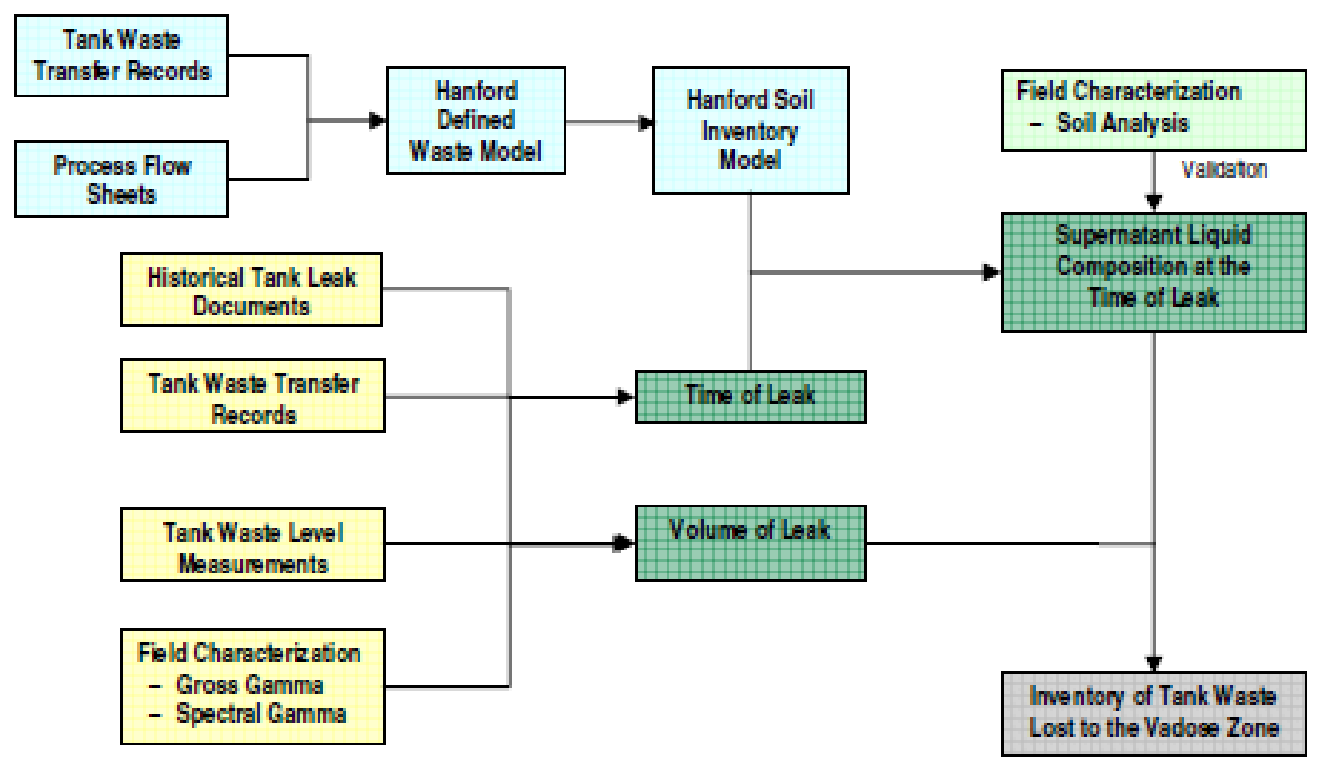

Figure D.3. Logic Diagram for the SST Leak Reassessment Efforts (from DOE/ORP 2010) 
The protocol is documented in:

- Field JG, JP Harris, and ME Johnson. 2007. Process to Assess Tank Farm Leaks in Support of Retrieval and Closure Planning. RPP-32681, Rev. 0, CH2M Hill Hanford Group, Inc., Richland, WA.

To date the following SST farms have been reevaluated using the protocol shown in Figure D.3 and reports produced:

- Aruwah MR, JG Field, and LA Fort. 2011. Hanford B-Farm Inventory Assessments Report. RPP-RPT-49089, Rev. 0, Washington River Protection Solutions LLC, Richland, WA.

- Field JG. 2010. Hanford SX-Farm Leak Assessments Report. RPP-ENV-39658, Rev. 0, Washington River Protection Solutions LLC, Richland, WA.

- Field JG. 2010. Hanford TY-Farm Leak Assessments Report. RPP-RPT-42296, Rev. 0, Washington River Protection Solutions LLC, Richland, WA.

- Field JG, JM Barton, BN Hedel, LA Fort, and MI Wood. 2011. Hanford BY-Farm Leak Assessments Report. RPP-RPT-43704, Rev. OA, Washington River Protection Solutions LLC, Richland, WA.

- Field JG and LA Fort. 2013. Hanford 241-T Farm Leak Assessment Report. RPP-RPT-55084, Rev. 0, Washington River Protection Solutions LLC, Richland, WA.

- Field JG and LA Fort. 2013. Hanford 241-TX Farm Leak Assessment Report. RPP-RPT-50870, Rev. 0, Washington River Protection Solutions LLC, Richland, WA.

- Field JG, LA Fort, BN Hedel, and MI Wood. 2011. Hanford 241-U Farm Leak Assessment Report. RPP-RPT-50097, Rev. 0, Washington River Protection Solutions LLC, Richland, WA.

- Field JG, LA Fort, and MI Wood. 2011. Hanford BX-Farm Leak Assessments Report. RPP-RPT-47562, Rev. 0, Washington River Protection Solutions LLC, Richland, WA.

- Field JG, LA Fort, A Shrum, and MI Wood. 2011. Hanford 241-S Farm Leak Assessment Report. RPP-RPT-48589, Rev. 0, Washington River Protection Solutions LLC, Richland, WA.

- Johnson ME. 2008. Hanford A and AX-Farm Leak Assessments Report: 241-A-103, 241-A-104, 241-A-105, 241-AX-102, 241-AX-104, 241-A-105, 241-AX-102, 241-AX-104 and Unplanned Waste Releases. RPP-ENC-37956, Rev.1, CH2M Hill Hanford Group, Inc. Richland, WA.

- Fort LA, JG Field, and BN Hedel. 2011. Hanford C-Farm Leak Assessments Report. RPP-ENV-33418, Rev. 2, Washington River Protection Solutions, LLC, Richland, WA.

In addition to these SST farm assessments, there is a monthly Hanford tank report that tabulates the status of SST integrity, the timing of past releases of fluids, the current estimated volumes remaining in each tank, and the retrieval activities. This series of monthly status reports in the past generally were referred to as the "Hanlon reports" (e.g., HNF-EP-0182, Rev. 19; Hanlon 2006) and now are authored by Rogers (e.g., HNF-EP-0182-Rev.309; Rogers 2014). A second resource is Field and Jones 2006, which revisited the timing of past releases and the estimated release volumes. Field and Jones (2006) release volume estimates are identical to those used in the current version of the SIM (Corbin et al. 2005). 
Other valuable resources that discuss the impacts of past SST leaks and long-term leaching of residual sludge left in SSTs after retrieval (and regulatory acceptance) on potential groundwater risks include Chapter 9, Tank Waste Inventory In The Vadose Zone, Chapter 27, Future Impacts, and Chapter 28 Cumulative Impacts from the Hanford Site, all part of DOE/ORP-2010. One of the most important findings is that the biggest source of future groundwater impacts related to Hanford SSTs comes from wastes already released (past tank leaks and infrastructure releases) and not from the residual wastes left in the tanks after retrieval. Figure D.4 shows the estimated release volume (1000 gal) and ${ }^{99} \mathrm{Tc}$ inventory (Ci) in the release for the four largest known SST releases. These four releases account for about $85 \%$ to $90 \%$ of the total estimated ${ }^{99} \mathrm{Tc}$ release $(100 \mathrm{Ci}$; see Table 6.1$)$ from SSTs and their infrastructure to the vadose zone sediments.

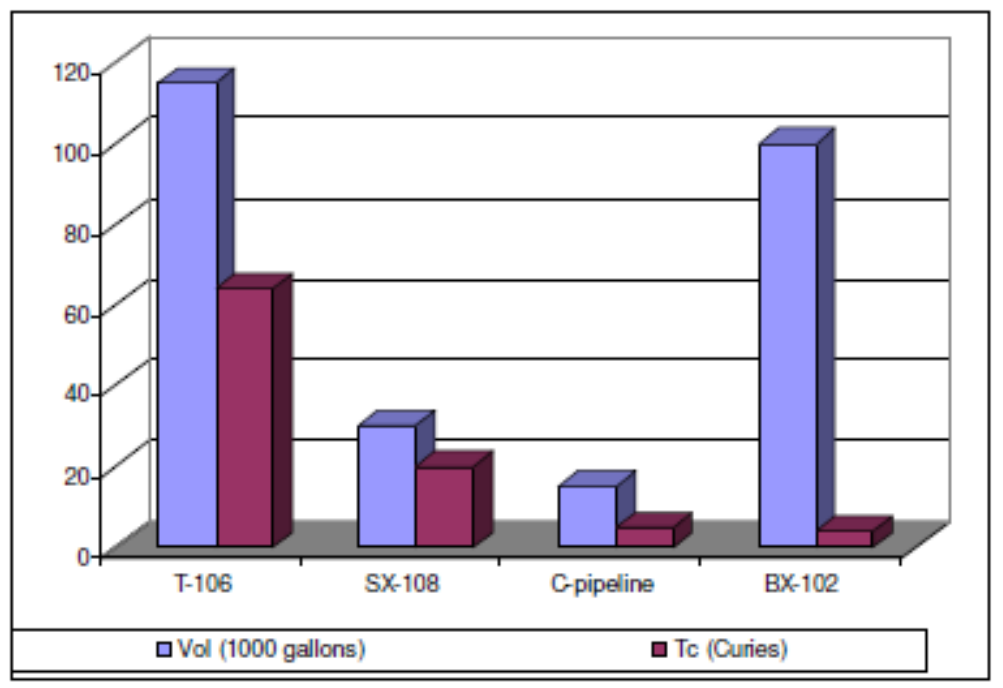

Figure D.4. Estimated Volume and ${ }^{99} \mathrm{Tc}$ Inventory in the Four Largest SST Releases (from DOE/ORP 2010)

\section{Other SST Resources Cited:}

- Corbin RA, BC Simpson, MJ Anderson, WF Danielson III, JG Field, TE Jones, and CT Kincaid. 2005. Hanford Soil Inventory Model, Rev 1. RPP-26744, CH2M Hill Hanford Group, Inc., Richland, WA.

- DOE/ORP 2005-01, Initial Single-Shell Tank Performance Assessment for the Hanford Site, DOE/ORP-2005-01, Office of River Protection, U.S. Department of Energy, Richland, WA.

- DOE/ORP. 2010. RCRA Facility Investigation Report for Hanford Single-Shell Tank Waste Management-Tier 1 \& 2. DOE/ORP-2008-01 Rev. 1 Reissue, Office of River Protection, U.S. Department of Energy, Richland, WA.

- Field JG and TE Jones. 2006. Tank Farm Vadose Zone Contamination Volume Estimates. RPP-23405, Rev. 2, CH2M Hill Hanford Group, Inc., Richland, WA.

- Hanlon BM. 2006. Waste Tank Summary Report for Month Ending June 30, 2006. HNF-EP-0182-Rev. 19, CH2M Hill Hanford Group, Inc., Richland, WA. 
- Rogers MJ. 2014. Waste Tank Summary Report for Month Ending December 31, 2013. HNF-EP-0182-Rev. 309, Washington River Protection Solutions, LLC, Richland, WA.

\section{D.3 Useful References for Finding Input Data for Contaminant Conceptual Model Development and ${ }^{99} \mathrm{Tc}$ Inventories}

One roll-up of ${ }^{99} \mathrm{Tc}$ inventories in the various "boxes" or "pools" that constitute the Hanford Site was provided in DOE/ORP 2010 and is reproduced here as Table D.2.

Table D.2. Estimate of ${ }^{99} \mathrm{Tc}$ Inventories and Waste Volumes at the End of WTP Mission (from DOE/ORP 2010, Table 2.1)

\begin{tabular}{lrr}
\hline \multicolumn{1}{c}{ Facility } & \multicolumn{1}{c}{ Volume } & \multicolumn{1}{c}{ Technetium-99 } \\
(Ci)
\end{tabular}

Current volumes and estimates of chemical and radionuclide contaminants released to each crib/trench/pond, etc. can be found in:

- Corbin RA, BC Simpson, MJ Anderson, WF Danielson III, JG Field, TE Jones, and CT Kincaid. 2005. Hanford Soil Inventory Model, Rev 1. RPP-26744, CH2M Hill Hanford Group, Inc., Richland, WA. This document was also released at the same time as PNNL-15367 by Pacific Northwest National Laboratory, Richland, WA. This document has electronic appendices with all the data. However, SIM (Soil Inventory Model) is no longer being updated.

Groundwater annual reports are good resources for current estimates of the location and movement of ${ }^{99} \mathrm{Tc}$ plumes as well as discussions on probable sources, current and future remediation plans, and in some cases discussion of impacts of human health and the environment:

\section{http://www.hanford.gov/page.cfm/SoilGroundwaterAnnualReports}

Six annual reports (2007 through 2012) are currently on this web site. Earlier reports can be found on redirected URL links accessed by clicking the following links. After being redirected, scroll down and click on the link "View Document Here."

- Earlier year annual reports such as PNNL-Pacific Northwest National Laboratory. 1996. Hanford Site Groundwater Monitoring for Fiscal Year 1996. PNNL-11470, Pacific Northwest National Laboratory, Richland, WA. Available at:

http://www2.hanford.gov/arpir/?content=findpage\&AKey=D199132964. 
- PNNL. 1997. Hanford Site Groundwater Monitoring for Fiscal Year 1997. PNNL-11793, Pacific Northwest National Laboratory, Richland, WA.

- PNNL. 1998. Hanford Site Groundwater Monitoring for Fiscal Year 1998. PNNL-12086, Pacific Northwest National Laboratory, Richland, WA. Available at: http://www2.hanford.gov/arpir/?content=findpage\&AKey=D199091099.

- PNNL. 1999a. Hanford Site Groundwater Monitoring for Fiscal Year 1998. PNNL-12086, Pacific Northwest National Laboratory for the U.S. Department of Energy, Richland Operations Office, Richland, WA.

- PNNL. 1999b. Hanford Site Groundwater Monitoring for Fiscal Year 1999. PNNL-13116, Pacific Northwest National Laboratory, Richland, WA. Available at: http://www2.hanford.gov/arpir/?content=findpage\&AKey=D2736610 and http://www2.hanford.gov/arpir/?content=findpage\&AKey=D2736978.

These groundwater annual reports are available directly on the PNNL publications web site:

- PNNL. 2000. Hanford Site Groundwater Monitoring for Fiscal Year 2000. PNNL-13404, Pacific Northwest National Laboratory, Richland, WA. Available at: http://www.pnl.gov/main/publications/external/technical_reports/PNNL-13404.pdf.

- PNNL. 2001. Hanford Site Groundwater Monitoring for Fiscal Year 2001. PNNL-13788, Pacific Northwest National Laboratory, Richland, WA. Available at: http://www.pnl.gov/main/publications/external/technical_reports/PNNL-13788.pdf.

- PNNL. 2002. Hanford Site Groundwater Monitoring for Fiscal Year 2002. PNNL-14187, Pacific Northwest National Laboratory, Richland, WA. Available at: http://www.pnl.gov/main/publications/external/technical_reports/PNNL-14187.pdf.

- PNNL. 2003. Hanford Site Groundwater Monitoring for Fiscal Year 2003. PNNL-14548, Pacific Northwest National Laboratory, Richland, WA. Available at: http://www.pnl.gov/main/publications/external/technical_reports/PNNL-14548.pdf.

- PNNL. 2004. Hanford Site Groundwater Monitoring for Fiscal Year 2004. PNNL-15070, Pacific Northwest National Laboratory, Richland, WA. Available at: http://www.pnl.gov/main/publications/external/technical_reports/PNNL-15070.pdf.

- PNNL. 2005. Hanford Site Groundwater Monitoring for Fiscal Year 2005. PNNL-15670, Pacific Northwest National Laboratory, Richland, WA. Available at: http://www.pnl.gov/main/publications/external/technical_reports/PNNL-15670.pdf.

- PNNL. 2006. Hanford Site Groundwater Monitoring for Fiscal Year 2006. PNNL-16346, Pacific Northwest National Laboratory, Richland, WA. Available at: http://www.pnl.gov/main/publications/external/technical reports/PNNL-16346.pdf.

Commonly sought Hanford Environmental Information System (HEIS) well-monitoring data, tracking contaminants from about 1950 to the present, can be accessed at http://environet.hanford.gov/eda/. 
PNNL-23319

EMSP-RPT-022

\section{Distribution*}

No. of

Copies

4 U.S. Department of Energy

Office of Environmental Management

DJ Koutsandreas

NP Machara

JA Poppiti

SP Schneider

4 U.S. Department of Energy

Office of River Protection

JA Diediker

RA Gilbert

CC Harrington

SH Pfaff

4 Washington River Protection Solutions

WG Ramsey

RA Robbins

KH Subramanian

DJ Swanberg

3 Savannah River National Laboratory

DI Kaplan

SL Marra

DJ McCabe
No. of

Copies

15 Pacific Northwest National Laboratory

CF Brown

SA Bryan

TG Levitskaia

GJ Lumetta

JJ Neeway

RA Peterson

NP Qafoku

BM Rapko

S Schlahta

RJ Serne

W Um

JD Vienna

DM Wellman

JH Westsik, Jr

Information Release

*All distribution will be made electronically. 




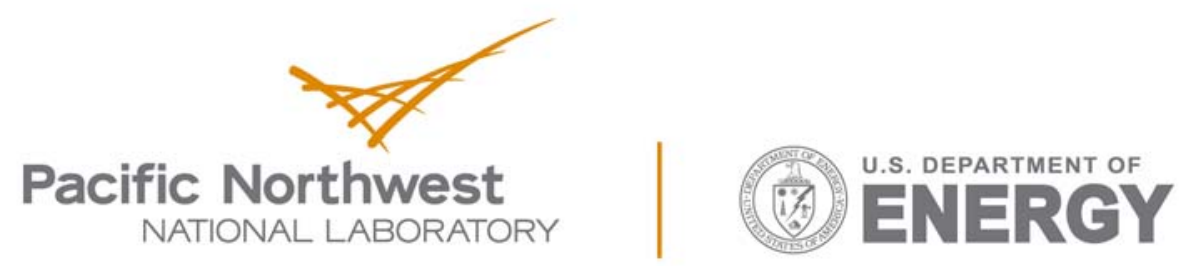

Proudly Operated by Battelle Since 1965

902 Battelle Boulevard

P.O. Box 999

Richland, WA 99352

1-888-375-PNNL (7665)

www.pnnl.gov 